\title{
Pacific Northwest Laboratory Annual Report for 1979 \\ to the DOE Assistant Secretary for Environment
}

Part 3 Atmospheric Sciences February 1980

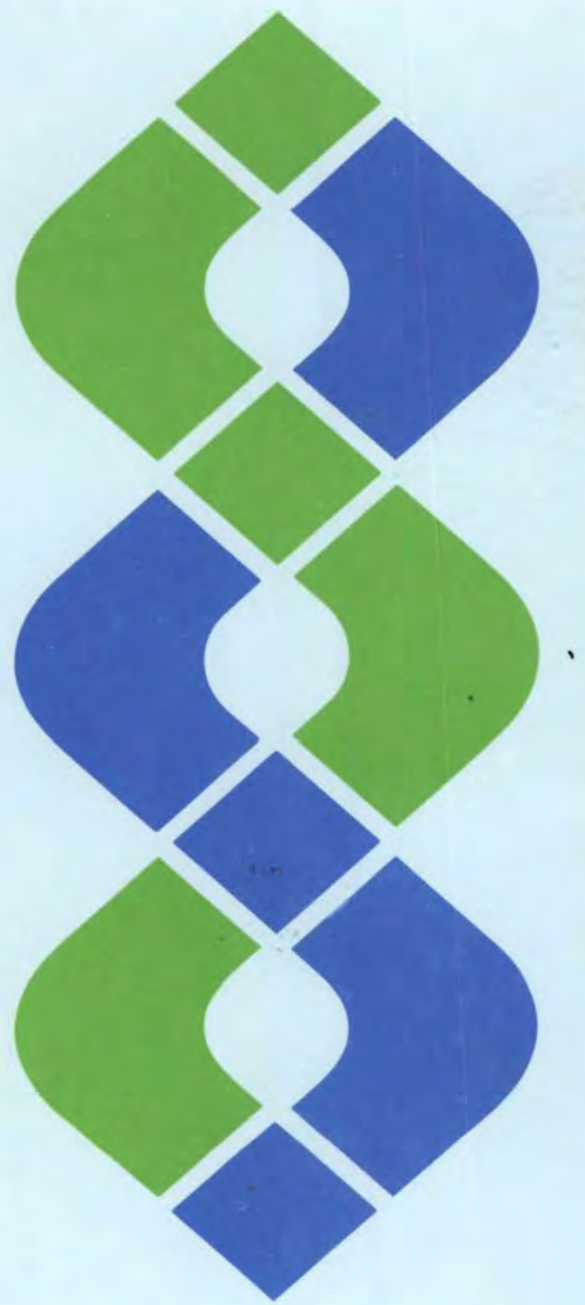

Prepared for the U.S. Department of Energy under Contract EY-76-C-06-1830

Pacific Northwest Laboratory Operated for the U.S. Department of Energy by Battelle Memorial Institute

\section{Battelle}




\title{
NOTICE
}

This report was prepared as an account of work sponsored by the United States Government. Neither the United States nor the Department of Energy, nor any of their employees, nor any of their contractors, subcontractors, or their employees, makes any warranty, express or implied, or assumes any legal liability or responsibility for the accuracy, completeness or usefulness of any information, apparatus, product or process disclosed, or represents that its use would not infringe privately owned rights.

The views, opinions and conclusions contained in this report are those of the contractor and do not necessarily represent those of the United States Government or the United States Department of Energy.

\author{
PACIFIC NORTHWEST LABORATORY \\ operated by \\ BATTELLE \\ for the \\ UNITED STATES DEPARTMENT OF ENERGY \\ Under Contract EY-76-C-06-1830
}

Printed in the United States of Am
Available from
National Technical Information Se
United States Department of Comm
5285 Port Royal Road
Springfield, Virginia 22151
Price: Printed Copy $\$$




\section{Pacific Northwest Laboratory} Annual Report for 1979

\section{to the}

\section{DOE Assistant Secretary for}

\section{Environment}

\section{Part 3 Atmospheric Sciences}

C. E. Elderkin and Staff Members of Pacific Northwest Laboratory

February 1980

Prepared for

the U.S. Department of Energy

under Contract EY-76-C-06-1830

Pacific Northwest Laboratory

Richland, Washington 99352 


\section{PREFACE}

Pacific Northwest Laboratory's (PNL) 1979 Annual Report to the Department of Energy (DOE) Ass istant Secretary for Environment describes research in environment, health, and safety conducted during fiscal year 1979. The report again consists of five parts, each in a separate volume.

The five parts of the report are oriented to particular segments of our program. Parts 1-4 report on research performed for the DOE Office of Health and Environmental Research. Part 5 reports progress on all other research performed for the Assistant Secretary for Environment, including the Office of Technology Impacts and the Office of Environmental Compliance and Overview. Each part consists of project reports authored by scientists from several PNL research departments, reflecting the interdisciplinary nature of the research effort. Parts 1-4 are organized primarily by energy technology.

The parts of the 1979 Annual Report are:

Part 1: Biomedical Sciences

$$
\text { Program Manager - H. Drucker D. L. Felton, Editor }
$$

Part 2: Ecological Sciences

Program Manager - B. E. Vaughan B. E. Vaughan, Report Coordinator

C. H. Connally, Editor

Part 3: Atmospheric Sciences

Program Manager - C. E. Elderk in R. L. Drake, Report Coordinator

G. B. Long, Editor

Part 4: Physical Sciences

Program Manager - J. M. Nielsen

J. M. Nielsen, Report Coordinator

J. L. Hooper, Editor

Part 5: Environmental Assessment, Control, Health and Safety.

Program Managers - D. L. Hesse 1

S. Marks

W. J. Bair, Report Coordinator

C. M. Unruh

R. W. Baalman, C. W. Dotson, Editors 
Activities of the scientists whose work is described in this annual report are broader in scope than the articles indicate. PNL staff have responded to numerous requests from DOE during the year for planning, for service on various task groups, and for special assistance.

Credit for this annual report goes to many scientists who performed the research and wrote the individual project reports, to the program managers who directed the research and coordinated the technical progress reports, to the editors who edited the individual project reports and assembled the five parts, and to Dr. Ray Baalman, editor in chief, who directed the total effort.

\author{
W. J. Bair, Manager \\ S. Marks, Associate Manager \\ Environment, Health, and Safety Research \\ Program
}

Previous Reports in this series:

\title{
Annual-Report for
}

\begin{tabular}{|c|c|}
\hline 1951 & $W-25021, \quad H W-25709$ \\
\hline 1952 & $\mathrm{HW}-27814, \mathrm{HW}-28636$ \\
\hline 1953 & $\mathrm{HW}-30437, \mathrm{HW}-30454$ \\
\hline 1954 & $\mathrm{HW}-30306, \mathrm{HW}-33128, \mathrm{HW}-35905, \mathrm{HW}-35917$ \\
\hline $\begin{array}{l}1955 \\
1956\end{array}$ & $\begin{array}{l}H W-39558, H W-41315, H W-41500 \\
H W-47500\end{array}$ \\
\hline 1958 & $\begin{array}{l}H W-53500 \\
H W-59500\end{array}$ \\
\hline 1959 & $H N-638 \geq 4, H N-65500$ \\
\hline 1960 & $\mathrm{HW}-59500, \mathrm{HW}-70050$ \\
\hline 1961 & HWW $-72500, H W-73337$ \\
\hline 1962 & $\mathrm{HW}-75000, \mathrm{HW}-77609$ \\
\hline 1963 & $\mathrm{HW}-80500, \mathrm{HW}-81746$ \\
\hline 1.964 & BNWL-122 \\
\hline 1965 & BNWL-280, BNWL-235, Vo 1. 1-4, BNWL-361 \\
\hline 1966 & BNWL-480, Vol. 1, BNWL-481, Vol. $2, \mathrm{Pt} .1-4$ \\
\hline 1967 & BNWL-714, Vol. 1, BNWL-715, Vol 2, Pt. 1-4 \\
\hline 1968 & BNWL-1050, Vo 1. 1, Pt. 1-?, BNWL-1051, Vo 1. ?, Pt. 1-3 \\
\hline 1969 & BNWL-1306, Vol. 1, Pt. 1-2, BNWL-1307, Vol. 2, Pt. 1-3 \\
\hline 1970 & BNWL-1550, Vol. 1, Pt. 1-2, BNWL-1551, Vol. ?, Pt. 1-2 \\
\hline 1 & BNWL-1650, Vol. 1, Pt. 1-2, BNWL-1651, Vol. ?, Pt. 1-2 \\
\hline 1972 & BNWL-1750, Vol. 1, Pt. 1-2, BNWL-1751, Vol. 2, Pt. 1-? \\
\hline 1973 & BNWL-1850, Pt. 1-4 \\
\hline & BNWL-1950, Pt. $1-4$ \\
\hline 1975 & BNWL-2000, Pt. $1-4$ \\
\hline & BNWL -2100 , Pt. $1-5$ \\
\hline & PNL-2500, Pt. $1-5$ \\
\hline 278 & PNL -28 \\
\hline
\end{tabular}




\section{FOREWORD}

The goals of atmospheric research at Pacific Northwest Laboratory (PNL) are to assess, describe and predict the nature and fate of atmospheric pollution and to study the impacts of pollutants on local, regional and global climates. The pollutants being investigated are those resulting from the development and use of four energy resources: coal, gas, oil and nuclear power. In the course of this research, investigative tools are also being developed and atmospheric assessments are being made that will contribute to the development of environmentally sound oil shale, solar and fusion energy resources.

COAL, GAS AND OIL COMBUSTION

The behavior of air pollution resulting from fossil-fuel power plants is being explained. Involved in making this explanation are these factors: the type of pollutants emitted, their transport and diffusion in the air, their physical and chemical transformations during transport, their removal by wet and dry deposition processes, and their impacts on climate, bodies of water and living species. Since the result of the current and projected coal and oil utilization is the release of large quantities of particulate matter and sulfur and nitrogen compounds, current research is being conducted primarily in the Atmospheric Studies in Complex Terrain (ASCOT) and in the Multistate Atmospheric Power Production Pollutant Studies (MAP3S).

\section{FISSION AND FUSION}

Concern about long-lived particulates (i.e., plutonium and other radionuclides) released to the environment from fission and fusion plants indicates that the deposition and resuspension of the se substances must be studied. For example, because the primary hazard from plutonium is inhalation, its residence in the atmosphere must be clearly defined. Current research, therefore, is evaluating the removal of particulates from the atmosphere by deposition (which limits initial exposure) and any future resuspension from the surface (which continues the potential for inhalation).

\section{OIL SHALE}

The mountainous oil shale regions of Colorado, Utah and Wyoming present a particularly difficult air pollution problem because air may be trapped in the valleys of these regions for extended periods of time under certain meteorological conditions. Especially stringent siting requirements, therefore, must be fulfilled to meet State and Federal air quality standards. Adequate models and field measurements of the complex airflow and dispersion conditions in this complex area are not available; they must be developed to assure acceptable siting of oil shale facilities. PNL has undertaken the assessment of the requirements for the proper modeling activities and field measurement programs that will contribute to this very important area of research, as well as to the development of solar and geothermal energy.

The description of atmospheric research at PNL is organized in terms of energy technologies:

- Coal, Gas and 0il

- Fission and Fusion

- 0il Shale

This report describes the progress in FY 1979 for each of these technologies. A divider page summarizes the goals of each area and lists, as bulleted items, project titles that fund research in each technology. Contributions under project titles marked with asterisks were transferred to the Environmental Protection Agency in midyear.

R. L. Drake Program Coordinator 



\section{CONTENTS}

PREFACE

FOREWORD

COAL, GAS AND OIL

Project ASCOT--Pacific Northwest Laboratory's Contribution to the Department of Energy's Multilaboratory Complex Terrain Field Program, July 1979 - M. M. Orgill, T. W. Horst, R. I. Schreck, D. W. Glover, P. W. Nickola, 0. B. Abbey and

J. C. Doran.

Net Radiation Measurements at Geysers Geothermal Site--Project ASCOT, July 1979 -

P. W. Nickola, M. M. Orgill, N. S. Laulainen, J. C. Doran and D. W. Glover

Fluorescent Particulate Tracer Experiments at Geysers Geothermal Site--Project

ASCOT, July 1979 - P. W. Nickola

Tethersonde Data at the Geysers Geothermal Site--Project ASCOT, July 1979 -

M. M. Orgi11, R. I. Schreck, and T. W. Horst (Pacific Northwest Laboratory)/

W. D. Neff and R. S. Larson (NOAA Wave Propagation Laboratory)

Micrometeorological Measurements During Drainage Wind Periods in the Geysers

Area - J. C. Doran, 0. B. Abbey and T. W. Horst

Sulfur Surface Flux Measurements - J. G. Droppo

Sensitivity of Particle Deposition to Changes in Deposition Velocity - J. C. Doran

Application of the Modified Source Depletion Model - T. W. Horst

Aircraft Measurements of Turbidity in Urban and Rural Atmospheres - N. S. Laulainen and A. J. Alkezweeny

Pollutant Transformations in the Atmosphere - D. R. Kalkwarf and S. R. Garcia

Atmospheric Carbon Dioxide Abundance - An Archival Study of Spectroscopic Data -

G. M. Stokes

Drift from Mechanical Draft Cooling Towers - N. S. Laulainen . . . . .

Development of a National Interregional Transport Matrix for Emitted Fine Par-

ticulates - W. J. Eadie, W. E. Davis and W. F. Sandusky

The Use of Time-Averaged Precipitation for Wet Removal in a Regional Air Pollu-

tion Assessment Model - W. E. Davis and W. J. Eadie.

A New Regional-Scale Assessment Method Based on Assessments at Regularly Spaced Grid Points - W. E. Davis and W. J. Eadie.

The MAP3S Precipitation Chemistry Network: Progress and Recent Results -

M. Terry Dana, D. R. Drewes, D. W. Glover, S. D. Harris and J. E. Rothert

Chemical Laboratory Activities and Quality Control Results for the MAP3S Program -

J. E. Rother

Sulfur Wet Deposition in the Northeast United States: Winter 1978-1979 -

M. Terry Dana

Predictions of Incloud Conversion Rates of Sulfur Dioxide to Sulfate Based Upon a Simple Chemical and Dynamical Model - B. C. Scott 
Wet Sulfate Deposition in Winter Storms - B. C. Scott . . . . . 46

Empirical Evidence for Nucleation as a Mechanism for Introducing Sulfate Into Precipitation - C. M. Berkowitz . . . . . . . . . . . . 48

A Generalized One-Dimensional Model of Reactive Pollutant Behavior, Including Dry Deposition, Precipitation Formation and Wet Removal - J. M. Hales . . . 51

Comparison Between Polluted and Clean Air Masses Over Lake Michigan -

A. J. Alkezweeny and N. S. Laulainen. . . . . . . . . . . . 53

Gas to Particle Conversion in Urban Plumes - A. J. Alkezweeny . . . . . 56

The Impact of Fair-Weather Cumulus Clouds on Atmospheric Pollutants -
A. J. Alkezweeny.
.

Relationship Among Secondary Pollutants - A. J. Alkezweeny . . . . . $\quad$. 61

Measurement of Atmospheric Hydrogen Peroxide - R. N. Lee . • . . . $\quad$ • 63

Tests for the Evaluation of an Airbonre Aerosol Sampling System and Filter Analysis Methodologies - R. N. Lee . . . . . . . . . . . . . . . . 64

Design of a High-Volume Air Sampling System for Aircraft Research - D. A. Arbuthnot and J. M. Hales . . . . . . . . . . . . . . . . . . 65

Development of an In-Flight Calibrator for Sulfur Dioxide and $\mathrm{NO}_{\mathrm{X}}$ Monitoring

Systems - K. M. Busness and J. M. Hales. . . . . . . . . 66

MAP3S Modeling: Annual Progress, FY 1979 - D. J. McNaughton . . . . . 68

Initial Comparisons of SURE/MAP3S Sulfur Oxides Observation with Long-Term Regional Model Predictions - D. J. McNaughton . . . . . . . . . . . . 69

Emission Source Specification in a Regional Pollutant Transport Model -

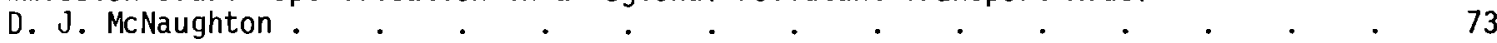

A Study of HTO Plume Washdown in an Eight-Layer Computer Model - W. E. Davis . $\quad 76$

A Method of Initialization of Wind Fields Over a Region for the Primitive Forecast

Equations - C. H. Huang and R. L. Drake . . . . . . . . . . 79

Back Trajectories Using an Eight-Layer Diabatic Model - W. E: Davis . . $\quad .84$

Model ing Evidence of Incloud Transformation of Sulfur Dioxide to Sulfate -

FISSION AND FUSION

Literature Ranges of Particle Dry Deposition Velocities - G. A. Sehmel • • $\quad 95$

Literature Ranges of Dry Deposition Velocities for Gases - G. A. Sehmel . . $\quad 97$

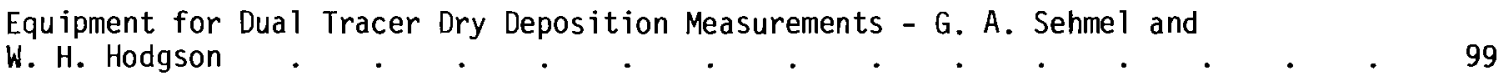

Literature Ranges of Wind and Mechanically Caused Resuspension Factors - G. A. Sehmel 102

Wind-Caused Particle Resuspension Rates at Two Sites - G. A. Sehmel · $\quad$ - 104

Airborne Plutonium Transported During Southwesterly Winds Near the Hanford Prosser Barricade - G. A. Sehmel . . . . . . . . . . . . 
Atmospheric Radionuclide Concentrations at Richland, Washington and Barrow, Alaska -

J. A. Young and C. W. Thomas

Correlations of Extreme Air Temperatures at $30 \mathrm{~cm}$ and $120 \mathrm{~cm}$ on the ALE Reserve, Hanford - J. M. Thorp.

Comparative Study of the Hanford Dispersion Model - J. G. Droppo . . . $\quad 126$

OIL SHALE

Assessment of Research Needs in the $0 i 1$ Shale Industry - G. B. Parker . . . 133

Basis and Design of Atmospheric Transport Studies Proposed for the $0 i 1$ Shale Region -

G. A. Sehmel

Aerosol, Trace Elements and Visibility Measurements in Mountainous Terrain -

M. M. Orgill, N. S. Laulainen, D. R. Drewes and R. N. Lee . . • . . 139

Hanford Turbidity Durïng 1979 - N. S. Laulainen . . . . . . . . 143

Differential Turbidity at Hanford - N. S. Laulainen, E. W. Kleckner, J. J. Michalsky and G. M. Stokes.

PUBL ICATIONS AIND PRESENTATIONS

AUTHOR INDEX

ORGANIZATION CHART 



\section{Coal, Gas \\ and Oil}




\section{COAL, GAS AND OIL}

- Atmospheric Diffusion in Complex Terrain

- Atmospheric Boundary Layer Studies

- Radiative Effects of Clouds and Aerosols

- Pollutant Transformation in the Atmosphere

- Atmospheric Carbon Dioxide - An Archival Study of Spectroscopic Data

- Meteorological Effects of Thermal Energy Releases (METER)

- National Interregional Air Residual Transfer

- Precipitation Scavenging in MAP3S

- Aerosol and Trace Gas Transformations

- Research Aircraft Operations

- MAP3S Modeling Studies

As the use of fossil fuels as an energy source increases, so too will air pollutants, such as sulfur, nitrogen compounds and trace metals, produced by the combustion and conversion of these fuels. The analysis of the fate of these pollutants from source to receptor is most urgent so that the nation's energy plan can proceed efficiently and be environmentally sound.

The research activities at PNL are basically related to two interlaboratory programs: the ASCOT Program of DOE and the MAP3S Program of EPA/DOE. The ASCOT Program is currently concerned with the Geysers Geothermal Site in California, but future studies will be centered at other complex terrain sites in the West. The MAP3S Program is being conducted over the northeast quadrant of the United States and is concerned with the ultimate fate of atmospheric sulfur compounds.

The field activities in the ASCOT Program include the micrometeorological description of drainage winds, radiation measurements, and tracer experiments. The multidiscipline activities of the MAP3S Program consist of:

- data analysis and flight operations based at Muskegon, Michigan

- the Precipitation Chemistry Network in the eastern mountains, midwestern plains and coastal areas

- the incloud scavenging studies over Lake Michigan

- the laboratory analysis of sulfur and nitrogen compounds and trace metals at Hanford

- the trajectory modeling studies being formulated at Hanford.

The results from the ASCOT and MAP3S Programs will contribute to our ability to assess the impacts of the country's energy plan. 
Other work being conducted at PNL includes several dry deposition studies of gases and particles, assessment of the time evolution of atmospheric carbon dioxide, development and improvement of regional assessment models for airborne pollutants, and the determination of the interactions between cooling tower plumes and local weather and climate. 


\section{- Atmospheric Diffusion in Complex Terrain}

Objectives of this study are:

- Defining and developing a long-range technical plan for studying the transport and diffusion of pollutant particles and gases over complex landforms.

- Reviewing past theoretical, numerical and field studies pertinent to diffusion in complex terrain.

- Assisting a multilaboratory program studying diffusion in complex terrain by providing methodologies and techniques of analyses for transport and diffusion over a variety of complex landforms.

Project ASCOT--Pacific Northwest Laboratory's Contribution to the Department of Energy's Multilaboratory Complex Terrain Field Program, July 1979

M. M. Orgill, T. W. Horst, R. I. Schreck, D. W. Glover, P. W. Nickola, O. B. Abbey and J. C. Doran

During the week of September 28 to October 1, 1976, a joint Energy Research and Development Administration/Environmental Protection Agency (ERDA/EPA) workshop was conducted in Albuquerque, New Mexico (Barr et al. 1977) to consider what research programs are necessary to increase understanding of transport and diffusion of pollutants over complex landforms. The workshop proposed a broad research program that would address the air quality assessment aspects of various energy conversion developments in complex terrain throughout the United States, and particularly in the western states. Some of the recommendations of the workshop were:

- An integrated program of mathematical model development, field experiments, physical model experiments and theoretical research involving air pollution meteorology in complex terrain should be supported for a period of 3 to $5 \mathrm{yr}$.

- Several complex terrain research sites should be established as focal points of well planned field measurement programs.

In the fall of 1978, the Department of Energy, Office of Health and Environmental
Research (DOE/OHER) selected Lawrence Livermore Laboratory (LLL) to direct a multilaboratory program to conduct studies in complex terrain. The project was named Project ASCOT (Atmospheric Studies in Complex Terrain). One of the goals of Project ASCOT is to put into action the recommendations of the Albuquerque workshop. Therefore, Project ASCOT has selected the Geysers Geothermal Resource Area (GGRA) in northern California as an initial site for conducting field and model studies.

The purpose of the report here is to describe Pacific Northwest Laboratory's (PNL) contribution to the ASCOT field project between July 15 to 28,1979 . The objective of the field project was to make a relatively intensive multilaboratory effort to collect field data on the drainage wind phenomenon in the Anderson Creek area of GGRA. The GGRA is being investigated for future expansion of electrical generation operations that presently exist west of the Anderson Creek area. One of the most critical issues at the GGRA is the control of hydrogen sulfide emissions. These emissions are released to the atmosphere at several 10cations within the power plant complex and are transported to the surrounding regions by a combination of synoptic and local wind regimes. Because these emissions can result in an odor nuisance if the concentrations are sufficiently high, there is interest in the drainage wind phenomenon at the GGRA.

The site of the present field operations, primarily Anderson Creek, is located approximately $40 \mathrm{~km}$ north of the city of Santa 
Rosa and about $65 \mathrm{~km}$ east of the Pacific ocean. The topography is dominated by the Maycamas Mountains, a major ridge Tine that runs nearly north and south forming the border between Lake and Sonoma counties. A series of relatively small valleys run northwesterly and southeasterly from the ridge line. Anderson Creek Valley has a southeast exposure and the following approximate dimensions:

- width of valley floor 1 to $2 \mathrm{~km}$

- distance between ridge lines

१8 $\mathrm{km}$

- 1ength of valley v10 km

- height of ridge lines above valley floor (average)

$\sim 731 \mathrm{~m}$

- slope of valley 20.041 to 0.224

PNL's field effort consisted of the fol1owing tasks:

1) collecting wind, turbulence and temperature data at four levels from a $30-\pi$ tower located at the entrance of Anderson Creek Valley (Diamond D Ranch); soil temperatures and net radiation measurements were also obtained;

2) collecting temperature, humidity, pressure and wind data up to about $1000 \mathrm{~m}$ with a mobile tethersonde;

3) operating a monostatic acoustic sounder for obtaining data on the height and structure of temperature inversion and thermals;

4) establishing and operating a network of five sampling stations for sampling fluorescent particles (FP) tracer released in the upper part of Anderson Creek;

5) collecting supplemental net radiation and surface wind data.

The general topography of Anderson Creek and the location of the various field operations is shown in Figure 1. Many of the field operations, with the exception of the tower, were conducted at PDC-1 well site at approximately $840 \mathrm{~m}$ above sea level. On the evening of July 16 a tethersonde was

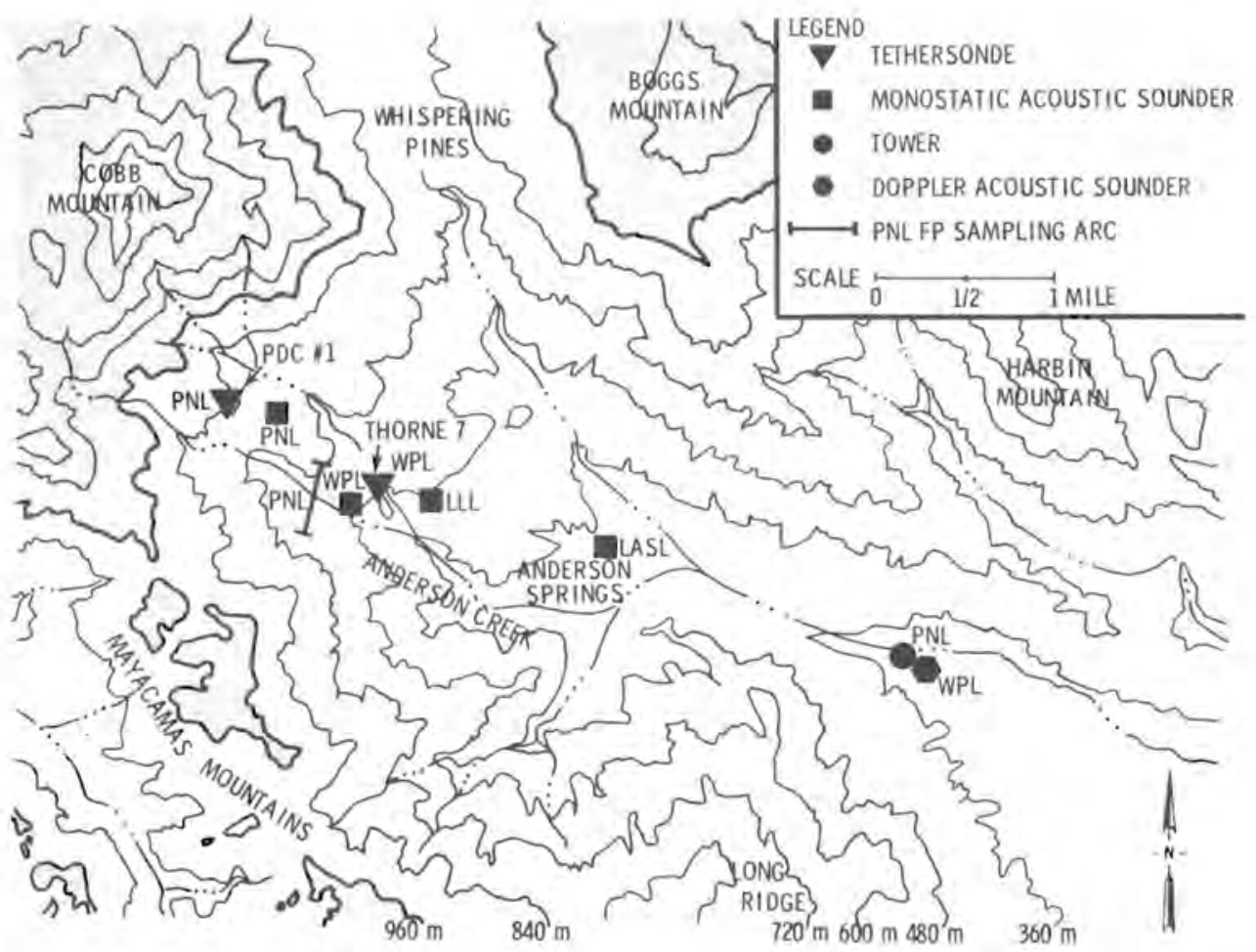

FIGURE 1. General Topography of Anderson Creek and Location of Project ASCOT Field Operations 
operated at the Diamond D Ranch location in conjunction with the tower and the dual doppler acoustic sounder of the Wave Propagation Laboratory (WPL).

The main objective of the field effort was to define wind velocity and temperature structure, drainage layer depth, turbulence, and transport along Anderson Creek drainage basin. Therefore, much of the operation was conducted during the nighttime hours. Figure 2 indicates the chronological time periods in which data were obtained from the various sensors. Thunderstorms during the evening of July 20 and gusty winds during the evening of July 27 limited data collection on those dates. Data collection during the daytime hours were limited because manpower was not available for a 24-hr operation.

Preliminary results from the tower measurements, net radiation, tethersonde, and FP sampling are discussed later in this Annual Report. Project ASCOT has tentative plans for a second intensive field effort at the GGRA during September 1980.

\section{Reference}

Barr, S. et al. 1977. Workshop on Research Needs for Atmospheric Transport and Diffusion in Complex Terrain. CONF-7609160, September 28-30, 1976, ATbuquerque, NM.
Net Radiation Measurements at Geysers Geothermal Site--Project ASCOT, July 1979

P. W. Nickola, M. M. Orgill,

N. S. Laulainen, J. C. Doran and

D. W. Glover

The radiation balance at the earth's surface is of concern in the development of atmospheric dispersion models. In particular, the rate of surface cooling is an important factor in valley drainage flow. Valley drainage flow was one of the focal studies of the Atmospheric Studies in Complex Terrain (Project ASCOT) field measurements program during 1979. Pacific Northwest Laboratory (PNL) deployed net radiometers (a) at two valley locations during the Project ASCOT July 1979 field program.

Although the two sensors used were identical, the methods of processing and recording the sensor outputs were not. The output of the Diamond D radiometer (at a downvalley location) was amplified, scanned once per second, digitized and recorded on a 9-track magnetic tape. The taped digital data were processed by computer with the output being 15 -min mean values of net

(a) Temperature-compensated Miniature Net Radiometer manufactured by Micromet Instruments, Bothel1, WA.

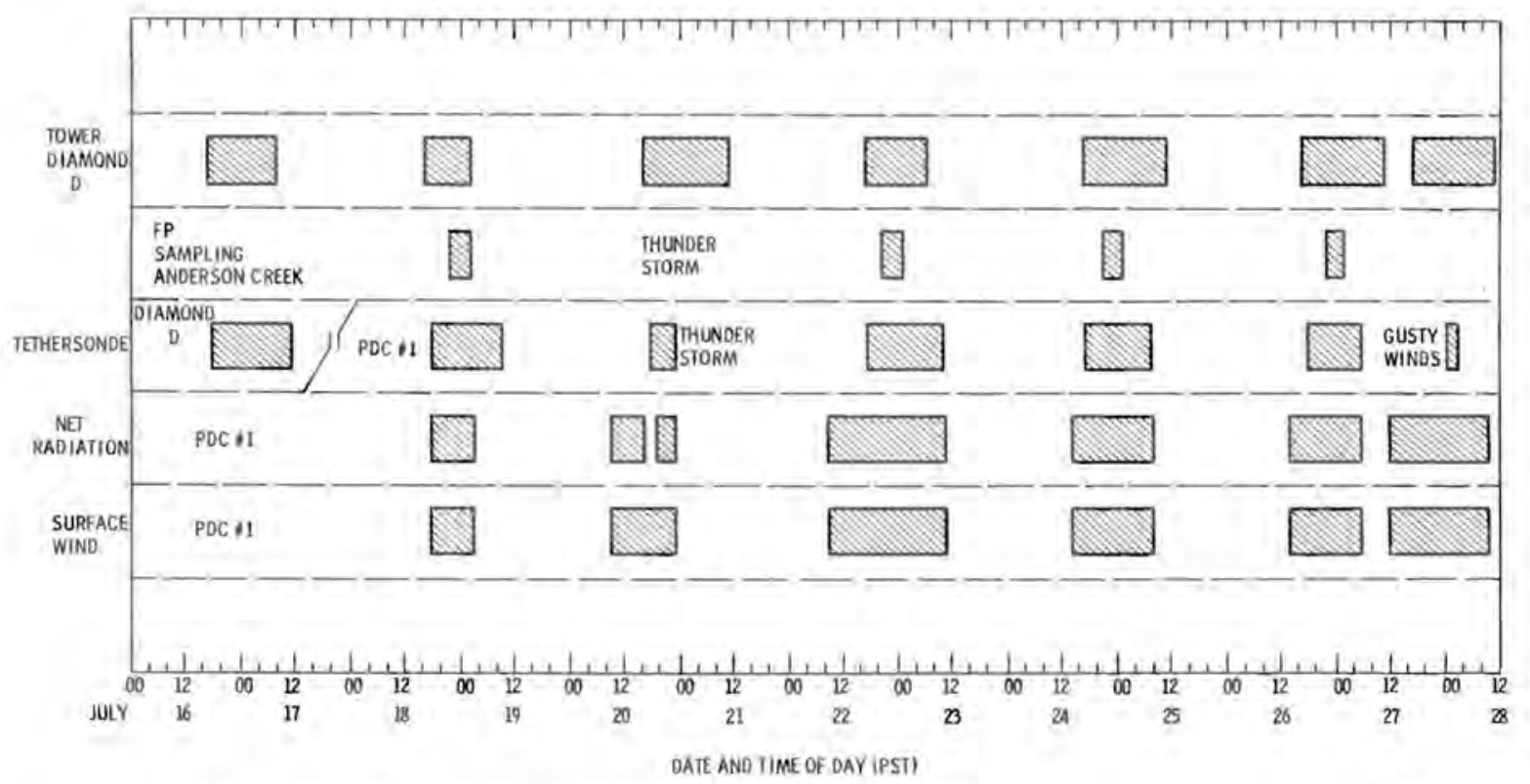

FIGURE 2. PNL's Data Collection Time Periods for Project ASCOT During fuly 1979 at Anderson Creek Valley 
radiation. The output of the radiometer at PDC-1 (at an up-valley location) was amplified, and the resultant analog signal was recorded on a strip chart. The strip chart was reduced by manually averaging over 10-min increments.

Measurements were not continuous at either site but were centered around selected, intensive, measurement periods. Figure 3 displays the times and magnitude of net radiation measurements for the 13 days of field measurements. The duration of an individual Diamond $D$ experiment was limited by the approximate $19 \mathrm{hr}$ of data that could be recorded on one magnetic tape with the selected $1-\mathrm{sec}$ scan rate. The PDC-1 data were restricted to periods when an electrical power generator was in operation at the site.

Although this note is not intended as indepth examination of the radiometer data, some preliminary comments and observations based on the analog traces of Figure 3 are in order.

The period of net positive radiation is about $12 \mathrm{hr} /$ day at each site, with positive values starting at about 0600 PST and ending shortly after 1800 PST.

The daytime net radiation at the Diamond $D$ site is greater than that at the PDC-1 site on all occasions where comparison is possible. This observation suggests a larger albedo at the PDC-1 site.

At night, the net outward flux of radiation from PDC-1 was slightly greater than at Diamond $D$ for the first four comparisons, i.e., through July 25; but the last two comparisons reverse this trend. Pertinent to this reversal is the fact that the PDC-1 radiometer was moved from over a gravel surface to over a grassy surface on the afternoon of July 26 . The change in character of nighttime net radiation following this instrument relocation could possibly result from a thermally insulating effect of the vegetation and the porous, grassy surface compared to the previous compact, bare, gravel surface. Since the daytime outward fluxes on July 27 and 28 remain greater at Diamond $D$ than at PDC-1, it appears that the albedo of the PDC-1 site remained greater than that at Diamond $D$. The surface beneath the Diamond $D$ net radiometer also had grass and weeds--a vegetative cover in the fenced area of the plowed field where the Diamond $D$ instrumentation was exposed.

The fluctuation of the radiation balance near sunset at Diamond D on July 16,18 and
20 likely resulted from trees to the northwest of the radiometer. The fluctuation diminished on July 20 and was not observed on subsequent dates. This change likely reflects the changing azimuth of the setting sun.

Most nights were essentially cloud free. A dramatic exception was on the evening and night of July 20 . Skies were overcast with thunderstorms in the area. The cloud cover resulted in reduced outgoing radiation that night.

Although only analog traces of the net radiation data are presented here, data from Diamond $D$ and from PDC-1 are available in digital form.

Fluorescent Particulate Tracer Experiments at Geysers Geothermal Site--Project ASCOT, JuTy 1979(a)

P. W. Nickola

Project ASCOT (Atmospheric Studies in Complex Terrain) is a Department of Energy (DOE)-sponsored program designed to develop technology needed to perform air quality impact assessments in areas of complex terrain. An early goal of Project ASCOT is to investigate through a field measurements program drainage flows in a "typical" valley. To this end, an intensive multilaboratory field program was conducted in the Anderson Creek Valley near Middletown, California during the period July 15 to July 28, 1979.

Among the field experiments performed during this period were atmospheric tracer releases. Personnel from Los Alamos Scientific Laboratory (LASL) released fluorescent particulate (FP) tracer during 4 nights when drainage flow was anticipated. Tracer release was from a point near the head of Anderson Creek at an elevation of about $1140 \mathrm{~m}(3730 \mathrm{ft}) \mathrm{ms} 1$. Tracer releases lasted from 21 to $25 \mathrm{~min}$, whereas down-valley sampling persisted for a minimum of $2 \mathrm{hr}$ at each of the five LASL sampling locations. The LASL sampling was performed at near-stream-bed locations at distances 2.7 to $7.6 \mathrm{~km}$ from the release point. At three of the five LASL sampling sites, samplers were operated in sequential fashion in order to obtain a measure of the

(a) Research also part of Atmospheric Boundary Layer Studies. 


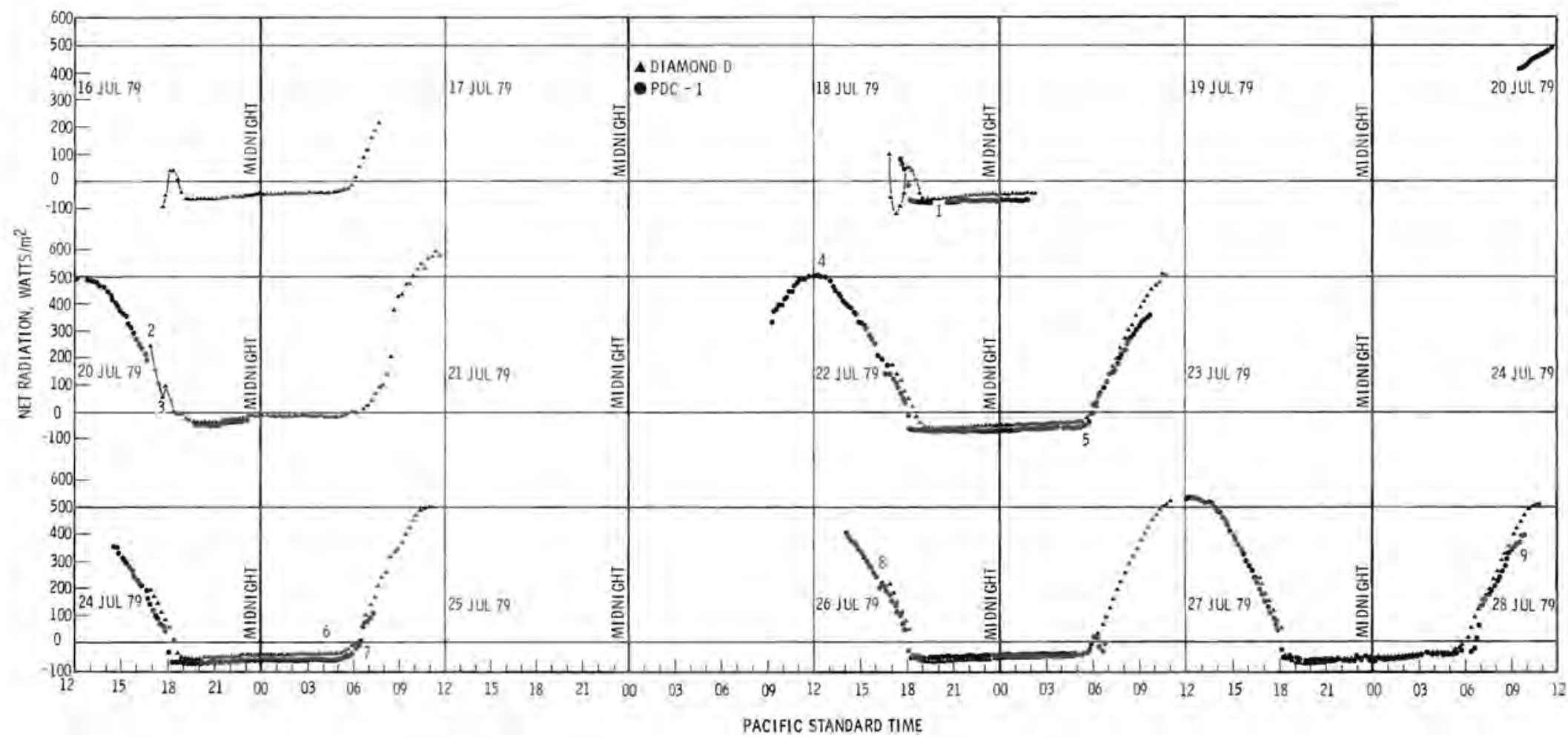

1) PDC-1; Strip chart pen problem.

2) Diamond D: Sensor moved to new location to avoid mid-afternoon tower shadow; moved before start of data collection on July 20,1979

) PCD-1: Strip chart jammed from about 1645 to 1940

4) PDC-1, 1230: Change from nitrogen purge gas to helium.

5) PDC-1, 0531: "Sun just up over mountains to east."

6) PDC-1, 0400: "Dawn light" visible.

7) PDC-1, 0614: "Cloudy. Altocumulus scattered to the east."

8) PDC-1, 1554 to 1607: "Moved radiometer to different location." The radiometer was over a gravel surface and was moved to "grassy surface."

9) PDC-1, 0930: "Weather clear."

FIGURE 3. Net Radiation versus Time for Thirteen Days of Field Experiments, July 1979 
history of tracer concentration. Integrating samplers were operated at all five sites. The samplers used by LASL were Rotorods.

Pacific Northwest Laboratory (PNL) complemented the LASL tracer sampling by operating membrane filter samplers at five sampling locations. Whereas the LASL sampling was designed to define down-valley profiles of FP concentration, the PNL sampling was designed to examine the cross-valley profile. The PNL samplers were located near the intersection of Anderson Creek and Socrates Mine Road, a distance about $2.7 \mathrm{~km}$ from the release point. An integrated sample as well as sequential samples were collected at the creek-road intersection (at the same location as an LASL sampling station), but unattended integrating samplers only were operated at four stations north and south of the creek bed.

The bottom portion of Figure 4 gives a cross-valley profile of elevation along a roughly north-south line near the PNL samplers. Although it would have been preferable to space samplers evenly with respect to elevation or distance, dense vegetation and steep terrain made such a sampling layout impractical. Sampling locations (triangles) on Figure 4 were plotted on the basis of elevation (not north-south distance from the Anderson (reek center position).

The data plotted in the upper portion of Figure 4 show the distribution of FP concentration observed during each of the four tracer releases as determined from the integrating samplers. These samplers were in operation at the start of tracer release and continued for at least $2 \mathrm{hr}$. Tracer release dates and durations are 1 isted at the right of the figure. The open circles at the Anderson Creek location represent the concentration derived from integration of the 9 to 12 sequential filter samplers operated at that location. They show reasonable agreement with the integrated sampler concentrations.

Al though Figure 4 indicates that the maximum tracer concentration was not observed at the Anderson Creek sampler during any field test, the data from Tests 1,3 , and 4 are in basic agreement with the picture of a cool mass of air draining down-valley. However, there is little doubt that the plume centerline during Test 2 was considerably north of the lower portion of the creek valley. Since the meteorology associated with the field tests is not available at this writing, the reason for the cross-
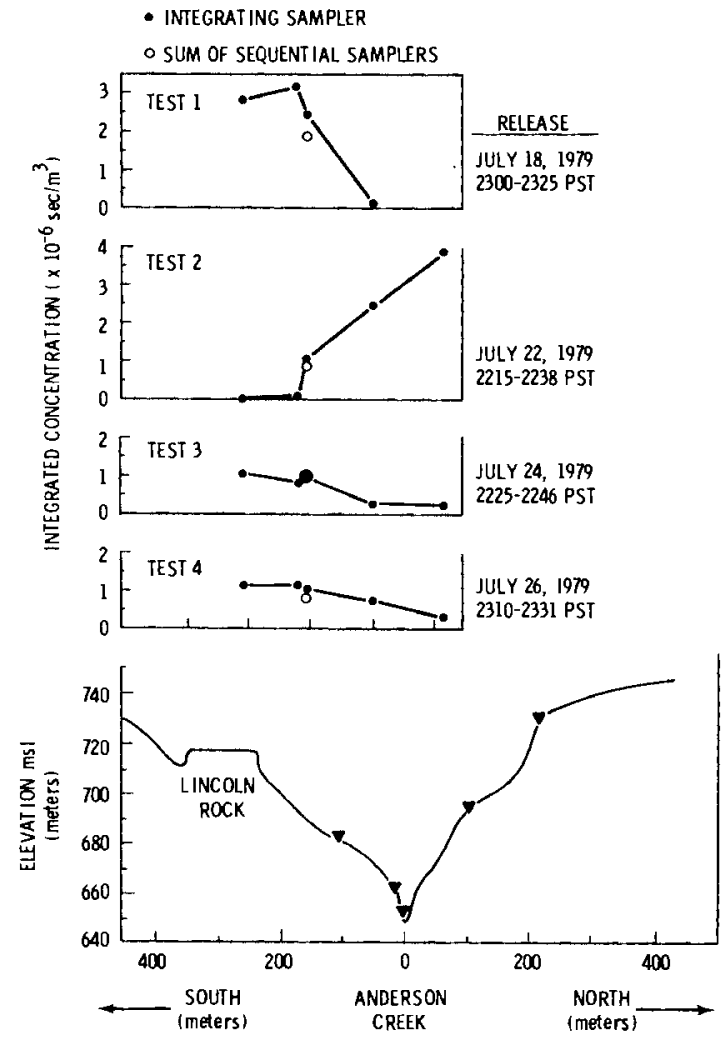

FIGURE 4. Cross-Valley Profiles of Tracer Concentration and of Terrain Elevation at $2.7 \mathrm{~km}$ from Tracer Release Point

valley plume component can only be speculated. It is possible that the distribution along the north wall of the valley results from a down-valley drainage modified by a gradient wind with a southerly component.

In order to be able to derive at least a "bal1-park" estimate of the lateral spread $\left(\sigma_{y}\right)$ of the tracer plume, the concentration profiles of Figure 4 were extrapolated to the south for Tests 1,3 , and 4 . Although an attempt was made to give an appearance of symmetry in the extrapolation, the procedure was very subjective. The $\sigma_{y}$ values derived for Tests 1,3 , and 4 were, respectively, 71,122 and $144 \mathrm{~m}--\mathrm{val} l u e s$ that are commensurate with those found in flat terrain at night for a similar downwind distance.

Figure 5 presents the results of the sequential sampling at the Anderson CreekSocrates Mine Road crossing. Sequential sampling increments were 15 min during Test 1 and 10 min during the other three tests. A comparison of the duration of 


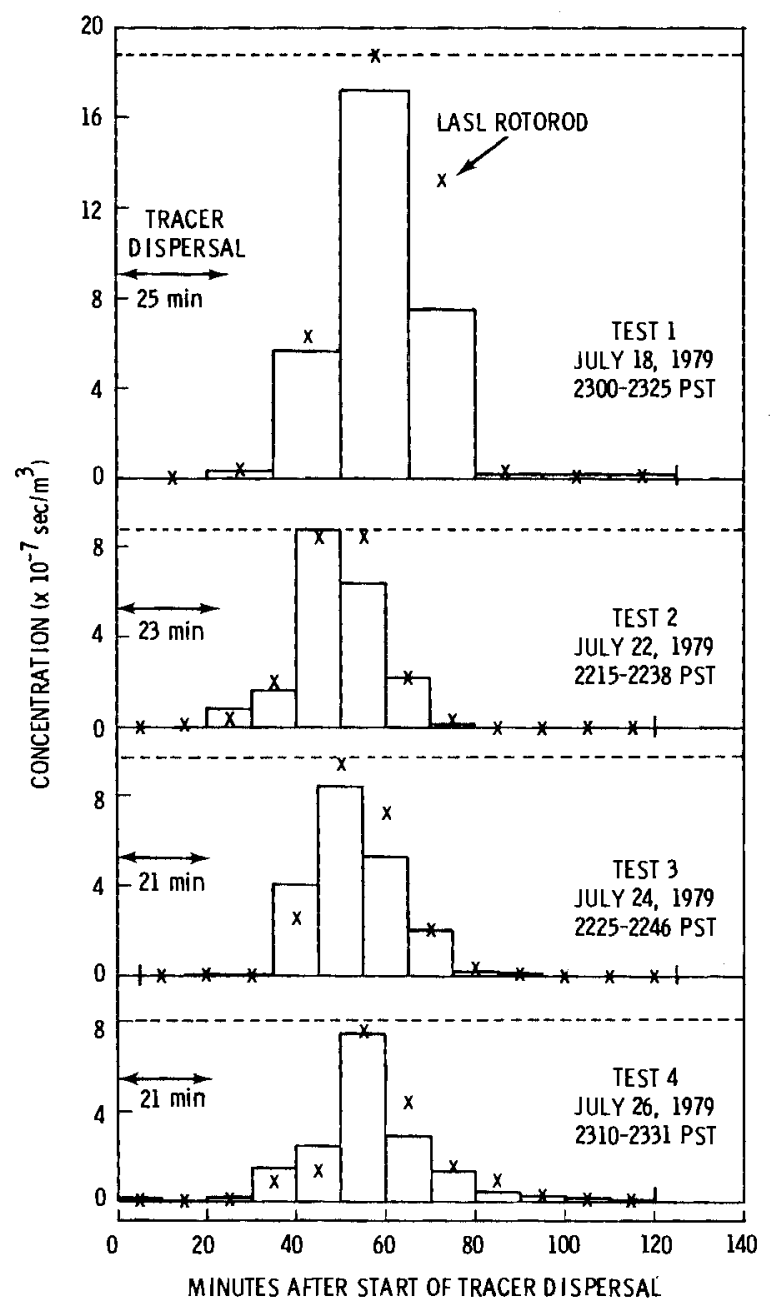

FIGURE 5. Tracer Concentration versus Time at Anderson Creek-Socrates Mine Road Crossing

tracer release (as depicted at the left for each test) with the duration of tracer passage at this $2.7-\mathrm{km}$ down-valley point reveals we11-above background concentrations for a period of at least twice the dispersal duration. The dotted lines, derived from the integrating samplers, indicate the concentration expected from a continuous plume. Note that only during Test 2 did the observed short-period concentration reach that expected continuous plume value. The " $x$ " symbols on Figure 5 represent the concentrations derived from LASL Rotorod samplers-samplers operated over the same time increments as the filter samplers.

On the basis of the 1979 experiments, it can be concluded that if crosswind tracer sampling is included in subsequent ASCOT field experiments, sampling should be extended much farther up the side of the valley.

Tethersonde Data at the Geysers Geothermal Site--Project ASCOT, July, 1979(a)

M. M. Orgi11, R. I. Schreck, T. W. Horst (Pacific Northwest Laboratory)

and W. D. Neff and R. S. Larson (Wave Propagation Laboratory)

Two mobile tethersonde units were utilized in the Anderson Creek area near Middletown, California during the July, 1979, field effort for Project ASCOT (Atmospheric Studies in Complex Terrain). One unit was from Pacific Northwest Laboratory (PNL) and the other from the Wave Propagation Laboratory (WPL) in Boulder, Colorado. On the evening of July 16, a cooperative effort between the two groups obtained tethersonde data at the Diamond $D$ Ranch site for $18 \mathrm{hr}$. After that period, the PNL tethersonde was located at the PDC-1 well site in the northwestern part of the Anderson Creek drainage $(840 \mathrm{~m})$ for the duration of the project.

WPL's tethersonde was located at the Thorne 7 well site $(600 \mathrm{~m})$ around $1.1 \mathrm{~km}$ southeast of the PDC-1 well site.

Data were obtained from both tethersonde sites for six nighttime and early morning periods. Vertical profiles of wind, temperature and humidity were taken about every hour except when strong winds, equipment malfunction or weather prevented them. A ground station received the data remotely, which was printed on a paper tape.

The PNL and WPL tethersonde data volume is in the process of being data-edited and plotted. Data are being placed on punch cards and after editing will be placed on a data tape. At the present time the edited, nonaveraged data are being processed by a computer plotting routine as shown in Figure 6 for preliminary assessment and analysis. The tethersonde data from both Anderson Creek sites and other data collected during this period will eventually be analyzed to define the vertical and horizontal mesoscale wind and temperature variations for this July period.

(a) Research also part of Atmospheric Boundary Layer Studies. 
TETHERSONDE (PNL) AT PDC-1 DATE. 0723790333 TO 0418 PST (TOP 0403)
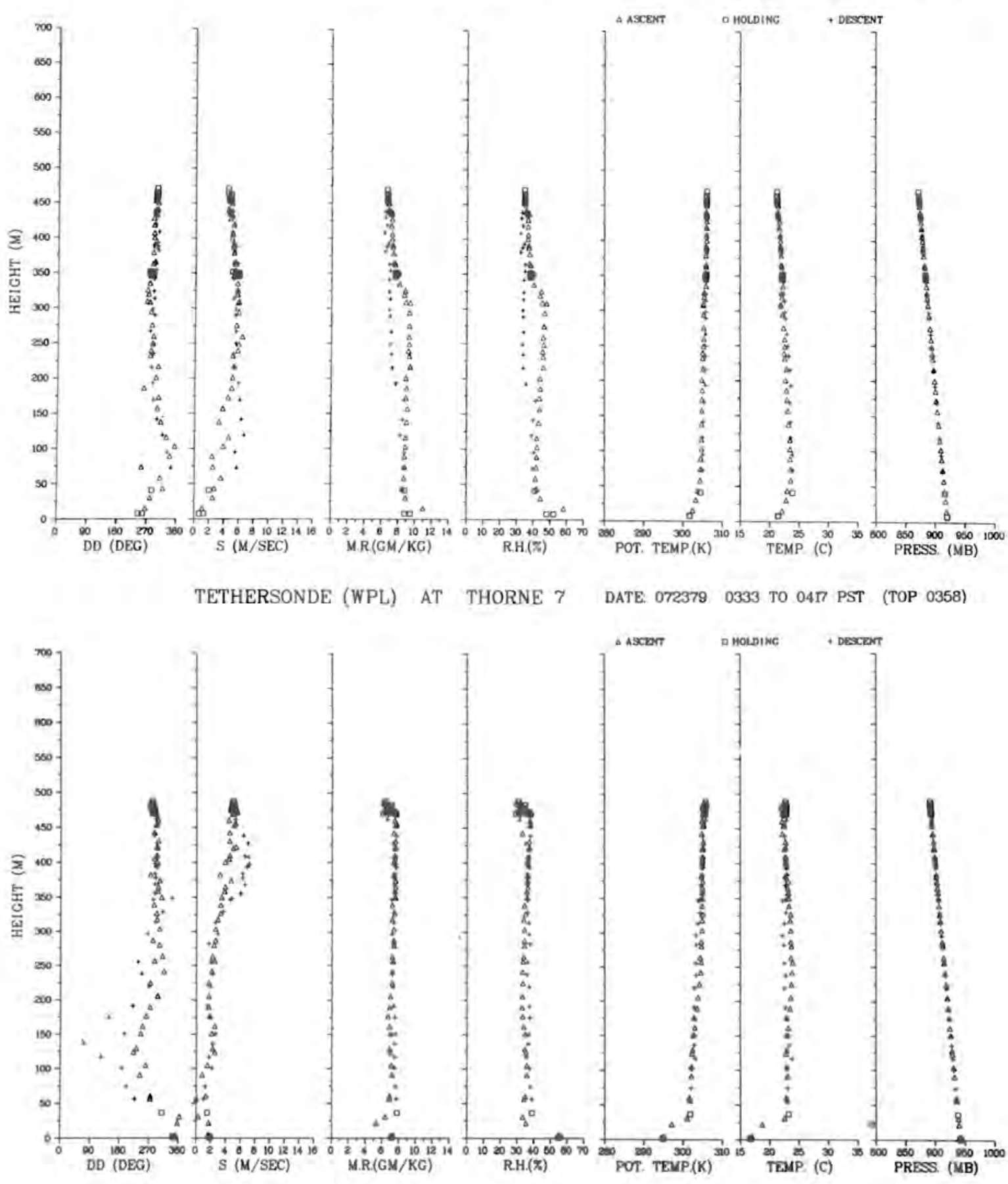

FIGURE 6. Tethersonde Data (PNL and WPL) for july 23, 1979 


\section{- Atmospheric Boundary Layer Studies}

Objectives of these studies are:

- Investigating the meteorological characteristics of the planetary boundary layer that pertain to pollutant transport and dry removal.

- Analyzing the transport and diffusion of pollutants in complex terrain, particularly in the Geysers Geothermal Area of California.

- Constructing simple models for the prediction of the depth, speed and direction of gravitycontrolled drainage flows and pollutant dispersion within these flows.

Micrometeorological Measurements During Drainage Wind Periods in the Geysers Area

J. C. Doran, O. B. Abbey and T. W. Horst

The Atmospheric Studies in Complex Terrain (ASCOT) Program is a multilaboratory, cooperative study of drainage flows in the Geysers area near Middletown, California. For the initial measurement period during the summer of 1979, Pacific Northwest Laboratory (PNL) installed a 30-m instrumented tower at the mouth of the Putah and Anderson creek drainage regions. The measurement site was located at the Diamond D Ranch, adjacent to a Doppler acoustic sounder operated by the National Oceanic ard Atmospheric Administration (NOAA) Wave Propagation Laboratory. The site was a large, open field partially obstructed by a line of trees approximately $20-\mathrm{m}$ high at the up-wind end of the field (Figure 7 ).

Aspirated thermistor and Gill UVW anemometers provided temperature and wind speed data at heights of 29.3, 22.8, 10.1 and $3.0 \mathrm{~m}$. Wet- and dry-bulb temperatures were measured at $2.4 \mathrm{~m}$, and soil temperatures were measured at 0.01 and $0.1 \mathrm{~m}$ below the surface. A net radiometer was also mounted on the tower at a height of $1 \mathrm{~m}$.

Data were recorded digitally on 9-track magnetic tape in either of two modes. During most of the summer, one scan of all instruments was taken every $10 \mathrm{sec}$; during a period of intensive measurements in July, the sampling rate was increased to 1 scan every sec.

In addition to providing generic information about the times and intensities of drainage winds, the data may be used for a number of more specific purposes. Measurements of the turbulent fluctuations of heat and wind velocity may be used to evaluate terms required in second-order closure models describing the development of drainage winds, and for diffusion models. Het radiation measurements are useful in the calculation of energy budgets. Developing profiles of drainage winds may be investigated in combination with the acoustic sounder measurements taken at the site. Low-frequency fluctuations in the wind as a result of oscillations in the stable drainage flow may also be discovered.

The data collected during this first season will be assessed in conjunction with the findings of other laboratories. These assessments will form the basis for a second, expanded program to be carried out in the summer of 1980.

\section{Sulfur Surface Flux Measurements}

J. G. Droppo

\section{Introduction}

The motivation for recent studies of surface pollutant fluxes derives from a need for better quantification of atmospheric pollutant budgets. Models of long-range sulfur transport are severely limited by the state-of-the-art definition of surface source/sink relationships.

Recent studies have made a major point that dry removal of air pollutants is not expected under all conditions. Because natural surfaces are sources as well as sinks for "air pollutants," "surface pollutant flux" or "surface flux" are proposed in lieu of terms implying either a surface sink or source for nonprecipitation surface pollutant fluxes. For example, a surface flux field study using flux chambers was able to 


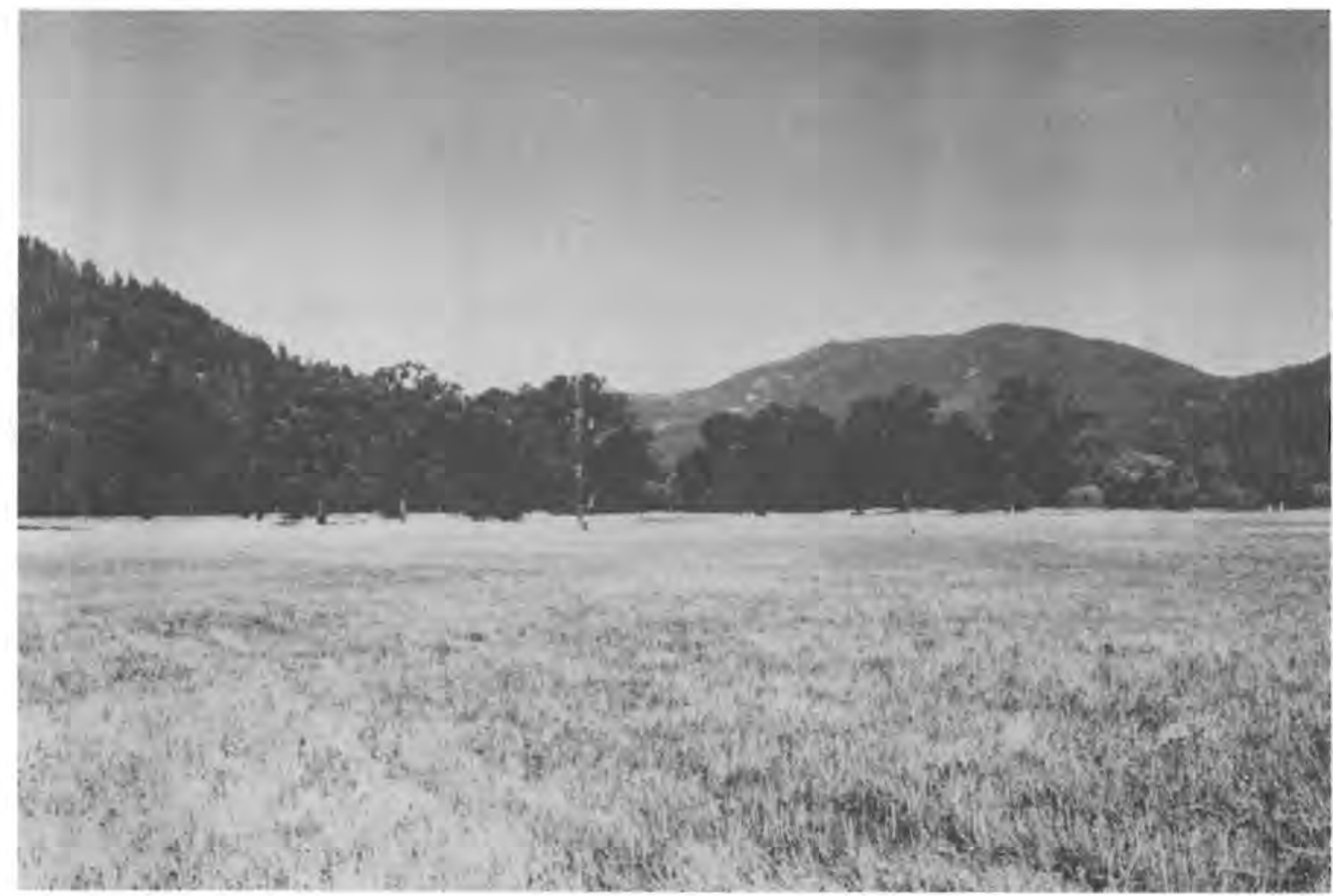

FIGURE 7. View of Instrumented Tower Looking Toward Putah and Anderson Creek Drainage Regions

define the natural sulfur source flux from salt marshes on the coast of North Carolina (Ameja et a1. 1979). Emission rates of sulfur compounds were measured.

Surface-layer flux research of sulfur compounds has comprised a major fraction of efforts for the past few years. These studies have been in two major groups: profile and eddy flux measurements. The surface flux rates for sulfur dioxide have also been the topic of a number of recent profile field studies that have provided a relative wealth of data on $\mathrm{SO}_{2}$ fluxes compared to just a few years ago.

In comparison to $\mathrm{SO}_{2}$, the number of reported studies of sulfur aerosol surface fluxes are fewer and have fewer data points. Studies of sulfur aerosol fluxes are inherently more difficult than those of $\mathrm{SO}_{2}$ as a result of much smaller relative flux rates. Recent studies tend to confirm previously postulated order of magnitude differences between these fluxes. Obtaining equivalent experimental accuracy for sulfur aerosols is made more difficult for both the profile and eddy flux approaches as a result of the smaller ratio between fluxes and the natural concentrations.

\section{Pacific Northwest Laboratory Particulate} Sulfur Flux Studies

Profile surface-layer sulfur flux studies at Pacific Northwest Laboratory (PNL) have been previously reported (Droppo et al. 1976; Droppo 1977; Droppo and Doran 1979). These studies entailed the acquisition of approximately $1 \mathrm{hr}$ of nucleopore filter samples taken at three log-spaced heights. The volume and temperature of air drawn through each filter was monitored to allow accurate flow corrections. The material on the filters was analyzed using a specially developed $X$-ray fluorescence procedure to maximize the accuracy of the gradient values. Three levels of detailed micrometeorological data were also recorded to define eddy diffusivities.

The results from three sites are presented here: Centralia (grassland), Hanford (arid vegetation), and Sangamon (cornfield). 
The Hanford tests on December 17, 1975 over arid surfaces during low winds produced results that most closely agreed with classical models of aerosol removal. In addition, the gradient accuracy appeared to be the best in the Hanford tests. Figure 8 shows one set of sulfur concentration, wind and temperature profiles at Hanford. Three levels were chosen as a minimum to define the gradient and provide an intermediate point to assess the accuracy of the gradient. Deviations from a linear fit with logarithmic height reflect both experimental variability and natural curvature although the Hanford tests indicated much better profile accuracy than did tests at other sites. Our current estimate is that the gradient accuracy ranges up to $\pm 5 \%$. Absolute accuracy for sulfur concentrations are not as good as the relative accuracy.

Table 1 contains two Hanford tests with near-background sulfur aerosol concentrations. The deposition velocities of a few centimeters per second agree with values extrapolated from wind tunnel tests, which may reflect the fact that the arid surfaces most closely match the wind tunnel surfaces. The

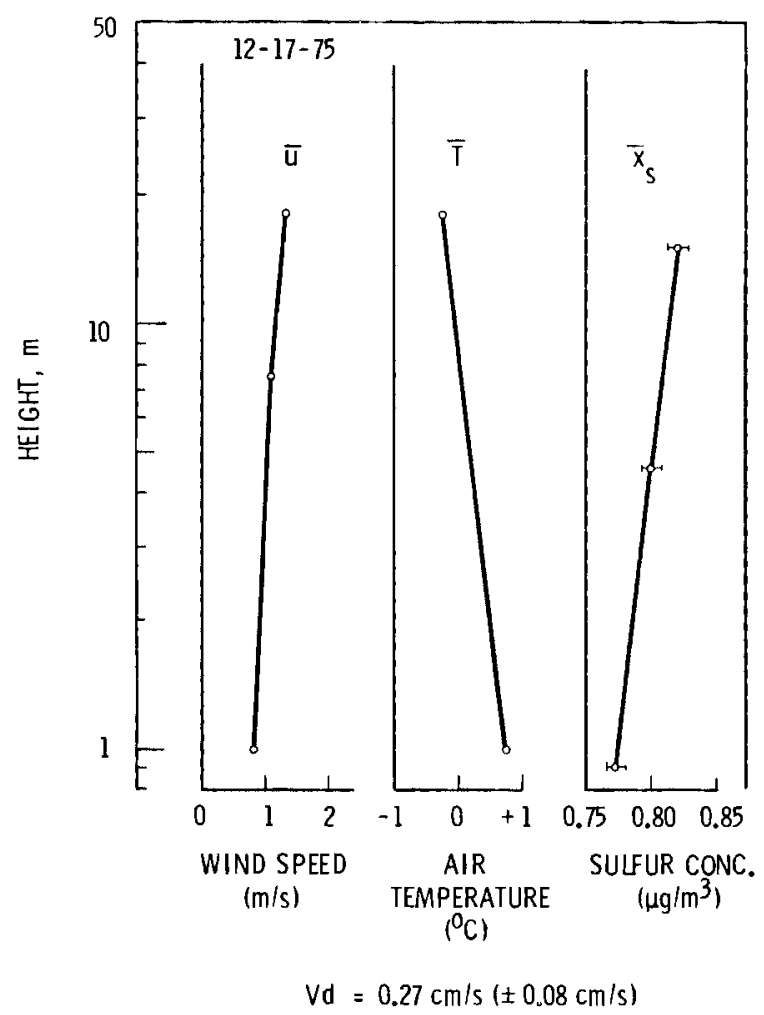

FIGURE 8. Particulate Sulfur, Wind, and Temperature Particles at Hanford (Error Bars Illustrate $\pm 1 \%$ Resolution)
TABLE 1. Summary of Results for Dry Deposition of Sulfur Aerosols

\begin{tabular}{|c|c|c|c|c|c|}
\hline Test & $\begin{array}{r}V_{d} \\
(\mathrm{~cm} / \mathrm{s}) \\
\end{array}$ & $\begin{array}{c}\mathrm{R}_{\mathrm{T}} \\
(\mathrm{s} / \mathrm{cm}) \\
\end{array}$ & $\begin{array}{r}R_{a} \\
(\mathrm{~s} / \mathrm{cm}) \\
\end{array}$ & $\begin{array}{r}R_{\mathrm{S}} \\
(\mathrm{s} / \mathrm{cm}) \\
\end{array}$ & $\begin{array}{r}\mathrm{u}(17 \mathrm{~m}) \\
(\mathrm{m} / \mathrm{s}) \\
\end{array}$ \\
\hline 1 & 0.10 & 10.0 & 2.3 & 7.7 & 1.13 \\
\hline 3 & 0.27 & 3.7 & 0.44 & 3.3 & 1.28 \\
\hline
\end{tabular}

values computed with momentum eddy diffusivities, and the atmospheric resistances are momentum transfer resistances and the surface resistances are residual resistances.

The data taken over nonarid vegetation show quite a different trend. Daytime particulate sulfur gradients consistently indicate a surface source term. Figures 9 and 10 show the sulfur profiles for the Centralia and Sangamon sites, respectively. These figures are presented to illustrate trends in profiles.

Centralia daytime tests (May 1975) consistently had negative gradients--the profiles at lower concentrations had about the same percentage change as profiles at higher concentrations. Much of the consistency is likely the result of the similar midday conditions for these tests.

Sangamon daytime tests (July 1976) also had consistently negative gradients. The only test that suggested a surface sink for sulfur particulates occurred at the higher ambient sulfur concentrations. The profile with the lowest concentrations provides an interesting insight to particulate surface/ sink processes. The order of magnitude change in sulfur concentration over the profile is not unreasonable for the early morning time of this test.

The $X$-ray fluorescence analysis of the Sangamon data provides comparable accuracy of relative concentration of elements other than sulfur. Figure 11 shows the profiles of sulfur and three other elements. The ordering of the gradients are consistent between all three levels and indicate different vertical flux rates for each of the elements--including a reversal to a flux downward for silicon. The ordering of the profiles was the same for other tests. 


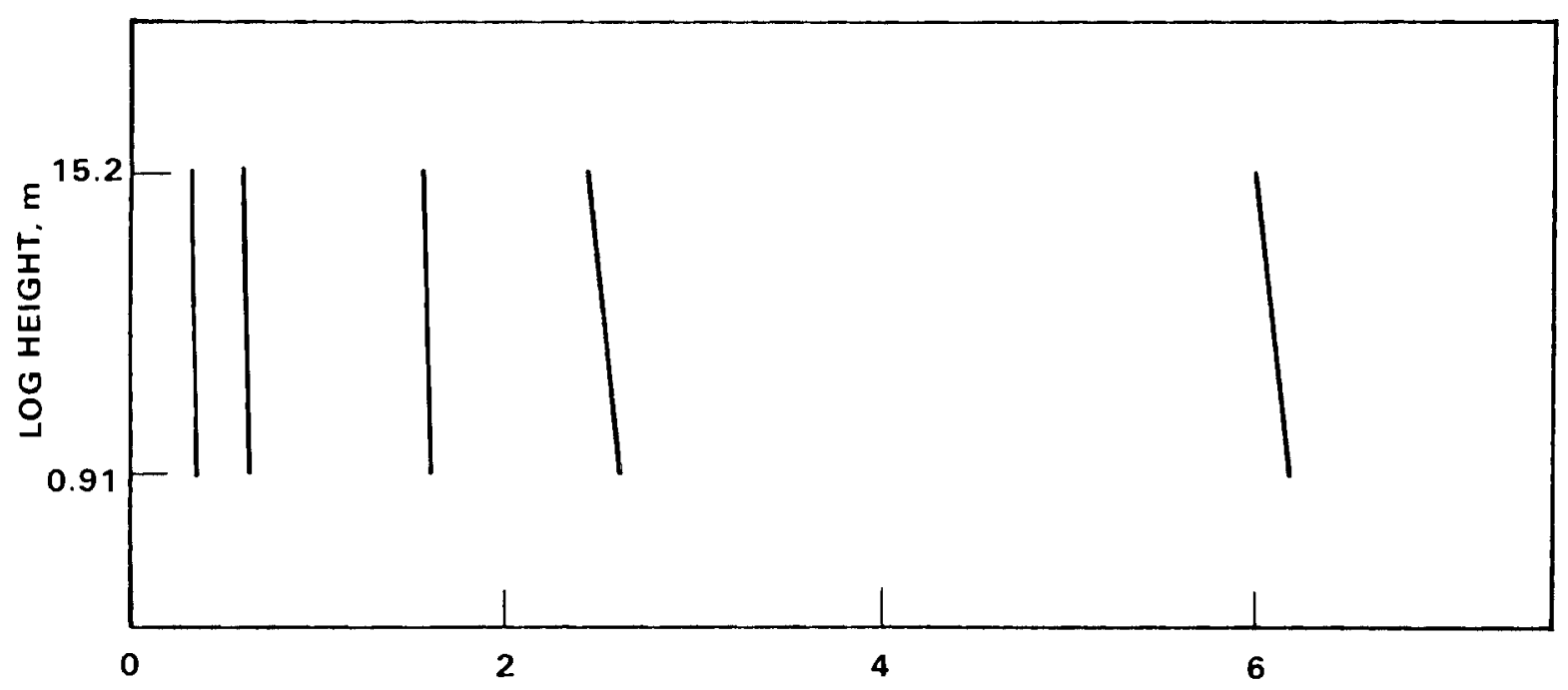

SULFUR CONCENTRATION.

$\mu g / m^{3}$

FIGURE 9. Centralia Particulate Sulfur Profiles

JULY 1976 GRADIENTS OVER CORN

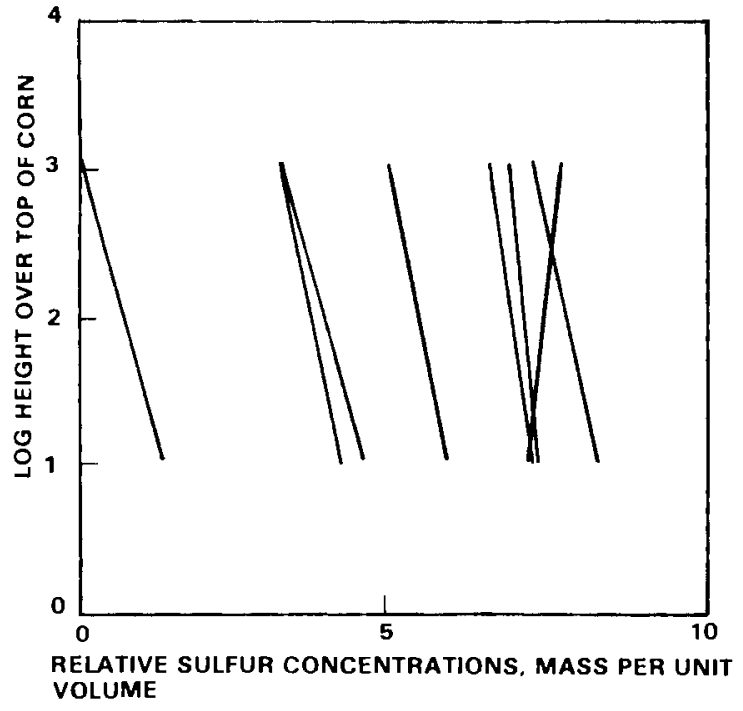

FIGURE 10. Sangamon Particulate Profiles
JULY 1976 GRADIENTS OVER CORN

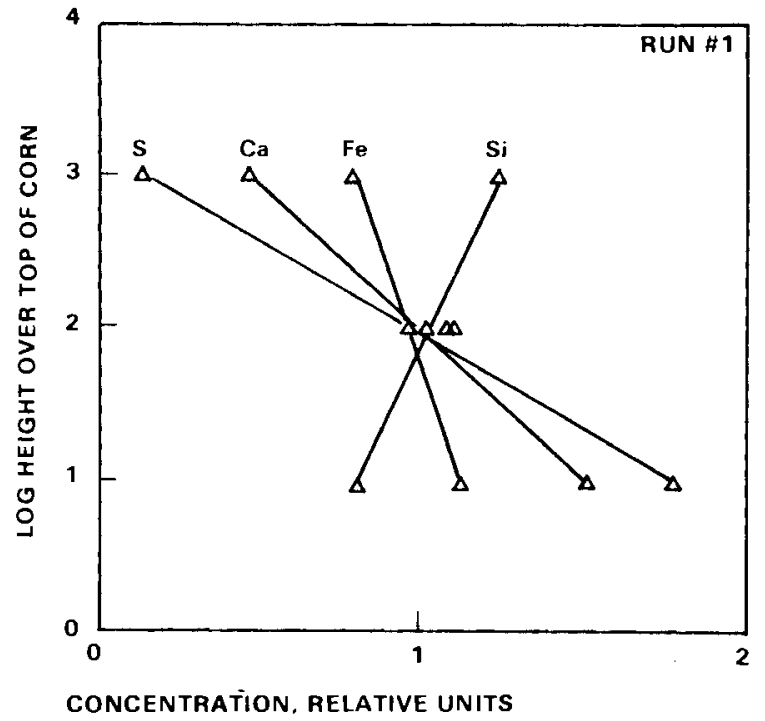

FIGURE 11. Normalized Sangamon Particulate Profiles for Various Elements 
Figure 12 shows a comparison of gradients normalized to the upper heights with this test and two other tests. The order of sorting of gradients is the same; the direction of the silicon gradient has reversed.

Uncertainties in the physical interpretation of the gradients have precluded computation of specific flux rates. If a gradient flux is assumed, the order of magnitude of these gradients indicates the source term equivalent in magnitude but reversed in size to removal rates predicted by deposition velocities of a few centimeters per second.

The particulate source/sink processes over natural surfaces camnot be considered as a simple one-directional single rate flux. There is evidence that natural surfaces may be either sinks or sources of sulfur particulates. The non-equivalent normalized gradients for different elements (Figures 11 and 12) illustrate the potential complexity of the fluxes or the processes defining the shape of the profiles.

The state-of-the-art in surface flux measurements has not yet been able to meet the information need; sulfur sink/source surface processes are only incompletely understood. The way is open for improvement of current or development of new experimental approaches.

\section{References}

Ameja, U. P., J. H. Overton, L. T. Cupitt, J. L. Durham and W. E. Wilson. 1979. "Direct Measurements of Emission Rates of Some Atmospheric Biogenic Sulfur Compounds." Tellus. $31: 174-178$.

Droppo, J. G., D. W. Glover, 0. B. Abbey, C. W. Spicer and J. Cooper. 1976. "Measurement of Dry Deposition of Fossil Fuel Pollutants." Final Report under EPA Contract 68-02-1747, Pacific Northwest Laboratory, Richland, WA.

Droppo, J. G. 1977. "Proof Test of a System to Measure the Dry Deposition of Sulfur Aerosol in the Plume from a Northwest Fossil Fuel Power Plant." In Pacific Northwest Laboratory Annual Report of 1976 to the ERDA Assistant Administrator for Environmental Safety, Part 3, Atmospheric Sciences. BNWL2100 PT3, Pacific Northwest Laboratory, Richland, WA.

Droppo, J. G. and J. C. Doran. 1979. "Measurements of Surface Layer Turbulent Ozone Flux Processes." Preprints of the Fourth Symposium on Turbulence, Diffusion and Air Pollution, Reno, NV, American Meteorological Society, Boston, MA.

\section{NORMALIZED GRADIENTS OVER CORN - JULY 1976}

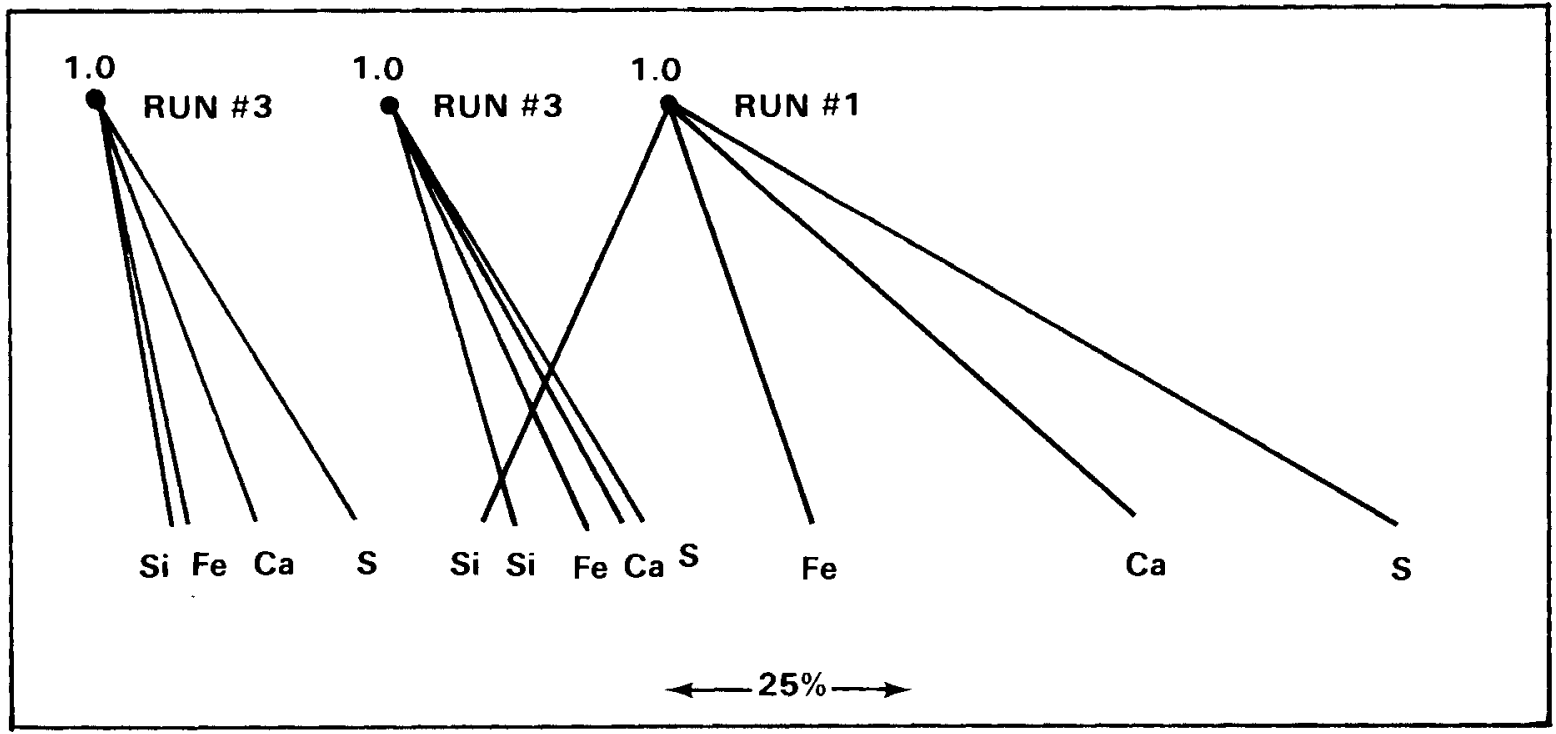

FIGURE 12. Normalized Particulate Gradients for Three Sangamon Tests 

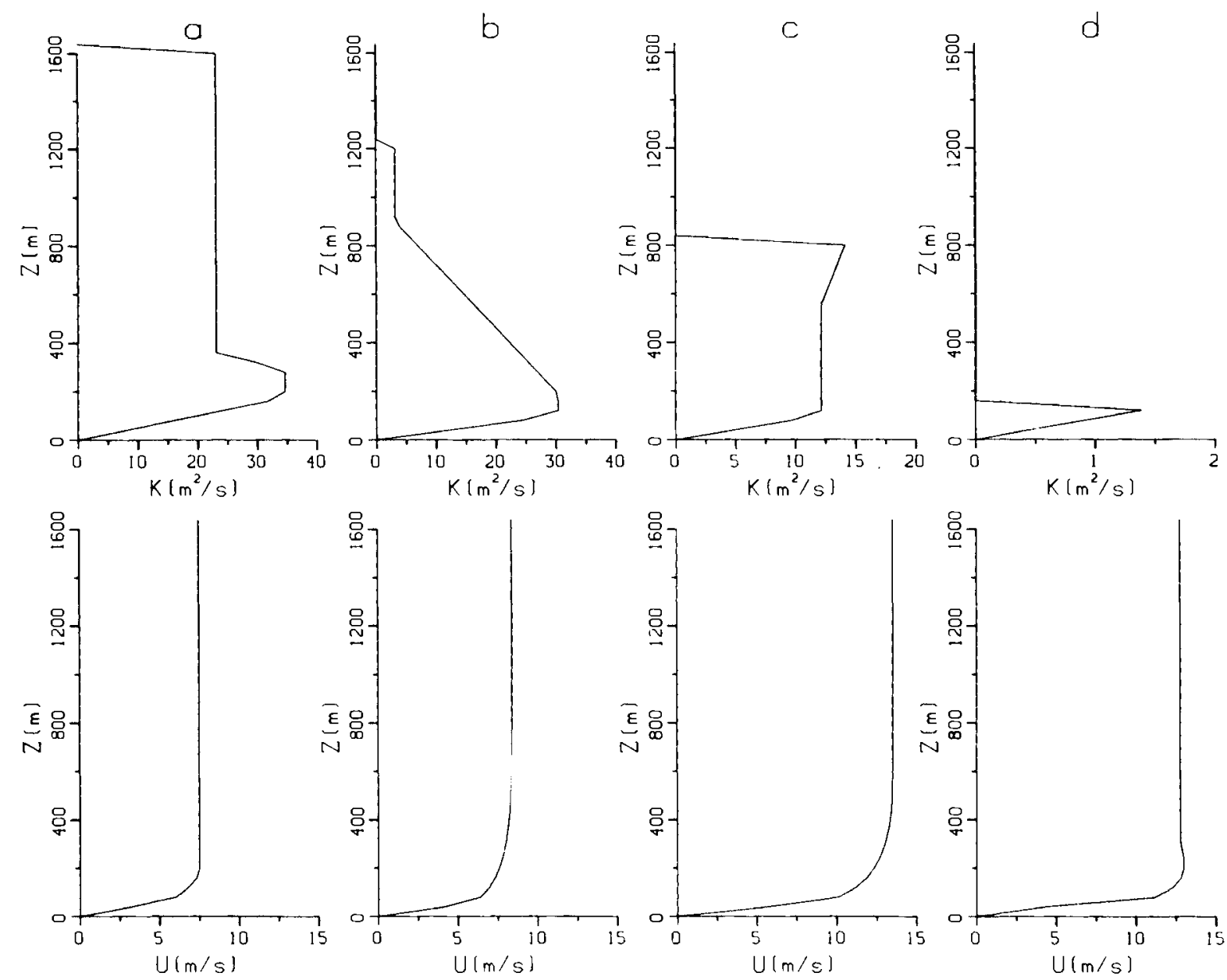

FIGURE 13. Eddy Diffusivity Profiles (Top) and Wind Speed Profiles (Bottom) for a) Moderately Unstable, b) Slightly Unstable, c) Neutral and d) Stable Conditions

While the fractional losses of material for these two cases are periodically the same, significantly different behavior is observed at other times. The differences are most striking if the ground-level concentrations are considered, since these are most sensitive to the differences in $v_{d}\left(z_{*}\right)$. Figure 14 shows the suspension ratios in the lowest $40 \mathrm{~m}$ as a function of downwind distance after 60 and $72 \mathrm{hr}$. The suspension ratio is defined here as the amount of material in the air divided by the amount that would have been present without deposition. The details of the concentration distribution are clearly dependent on the diurnal variations in both stability and $v_{d}\left(z_{\star}\right)$.

These results show that the determination of appropriate values of $v_{d}\left(z_{*}\right)$ for particles is more important than has been gener- ally acknowledged and underscore the necessity for additional measurements in this area.

\section{References}

Clarke, R. H. 1970. "Observational Studies in the Atmospheric Boundary Layer." Quart. J. R. Met. Soc. 96:91-114.

Draxler, R. R. and W. P. Elliott. 1977. "Long-Range Travel of Airborne Material Subjected to Dry Deposition." Atmos. Environ. $4: 35-40$.

Egan, B. A. and J. R. Mahoney. 1972. "Numerical Modeling of Advection and Diffusion of Urban Area Source Pollutants." J. Appl. Met. 11:312-322. 
Sensitivity of Particle Deposition to Changes in Deposition Velocity

\section{J. C. Doran}

In the past few years, the effects of varying deposition velocities on the removal rates of gaseous pollutants have begun to receive greater attention. In addition, recent experiments (Wesely et a1. 1977; Hicks and Wesely 1978) have shown that the commonly accepted value of $00.1 \mathrm{~cm} \mathrm{~s}^{-1}$ for the deposition velocity of small particles may be a considerable underestimate, and that substantial diurnal fluctuations in the deposition velocity are not uncommon. These findings are particularly significant since the aerodynamic resistance to vertical transport is relatively less important in cases where the surface resistance is large. This is generally assumed to be true for small particles. As a result, variations in the surface resistance (or deposition velocity) may have a correspondingly larger effect on pollutant removal than would be true for gaseous contaminants. In the present study, a relatively simple model is utilized to examine the sensitivity of particle deposition to changes in the deposition velocity when this parameter is smal1. The model incorporates the diurnal variations of winds, eddy diffusivities, and surface resistance terms, and illustrates the complexity of the interactions of these factors in determining concentration patterns for pollutants.

The basic equation describing the plume behavior in the model is the standard timedependent gradient transport formulation for two-dimensional flow:

$$
\frac{\partial \bar{c}}{\partial t}+\bar{u}(z) \frac{\partial \bar{c}}{\partial x}=\frac{\partial}{\partial z}\left(K(z) \quad \frac{\partial \bar{c}}{\partial z}\right)
$$

where $\bar{c}$ is the concentration averaged over a rectangular grid element, $\bar{u}(z)$ is the height-dependent mean velocity, and $K(z)$ is the eddy diffusivity. The diffusing pollutant is assumed to be removed at some height $z_{\star}$, and this process is described by the boundary condition

$$
\left.K(z) \frac{\partial \bar{c}}{\partial z}\right|_{z=z_{\star}}=v_{d}\left(z_{\star}\right) \bar{c}\left(z_{\star}\right)
$$

where $v_{d}\left(z_{*}\right)$ is a specified deposition velocity. The height $z_{*}$ need not be equivalent to $z_{Q}$, the roughness length for momentum, but in the absence of tall vegetation canopies $z_{\star}$ and $z_{0}$ are probably comparable.
For the model, a value of $5 \mathrm{~cm}$ was chosen for $z_{\star}$; the method outlined below can readily be modified for other values.

The diurnal cycle of wind and stability was divided into four periods:

- Stable conditions were in effect from 0000 to 0700 and from 2100 to $2400 \mathrm{hr}$.

- Neutral conditions prevailed form 0700 to 1000 and from 1900 to $2100 \mathrm{hr}$.

- Slightly unstable conditions ran from 1000 to 1400 and from 1700 to $1900 \mathrm{hr}$.

- Moderately unstable conditions occurred between 1400 and $1700 \mathrm{hr}$.

The wind and eddy diffusivity profiles for these categories were adopted from the profiles given by Clarke (1970) and are shown in Figure 13. Above a mixing height $H$, which also varies with time, $K(z)$ is assumed to be zero so that turbulent mixing is suppressed.

Equation (1) was solved using a modified combination of schemes suggested by Egan and Mahoney (1972) and Draxler and Elliot (1977). A continuous source was assumed at a height of $100 \mathrm{~m}$, corresponding to a moderately high stack.

Various initial release times were used and the resulting depletion of material studied. For an initial release at 0000 , the fractions of emitted material lost after $24 \mathrm{hr}$ were $0.067,0.149$, and 0.232 for $v_{d}\left(z_{\star}\right)$ values of $0.1,0.3$ and $0.5 \mathrm{~cm} \mathrm{~s}^{-1}$, respectively. These relative differences are much greater than would be the case if, for example, values of $1.0,3.0$, and $5.0 \mathrm{~cm} \mathrm{~s}^{-1}$ were chosen for $v_{d}\left(z_{\star}\right)$.

Hicks and Wesely (1978) have also shown evidence for a diurnal variation in the values of $v_{d}\left(z_{*}\right)$, with the highest values occurring during the afternoon hours. Although no general conclusions were drawn from their preliminary study, it is interesting to examine the consequence of such behavior if it is applied to areas other than the pine forest over which their measurements were obtained. To simulate this variation, it was assumed that the deposition velocity $v_{d}\left(z_{\star}\right)$ attained values of $0.1,0.3,0.5$ and $0.567 \mathrm{~cm} \mathrm{~s} \mathrm{~s}^{-1}$ during stable, neutral, slightly unstable and moderately unstable periods, respectively. This distribution gave a daily average of $0.3 \mathrm{~cm} \mathrm{~s}^{-1}$, and the results were compared with those obtained for a fixed value of $v_{d}\left(z_{\star}\right)$ of $0.3 \mathrm{~cm} \mathrm{~s}^{-1}$. 

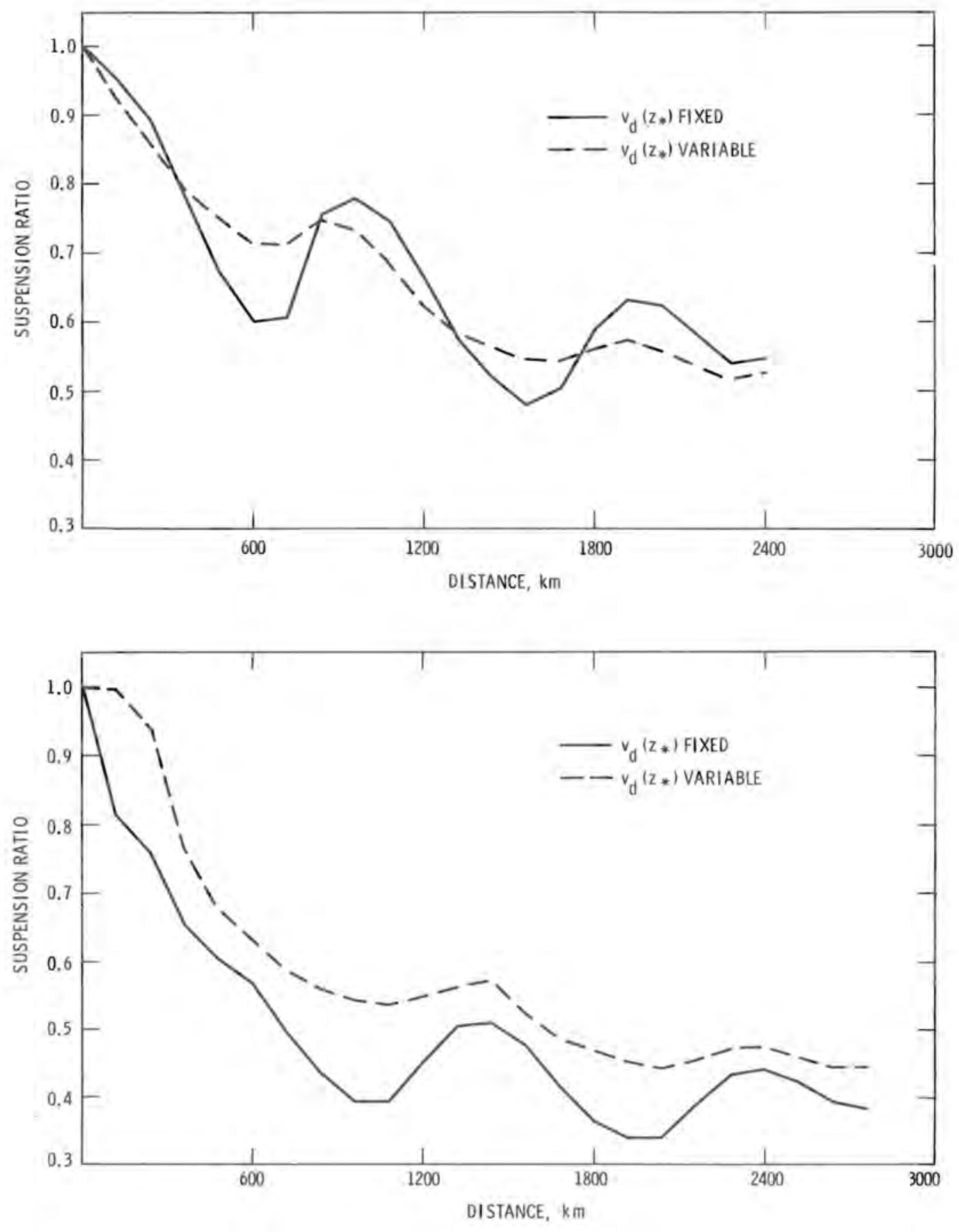

FIGURE 14. Suspension Ratio in Lowest $40 \mathrm{~m}$ as a Function of Downwind Distance. $v_{d}\left(z_{*}\right)+0.3 \mathrm{~cm} \mathrm{~s}^{-1}$ and $v_{d}\left(z_{*}\right)$ Variable with Temporal Average Value of $0.3 \mathrm{~cm} \mathrm{~s}^{-1}, 60 \mathrm{Hr}$ After Initial Release (Upper) and $72 \mathrm{Hr}$ After Initial Release (Lower) 
Hicks, B. B. and M. L. Wesely. 1978. "Recent Results for Particle Deposition Obtained by the Eddy-Correlation Method." Paper presented at the American Institute for Chemical Engineers 85th National Meeting, June 4-8, 1978, Philadel phia, PA.

Wesely, M. L. and B. B. Hicks, 1977. "Some Factors That Affect the Deposition Rates of Sulfur Dioxide and Similar Gases on Vegetation." J. Air Pol1. Control Assoc. 27:11101116 .

Wesely, M. L., B. B. Hicks, W. P. Dannevik, S. Frisella and R. B. Husar. 1977. "An Eddy-correlation Measurement of Particulate Deposition from the Atmosphere." Atmos. Environ. 11:561-563.

Application of the Modified Source Depletion Model

T. W. Horst

Horst (1979) proposed a modification of the source-depletion diffusion-deposition model, and its predictions compared quite well to the surface-depletion model when using a Lagrangian similarity diffusion model. However, the Lagrangian similarity model is theoretically limited to near-surface releases and short downwind distances. Since the Gaussian diffusion model with empirical formulas for $\sigma_{z}$ has a broader potential application, the aerodynamic resistance of the Gaussian diffusion model has been derived for use in the modified source depletion model. The resulting predictions are shown here to compare very well with the surface depletion model. A procedure is also suggested for use with particles that have a finite settling velocity.

\section{The Gaussian Diffusion Model}

The modified source depletion model predicts the crosswind-integrated airborne contamination as the result of a point source to be

$$
\bar{c}^{y}(x, z)=Q(x) D(x, z, h) P(x, z)
$$

where $h$ is the source height, $z$ is the receptor height and $x$ is the downwind separation of source and receptor. The function $D(x, z, h)$ describes the diffusion from a unit source of nondepositing contaminant. For the common Gaussian plume model

$$
\begin{aligned}
D(x, z, h)= & \frac{1}{\sqrt{2 \pi u} \sigma_{z}}\left\{\exp \left[\frac{-(z-h)^{2}}{2 \sigma_{z}{ }^{2}}\right]\right. \\
& \left.+\exp \left[\frac{-(z+h)^{2}}{2 \sigma_{z}{ }^{2}}\right]\right\}
\end{aligned}
$$

where $u$ is the mean wind speed and $\sigma_{z}$ is the vertical diffusion parameter. The source strength $Q_{0}$ is reduced as a function of downwind distance to account for the loss of airborne contaminant by deposition,

$Q(x)=$

$Q_{0} \exp \left\{-\int_{0}^{x} v_{d}\left(z_{\star}\right) D\left(x^{\prime}, z_{\star}, h\right) P\left(x^{\prime}, z_{\star}\right) d x^{\prime}\right\}$.

Here $v_{d}\left(z_{\star}\right)$ is the deposition velocity evaluated at height $z_{\star}$.

Since deposition preferentially removes the contaminant at ground-level, the vertical distribution is altered from the nondepositing form (2). This is predicted by the profile function

$$
P\left(x, z_{\star}\right) \simeq\left\{1+\frac{v_{d}}{\Delta z} \int_{0}^{\Delta z} R\left(z, z_{\star}\right) d z\right\}^{-1}
$$

where $\Delta z=\sqrt{\pi / 2} \sigma_{z}$ and $R$ is the aerodynamic resistance

$$
R\left(z, z_{\star}\right)=\int_{z_{\star}}^{z} \frac{d z^{\prime}}{K\left(z^{\prime}\right)}
$$

The eddy diffusivity $k$ is related to the diffusion parameter $\sigma_{z}$ by

$$
\sigma_{z} \frac{d_{\sigma_{z}}}{d x}=\frac{k}{u}
$$

Substituting (6) and

$$
\frac{d \bar{z}}{d \sigma_{z}}=\sqrt{\frac{2}{\pi}}
$$

into (5) gives

$$
R\left(z, z_{\star}\right)=\frac{1}{u} \sqrt{\frac{2}{\pi}} \int_{x\left(z_{\star}\right)}^{x(z)} \frac{d x}{\sigma_{z}} .
$$


Figure 15 shows the deposition-caused reduction of the ground-level airborne contamination as calculated by the modified source depletion model, Equations (1) to (4) and (8). Also shown are the predictions of the Chamberlain source depletion model,

$P(x, z)=1$, and the surface depletion model. The calculations were made for a source height of $10 \mathrm{~m}$ and a ratio of the deposition velocity to friction velocity, $v_{d} / u_{*}$, equal to 0.03. This corresponds to a single particle size; the variation of $v_{d} / u$ with atmospheric stability or Pasquill category results from the dependence of $u_{\star} / u$ on

stability. The agreement between the modified source depletion model and the surface depletion model, an exact solution for nonsettling particles, is quite good.

\section{Settling Particles}

Equations (2) and (4) are for nonsettling particles, $v_{S}=0$. A common procedure for settling particles is to replace the source height in (2) with

$$
h^{\prime}=h-v_{s} x / u \text {. }
$$

This is not an exact solution, but is probably a reasonable approximation for $v_{S} x /$ uh $<1$. Equation (4) is then modified by replacing $v_{d} R$ with

$$
\frac{v_{d}-v_{s}}{v_{s}}\left(1-e^{-v_{s} R}\right)
$$

The settling particle model will be tested against a K-theory model during FY 1980.

\section{Reference}

Horst, T. W. 1979. "A Simple Correction to the Source Depletion Model." In Pacific Northwest Laboratory Annual Report for 1978 to the DOE Assistant Secretary for Environment, Part 3, Atmospheric Sciences. PNL2850 PT3, Pacific Northwest Laboratory, Richland, WA.

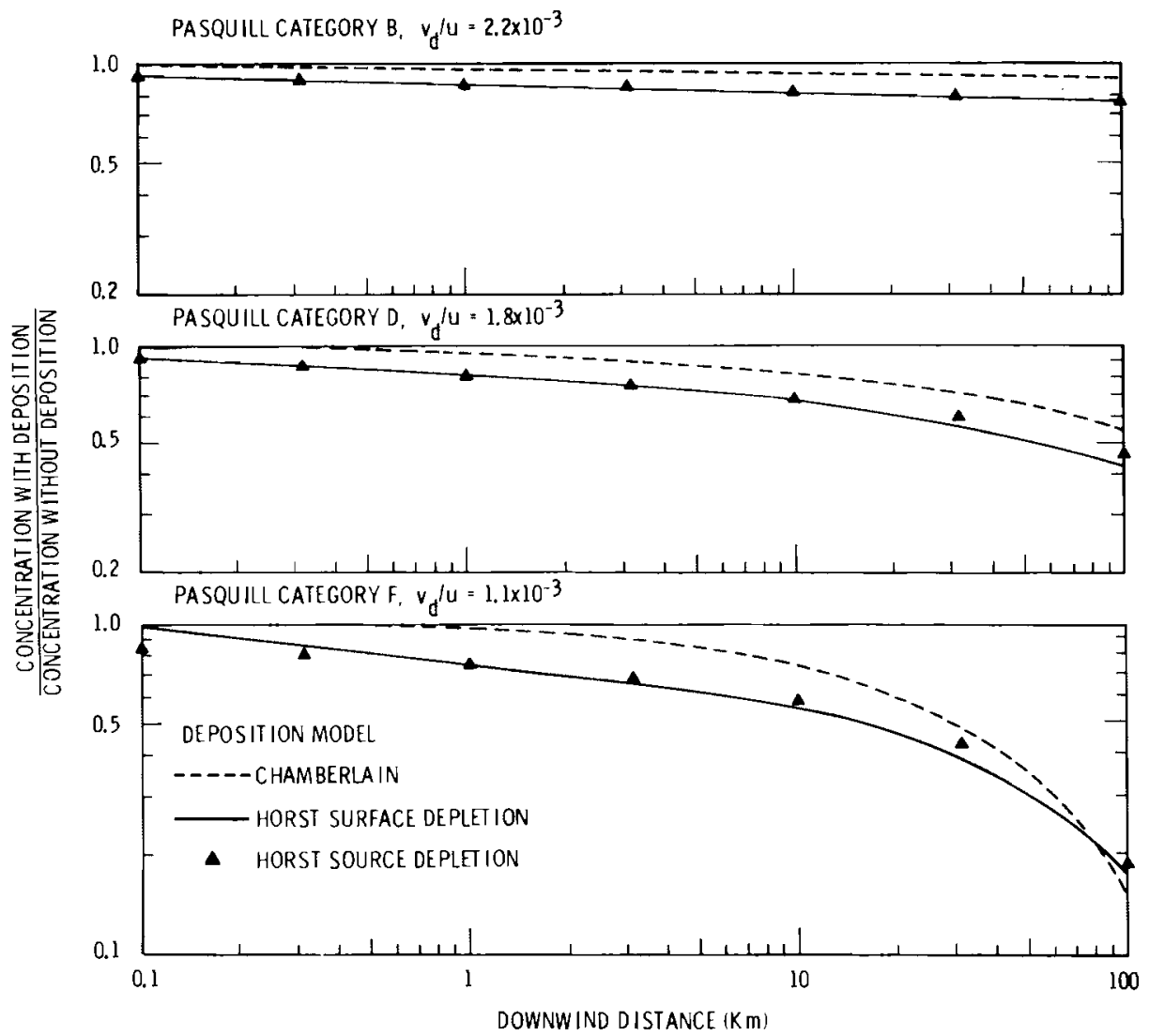

FIGURE 15. A Comparison of Gaussian Diffusion-Deposition Models for $\mathrm{h}=10 \mathrm{~m}, \mathrm{v}_{\mathrm{d}} \mathrm{u}_{*}+0.03, \mathrm{Z}_{*}=3 \mathrm{~cm}$ 


\section{- Radiative Effects of Clouds and Aerosols}

Objectives of this study are:

- Measuring energy-related aerosol radiative properties and relating them to aerosol physical and chemical properties.

- Measuring upwelling and downwelling short- and longwave radiation at various levels within the planetary boundary layer.

- Determining radiative effects of clouds, particularly those that have been influenced by energyrelated pollutants.

- Modeling radiative transfer in the planetary boundary layer using measured aerosol radiative properties and fluxes.

Aircraft Measurements of Turbidity in Urban and Rural Atmospheres

N. S. Laulainen and A. J. Alkezweeny

Efforts have been underway at Pacific Northwest Laboratory (PNL) since 1975 to understand the effects of aerosol layers on the redistribution of solar radiation and on the heat balance at the earth's surface. Initial experiments were concerned with the simultaneous measurements of turbidity (aerosol optical depth), aerosol size distribution and the light-scattering extinction coefficient as a function of altitude in a variety of air-mass types and locations (Alkezweeny and Laulainen 1975a, 1976b; Laulainen et al. 1978). Additional experiments were conducted over Lake Michigan in August 1976 and June 1979. During the June 1979 experiment, solar radiation sensors were included. The experiment plan for the June 1979 study is discussed here first, followed by a summary of the results of the August 1976 study.

Energy-related atmospheric aerosols, resulting primarily from the combustion of fossil fuels, are believed to potentially contribute to alteration of atmospheric heating and cooling patterns. There is a national need to develop the means for modeling and predicting the response of weather and clinate to present and future emissions of these pollutants. Clearly, a necessary ingredient in fulfilling these modeling objectives is to specify aerosol optical properties in more detail than is presently available and to relate them to aerosol physical and chemical properties.
A suitable experiment plan would consist of a combination of measurements obtained from surface stations and instrumented aircraft flying within and above the mixed layer. Surface measurements would include direct, total and diffuse radiation fluxes and spectral turbidities. Aircraft measurements would include aerosol concentration and size distribution, aerosol composition and mass loading, aerosol light absorption extinction coefficients, upward and downward shortwave radiation fluxes, including total and spectrally resolved components, and longwave radiation fluxes. A full complement of such measurements were carried out during the June 1979 study. Analysis of these data is now in progress; hence, results for this study are not yet available.

However, analysis of the August 1976 data has been completed. Aerosol size distributions and chemical composition data are discussed elsewhere in this Annual Report. The results of the turbidity measurements and comparisons of aerosol extinction coefficients derived from them with those calculated from the measured aerosol size distributions and those measured directly with an integrating nephelometer are discussed.

Aerosol characteristics of two different airmasses were investigated in the study. On August 21 an airmass over lower Lake Michigan, dominated by aerosol from the Chicago/Gary urban and industrial area, was studied, and a clean airmass, which had moved in over upper Lake Michigan from (presumably) rural areas in Canada, was examined on August 29. 
Figure 16 compares the measured size distributions for both days. Pronounced differences, as much as factor of 30 to 50 , are seen in the aerosol volumes in the accumulation mode (diameters 0.1 to $1 \mu \mathrm{m}$ ). Even the coarse particle modes (diameters $>1 \mathrm{~mm}$ ) show a difference as much as a factor of 10. For visible light wavelengths, only the accumulation mode contributes significantly to extinction and turbidity (Thielke et al. 1972),

Multiwavelength turbidities were determined from direct solar beam measurements with a hand-held sunphotometer (Laulainen et a1 1978). For the purposes of this discussion, only the turbidities at the 557.8-nm wavelength are discussed. However, similar results would apply for the other bands, The turbidity results are summarized in Table 2.

Aerosol extinction coefficients may be derived from the turbidity values obtained at each altitude by the expression

$$
b_{\text {ext }}=\Delta t / \Delta h
$$

where $b$ is the average extinction coefficient for the layer and $\Delta \tau$ is the turbidity difference between $h$ and $h+\Delta h$, respectively, and $h_{u}$ is the altitude. Since $T$ is unitless, $b$ has the units of (length) ${ }^{-1}$.

Aerosol extinction coefficients may be calculated from the measured size distributions at each altitude with the aid of Mie theory and the equation:

$$
b_{\text {ext }}^{\text {calc }}=\sum_{i} \sigma\left(D_{p i}, n\right) \Delta N\left(D_{p i}\right)
$$

where $\sigma\left(D_{p i}, n\right)$ is the Mie extinction cross section per particle of geometric mean diameter $\mathrm{D}_{\mathrm{p} i}$, and $\Delta \mathrm{N}\left(\mathrm{D}_{\mathrm{pi}}\right)$ is the number of particles in the internal $\Delta \log D_{\text {pi }}$. The sum is over all measured size intervals. A value of $n=1.5$ was used in the calculations at a wavelength of $\lambda=557.8 \mathrm{~nm}$.

The values of bext from Equation (1), bext from Equation (2) and bscatt from the nephelometer measurements are listed in Table 2 for each altitude. The agreement
AEROSOL SIZE DISTRIBUTION-VOLLME

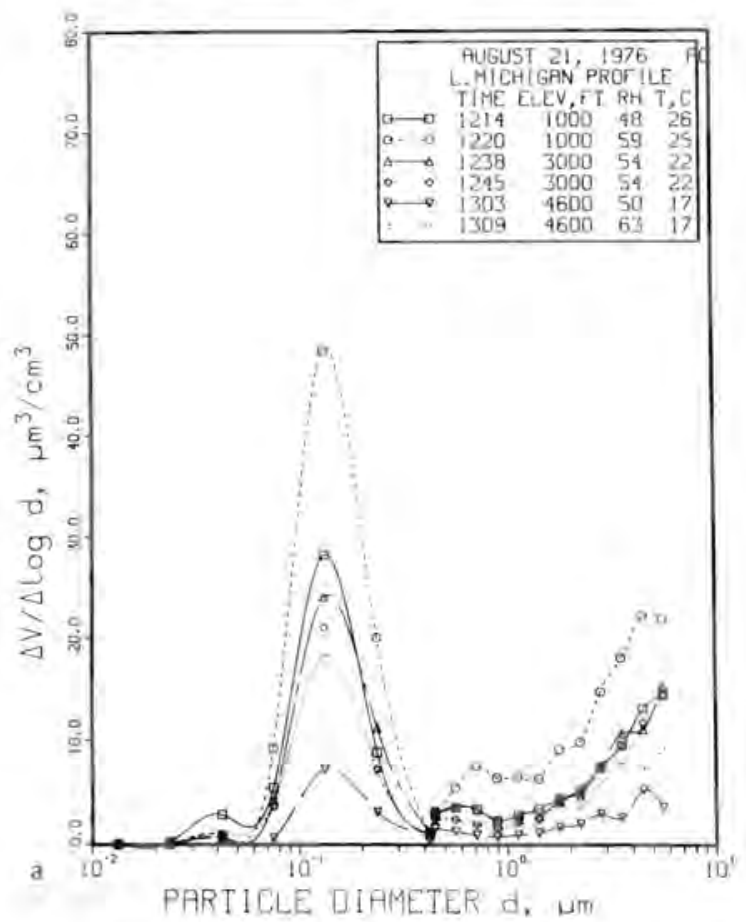

ALROSOL SIZE DISTRIBUTEDN-VOLUME

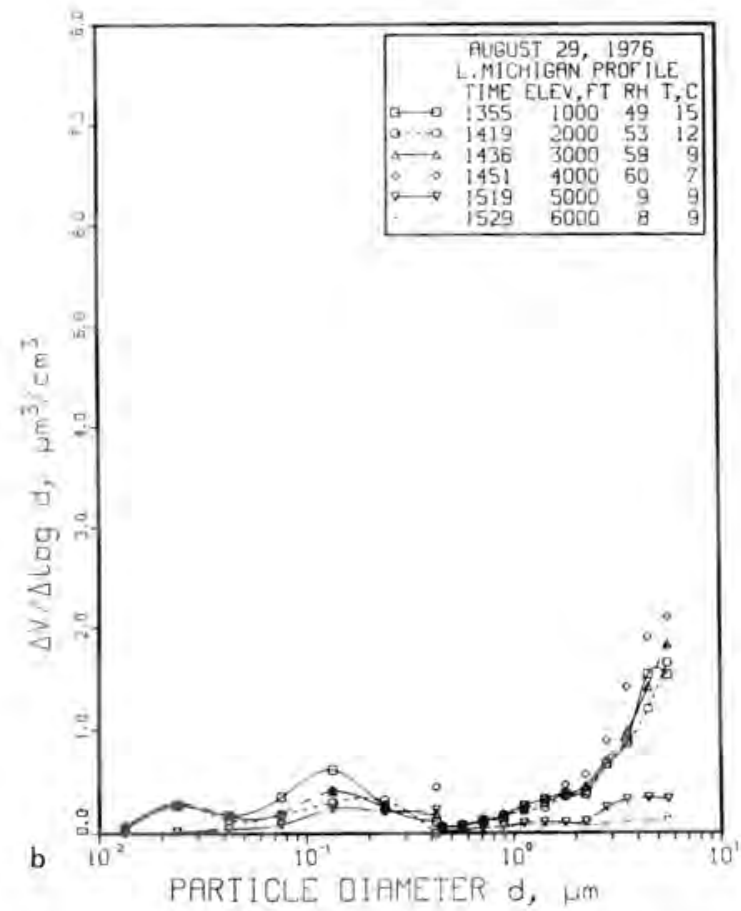

FIGURE 16A,B. Aerosol Volume Size Distributions as a Function of Altitude for August 21 and August 29, 1976. 
TABLE 2. Comparison of Aerosol Extinction (Scattering) Coefficients at Different Altitudes Obtained from Aerosol Optical Depth (Turbidity) Measurements, Calculated from Measured Size Distributions, and Measured Directly with an Integrating Nephelometer.

\begin{tabular}{|c|c|c|c|c|c|c|}
\hline $\begin{array}{l}\text { Profile } \\
\text { Id }\end{array}$ & $\begin{array}{c}\text { Flight } \\
\text { Altitude } \\
\text { (m) }\end{array}$ & $\begin{array}{l}\text { Ave. Layer } \\
\text { Altitude } \\
\text { (m) }\end{array}$ & $\begin{array}{c}\text { Measured } \\
\text { Aerosol } \\
\text { Optical } \\
\text { Depth }\end{array}$ & $\frac{\Delta \tau}{\Delta \mathrm{h}}$ & $\begin{array}{c}\text { Computed } \\
\text { bext } \\
\left(10^{-4} \mathrm{~m}^{-1}\right)\end{array}$ & $\begin{array}{c}\text { Nephelometer } \\
b_{\text {ext }} \\
\left(10^{-4} \mathrm{~m}^{-1}\right)\end{array}$ \\
\hline $\begin{array}{l}\text { August 21, } 1976 \\
\text { Traverse A }\end{array}$ & $\begin{array}{r}305 \\
915 \\
1400 \\
1830\end{array}$ & $\begin{array}{r}610 \\
1160 \\
1615\end{array}$ & $\begin{array}{l}0.374 \\
0.154 \\
0.109 \\
0.053\end{array}$ & $\begin{array}{l}3.62 \\
0.93 \\
1.30\end{array}$ & $\begin{array}{l}0.90 \\
0.58 \\
0.35 \\
0.012\end{array}$ & $\begin{array}{l}2.30 \\
1.37 \\
1.25 \\
0.30\end{array}$ \\
\hline $\begin{array}{l}\text { August } 21,1976 \\
\text { Traverse B }\end{array}$ & $\begin{array}{r}305 \\
915 \\
1130 \\
1310\end{array}$ & $\begin{array}{r}610 \\
1020 \\
1220\end{array}$ & $\begin{array}{l}0.327 \\
0.192 \\
0.061 \\
0.054\end{array}$ & $\begin{array}{l}2.21 \\
6.1 \\
0.39\end{array}$ & $\begin{array}{l}1.19 \\
0.65 \\
0.62 \\
0.26\end{array}$ & $\begin{array}{l}1.75 \\
1.50 \\
1.55 \\
0.45\end{array}$ \\
\hline August 29,1976 & $\begin{array}{r}305 \\
610 \\
915 \\
1220 \\
1525 \\
1830\end{array}$ & $\begin{array}{r}460 \\
765 \\
1070 \\
1375 \\
1680\end{array}$ & $\begin{array}{l}0.080 \\
0.076 \\
0.071 \\
0.066 \\
0.057 \\
0.048\end{array}$ & $\begin{array}{l}0.13 \\
0.16 \\
0.16 \\
0.30 \\
0.30\end{array}$ & $\begin{array}{l}0.03 \\
0.02 \\
0.03\end{array}$ & $\begin{array}{l}0.07 \\
0.06 \\
0.06 \\
0.07 \\
0.03 \\
0.03\end{array}$ \\
\hline
\end{tabular}

between the various values is quite poor, even between $b_{\text {ext }}^{\text {calc }}=b_{\text {scatt }}^{\text {calc }}$ and $b_{\text {scatt }}$. The reason for these discrepancies is not yet known. Improvements are being made in the aerosol size measurements in order to el iminate some of the uncertainty in the calculations. Sunphotometer measurements were difficult at best from the aircraft and any horizontal spatial inhomogeneities in the aerosol layer (which were quite apparent in the nephelometer record) and cloudiness may have also contributed to the rather poor extinction values.
The measurements described in this article represent a first step in evaluating the effects of aerosol layers on the redistribution of solar radiation and on the heat balance at the earth's surface.

\section{References}

Alkezweeny, A. J. and N. S. Laulainen. 1976a. "Simultaneous Aerosol Size Distributions and Turbidity Meausrements Over a Metropolitan Area." In Atmospheric Pollution, ed. M. Benare, pp. 487-493. Elsevier, Anisterdam. 
Al kezweeny, A. J. and N. S. Laulainen. 1976b. "Airborne Measurements of Particle Size Distribution Light Scattering and Turbidity at Different Altitudes." Paper presented at a Topical Meeting on Atmospheric Aerosols, Their Optical Properties and Effects, Williamsburg, OSA and NASA.

Laulainen, N. S., A. J. Alkezweeny and J. M. Thorp. 1978. "Simultaneous Aerosol Size Distribution and Turbidity Measurements Over St. Louis During METROMEX 1975." J. Appl. Meteor. 17:615-626.
Thielke, J. F., R. J. Charlson, J. W. Winter, N. C. Ahlquist, K. T. Whitby, R. B. Husar and B. Y. H. Liu. 1972. "Multi-wavelength Nephelometer Measurements in Los Angeles Smog Aerosols. 2. Correlations with Size Distributions, Volume Concentrations." J. Colloid Interface Sci. 39:252-259.

\section{- Pollutant Transformation in the Atmosphere}

Objectives of this study are:

- Measuring chemical transformation rates of polynuclear aromatic hydrocarbons and other organic compounds emitted by fossil-fueled power plants.

- Correlating transformation rates with distance from the source, ambient temperature, light intensity and concentrations of sulfur dioxide, nitrogen oxides, and ozone.

- Evaluating the results of laboratory studies on discrete reaction steps in the overall transformation processes.

\section{Pollutant Transformations in the Atmosphere}

D. R. Kalkwarf and S. R. Garcia

A variety of polycyclic aromatic hydrocarbons (PAHs) and other undesirable organic pollutants are emitted by coal-fired power plants. Exposure of these substances to sunlight and reactive atmospheric components, e.g., ozone, nitrogen oxides and sulfur dioxides may convert PAHs into either less noxious compounds or more potent carcinogens. The purpose of this study is to identify transformations of PAHs that occur at significant rates in the atmosphere. This information is needed to more accurately assess the environmental impact of coal-fired power plants.

Laboratory experiments during FY 1979 focused on measuring the sublimation halftimes of PAHs so that their distribution between vapor and fly ash states in the atmosphere could be evaluated. These atmospheric distributions are significant since several PAHs are known to be more reactive in the adsorbed state. Also, concentra- tions of PAHs in particulate samples must generally be corrected for sublimation losses during high-volume sampling.

In addition, a new helicopter-mounted, vapor/particulate sampler was developed and used to sample air along the stack-emission plume at Colstrip, Montana. Fluoranthene and pyrene were found to be largely in the vapor phase, whereas benzo[a]pyrene and perylene were completely adsorbed on particulates. After correction of data for dilution as a result of plume dispersion, the degradation half-distances for fluoranthene and pyrene were both found to be $7 \mathrm{~km}$.

Sublimation half-times of fluoranthene, pyrene and chrysene from coal fly ash were measured and compared with calculated values for the pure compounds. Experiments were conducted in both static air and air flowing with a linear velocity of $0.7 \mathrm{~ms}^{-1}$, typical of high-volume samplers. Fly ash from electrostatic precipitators was cleaned by extraction with dichloromethane and then allowed to readsorb measured amounts of PAHs equivalent to a surface monolayer. For 
measurements in static air, samples of this loaded fly ash were encased in sealed polyethylene envelopes. These envelopes acted as perfect sinks for the PAH vapors and were extracted periodically with dichloromethane to determine the amounts of sublimed material. For measurements in air at $0.7 \mathrm{~ms}^{-1}$, samples of loaded fly ash were held on the glass filter of an operating, high-volume air-sampler and extracted periodically to determine the residual PAH content. Results of the latter experiments are shown in Figure 17.

Sublimation half-times for the pure compounds were calculated by means of the Hertz-Knudsen equation (Sherwood and Johannes 1962). For a monolayer of adsorbed material, this can be written as $\mathrm{dw} / \mathrm{dt}=$ wap $(M / 2 \pi R T)^{0.5}$, where $w$ is the weight of compound with molecular weight $M$ remaining at time $t, a$ is the specific surface area of the compound and $p$ is the vapor pressure of the compound at temperature T. Using computed values for a and literature values for $p$, sublimation half-times were calculated and are shown in Table 3 along with those measured for adsorbed forms of the compounds.

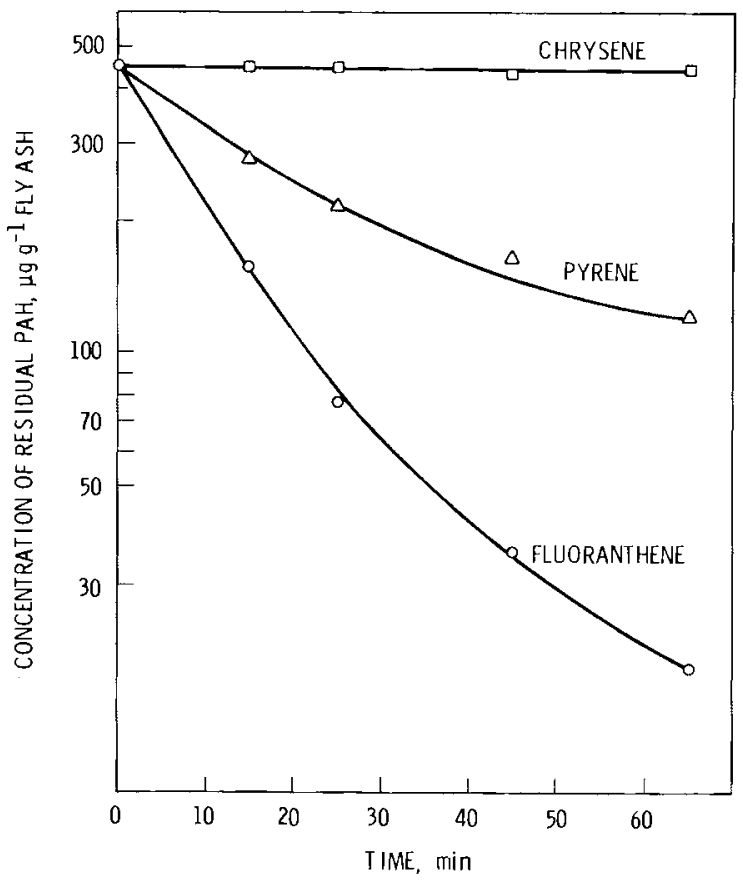

FIGURE 17. Sublimation of Polycyclic Aromatic Hydrocarbons from Fly Ash into $0.7 \mathrm{~ms}^{-1} \mathrm{Air}$ at $22^{\circ}$

TABLE 3. Sublimation Half-Times of Polycyclic Aromatic Hydrocarbons Adsorbed on Fly Ash and in the Pure State

\begin{tabular}{|c|c|c|c|c|}
\hline Compound & Temp. & $\begin{array}{c}\text { Vapor } \\
\text { Pressure }\end{array}$ & $t_{0.5}$ (pure) $^{(a)}$ & $t_{0.5}$ (adsorbed) $)^{(b)}$ \\
\hline Fluoranthene & $-14^{\circ} \mathrm{C}$ & $10^{-6} \mathrm{~Pa}$ & $10^{2} \mathrm{~s}$ & $10^{6} \mathrm{~s}$ \\
\hline Fluoranthene & 4 & $10^{-5}$ & $10^{1}$ & $10^{5}$ \\
\hline Fluoranthene & 22 & $10^{-4}$ & $10^{0}$ & $10^{4}\left(10^{3}\right)$ \\
\hline Pyrene & -14 & $10^{-6}$ & $10^{2}$ & $10^{6}$ \\
\hline Pyrene & 4 & $10^{-5}$ & $10^{1}$ & $10^{5}$ \\
\hline Pyrene & 22 & $10^{-4}$ & $10^{\circ}$ & $10^{4}\left(10^{3}\right)$ \\
\hline Chrysene & -14 & $10^{-9}$ & $10^{6}$ & - \\
\hline Chrysene & 4 & $10^{-8}$ & $10^{4}$ & $10^{7}$ \\
\hline Chrysene & 22 & $10^{-7}$ & $10^{3}$ & $10^{7}\left(10^{6}\right)$ \\
\hline
\end{tabular}

(a) Values calculated for a monomolecular layer with the Hertz-Knudsen equation.

(b) Values without parentheses are those measured for samples in static air; values inside parentheses are those measured for samples in $0.7 \mathrm{~ms}^{-1}$ air. 
Comparison shows that adsorption on fly ash increased the sublimation half-times of PAHs by 3 to 4 orders of magnitude. However, even adsorbed PAHs were found to sublime from fly ash with a half-time of less than an hour if their vapor pressures were $10^{-3} \mathrm{~Pa}$ or greater.

A two-stage sampling system was developed for measuring the atmospheric distribution of PAHs between vapor and fly ash. A glass fiber filter to collect particulates was followed by a bed of Tenax GC to adsorb organic vapors. Greater than $90 \%$ retention of fluoranthene was achieved in this bed during the usual 1-hr, high-volume, air-sampling period. Analyses of the extracts from the filter and Tenax bed together with sublimation half-times allowed calculation of the atmospheric ratio, $\mathrm{Ra}$, of $\mathrm{PAH}$ in the vapor state to that on particulate matter, e.g., $R_{a}=\left(R_{m}+1\right)\left[\exp \left(-0.693 t / t_{0.5}\right)-1\right]$. Here $R_{m}$ is the ratio of PAH on the Tenax to that on the filter, $t_{0.5}$ is the sublimation halftime of the PAH and $t$ is the sampling time.

The two-stage sampling system was mounted on a helicopter and used to sample the emis- sion plume from the power plants at Colstrip, Hontana. Except for the inclusion of the Tenax vapor-traps, the procedure was the same as that described in the Annual Report for FY 1978 (Kalkwarf and Garcia 1979). Calcium emitted from the stacks was again collected and analyzed separately to follow the dilution of the plume with distance. Results from these sampling operations, corrected for sublimation of PAHs during the sampling time, are listed in Table 4. Comparison shows that substantial amounts of fluoranthene and pyrene were in the vapor phase, whereas all the perylene and benzo[a]pyrene were on particulates.

Samples taken March 16, 1979, provided the most complete data to show the degradation of PAHs with distance from the stacks. At each sampling point, vapor and particulate concentrations of a PAH were added, divided by the concentration of calcium and plotted versus distance as shown in Figure 18. Although measured concentrations of all PAHs at $1.6 \mathrm{~km}$ from the stacks appear unreasonably low, concentrations measured further out indicate that fluoranthene and pyrene have degradation half-distances of

TABLE 4. Concentrations of Polycyclic Aromatic Hydrocarbons in the Atmosphere at Various Distances Downwind from the Colstrip Stacks

Compound, $\mathrm{ng} / \mathrm{m}^{3}$

\begin{tabular}{|c|c|c|c|c|c|c|c|c|c|c|c|}
\hline \multirow[b]{2}{*}{ Date } & \multirow{2}{*}{$\begin{array}{c}\text { Distance, } \\
\mathrm{km}\end{array}$} & \multirow{2}{*}{$\begin{array}{c}\text { Temperature, } \\
{ }^{\circ} \mathrm{C}\end{array}$} & \multicolumn{2}{|c|}{ Fluoranthene } & \multicolumn{2}{|c|}{ Pyrene } & \multicolumn{2}{|c|}{ Perylene } & \multicolumn{2}{|c|}{ Benzo[a]pyrene } & \multirow{2}{*}{$\frac{\text { Calcium }}{\text { Particle }}$} \\
\hline & & & Particle & Vapor & Particle & Vapo & Particle & Vapor & Particle & Vapor & \\
\hline $\begin{array}{l}\text { March 13, } \\
1979\end{array}$ & $\begin{array}{c}-0.4^{(a)} \\
0.4 \\
1.6\end{array}$ & $\begin{array}{l}3 \\
3 \\
6\end{array}$ & $\begin{array}{l}\text { n.d. (b) } \\
\text { n.d. (b) } \\
\text { n.d. (b) }\end{array}$ & $\begin{array}{r}\text { n.d. } \\
9.0 \\
\text { n.d. }\end{array}$ & $\begin{array}{r}\text { n.d. } \\
35.0 \\
\mathrm{H}\end{array}$ & $\begin{array}{r}\text { n.d. } \\
16 \\
15\end{array}$ & $\begin{array}{r}\text { n.d. } \\
1.5 \\
\text { n.d. }\end{array}$ & $\begin{array}{l}\text { n.d. } \\
\text { n.d. } \\
\text { n.d. }\end{array}$ & $\begin{array}{r}\text { n.d. } \\
0.5 \\
\text { n.d. }\end{array}$ & $\begin{array}{l}\text { n.d. } \\
\text { n.d. } \\
\text { n.d. }\end{array}$ & $\begin{array}{r}30 \\
3000 \\
850\end{array}$ \\
\hline $\begin{array}{l}\text { March 14, } \\
1979\end{array}$ & $\begin{array}{c}-0.4^{(\mathrm{a})} \\
1.6 \\
8.0 \\
16.0\end{array}$ & $\begin{array}{l}3 \\
2 \\
3 \\
4\end{array}$ & $\begin{array}{l}\text { n.d. } \\
\text { n.d }(\text { (b) } \\
\text { n.d. } \\
\text { n.d. (b) }\end{array}$ & $\begin{array}{l}\text { n.d. } \\
27.0 \\
\text { n.d. } \\
\text { n.d. }\end{array}$ & $\begin{array}{l}\text { n.d. } \\
\text { n.d. } \\
\text { n.d. } \\
\text { n.d. }\end{array}$ & $\begin{array}{c}\text { n.d. } \\
22 \\
\text { n.d. } \\
\text { n.d. }\end{array}$ & $\begin{array}{r}\text { n.d. } \\
1.9 \\
0.4 \\
1.6\end{array}$ & $\begin{array}{l}\text { n.d. } \\
\text { n.d. } \\
\text { n.d. } \\
\text { n.d. }\end{array}$ & $\begin{array}{r}\text { n.d. } \\
1.5 \\
0.5 \\
\text { n.d. }\end{array}$ & $\begin{array}{l}\text { n.d. } \\
\text { n.d. } \\
\text { n.d. } \\
\text { n.d. }\end{array}$ & $\begin{array}{r}90 \\
1500 \\
250 \\
350\end{array}$ \\
\hline $\begin{array}{l}\text { March 15, } \\
1979\end{array}$ & $\begin{array}{c}-0.4^{(a)} \\
0.8 \\
8.0 \\
16.0\end{array}$ & $\begin{array}{r}9 \\
10 \\
10 \\
11\end{array}$ & $\begin{array}{l}\text { n.d. (b) } \\
\text { n.d. (b) } \\
\text { n.d. (b) } \\
\text { n.d. (b) }\end{array}$ & $\begin{array}{r}\text { n.d. } \\
25.0 \\
5.6 \\
\text { n.d. }\end{array}$ & $\begin{array}{l}\text { n.d. } \\
12.0 \\
18.0 \\
\text { n.d. }\end{array}$ & $\begin{array}{r}\text { n.d. } \\
50 \\
16 \\
12\end{array}$ & $\begin{array}{r}\text { n.d. } \\
4.5 \\
0.8 \\
\text { n.d. }\end{array}$ & $\begin{array}{l}\text { n.d. } \\
\text { n.d. } \\
\text { n.d. } \\
\text { n.d. }\end{array}$ & $\begin{array}{r}\text { n.d. } \\
3.5 \\
\text { n.d. } \\
\text { n.d. }\end{array}$ & $\begin{array}{l}\text { n.d. } \\
\text { n.d. } \\
\text { n.d. } \\
\text { n.d. }\end{array}$ & $\begin{array}{r}150 \\
2500 \\
160 \\
280\end{array}$ \\
\hline $\begin{array}{l}\text { March 16, } \\
1979\end{array}$ & $\begin{array}{c}-0.4^{(\mathrm{a})} \\
1.6 \\
9.6 \\
16.0 \\
32.0\end{array}$ & $\begin{array}{r}12 \\
9 \\
9 \\
11 \\
10\end{array}$ & $\begin{array}{l}\text { n.d. (b) } \\
\text { n.d. (b) } \\
\text { n.d. (b) } \\
\text { n.d. (b) } \\
\text { n.d. (b) }\end{array}$ & $\begin{array}{r}\text { n.d. } \\
24.0 \\
13.0 \\
6.0 \\
0.5\end{array}$ & $\begin{array}{l}\text { n.d. } \\
\text { n.d. } \\
\text { n.d. } \\
\text { n.d. } \\
\text { n.d. }\end{array}$ & $\begin{array}{r}\text { n.d. } \\
63 \\
24 \\
18 \\
1.5\end{array}$ & $\begin{array}{r}\text { n.d. } \\
1.8 \\
1.5 \\
\text { n.d. } \\
\text { n.d. }\end{array}$ & $\begin{array}{l}\text { n.d. } \\
\text { n.d. } \\
\text { n.d. } \\
\text { n.d. } \\
\text { n.d. }\end{array}$ & $\begin{array}{r}\text { n.d. } \\
2.4 \\
0.5 \\
\text { n.d. } \\
\text { n.d. }\end{array}$ & $\begin{array}{l}\text { n.d. } \\
\text { n.d. } \\
\text { n.d. } \\
\text { n.d. } \\
\text { n.d. }\end{array}$ & $\begin{array}{r}240 \\
2500 \\
400 \\
510 \\
190\end{array}$ \\
\hline
\end{tabular}

(a) Upwind measurement

(b) n.d. $=$ nondetectable $=<0.5 \mathrm{ng} / \mathrm{m}^{3}$ 


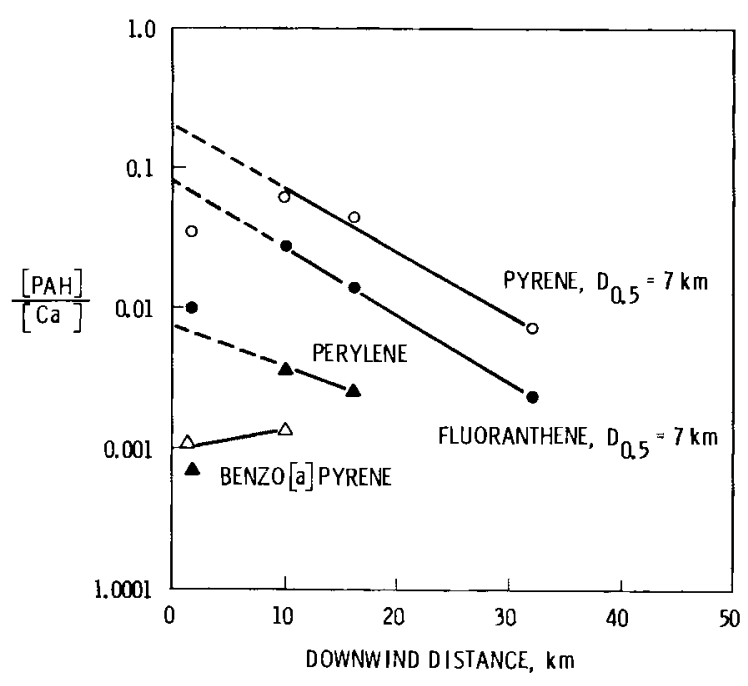

FIGURE 18. Degradation of Polycyclic Hydrocarbons (PAHs) with Distance from the Colstrip Stacks on March 16, 1979 ([PAH]/[Ca] Ratios Used to Adjust

Data to Constant Plume Density)
$7 \mathrm{~km}$. These values can be compared with the values of $3 \mathrm{~km}$ and $8 \mathrm{~km}$ for fluoranthene and pyrene at this site during the preceding July (Kalkwarf and Garcia 1979). Since concentrations of perylene and benzo[a]pyrene were only a few-fold higher than their detection levels, their degradation rates could not be evaluated.

\section{References}

Kalkwarf, D. R, and S. R. Garcia. 1979. "Pollutant Transformation in the Atmosphere." In Pacific Northwest Laboratory Annual Report for 1978 to the DOE Assistant Secretary for Environment, Part 4, Physical Sciences. PNL-2850, PT4, Pacific Northwest Laboratory, pp. 1.3-1.5, Richland, WA.

Sherwood, T. K. and C. Johannes. 1962. "The Maximum Rate of Sublimation of Solids." Am. Inst. Chem. Eng. J. 8:590-593.

\section{- Atmospheric Carbon Dioxide Abundance - An Archival Study of Spectroscopic Data}

Objectives of this study are:

- Determining the current and past abundance of the carbon dioxide in the earth's atmosphere by spectroscopic means.

- Providing independent corroboration of the $\mathrm{CO}_{2}$ increase that has been observed with mass spectrometers.

- Extending the knowledge of the total atmospheric $\mathrm{CO}_{2}$ burden back to a time for which no information now exists.

Atmospheric Carbon Dioxide Abundance--An Archival Study of Spectroscopic Data

\section{G. M. Stokes}

The relationship between the atmospheric abundance of carbon dioxide and various anthropogenic factors, most notably fossil fuel burning, has become a matter of great concern. Carbon dioxide has a significant effect on the average temperature of the earth's surface and lower atmospheric layers. These temperature changes are largely a re- sult of the gas's large infrared opacity that produces a "greenhouse effect." Because of the importance of $\mathrm{CO}_{2}$ to the energy budget of the atmosphere, the possibility exists that changes in its abundance could have a major effect on the earth's climate.

In order to understand how man's consumption of fossil fuels could affect climate through changes in the atmospheric $\mathrm{CO}_{2}$ abundance, it is necessary to understand all the factors that control the atmospheric abundance of $\mathrm{CO}_{2}$. Unfortunately, the atmosphere 
represents a relatively small reservoir of carbon when compared to other reservoirs, such as the deep oceans or sedimentary deposits. As a result, relatively modest changes in these much larger reservoirs can have an overwhelming effect on the atmospheric $\mathrm{CO}_{2}$ abundance. It is, therefore, not surprising that there continue to be intense debates as to which processes affecting which sources and sinks of carbon control the atmospheric $\mathrm{CO}_{2}$ abundance.

An interest in the historical changes in atmospheric $\mathrm{CO}_{2}$ abundance has led to a critical evaluation of the existing data that may relate to that abundance. As a result, an attempt is being made to extract knowledge about the abundance of $\mathrm{CO}_{2}$ from spectra of the sun that have been accumulated since the 1890s.

As sunlight passes through the atmosphere of the earth, the molecules in the atmosphere absorb and scatter the radiation. A substantial fraction of this absorption is caused by the excitation of various energy levels in atmospheric molecules. Absorption of this kind occurs at specific wavelengths and results in what are called absorption lines. The strength of these lines is primarily a function of the properties of the molecule and the amount of the molecule between the observer and the sun. It should, therefore, be possible to determine from spectra of the sun the amount of $\mathrm{CO}_{2}$ in the atmosphere. Such spectroscopic data exists for a period extending back to at least the mid-1890s when Samuel P. Langley began observing and recording the spectrum of the sun with a prism spectrobolograph.

The current program has been organized to collect and evaluate the spectra of the sun that have been accumulated over the past $90 \mathrm{yr}$ and that are now found in the archives of various institutions, such as the Smithsonian Astrophysical Observatory.

Although in principle the analysis of these spectra to extract atmospheric $\mathrm{CO}_{2}$ abundance is quite simple, there are several practical problems that must be surmounted. The most important is the identification and correction of sources or systematic error both in the observations and in the analysis of the data. The program goal is to determine changes in the atmospheric $\mathrm{CO}_{2}$ abundance to an accuracy of 1 to $2 \%$ over the $90 \mathrm{yr}$ period of data collection. Since this determination must be of very high quality, great care must be taken at each stage of the analysis.

Three major precautions are being taken to guarantee the quality of the analysis. First, the abundance of molecular oxygen $\left(0_{2}\right)$ is being determined from the same spectral data. Since the atmospheric abundance of $\mathrm{O}_{2}$ is not expected to have changed over the period of the study, its abundance can be considered a control. Second, because most of the data being analyzed has been taken at lower spectral resolution than is possible with modern techniques, weak lines of other gases, such as water, may contaminate the lines of $\mathrm{CO}_{2}$ and $\mathrm{O}_{2}$ by an unknown amount. Using very high spectral resolution, new data has been accumulated at Kitt Peak National Observatory for the identification of these weak interfering lines. Finally, the facilities of Kitt Peak National Observatory are also being used in a search for other sources of systematic error that might affect the analysis of older data.

At present several major solar spectral atlases are being analyzed for $\mathrm{CO}_{2}$ abundances. A major effort is also underway to digitize spectra accumulated during the Smithsonian Solar Constant program. This collection represents 3000 days of observations taken from 1920 to 1950 at a variety of sites. Finally, the archives of many institutions are being combed for additional spectra. Eventually, this data should provide a record of the atmospheric $\mathrm{CO}_{2}$ abundance of sufficient accuracy to test various models of the carbon cycle. 


\section{- Meteorological Effects of Thermal Energy Releases (METER)}

Objectives of this study are:

- Developing technical data bases for assessing the potential effects of waste heat sources on weather, climate aind ecosystems.

- Determining the importance of waste heat releases on the spacing and location of groups of thermal power plants.

- Conducting field studies on surface shadowing by cooling tower plumes, surface deposition of chemical drift from towers, augmented precipitation as the result of scavenging of plumes, and increased incidence of fogging and icing from plumes.

Drift from Mechanical Draft Cooling Towers

\section{N. S. Laulainen}

A comprehensive experiment to study drift from mechanical draft cooling towers was conducted during June 1978 at the Pacific Gas and Electric Company's (PG\&E) Pittsburg Power Plant at Pittsburg, California. The objective of the experiment was to establish a data base for use in drift deposition model validation. This objective was achieved by the simultaneous measurement of cooling tower source emission parameters, meteorological variables and drift deposition patterns during seven of eight test runs. The results from six of these test runs are presented and discussed here.

Environmental Systems Corporation (ESC) conducted the source characterization measurements. These measurements included cooling tower emission parameters, such as updraft velocity and temperature profiles, 1 iquid and mineral mass drift emission rates, and drift droplet size distributions. ESC also provided plant and cooling tower operational parameters obtained either from its own measurement program or from the PG\&E plant log.

Pacific Northwest Laboratory (PNL) carried out the meteorological and surface drift measurements. The meteorological measurements included wet- and dry-bulb temperatures and wind speeds and directions on a continuous basis from sensors on a 10-m tower, and on an intermittent basis from an instrumented, tethered-balloon system. The latter measurements provided information on the vertical structure of temperature, moisture and mass transport. Surface deposition measurenents included both droplet and bulk mineral mass deposition rates.
Substantial variation in drift emissions were noticed. Large day-to-day variations for a given cell and large cell-to-cell variations were observed. Because of the large variability of drift mass emission, a representative emission rate per cell was calculated by ESC using a weighted average based on both the pretest survey and the detailed characterization of seven cells. Because the problem of deriving a total droplet emission spectrum and rate from one or two towers was complicated, the modeler must decide on the amount of detail he needs to satisfactorily predict downwind deposition patterins.

Assuming that ESC's averaging procedure was reasonable, the emission rate per cell was found to be $4.8 \mathrm{~g} \mathrm{~s}^{-1}$. If all $26 \mathrm{cells}$ were operating, the total emission rate would be $124 \mathrm{~g} \mathrm{~s}^{-1}$. The latter value may be uncertain by anywhere from 30 to $70 \%$, depending upon the validity of the averaging procedure. With a total circulating water flow rate of $20 \mathrm{~m}^{3} \mathrm{~s}^{-1}$, the $124 \mathrm{~g} \mathrm{~s}^{-1}$ emission rate corresponds to a drift fraction of $0.0006 \%$ compared to the guaranteed drift rate of $0.004 \%$.

Comparison of drift droplet size distributions emitted form a reference cell on Tower 7-1 using several techniques was not as satisfactory as originally planned. The sensitive paper (SP) and light scattering (PILLS) devices were compared only on one day as a result of equipment malfunction. The results indicated that the PILLS device produced drift mass emission rates that were typically $20 \%$ lower than the SP method. On the other hand, data from the photographic device were not compared with simultaneous $\mathrm{SP}$-acquired data since these measurements were acquired nearly a month after completion of the main drift experiment. 
Consequently, although the photographic data show variations similar to those obtained by the SP method, there was no way of proving whether the cooling towers were operating in similar modes during the two different test periods.

Meteorological conditions during the drift study were characterized by relatively high winds, warm temperatures and moderate humidities. The relatively high winds increased the uncertainty in the measured deposition patterns. In spite of the large (factor of 2 or 3 ) uncertainty in the measured deposition rates, preliminary calculations of drift deposition rates by ESC using its own model and the source and meteorological data described above are in agreement with each other for Test Run 1 , June 16, 1978.

Mineral depositions arising mainly from blowing dust produced substantial interference with the downwind deposition patterns, especially at the greater downwind distances where drift deposition rates were small. The measured drift mineral deposition rates were uncertain by as much as a factor of two or more after this variable background component was estimated and subtracted from the total deposition rates. The effects of various structures, such as the electrical switchyards at the plant, were apparent in data for the 3 days when winds were from the west or west-northwest.

Droplet deposition rates were also uncertain as a result of the relatively high winds, which produced droplet stains on the sensitive papers that were streaked and difficult to analyze in an automated manner. Calibration of sensitive papers for droplets incident as oblique angles was necessary to properly interpret these data.

In addition, the meteorological conditions during the test period did not provide drift data representative of all the conditions that would be encountered at the Pittsburg Plant, but they probably gave a reasonable picture of drift emissions and depositions during the dry, warm-to-hot summer conditions of the area. Winds were typically $5 \mathrm{~m} \mathrm{~s}^{-1}$ or larger from the 240 to $300^{\circ}$ direction. Relative humidities and dry-bulb temperatures were typically 50 to $60 \%$ and 15 to $20 \mathrm{C}$, respectively, during the experiment. Such warm temperatures, low humidities and high winds had the effect of rapidly drying out the drift droplets and dispersing them over a broad area. From a practical, experimental point of view, these conditions meant that the anticipated drift accumulation at the receptors was much smaller than what one might observe in the winter months at this site.

Comparison of several systems used for the measurement of various meteorological variables, in particular the vertical profile of wind direction and speed, were carried out. In general, there was favorable agreement between the in situ and remotesensing measurements.

In view of the uncertainties that arose in the interrogation of the deposition SP as a result of using an incorrect calibration equation and as a result of problems of measurement of the droplet stains with an automated scanning and reading device, certain (or all) of the SPs could be remeasured using a more manual approach.

Although the experiment plan had the benefit of input from several other groups that have been involved in drift experiments (e.g., the Chalk Point Cooling Tower Project), several improvements to the experiment design could have been made. Larger deposition pans would have made the analysis of the bulk mineral deposition much easier and less uncertain. Some kind of wind screen to reduce the horizontal wind component might have allowed for better control of the SP stain images. High-volume samplers should have been used to measure the air concentration of the dry nondepositing drift material.

While the present study did not encompass as wide a range of meteorological conditions as would be required for complete validation of various drift models, it has contributed a unique set of data for that purpose.

A complete discussion of this study may be found in Laulainen et al. (1979).

\section{Reference}

Laulainen, N. S., R. 0. Webb, K. R. Wilber and S. L. Ulanski. 1979. Comprehensive Study of Drift from Mechanical Draft Cooling Towers. PNL-3083, Pacific Northwest Laboratory, Richland, WA. 
Objectives of this study are:

\section{- National Interregional Air Residual Transfer}

- Developing national interregional transport matrices for emitted fine particulates and other pollutants.

- Using the derived matrices in models for assessing the air pollution impacts of future energy scenarios.

- Improving the air pollution models in order to produce more efficient and cost-effective assessments.

Development of a National Interregional Transport Matrix for Emitted Fine Particulates

W. J. Eadie, W. E. Davis and

W. F. Sandusky

One objective of the Regional Assessment Program (RAP) is to develop a useful tool for the Division of Environmental Impacts of the Department of Energy (DOE) to assess air quality impacts resulting from various predicted energy-technology use scenarios. This will then provide a basis for future National Energy Plan evaluations in estimating environmental and health effects. During FY 1979 Pacific Northwest Laboratory (PNL) developed a tool for assessing air quality impacts resulting from emitted fine particulates.

To develop this tool, fine particulate transport and removal calculations were made by use of a long-range transport model (Eadie and Davis 1979). A unit emission source was placed at the centroid of each National Air Quality Control Region (AQCR), and the air quality impact on each AQCR was computed. The final product of the calculations is a matrix of the average, fine particulate concentration for each receptor $A Q C R$ resulting from the unit fine particulate emission from each AQCR. The AQCR-toAQCR matrix is then utilized with any siting scenario of energy technology use to predict the air quality impact on any AQCR of the projected emissions from other AQCRs by multiplying the appropriate matrix elements by the projected emissions and suming the products over the emitting AQCRs. The matrix approach will allow the ranking of air quality impacts of various energy technology scenarios without rerunning the long-range transport model.
In order to investigate seasonal variations, 4 monthly, average matrices were produced using meteorological data from January, Apri1, July and October 1974. As shown in Table 5 where the matrix elements for some representative $A Q C R$ s are given, there can be significant variations in the matrix elements from one month to another. Missing data in the table means that there were no trajectories during that month from the source at the centroid of the emitter AQCR to any of the grid cells in the long-range transport model that contribute to the receptor AQCR. Very small matrix elements, such as for receptor AQCR 14 and emitter AQCR 65 in October 1974, arose when there were not enough trajectories from the emitter $A Q C R$ to the receptor $A Q C R$ for the monthly average concentration over the receptor AQCR to be of any significance. The month-to-month variations in the matrix elements shown in Table 5 demonstrate the need in long-range assessments for a long enough averaging time to assess mean impacts along with an estimate of variability.

To facilitate a monthly assessment for the source at the centroid of each of 238 AQCRs for each of $4 \mathrm{mo}$, a new technique was developed that used 86 emission grid points on a regularly spaced grid spanning the United States to estimate assessments that would be made for actual source locations. Assessments from the grid points near a source are weighted, shifted to the source location, and added together to form an assessment for that source. The advantage of using the assessment on a regularly spaced grid is to reduce the number of assessments to be carried out with the longrange transport model. 
TABLE 5. Monthly Variations in Long-Range Transport AQCR-to-AQCR Matrix Elements(a) for Fine Particulates as Calculated Using Meteorological Data from Four Months in 1974

Receptor AQCR

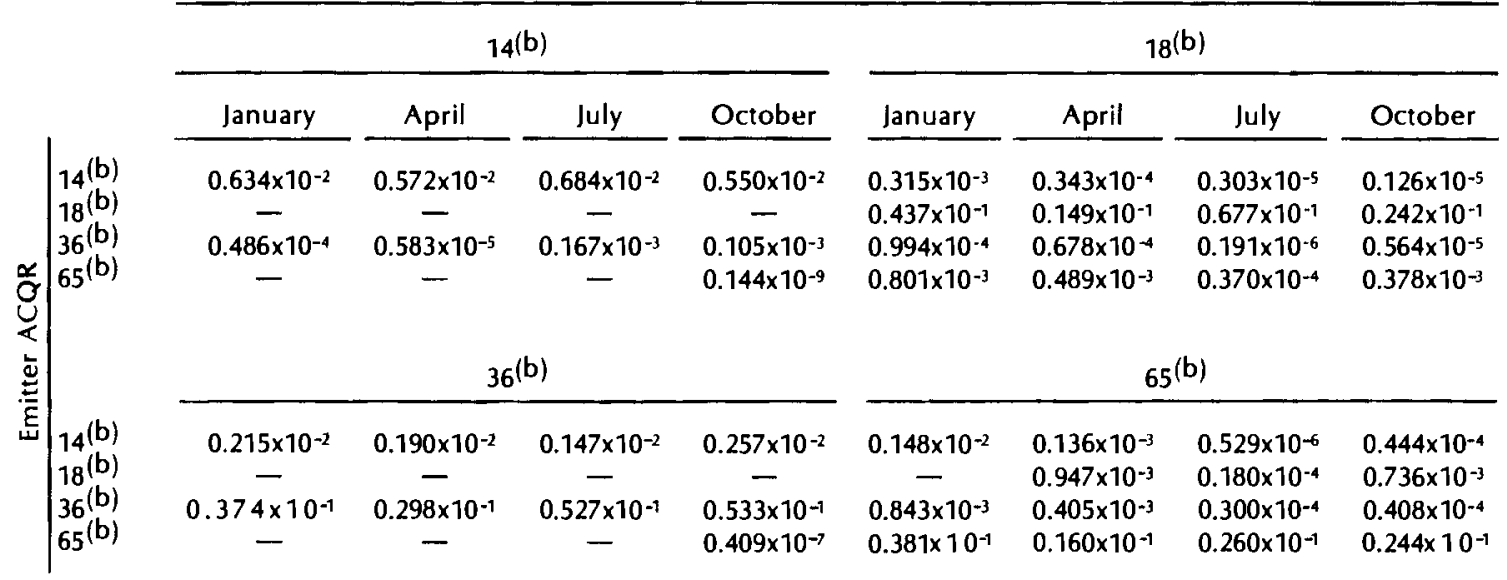

(a) Monthly average over receptor AQCR of fine particulate air concentrations in micrograms per cubic meter, resulting from 1.0 kiloton per year emission from a source at centroid of emitter AQCR.

(b) Counties included in AQCR:

- 14: AZ Apache, AZ Conconino, AZ Navajo, AZ Yavapai, CO Archuleta, CO Dolores, CO La Plata, CO Montezuma, CO San Juan, NM McKinley, NM San Juan, UT Emery, UT Garfield, UT Grand, UT Iron, UT Kane, UT San Juan, UT Washington, UT Wayne.

- 18: AR Crittenden, MS De Soto, TN Shelby.

- 36: CO Adams, CO Arapahoe, CO Boulder, CO Clear Creek, CO Denver, CO Douglas, CO Gilpin, CO Jefferson

- 65: IL Fulton, IL Hancock, IL Hendersen, IL Knox, IL McDonough, IL Mason, IL Peoria, IL Tazewell, IL Warren, IL Woodford, IA Des Moines, IA Lee.

\section{Reference}

Eadie, W. J. and W. E. Davis. 1979. The Development of a National Interregional Transport Matrix for Respirable Particulates. PNL-RAP-37, Pacific Northwest Laboratory, Richland, WA.

The Use of Time-Averaged Precipitation for Wet Removal in a Regional Air Pollution Assessment Model

\section{W. E. Davis and W. J. Eadie}

One of the problems that confronts regional-scale computer modelers is how to incorporate precipitation into a model with precipitation removal, in particular, what kind of average precipitation data should be used. A number of different approaches to this problem in regional-scale air pollution assessments have been used in the past. In Johnson, Wolf and Mancuso (1978) 6-hr precipitation was used for an assessment. In Eliassen (1978) 6- and 12-hr precipitation was used in an assessment for 1974. In Slinn (1978), a recommendation was made that researchers use a constant wet deposition velocity based on the average annual precipitation. At Pacific Northwest Laboratory (PNL), hourly precipitation is used for most assessments (Powell et al. 1979; McNaughton 1980).

However, the production of hourly precipitation tapes is long and costly. A computer program developed by Fox and Wendell (1977) at PNL took station file data from more than 3000 reporting stations in the United States and converted them to synoptic file data. These data in turn were gridded to be used in an assessment. The time, effort, and expense to produce these data can 
cause severe 1 imitations for regional-scale assessments produced on a limited budget. With this in mind, an alternative approach was considered at PNL.

A study by Wendel1, Powell and McNaughton (1977) demonstrated that the use of average precipitation would cause an overestimate of the amount of sulfate deposited in a regional study when compared to results using hourly precipitation. This prompted a paper by Davis (1979) that showed that increasing the averaging times increased the amount of deposition for washout ratios greater than $5 \times 10^{4}$. Davis showed that when the average precipitation, corrected to the average intensity during wet periods, was turned "on" and "off" with the average frequency and for the average duration of naturally occurring precipitation, the mass balance was approximately the same as when hourly precipitation was used. However, Davis's work was done with an idealized pollutant that neither dry-deposited nor underwent chemical transformation. It is the purpose of this article to test whether or not Davis's approach can be extended to an assessment using sulfur dioxide and $\mathrm{SO}_{4}$.

\section{Mode1}

The model used in this study is described in Eadie and Davis (1979). Only a brief discussion of the assumptions made in the model are presented here.

The model assumes hourly puffs that are advected in hourly steps using gridded 1 ayer-averaged wind $(100 \mathrm{~m}$ to $1000 \mathrm{~m})$. The vertical component of the wind is assumed to be zero. The following assumptions are made on a tmospheric diffusion:

- Horizontal diffusion is a function of synoptic-scale wind variation only.

- The vertical-turbulent diffusion parameterization is a function of stability in a specified diurnal cycle for all plume elements within the daytime mixed layer or the nocturnal stable layer.

- The depth of the daytime mixed layer is represented by a diurnal cycle in which a daytime layer increases from a minimum depth at sunrise to a maximum depth in the afternoon. A nocturnal layer builds to a lower depth.

- Depth of the boundary layer (mixed layer in daytime or nocturnal layer) for each hour determines which of two vertical dispersion regimes--mixed layer or above mixed layer-will be applied to a given plume element. Those elements released within the depth of the layer expand according to the stability of the hour; those released above the current depth of the layer expand as if the atmosphere were extremely stable. An exception to this method occurs when releases have expanded to the maximum depth of the mixed layer during the previous day; in this case, their expansion continues according to a fixed function of travel time independent of stability or layer depth.

- Depth of the mixed layer provides a vertical constraint for releases at heights within this layer. The depth of the nocturnal boundary does not serve as an analogous constraint.

- At the present stage of model development, terrain effects are neglected.

\section{Precipitation Frequency}

There are at least two recent papers that treat precipitation frequency: on a singlestation basis (Rohde and Grande 11 1972) and on a regional basis (Henmi and Reiter 1978). Rohde and Grandell have computed the duration of wet and dry periods for a single station in Europe using a year's data. Henmi and Reiter have produced an analysis of United States precipitation frequency east of $105^{\circ} \mathrm{W}$ longitude based on records for 61 stations for 1974. One can apply their results, or as has been done for one of the studies in this article, examine the weather maps for the month's data to be used and hand-compute a mean dry period and a mean duration of precipitation. Fisher (1978) applied the techniques of Rohde and Grandel1 to a regional-scale statistical model for Europe.

\section{Case Study}

Three sites were selected, Anaconda, Montana, Four Corners and central Arkansas, for July 1974.

For the two sites in the west, the average duration of precipitation of $3 \mathrm{hr}$ was selected for every $120 \mathrm{hr}$. These values were chosen based on a rough average of values presented by Henmi and Reiter (1978). A different set of averages was used for central Arkansas with $6 \mathrm{hr}$ of precipitation for every $60 \mathrm{hr}$.

The PNL model was run in four precipitation modes for each of these sites for hourly, six hourly, average precipitation 
turned "on" and "off" (on/off) and average precipitation. The coefficients used in this study for $\mathrm{SO}_{2}$ and $\mathrm{SO}_{4}$ are shown in Table 6. These were obtained from Sandusky, Eadie and Drewes (1979).

The results of the mass balance comparison (Table 7) using the average (on/off), average, and the six-hourly precipitation with the hourly precipitation results show very good agreement for all three sites. An examination of the air concentration deposition patterns for $\mathrm{SO}_{2}$ shows good agreement for all techniques.

However, when the deposition patterns for $\mathrm{SO}_{4}$ using the average precipitation (Figure 19) and the average precipitation (on/ off) (Figure 20) are compared to the pattern produced using the hourly precipitation (Figure 21), a wide variance appears. Even using six-hourly precipitation (Figure 22) can cause large differences in deposition when compared to the deposition from using hourly precipitation.
The widest variance occurs in $\mathrm{SO}_{4}$ wet, the amount deposited by washout, whereas increasing the averaging time increases the amount in wet deposition. Deposition patterns were quite different for the deposition calculated using hourly precipitation versus the deposition calculated using average precipitation (on/off) and average precipitation, which points out the importance of using hourly precipitation when considering episodal cases. The reason for the difference is that precipitation events are relatively infrequent and by using the timeaveraged precipitation, turning it "off" and "on" from 7 to 12 times a month will cause the deposition pattern to be heavily influenced as to when the precipitation is turned "off" and "on". However, for long-term assessments where a year's data is used, it is expected that these differences will probably average out and that the patterns will become more similar.

The use of average precipitation is discouraged in that the pattern does not tend

TABLE 6. Model Input Data

Time period for meteorological data

Advection grid spacing ( $35^{\circ} \mathrm{N}$ latitude)

Grid spacing for precipitation data and sampling of results $\left(35^{\circ} \mathrm{N}\right.$ latitude)

Effective stack height

Mixing height

Stability

Dry deposition velocities:

- $\mathrm{SO}_{2}$

- Sulfates

Wet removal coefficients ${ }^{(a)}$ :

- $\mathrm{SO}_{2}$

- Sulfates

Transformation rate of $\mathrm{SO}_{2}$ to sulfates

Percentage of emissions as primary sulfates

$\overline{(a)} \mathrm{P}=$ rainfall rates $\mathrm{mm} / \mathrm{hr}$
July 1-31, 1974

$321 \mathrm{~km}$

$32 \mathrm{~km}$

$200 \mathrm{~m}$

Variable

Variable

$1.4 \mathrm{~cm} / \mathrm{sec}$

$0.23 \mathrm{~cm} / \mathrm{sec}$

$0.058 \mathrm{P} / \mathrm{hr}$

$0.38 \mathrm{P} .73 / \mathrm{hr}$

$0.005 / \mathrm{hr}$

$0.02(2 \%$ of emission) 
TABLE 7. Mass Balance (\% of Release)

\begin{tabular}{|c|c|c|c|c|c|c|c|c|c|}
\hline Station & $\begin{array}{l}\text { Type } \\
\text { Precipi- } \\
\text { tation } \\
\end{array}$ & $\begin{array}{l}\mathrm{SO}_{2} \\
\text { Air } \\
\end{array}$ & $\begin{array}{l}\mathrm{SO}_{4} \\
\text { Air } \\
\end{array}$ & $\begin{array}{c}\mathrm{SO}_{2} \\
\frac{\text { Deposit }}{\left(\mathrm{SO}_{2} \text { Wet }\right)}\end{array}$ & $\begin{array}{c}\mathrm{SO}_{4} \\
\frac{\text { Deposit }}{\left(\mathrm{SO}_{4} \text { Wet }\right)}\end{array}$ & $\begin{array}{l}\mathrm{SO}_{2} \\
\mathrm{Off} \\
\end{array}$ & $\begin{array}{l}\mathrm{SO}_{4} \\
\mathrm{Off} \\
\end{array}$ & $\begin{array}{l}\mathrm{SO}_{2} \\
\text { Drop } \\
\end{array}$ & $\begin{array}{l}\mathrm{SO}_{4} \\
\text { Drop } \\
\end{array}$ \\
\hline \multirow[t]{4}{*}{$\begin{array}{l}\text { Anaconda, } \\
\text { Montana }\end{array}$} & hourly & 3.12 & 1.70 & $\begin{array}{l}84.31 \\
(4.15)\end{array}$ & $\begin{array}{c}8.95 \\
(5.60)\end{array}$ & 0.15 & 0.33 & 0.16 & 1.47 \\
\hline & 6-hourly & 3.13 & 1.57 & $\begin{array}{l}84.42 \\
(4.84)\end{array}$ & $\begin{array}{c}9.60 \\
(6.96)\end{array}$ & 0.13 & 0.24 & 0.14 & 0.76 \\
\hline & $\begin{array}{l}\text { average } \\
\text { (on/off) }\end{array}$ & 3.2 & 1.84 & $\begin{array}{l}84.06 \\
(3.23)\end{array}$ & $\begin{array}{c}8.93 \\
(5.72)\end{array}$ & 0.22 & 0.84 & 0.13 & 0.78 \\
\hline & average & 3.08 & 0.60 & $\begin{array}{l}84.29 \\
(3.95)\end{array}$ & $\begin{array}{l}11.30 \\
(9.64)\end{array}$ & 0.21 & 0.23 & 0.13 & 0.16 \\
\hline \multirow{4}{*}{$\begin{array}{l}\text { Four } \\
\text { Corners } \\
\text { Southwest } \\
\text { U.S. }\end{array}$} & hourly & 3.16 & 1.16 & $\begin{array}{l}84.69 \\
(6.46)\end{array}$ & $\begin{array}{c}9.39 \\
(6.64)\end{array}$ & 0 & 0 & 0.16 & 1.43 \\
\hline & 6-hourly & 3.19 & 1.19 & $\begin{array}{l}84.65 \\
(6.75)\end{array}$ & $\begin{array}{c}9.40 \\
(6.83)\end{array}$ & 0 & 0 & 0.18 & 1.39 \\
\hline & $\begin{array}{l}\text { average } \\
\text { (on/off) }\end{array}$ & 3.21 & 1.65 & $\begin{array}{l}84.51 \\
(5.75)\end{array}$ & $\begin{array}{c}9.32 \\
(6.41)\end{array}$ & 0 & 0 & 0.19 & 1.13 \\
\hline & average & 2.87 & 0.28 & $\begin{array}{l}85.11 \\
(7.70)\end{array}$ & $\begin{array}{c}11.46 \\
(10.30)\end{array}$ & 0 & 0 & 0.16 & 0.11 \\
\hline \multirow{4}{*}{$\begin{array}{l}\text { East } \\
\text { Central } \\
\text { Arkansas }\end{array}$} & hourly & 2.93 & 0.71 & $\begin{array}{l}84.81 \\
(6.99)\end{array}$ & $\begin{array}{r}10.46 \\
(7.85)\end{array}$ & 0.35 & 0.27 & 0.10 & 0.37 \\
\hline & 6-hourly & 2.74 & 0.30 & $\begin{array}{c}85.27 \\
(8.8)\end{array}$ & $\begin{array}{l}10.99 \\
(8.74)\end{array}$ & 0.28 & 0.15 & 0.09 & 0.18 \\
\hline & $\begin{array}{l}\text { average } \\
\text { (on/off) }\end{array}$ & 3.26 & 1.14 & $\begin{array}{l}84.65 \\
(7.52)\end{array}$ & $\begin{array}{l}10.41 \\
(8.48)\end{array}$ & 0.27 & 0.15 & 0.08 & 0.05 \\
\hline & average & 2.78 & 0.18 & $\begin{array}{l}85.25 \\
(8.92)\end{array}$ & $\begin{array}{c}11.33 \\
(10.28)\end{array}$ & 0.32 & 0.06 & 0.07 & 0.01 \\
\hline
\end{tabular}

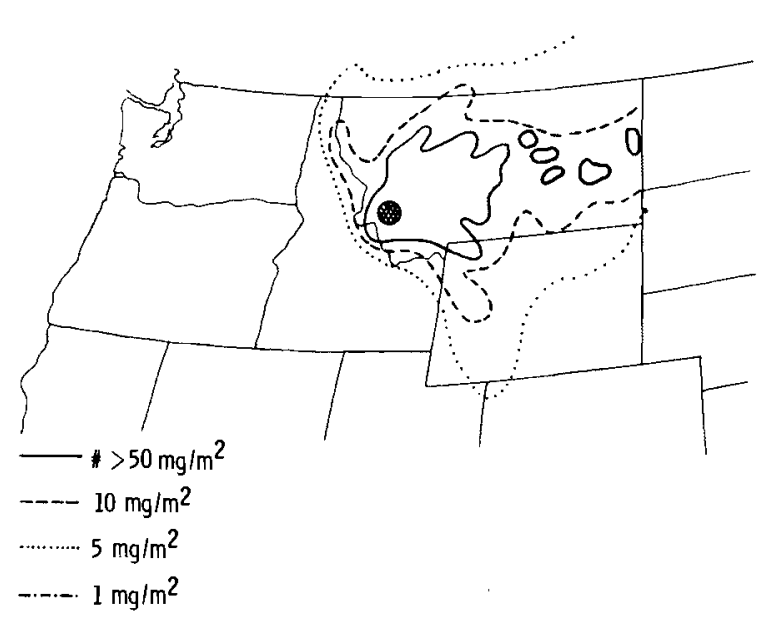

FIGURE 19. Time-Averaged Precipitation, $\mathrm{SO}_{4}$ Deposition, July 1974

to average out. This is based on the high deposition near the source as the result of scavenging for all puffs. When the rain is turned "on" and "off" with the approximate natural frequency, a better estimate of depo-

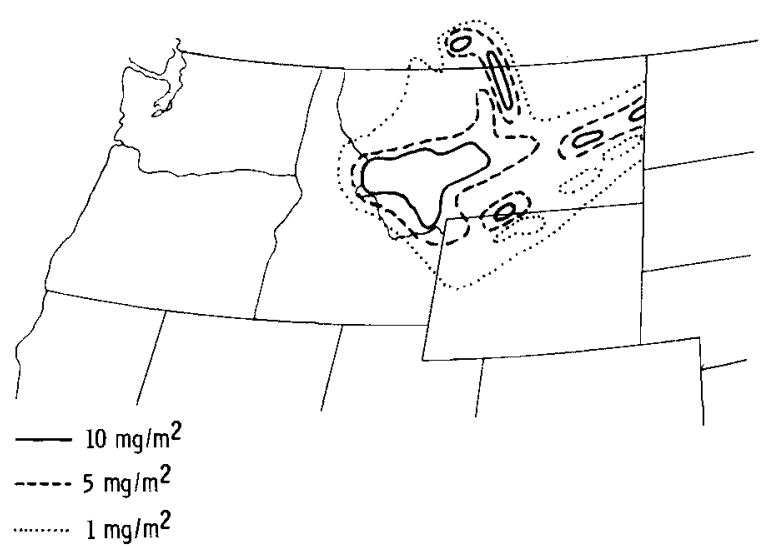

FIGURE 20. Time-Averaged Precipitation $(3 \mathrm{hr}$ on $/ 120 \mathrm{hr}$ off), $\mathrm{SO}_{4}$ Deposition, July 1974

sition is obtained. It is recommended that average precipitation using monthly values turned "on" and "off" with the average frequency be used in long-term assessments. 


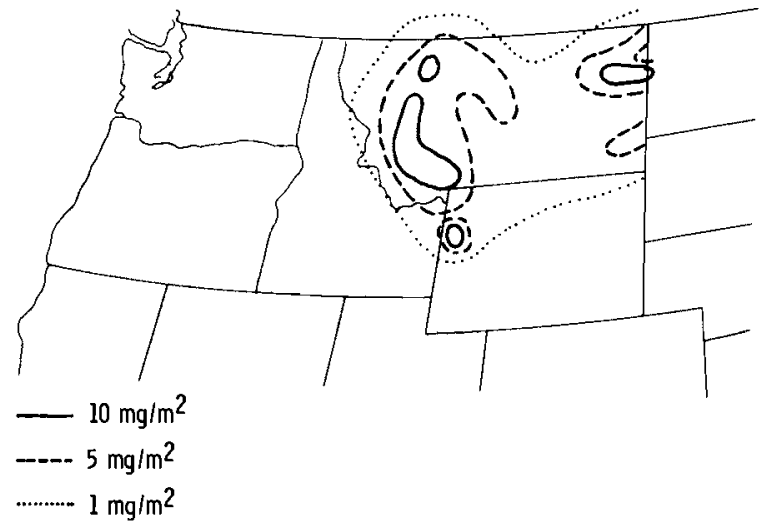

FIGURE 21. Hourly Precipitation, $\mathrm{SO}_{4}$ Deposition, July 1974

\section{References}

Davis, W. E. 1979. "The Effect of Using Time Averaged Precipitation for the Estimation of Wet Deposition in a Regional Scale Model." Presented at the Fourth Symposium on Turbulence, Diffusion, and Air Pollution, January 15-18, 1979, Reno, NV.

Eadie, W. J. and W. E. Davis. 1979. Development of a National Interregional Transport Matrix for Respirable Particulates. PNLRAP-37, Pacific Northwest Laboratory, Richland, WA.

El iassen, A. 1978. "The OCED Study of LongRange Transport of Air Pollutants: LongRange Transport Modelling." Atmos. Environ. 12:1-3.

Fisher, B. E. A. 1978. "The Calculation of Long-Term Sulphur Deposition in Europe." Atmos. Environ. 12:489-501.

Fox, T. D. and L. L. Wendel1. 1977. "Precipitation Data Base Manipulation for Use in Regional Transport and Removal Models." In Pacific Northwest Laboratory Annual Report for 1976 to ERDA, Part 3, Atmospheric Sciences. BNWL-2100 PT3, Pacific Northwest Laboratory, Richland, WA.

Henmi, T. and E. R. Reiter. 1978. "Regional Residence Time of Sulfur Dioxide Over the Eastern United States." Atmos. Environ. 12:1489-1495.

Johnson, W. B., D. E. Wolf and R. L. Mancuso. 1978. "Long-Term Regional Patterns and Transfrontier Exchanges of Airborne Sulfur Pollution in Europe." Atmos. Environ. $12(1-3)$.

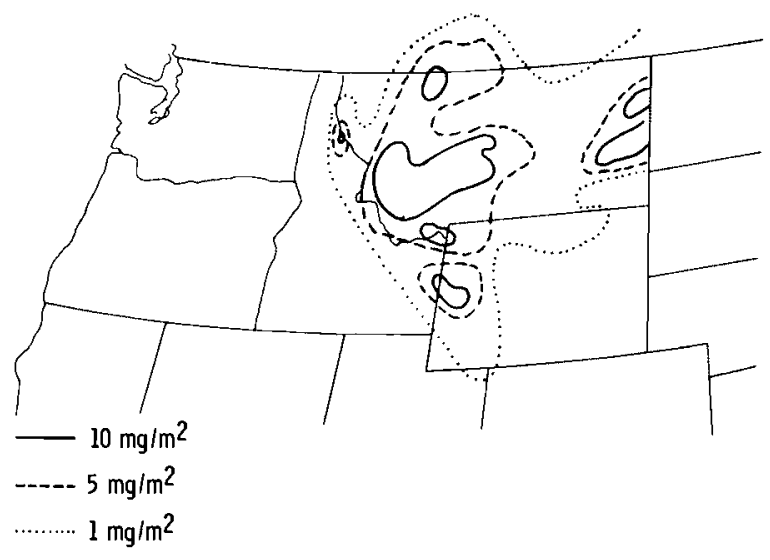

FIGURE 22. Six-Hour Precipitation, $\mathrm{SO}_{4}$ Deposition, July 1974

McNaughton, D. J. 1980. "Initial Comparisons of SURE/MAP3S Sulfur 0xide Observations with Long-Term Regional Model Predictions." Atmos. Environ. 14.

Powe11, D. C., D. J. McNaughton, L. L. Wendell and R. L. Drake. 1979. A Variable Trajectory Model for Regional Assessments of Air Pollution from Sulfur Compounds. PNL2734, Pacific Northwest Laboratory, Richland, WA.

Rohde, H. and J. Grandell. 1972. "On the Removal Time of Aerosol Particles from the Atmosphere by Precipitation Scavenging." Tellus. 24(5):442-454.

Sandusky, W. F., W. J. Eadie and D. R. Drewes. 1979. "Long-Range Transport of Pollutants in the Pacific Northwest." Presented at the 25th Annual Meeting of the Institute of Environmental Sciences, April 20May 3, 1979, Seattle, WA.

Slinn, W. G. N. 1978. "Parameterization for Resuspension and for Wet and Dry Deposition of Particles and Gases for Use in Radiation Dose Calculations." Nuclear Safety. $19(2): 205-219$.

Wende 11, L. L., D. C. Powell and D. J. McNaughton. 1977. "A Multi-Source Comparison of Real Time versus Time Average Precipitation Data on $\mathrm{SO}_{2}$ and Sulfate Particulate Removal in a Regional Assessment Mode." Presented at the Joint Conference on Applications of Air Pollution Meteorology, November 29-December 2, 1977, Salt Lake City, UT. 
A New Regiona1-Scale Assessment Method Based on Assessments at Regularly Spaced Grid Points

\section{W. E. Davis and W. J. Eadie}

Recently a number of environmental assessments have been carried out over the United States with a variable trajectory model to evaTuate the air quality impact of a variety of pollutants. In some of these cases, the number of the sources that have to be taken into account for a long-term assessment make the computer requirements of such an assessment prohibitive. In order to attempt to reduce the number of assessments, and thereby their cost, research at Pacific Northwest Laboratory (PNL) has been carried out to investigate a new approach for making a large number of assessments based on a relatively few number of assessments at regularly spaced intervals (Eadie and Davis 1980). In order to test whether such an ap- proach is valid, a series of case studies were carried out during FY 1979 using the PNL long-range transport model.

The PNL model simulates plume elements released hourly from an emission source. Five sources were used in one case study, where four of these formed a box at grid 10cations indicated in Figure 23, and the fifth was a source in the Four Corners area in Fiqure 24. The four gridded assessments used for this comparison were based on the National Meteorological Center (NMC) northern hemispheric grid. The assumptions made in the model are described in this Annual Report (see Davis and Eadie 1980).

This test was run for a simulation of emitted particulates in the respirable size ranges of approximately 0.1 to $3 \mu \mathrm{m}$ in dia with a dry deposition velocity of $0.23 \mathrm{~cm}$ $\sec ^{-1}$ and a wet removal rate of $0.38 \mathrm{P} .73 \mathrm{hr}^{-1}$, where $P$ is in $\mathrm{mm} \mathrm{hr}^{-1}$ (Eadie

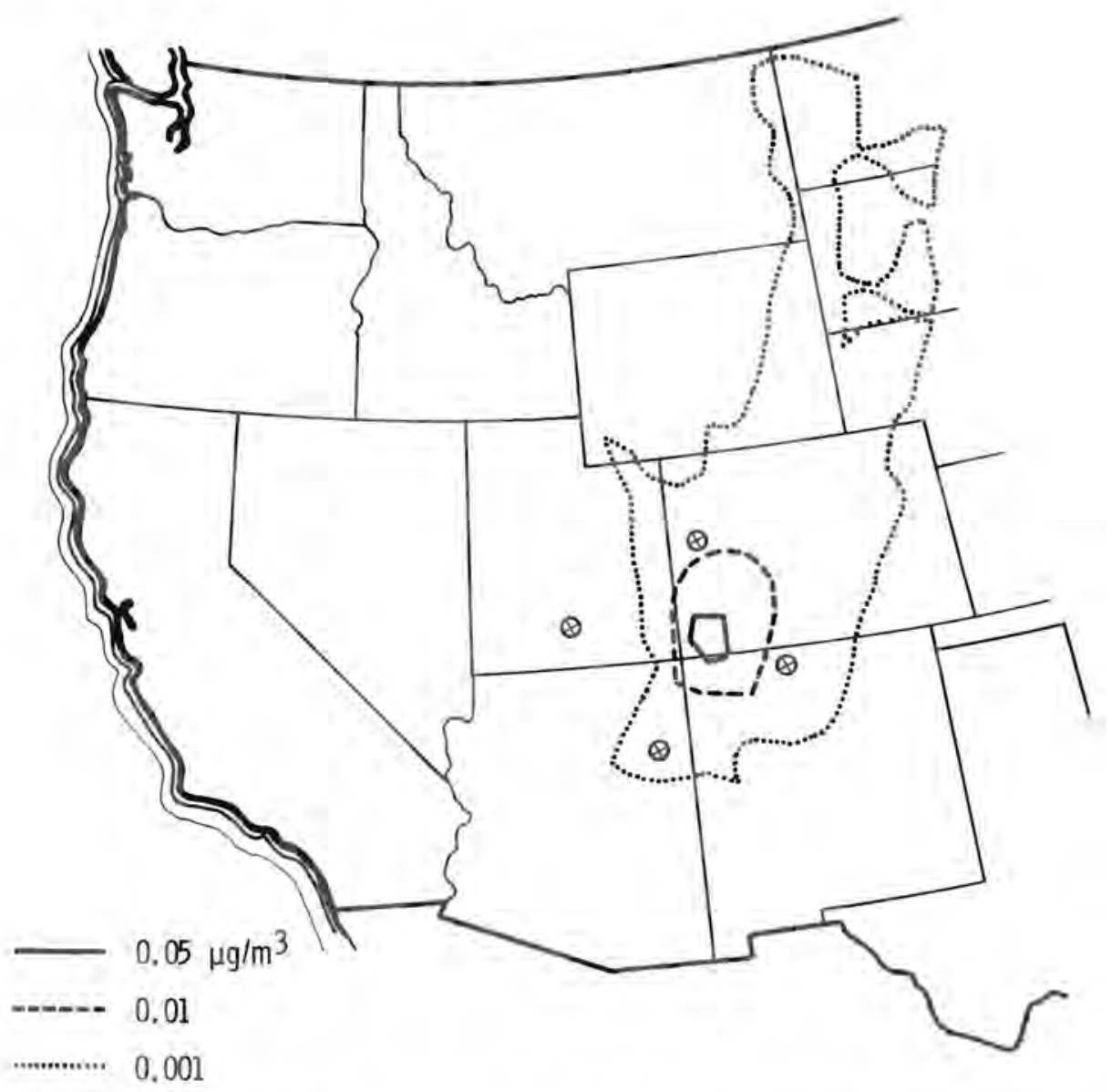

FIGURE 23. Weighted and Transposed Air Concentration Assessment for Four Corners for July 1974 


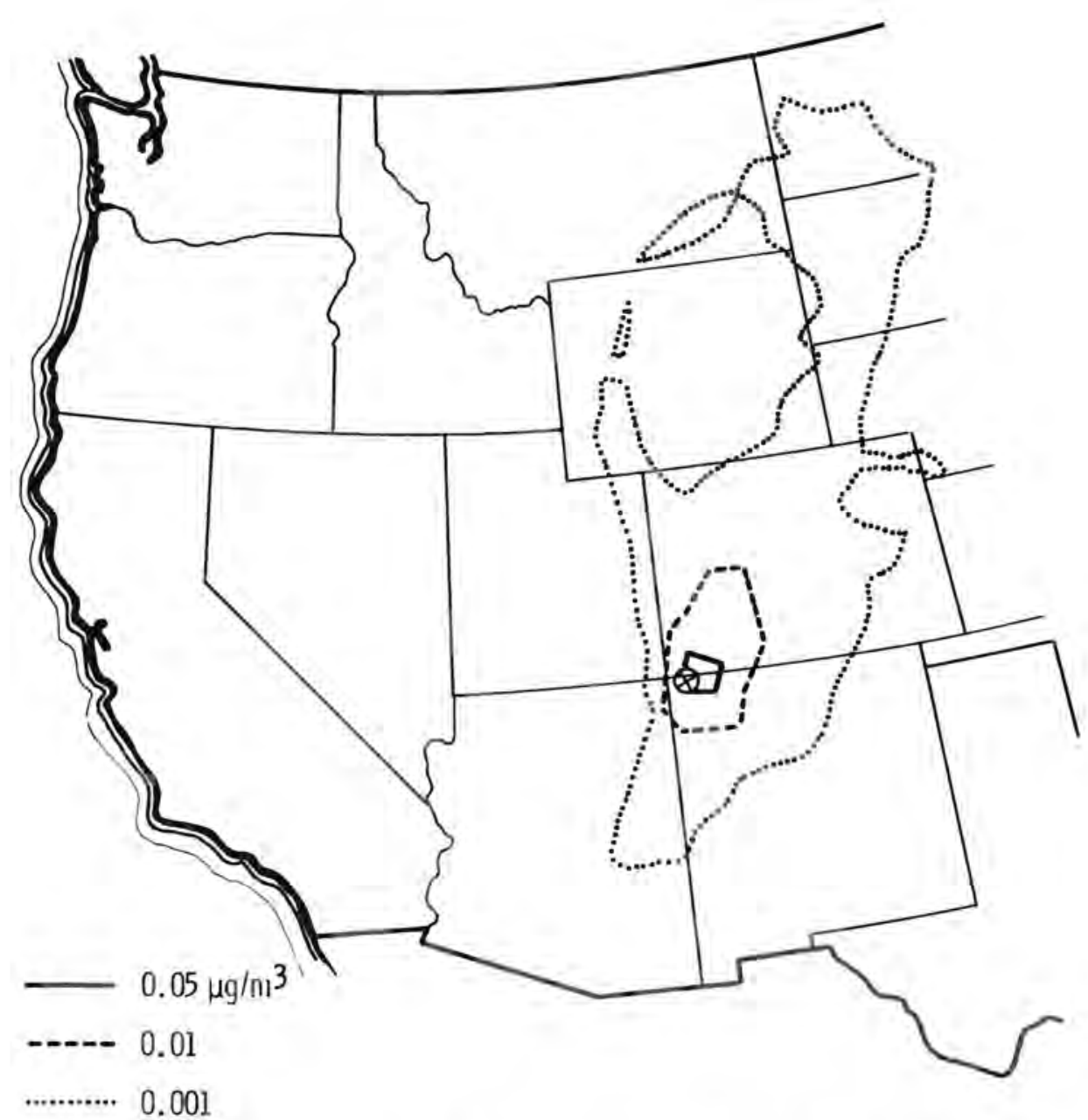

FIGURE 24. Air Concentration Assessment for Four Corners for July 1974

and Davis 1979). Hourly precipitation was used for wet removal in the test case.

The assessments were run for July 1974 for the four grid points and the source at Four Corners. The gridded assessments were weighted by the inverse square of their distance to the source point at Four Corners divided by the sum of the inverse square of the distances from each of the four grid points to the source. The four weighted assessments were then transposed to the source point and added together to form an estimated assessment for the source at Four Corners.

The results are shown in Figures 23 and 24 where Figure 23 shows the assessment com- puted from the gridded assessments and Figure 24 shows the source assessment. It should be noted that the mass balance was maintained for each assessment and, therefore, a1so for the weighted assessment shown in Figure 23.

The main differences that can be noted are that the air concentration pattern region in eastern Wyoming is not as low as in the source assessment. Other than a region in southeastern Montana where there is an underestimate by the weighted values, fairly good agreement was maintained between the two assessments for centerline values. 
These results were in basic agreement with earlier work by Davis where two annual assessments were compared where the source points were varied by 60 nautical miles (Figures 25 and 26). When the two assessments were transposed and a ratio taken of their air concentrations taken, in general the value of the ratio of $\sim 1$ existed out to 600 nautical miles downwind.

Further testing is underway to investigate the optimum grid spacing needed to provide a good estimate of assessments for all potential source locations in the continental United States.

\section{References}

W, J. Eadie and W. E. Davis. 1979. The Development of a National Interregional Transport Matrix for Respirable Particulates. PNL-RAP-37, Pacific Northwest Laboratory, Richland, WA.

W. E. Davis and W. J. Eadie. 1980. "The Use of Time-Averaged Precipitation for Wet Removal in a Regional Air Pollution Assessment Model." In Pacific Northwest Laboratory Annual Report for 1979 to the DOE Assistant Secretary for Environment, Part 3, Atmospheric Sciences. PNL-3300 PT3, Pacific Northwest Laboratory, Richland, WA.

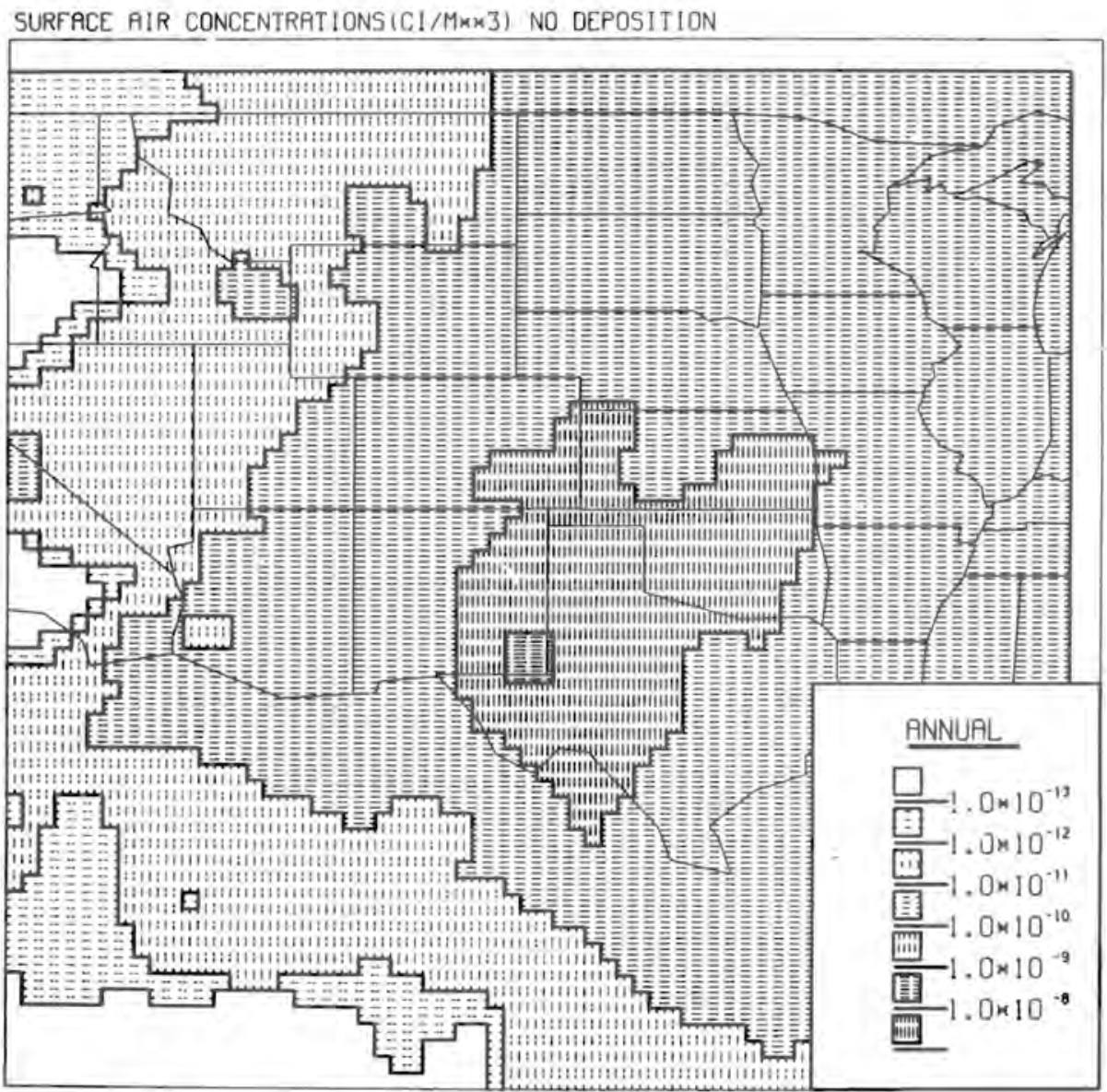

FIGURE 25. Annual Air Concentration Assessment at Carlsbad, NM, for 1975 


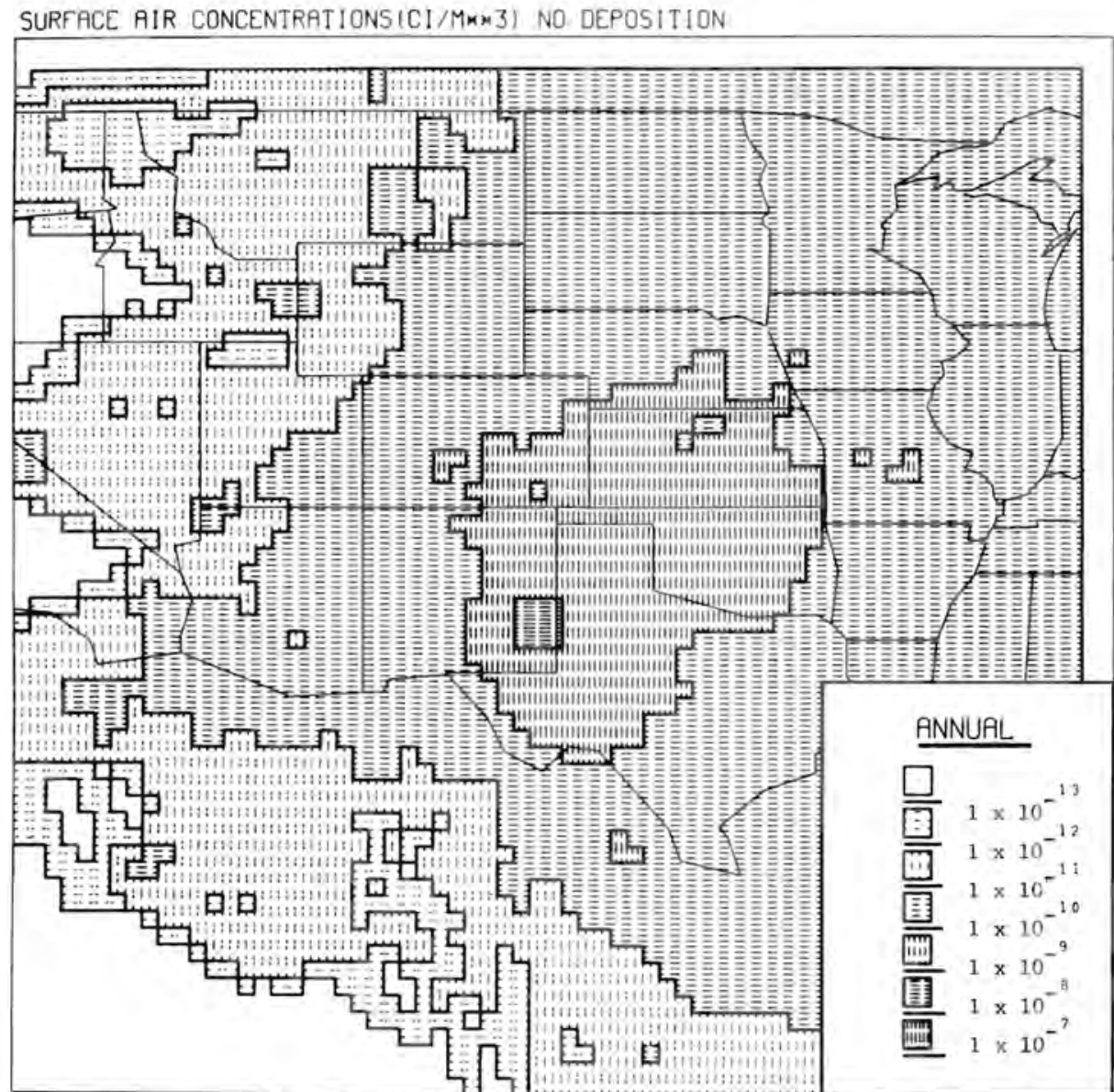

FIGURE 26. Annual Air Concentration Assessment 60 Nautical Miles North of Carlsbad, NM, for 1975 


\section{- Precipitation Scavenging in MAP3S*}

Objectives of this study are:

- Using field experiments and numerical modeling to determine causal relationships in the pollutionscavenging process so that valid techniques for calculating regional removal can be formulated.

- Collecting and analyzing precipitation chemistry samples from the Multistate Atmospheric Power Production Pollution Study (MAP3S) network in the northeastern United States.

- Data-banking precipitation scavenging and chemistry results for use in developing and testing theories and numerical models for the prediction of transport and deposition of fossil fuel pollutants.

The MAP3S Precipitation Chemistry Network: Progress and Recent Results

M. Terry Dana, D. R. Drewes, D. W. Glover, S. D. Harris and J. E. Rothert

The Multistate Atmospheric Power Production Pollution Study (MAP3S) network is beginning its fourth year of event sampling of wet deposition in the northeast United States region. Samples are chemically analyzed and the data reported as monthly reports within about 4 mo of arrival of samples at the laboratory. This time lag is expected to shorten to about 2 mo during FY 1980 since the completion of the Pennsylvania State University collector comparison study initiated in May 1978 has eased the laboratory sample burden considerably.

Weekly sampling, in addition to event sampling, has been underway at four sites for over a year. Initial results indicate that weekly samples (which are collected with Health and Safety Laboratory [HASL] samplers) show higher concentrations of the major ions $\mathrm{H}^{+}, \mathrm{NO}_{3}^{-}, \mathrm{SO}_{4}^{-}$and $\mathrm{NH}_{4}^{+}$than the mean of the event samples during the week. The reasons for these higher concentrations are unclear at present, and further careful analyses of results for an entire year of data will be completed and reported during the coming year.

The second periodic summary report of the MAP3S precipitation chemistry program (MAP3S 1979) lists complete chemical data for the period July 1977 to June 1978. Included are monthly mean deposition-weighted concentrations for the period, some of which are reproduced here in Figures 27 and 28 . The seasonal trends in sulfur dioxide and sulfate and the lack of significant trends in other species are evident.

More recent sulfur concentration data are given in "Sulfur Wet Deposition in the Northeast United States: Winter 1978-1979" in this Annual Report.

\section{$\underline{\text { Reference }}$}

MAP3S Precipitation Chemistry Network Participants. 1979. The MAP3S Precipitation Chemistry Network: Second Periodic Summary Report (July 1977 to June 1978). PNL-2829, Pacific Northwest Laboratory, Richland, WA.

*See Foreword 

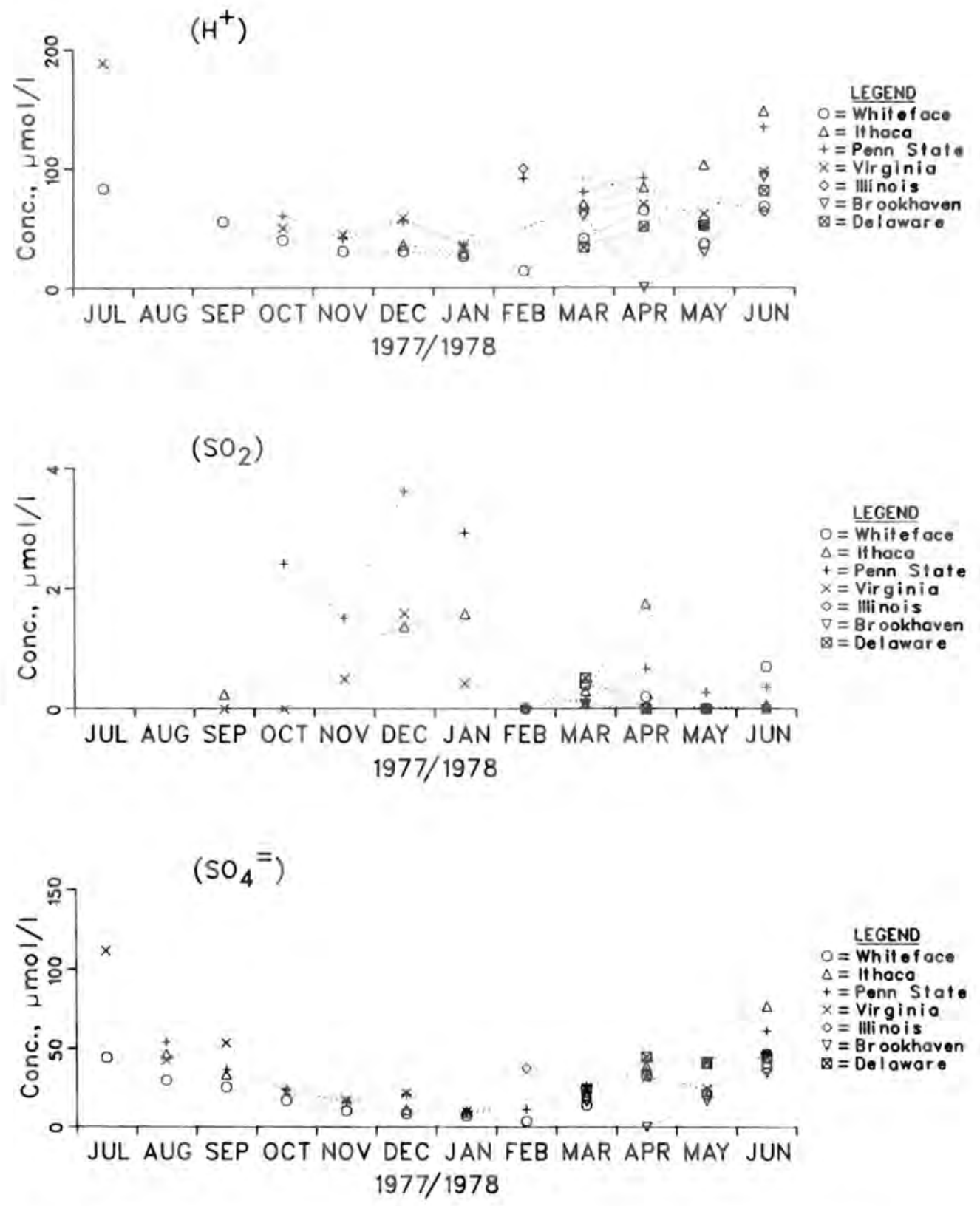

FIGURE 27. Monthly Mean Deposition-Weighted Concentrations for $\mathrm{H}^{+}$(from $\mathrm{pH}$ ), $\mathrm{SO}_{2}$, and $\mathrm{SO}_{4}^{-}$from the MAP3S Network 

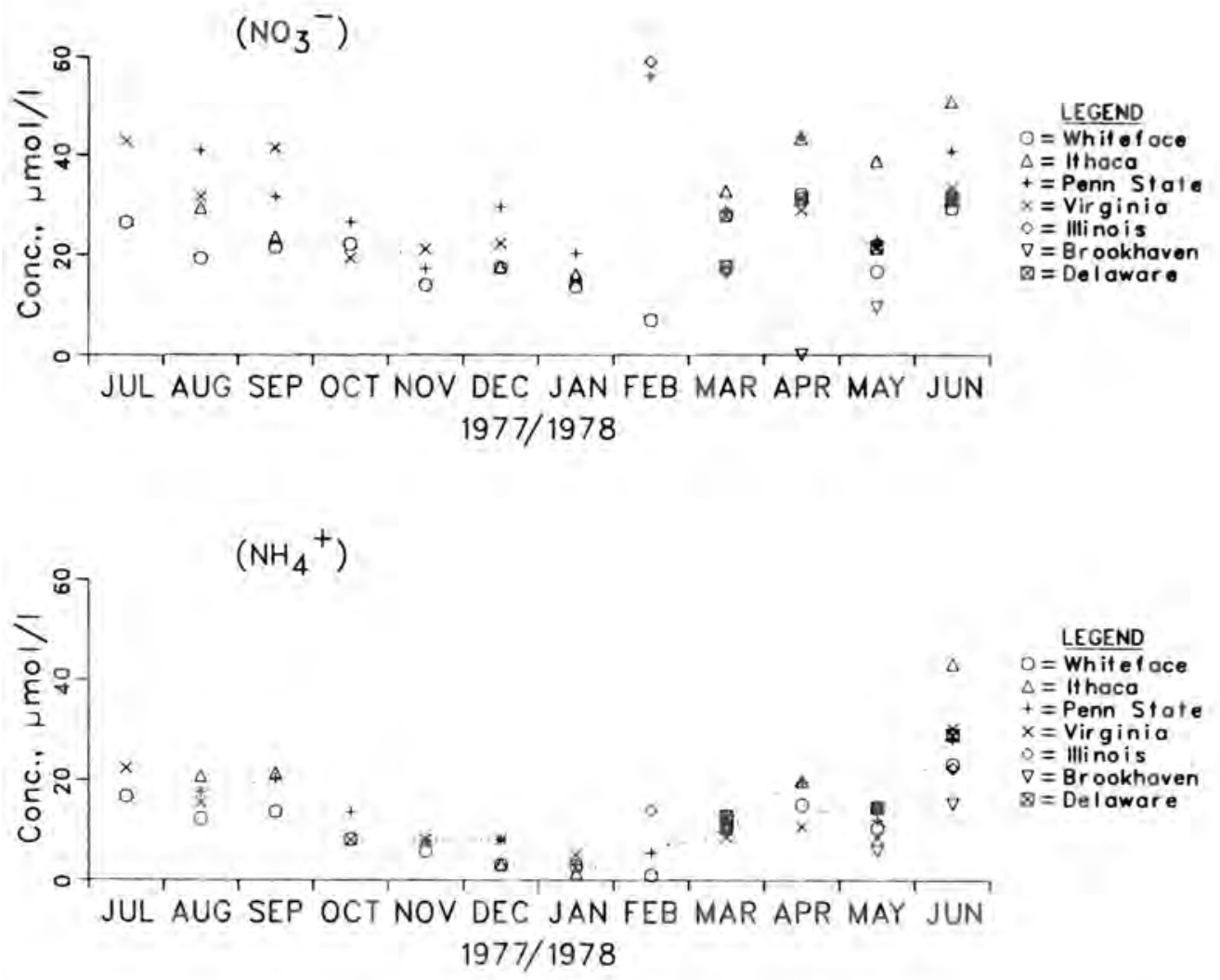

FIGURE 28. Monthly Mean Deposition-Weighted Concentrations for $\mathrm{NO}_{3}{ }^{-}$and $\mathrm{NH}_{4}{ }^{+}$from the MAP3S Network

Chemical Laboratory Activities and Quality Control ResuTts for the MAP3S Program

\section{J. E. Rothert}

Approximately 900 Precipitation Chemistry Network samples from the Multistate Atmospheric Power Production Pollution Study (MAP3S) program have been analyzed for $\mathrm{pH}$, conductivity, $\mathrm{SO}_{2}, \mathrm{SO}_{4}=, \mathrm{NO}_{2}^{-}, \mathrm{NO}_{3}-, \mathrm{Ca}^{+2}$, $\mathrm{Mg}^{+2}, \mathrm{Cl}^{-}, \mathrm{PO}_{4}^{-3}, \mathrm{NA}^{+}, \mathrm{NH}_{4}^{+}$, and $\mathrm{K}^{+}$during FY 1979. Two hundred fifty-six of these samples were part of the precipitation coTlector comparison study conducted at PennsyTvania State University by MAP3S. The other 650 samples were routine precipitation network week $7 y$ and event samples. There were also 59 quality control samples analyzed along with network samples. Another 100 samples were analyzed for the MAP3S field studies in Michigan.

Precipitation samples were processed in the laboratory at an average of 75 samples/ mo. January of 1979 was the peak analys is month with 120 MAP3S precipitation samples analyzed. Including the field studies samples and the quality control samples, approximately 90 samples/mo were analyzed for the 13 species for the MAP3S program.

The quality control samples included two types of samples. Sixteen were external, analyst-b1ind samples; 43 were internal, analyst-not-blind, replicate samples. After approximately every 10 network samples, an internal or external quality control sample was analyzed.

The field studies samples included precipitation samples, $\mathrm{SO}_{2}$ and particulate matter samples, and incloud scavenging samples from the field studies in Muskegon, Michigan. Not all of these samples were analyzed for the entire 13 species. Approximately 75 precipitation and incloud scavenging samples were analyzed for the entire 13 species.

In total, the chemical laboratory activities included analysis of approximately 1000 MAP3S program samples. The quality of these analyses were monitored by analyzing 
internal and external quality control samples along with the MAP3S samples on a routine basis. Approximately one quality control sample for every 20 MAP3S samples was analyzed.

Sulfur Wet Deposition in the Northeast United States: Winter 1978-1979

\section{Terry Dana}

A recent presentation (Dana 1979) presents an analysis of dissolved sulfur dioxide and sulfate deposition on the Multistate Atmospheric Power Production Pollution Study (MAP3S) Precipitation Chemistry Network for the winter of 1978-1979. The analys is follows up and supplements an earlier publication (Hales and Dana 1979) that dealt with earlier data and compared observations with predictions based on $\mathrm{SO}_{2}$ solubility theory.

Figures 29 and 30 show the ratio of dissolved $\mathrm{SO}_{2}\left(\mathrm{SO}_{\overline{3}}\right)$ to total sulfur $\left(\mathrm{SO}_{\overline{3}}\right.$ and $\mathrm{SO}_{4}^{\bar{*}}$ ) concentrations as observed at seven of the eight MAP3S sites. At all sites, the dissolved $\mathrm{SO}_{2}$ component is a significant fraction of the total sulfur in the wintertime, but the winter total sulfur concentration is only about one seventh of that occurring in the summer months (see, for example, Figure 27 of "The MAP3S Precipitation Chemistry Network: Progress and Recent Results" in this Annual Report). Users of sulfur deposition data should recognize that not a11 of the wintertime sulfur deposition is as sulfate, as has been routinely assumed in the past.

\section{References}

Dana, M. Terry. 1979. " $\mathrm{SO}_{2}$ Versus Sulfate Wet Deposition in the Eastern United States." Presented at the CACGP Symposium on the Budget and Cycles of Trace Gases and Aerosols in the Atmosphere, August 12-18, 1979, Boulder, CO.

Hales, J. M. and M. Terry Dana. 1979. "Regional-Scale Deposition of Sulfur Dioxide by Precipitation Scavenging." Atmos. Environ. 13:1121-1132.

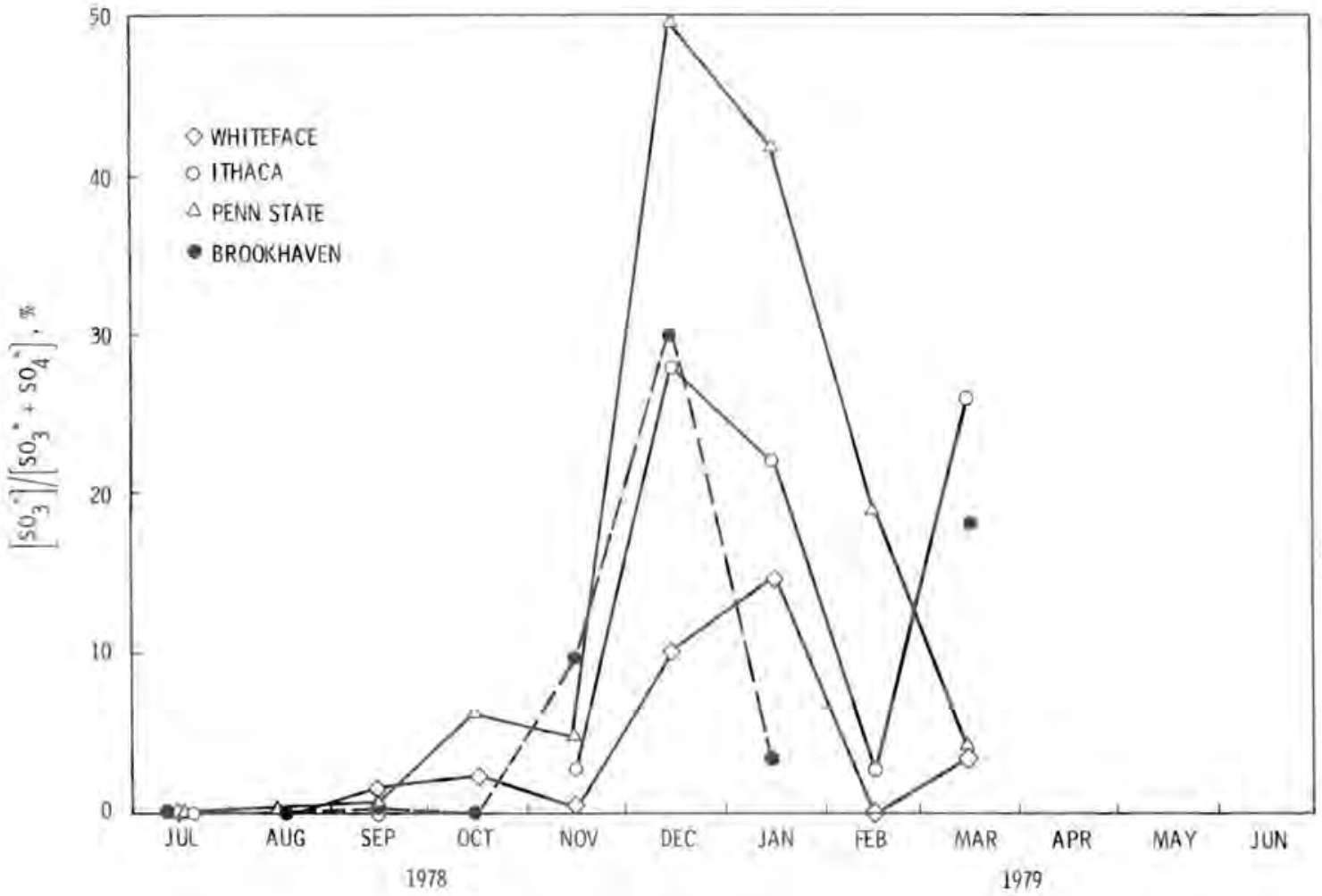

FIGURE 29. Ratio of Dissolved $\mathrm{SO}_{2}$ to Total Sulfur Concentrations (Monthly Mean Deposition-Weighted) at Four Northeastern United States Sites 


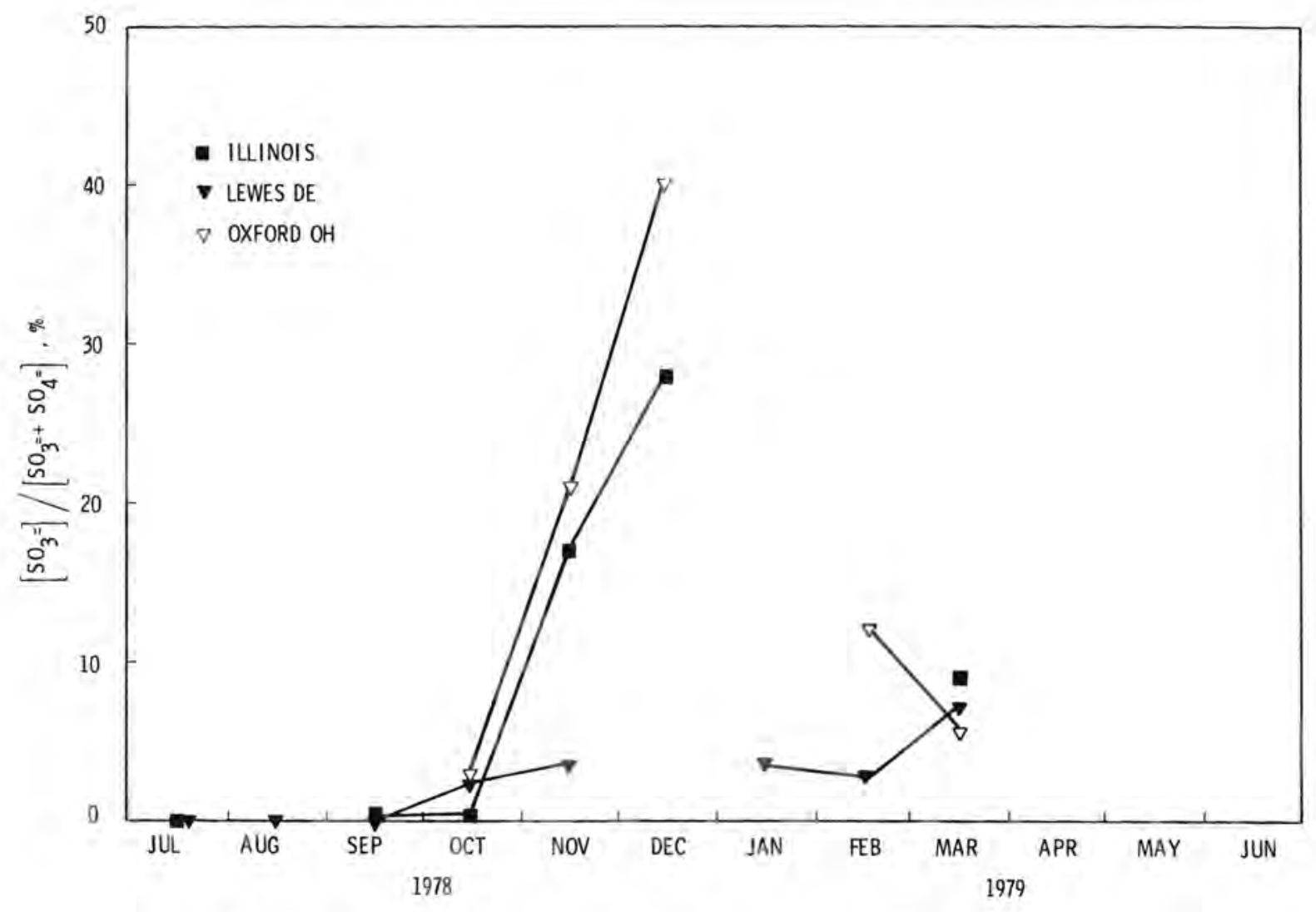

FIGURE 30. Ratio of Dissolved $\mathrm{SO}_{2}$ to Total Sulfur Concentrations (Monthly Mean Deposition-Weighted) at Three Midwest and Coastal Sites

Predictions of Incloud Conversion Rates of Sulfur Dioxide to Sulfate Based upon a Simple Chemical and Dynamical Model

\section{B. C. Scott}

A simple chemical model has been developed to estimate the percentage of total wet-deposited sulfate and nitrate that is oerived from an incloud, aqueous-phase conversion process. The model does not explicitly define a conversion mechanisim but assumes that the bulk of the sulfate originates either from nucleation of aerosol composed of $\left(\mathrm{NH}_{4}\right)_{2} \mathrm{SO}_{4}, \mathrm{NH}_{2} \mathrm{HSO}_{4}, \mathrm{CaSO}, \mathrm{MgSO}_{4}$, $\mathrm{K}_{2} \mathrm{SO}_{4}$ or from the conversion of $\mathrm{SO}_{2}$ to $\mathrm{SO}_{4}{ }^{-}$. Nitrate is assumed to originate from $\mathrm{NH}_{4} \mathrm{NO}_{3}$ or from some unspecified aqueous-phase conversion of $\mathrm{NO}_{2}$ to $\mathrm{NO}_{3}-$. Figure 31 schematically illustrates the aerosol components (materials in the boxes) that contribute to the ionic composition of the precipitation water (ions in the circles).
Further input to the model is provided by aerosol acidity measurements from Argonne National Laboratory (MAP3S 1979) that indicate that

$$
\frac{[\mathrm{H}]}{\left[\mathrm{SO}_{4}\right]}=0.3
$$

where $[\mathrm{H}]$ and $\left[\mathrm{SO}_{4}\right]$ represent molar concentrations of hydrogen and sulfate ion found in surface-level aerosol. Final model input are observations of major cation and anion concentrations in precipitation water.

Solving the system of available equations provides, the molar concentration of $\mathrm{H}_{2} \mathrm{SO}_{4}$ :

$$
\begin{aligned}
{\left[\mathrm{H}_{2} \mathrm{SO}_{4}\right]=} & {\left[\mathrm{SO}_{4}\right]-1.177 \mathrm{a} } \\
& -0.588\left[\left[\mathrm{NH}_{4}\right]-\left[\mathrm{NO}_{3}\right]+\left[\mathrm{HNO}_{3}\right]\right]
\end{aligned}
$$




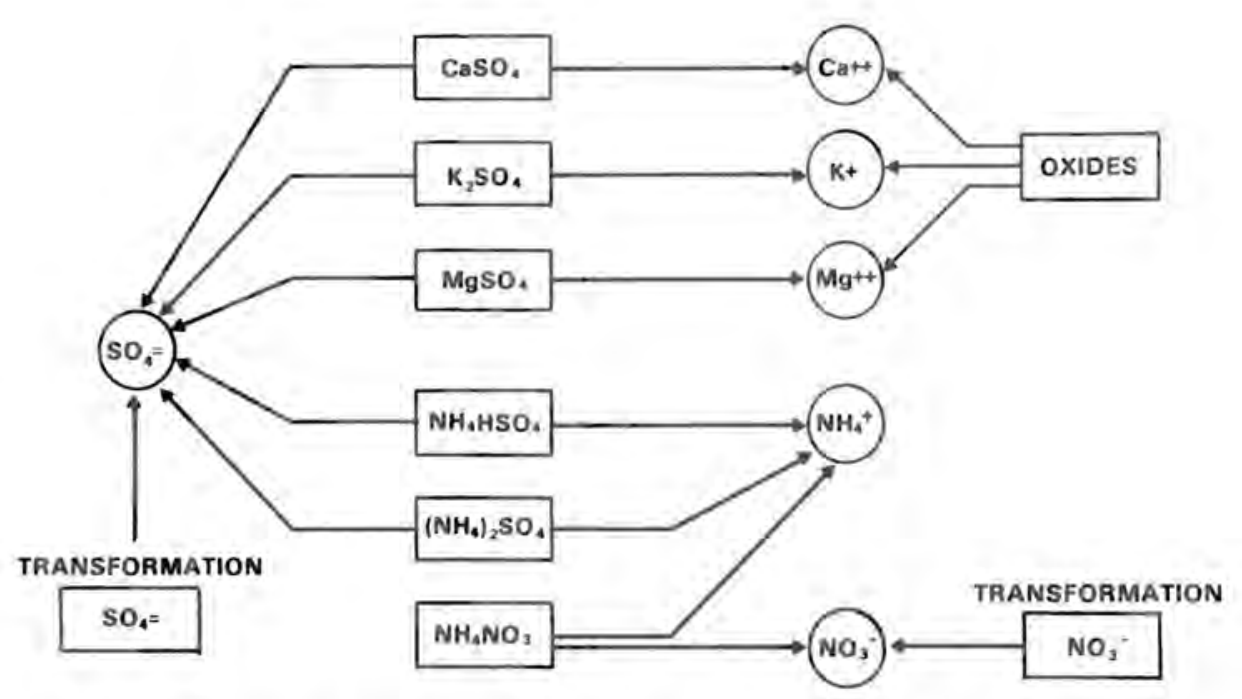

FIGURE 31. Aerosol Components Assumed to Contribute to the lonic Composition of Precipitation Water

where $\left[\mathrm{SO}_{4}\right],\left[\mathrm{NH}_{4}\right],\left[\mathrm{NO}_{3}\right]$ are the motar concentrations of sulfate, ammonium, and nitrate observed in the rain water. The value a represents the moles/l of sulfate contributed by $\mathrm{MgSO}_{4}, \mathrm{~K}_{2} \mathrm{SO}_{4}$ and $\mathrm{CaSO}_{4}$ and is taken to equal

$$
a=\frac{1}{2}[[\mathrm{Mg}]+[\mathrm{K}]] .
$$

Since the ambient aerosol is assumed not to contain any particles of $\mathrm{H}_{2} \mathrm{SO}_{4}$ or $\mathrm{HNO}_{3}$, these strong acids appearing in (2) represent the mass of material produced by incloud conversion processes. By assuming various values for $\left[\mathrm{HNO}_{\mathrm{g}}\right]$ in (2), for example,

$$
\left[\mathrm{HNO}_{3}\right]=\left[\mathrm{NO}_{3}\right]
$$

or

$$
\left[\mathrm{HNO}_{3}\right]=0,
$$

upper and lower bounds can be established for concentrations of $\left[\mathrm{H}_{2} \mathrm{SO}_{4}\right]$ and $\left[\mathrm{HNO}_{3}\right]$. Comparison of the moles of [ $\mathrm{SO}_{4}$ ] contributed by $\left[\mathrm{H}_{2} \mathrm{SO}_{4}\right]$ versus the total concentration of $\left[\mathrm{SO}_{4}\right]$ then yields the fraction of sulfate contributed by direct aerosol washout. Figure 32 represents an example of the above discussion for a series of sequential samples taken roughily every hour at two different locations (sites $A$ and $F$ ) near Muskegon, Michigan. For these data, sulfate contributed by $\mathrm{H}_{2} \mathrm{SO}_{4}$ ranges from 30 to $90 \%$ of the total sulfate, whereas nearly all of the nitrate fell in the form of $\mathrm{HNO}_{3}$.
Applying the above model to data from the Multistate Power Production Pollution Study (MAP3S) Precipitation Chemistry Network (MAP3S Precipitation Chemistry Network Participants 1979b) for the eastern United States results in predictions that 55 to $90 \%$ of the wet-deposited sulfate is the result of incloud conversion during winter, and 75 to $90 \%$ of the sulfate is a conversion product in the summer. Incloud conversion is predicted to account for 75 to $100 \%$ of the wet-deposited nitrate during the winter and 40 to $100 \%$ of the wet nitrate flux during the summer. The remainder of the sulfate and nitrate comes from wet removal of pre-existing aerosol that is drawn into the storm systems from clear air. In the winter season the bulk of the precipitation acidity appears to originate from $\mathrm{HNO}_{3}$, whereas during the summer, $\mathrm{H}_{2} \mathrm{SO}_{4}$ contributes the majority of the precipitation acidity.

The output from this chemical model has been used as input for a newly developed, simple storm model that applies over scales of $1000 \mathrm{~km}$ and is based upon pollutant and vapor fluxes into and out of a storm. Figure 33 schematically illustrates some of the concepts applied in the mode1. The flux of sulfate aerosol as a result of mean inflow and outflow from the storm system is represented by $(\rho U)$, and fallout of sulfate with precipitation is represented by (JC). Production of $\mathrm{H}_{2} \mathrm{SO}_{4}$ proceeds at a rate $\lambda$ and lasts over the time interval $\Delta t$. The time available for conversion, $\Delta t$, is further 


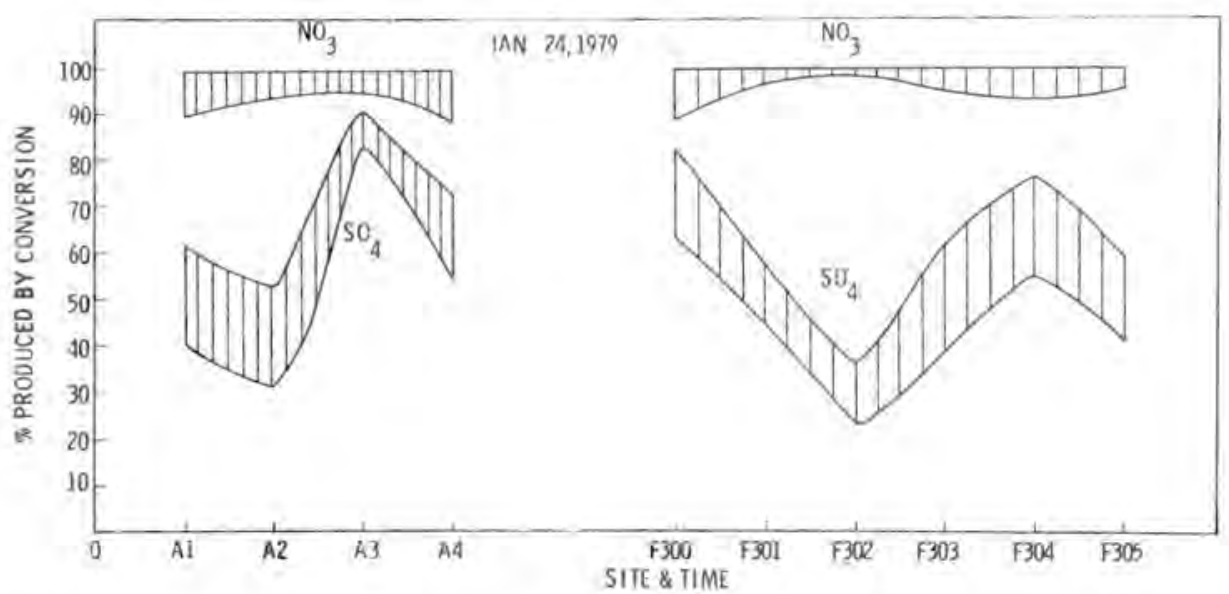

FIGURE 32. Percent of 50, and NO, Produced by Incloud Conversion as a Function of Time for Two Sampling Locations Near Muskegon, MI

\section{SULFATE MASS BUDGET}
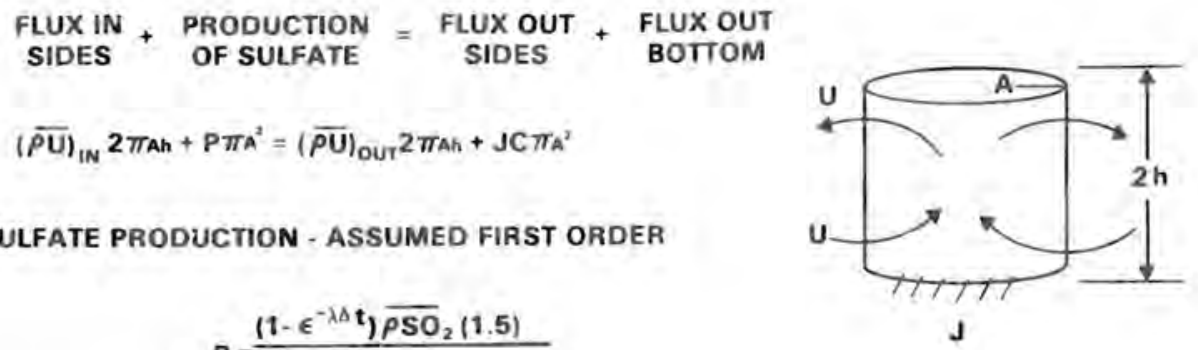

$\Delta t=$ AVERAGE TIME AVAILABLE TO DROPLETS FOR CONVERSION

$=\delta t_{\text {UP }}+\delta t_{\text {DOWN }}$

FIGURE 33. Schematic of Concepts Applied in the Dynamic Model of Storm Systems

subdivided into the average time available for a liquid cloud droplet to move upward in the cloud updraft before collection, and in addition, the average time available once the 1 iquid droplet has been collected by a raindrop or snowflake and is carried downward. During this downward path, no conversion is allowed until the collector particle falls below the freezing level.

The cloud model uses semi-empirical relationships to predict cloud updraft velocities, cloud heights and time available for conversion to occur within the condensed $\mathrm{Ti}$ quid water of the storm. Using this predicted conversion time and the value of mass produced by conversion from the chemical mo- del, values of incloud conversion rates for conversion of $\mathrm{SO}_{2}$ to $\mathrm{SO}_{4}=$ can be obtained. Application with the regional precipitation data from the MAP3S network yields incloud winter conversion rates of $\mathrm{SO}_{2}$ to $\mathrm{SO}_{4}=$ of near $1 \% h^{-1}$, whereas during the summer months, conversion rates are predicted to be near $10 \% \mathrm{~h}^{-1}$.

\section{References}

The Multistate Atmospheric Power Production Pollution Study (MAP3S). 1979. Progress Report for FY 1977 and FY 1978. DDE/EV-0040, U. S. Department of Energy, Assistant Secretary for Environment, Office of Health and Environmental Research. 
MAP3S Precipitation Chemistry Network Participants. 1979. The MAP3S Precipitation Chemistry Network: Second Periodic Summary Report (July 1977 to June 1978). PNL-2829, Pacific Northwest Laboratory, Richland, WA.

\section{Wet Sulfate Deposition in Winter Storms}

\section{B. C. Scott}

Beginning with the winter of 1976 to 1977, intensive experiments have been conducted yearly by Pacific Northwest Laboratory (PNL) in which simultaneous observations of precipitation chemistry and subcloud aerosol and gas concentrations were obtained. The experiments were performed in Muskegon, Michigan. One objective of these experiments was to relate sulfur deposition to ambient gas, aerosol and meteorological conditions. Summarized here are the results obtained for sulfur wet removal during 15 snowstorms occurring in a 3-yr period.

Quartz filters were used in aircraft high-volume samplers to obtain sulfate aerosol concentrations. The bulk of the sulfate aerosol measurements were obtained within $500 \mathrm{ft}$ of cloud base and represent averages over about $40 \mathrm{~min}$. Occasionally only one sample was obtained before weather condi- tions deteriorated sufficiently to force abandonment of below-cloud sampling with the aircraft. However, the bulk of the aerosol measurements reported here represent averages over two or more aircraft samples taken during the period when surface precipitation was being collected. During three of the storm events considered, the weather conditions prohibited airborne sampling, and sulfate aerosol concentrations were obtained from surface samples.

Surface precipitation samples were collected roughly every $\frac{1}{2}$ to $1 \mathrm{hr}$ and were analysed for major anions and cations. Sulfate concentrations were determined with an ion chromatograph and represent concentrations of sulfate and, additionally, dissolved sulfur dioxide expressed as sulfate. Spot checks of the data indicate the molar ratio of $\mathrm{SO}_{2} / \mathrm{SO}_{4}$ was generally about 0.1 al though occasionaliy the ratio approached 1.5 . The data are expressed in terms of a washout ratio (grams of $\mathrm{SO}_{4}$ per gram of water divided by grams of $\mathrm{SO}_{4}$ aerosol per gram of air).

The data fall into two distinct classes depending upon the nature of precipitation. The highest washout ratios (Figure 34 ) occurred on occasions with abundant cloud liquid water $\left(0.1\right.$ to $\left.0.3 \mathrm{~g} / \mathrm{m}^{3}\right)$ and rimed ice on the snow crystals. In those instances,

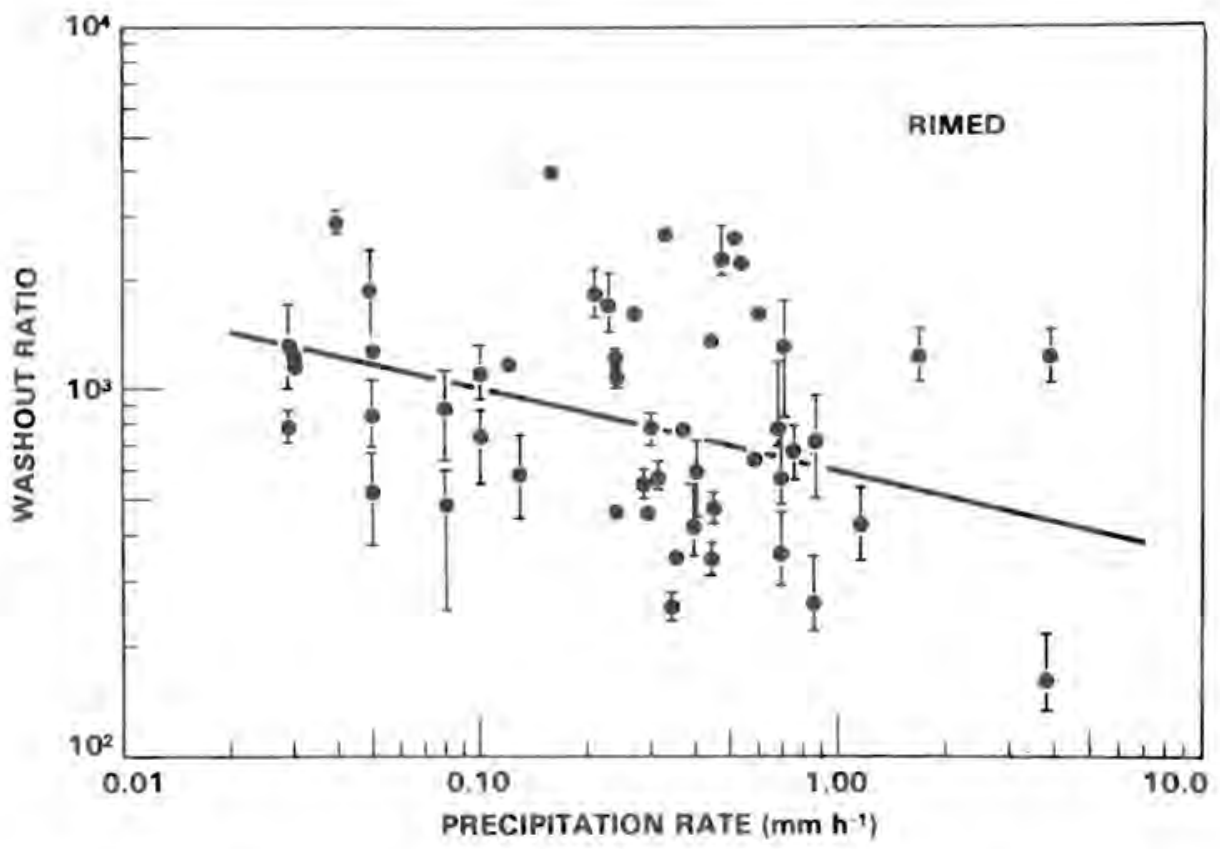

FIGURE 34. Sulfate Washout Ratio as a Function of Precipitation Rate for Rimed Particles. Solid Curve is from Washout Theory by Scott (1978). 
precipitation growth was primarily through collection of supercooled cloud droplets. However, when precipitation growth was primarily by vapor deposition and when negligible liquid water was detected in the clouds (Figure 35 ), washout ratios were approximately 10 to 50 times smaller than in the rimed case. In this latter case, removal appears to result primarily from snowflakes impacting with large micron-sized sulfate aerosol below cloud base.

The data in Figure 34 imply that sulfate is being deposited because 1) pre-existing sulfate aerosol has been drawn into the cloud, incorporated into the cloud water through nucleation and removed after collection by larger collector particles (snowflakes), and/or 2) $\mathrm{SO}_{2}$ has been rapidly converted to $\mathrm{SO}_{4}$ in the existing cloud water and then removed after collection of the cloud water by snowflakes. In the situations represented by the data of Figure 35 , the lack of liquid water precludes removal by of the above mechanisms.

The curve in Figure 34 represents theoretical predictions of sulfate removal for cold clouds (Scott 1978). Figure 36 more graphically illustrates the observed varia- tions about the predicted values. The theory leading to the predicted values is based upon the assumption that riming is a dominant growth mechanism. Thus, the data points associated with unrimed snow have been omitted from the comparison of Figure 36. The general trend of decreasing washout ratio with increasing precipitation rate is reproduced. In addition, roughly two thirds of the observations fall within a factor of two of the predicted values, and nearly all are within a factor of four. Some of the deviation from predicted values most certainly arises from uncertainties in air concentrations of $\mathrm{SO}_{4}$. Neglect of aqueous-phase transformation of $\mathrm{SO}_{2}$ to $\mathrm{SO}_{4}$ in the theory leading to the curve in Figure 34 also tends to produce an underprediction of sulfate wet deposition. However, the large variability in the data and deviations from predicted values indicate that much work remains to be done in identifying and parameterizing wet-removal mechanisms during storm periods.

\section{Reference}

Scott, B. C. 1978. "Parameterization of Sulfate Removal by Precipitation." J. Appl. Meteor. 17:1375-1389.

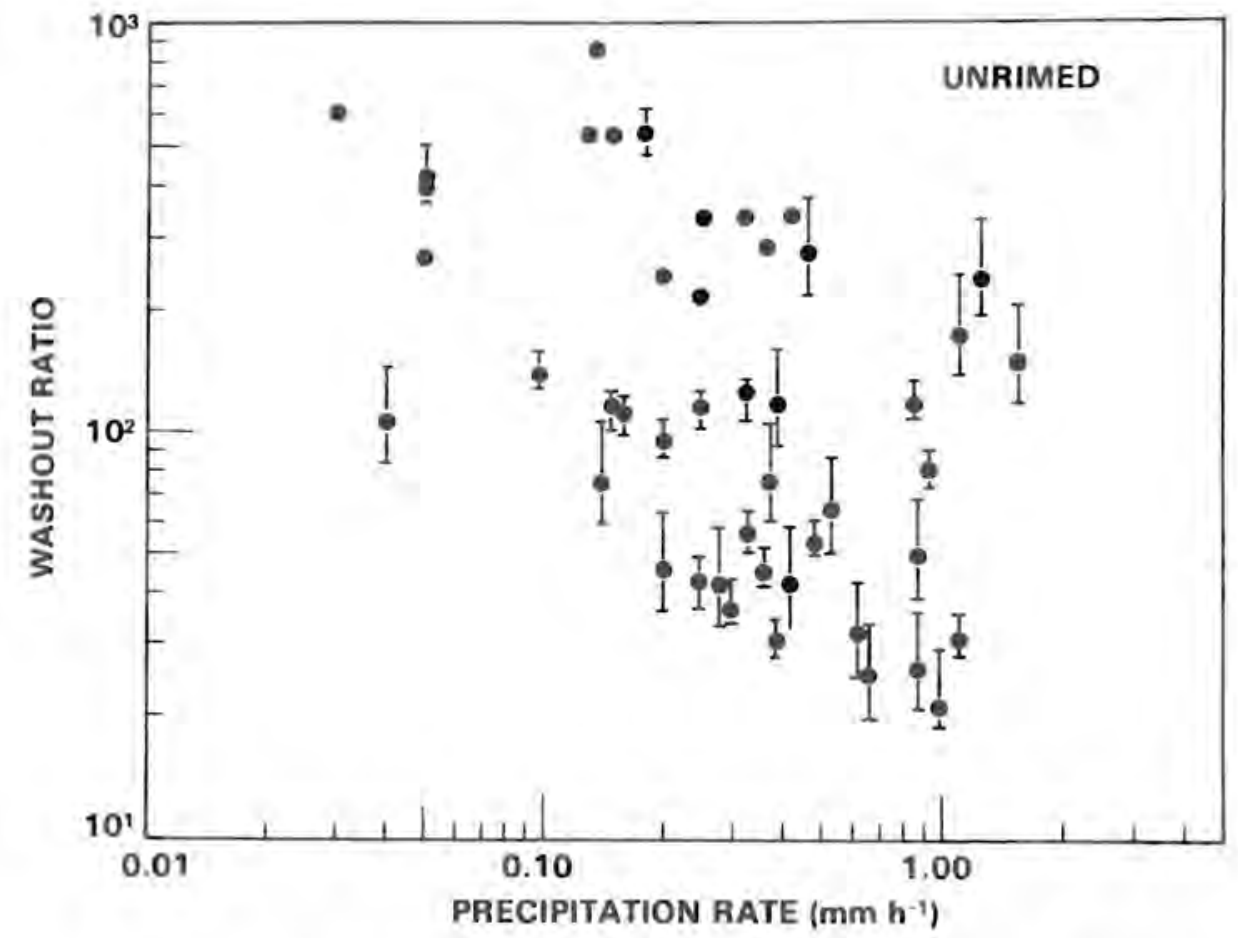

FIGURE 35. Sulfate Washout Ratio as a Function of Precipitation Rate for Unrimed Ice Particles 


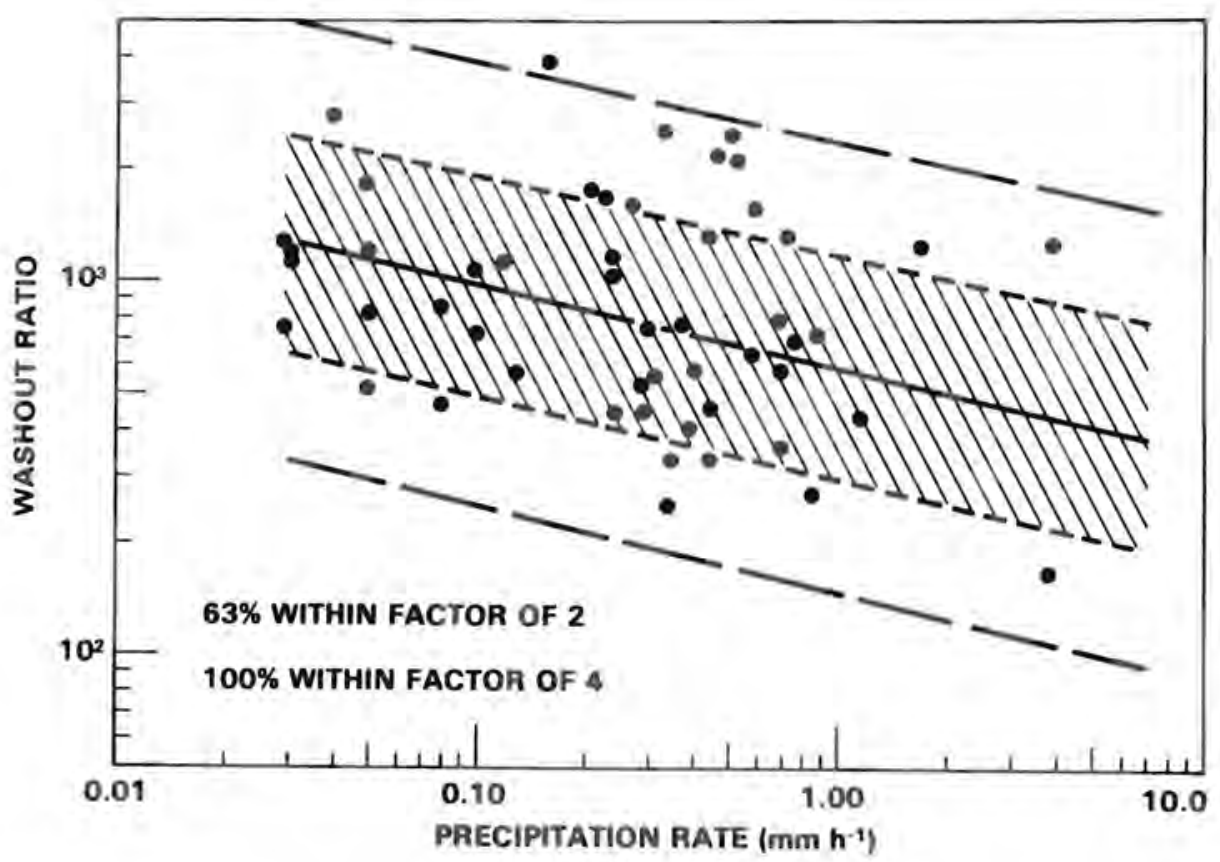

FIGURE 36. Sulfate Washout Ratio as a Function of Precipitation Rate for Rimed Particles. Solid line is from Scott's Theory (1978); small dashed line represents a factor of two deviations from theory; large dashed line represents a factor of four deviations from theory;

- represents observations.

Empirical Evidence for ivucleation as a Mechanism for Introducing Sulfate into Precipitation

\section{M. Berkowitz}

Several mechanisms are thought to exist that could explain how sulfur enters precipitation. Scott and Laulainen (1979) present case studies suggesting that cloud water sulfate concentrations can be accounted for by soluble sulfate aerosols at the cToud edges acting as cloud condensation nuclei (CCN). Another possible mechanism was proposed by Scott and Hobbs (1967) who suggested a series of oxidation reactions involving ammonia as a catalytic agent to explain sulfur concentrations in rainwater. Drewes and Hales (1978) have since shown that ammonia is about a factor of 10 Tess soluble at atmospheric conditions than previously thought, thus casting doubt on the effectiveness of these reactions.

However, should oxidation be a dominant mechanism for sulfate precipitation, one would expect a correlation between the concentration of sulfur dioxide in clear air and the concentration of sulfate in precipitation. This correlation might be antici- pated because the clear-air $\mathrm{SO}_{2}$ would be absorbed by the cloud water and subsequently oxidized to $\mathrm{SO}_{4}$. Additional1y, only a weak relation between the concentration of ambient $\mathrm{SO}_{4}$ and $\mathrm{SO}_{4}$ in the precipitation should be found. These suppositions assume that the $\mathrm{SO}_{2}$ absorbed by a cloud droplet is proportional to the vapor pressure of $\mathrm{SO}_{2}$ in the environment surrounding the droplet.

We might argue in a similar fashion that if nucleation of sulfate aerosols is the dominant mechanism, then a strong positive correlation should be found between the concentration of $\mathrm{SO}_{4}$ aerosol in the vicinity of precipitation and the concentration of $\mathrm{SO}_{4}$ in the precipitation, since more $\mathrm{SO}_{4}$ aerosols would imply more CCN.

To investigate the above ideas, the data of Tong et al. (1976) were used to estimate the clear-air sulfate concentrations from the emanation point of an air mass associated with sulfur rain events at Pennsylvania State University (Dana 1977; Dana 1979). These emanation points were defined as the regions where equivalent potential temperature $\left(\theta_{E}\right)$ trajectories could no longer be followed; it was assumed that $\theta \mathrm{E}$ surfaces grounded out at these points. These $\theta_{\mathrm{E}}$ 
surfaces were located by extrapolating between data on standard 12-hr weather maps using a skew T-log P chart. A boundary layer spiral matching lower- and upper-level winds specified the winds used for advection along the $\theta_{E}$ surfaces.

To estimate the air concentrations of $\mathrm{SO}_{4}$ and $\mathrm{SO}_{2}$ during the precipitation events, the regional-scale model of Wendell et a1. (1976) was used. Surface weather observations along the $\theta_{E}$ trajectories were examined to determine if wet removal was occurring.

Using $\theta_{\mathrm{F}}$ trajectories and Wendel1 et a1.'s model, 11 sulfur rain cases were ana1yzed (Figures 37 and 38). The 7 inear correTation coefficient $r$ between the computed air concentrations of $\mathrm{SO}_{2}$ and the observed precipitation $\mathrm{SO}_{4}$ was found to be 0.40 , whereas $r$ for the computed air concentrations of $\mathrm{SO}_{4}$ and the observed $\mathrm{SO}_{4}$ in precipitation was 0.84 . The line of best fit between $\mathrm{SO}_{2}$ air concentration and precipitation $\mathrm{SO}_{4}$ had a slope of $0,1 \mu \mathrm{g} \mathrm{m} \mathrm{m}^{-3}$ /

$\left(\mu\right.$ mole $\left.\ell^{-1}\right)$, which was half the slope for aqueous $\mathrm{SO}_{4}-\mathrm{SO}_{4}$ aerosol [s1ope $=0.2 \mu \mathrm{g} \mathrm{m}^{-3} /$ $\left(\mu\right.$ mole $\left.\left.e^{-1}\right)\right]$. Based on these results alone, one could suspect that nucleation was domi- nant over conversion as a mechanism for the occurrence of sulfur rain.

Several caveats should be inade with regard to these results. First, extrapolations performed with standard weather maps are always questionable; ideally, a complete set of TDF-1440 tapes (containing detailed surface observations) and upper air observations should have been used. Second, a constant precipitation based upon 3 hourly totals in the vicinity of this trajectory rate was used in evaluating wet deposition since no observed rates were available. Theory (Scott 1978) suggests that the sulfate concentration in precipitation should be a function of precipitation rate. And last, no effort was made to distinguish between the different precipitation mechanisms (e.g., rain versus snow) which are also thought to influence the concentration of sulfate in precipitation water.

\section{Acknowledgments}

The author is grateful to Bryan Scott for suggesting this project. Also, the assistance of John Thorp in deriving the of trajectories is very much appreciated.

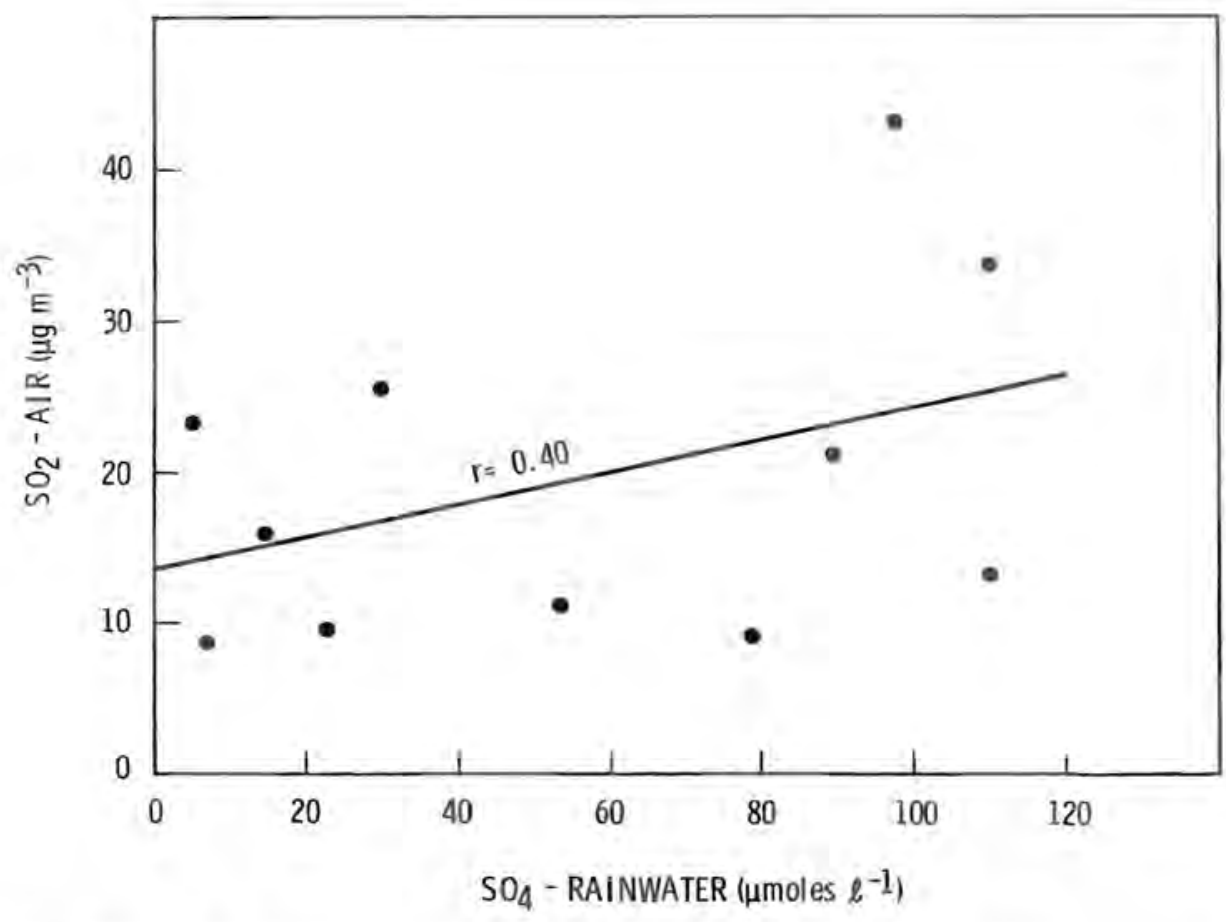

FIGURE 37. Estimated Concentrations of $\mathrm{SO}_{2}$ in Clean-Air $\left(\mathrm{Ng} \mathrm{m}^{-1}\right)$ as a Function of Observed $\mathrm{SO}_{4}$ in Rainwater ( $\mu$ moles $\ell^{-1}$ ) 


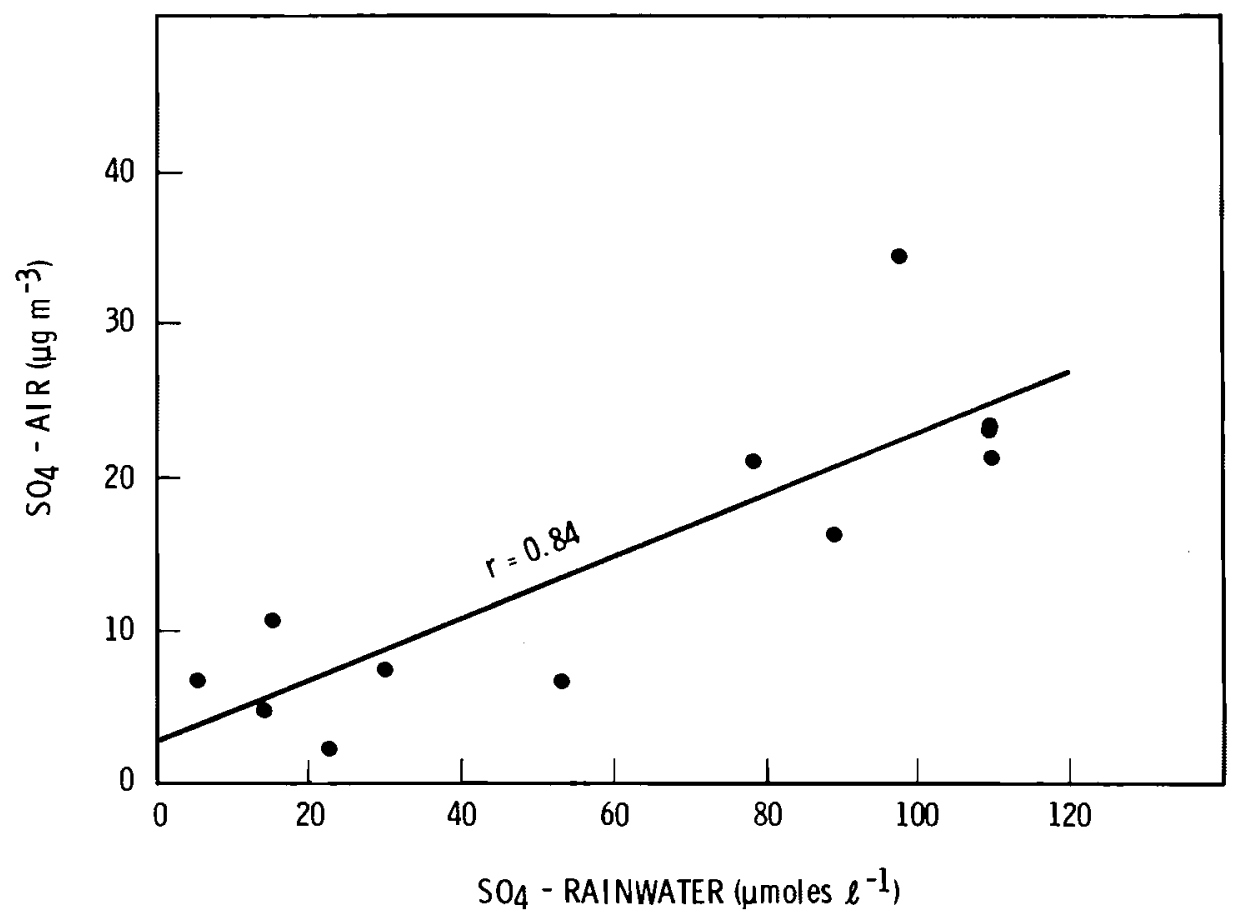

FIGURE 38. Estimated Concentrations of $\mathrm{SO}_{4}$ in Clear-Air $\left(\mu \mathrm{g} \mathrm{m}^{-3}\right)$ as a Function of Observed $\mathrm{SO}_{4}$ in Rainwater $\left(\mu\right.$ moles $\left.\ell^{-1}\right)$

\section{References}

Dana, M. T. 1977. The MAP3S Precipitation Chemistry Network: First Periodic Summary Report (September 1976 to June 1977). PNL2402, Pacific Northwest Laboratory, Richland, WA.

Dana, M. T. 1979. The MAP3S Precipitation Chemistry Network: Second Periodic Summary Report (July 1977 to June 1978). PNL-2829, Pacific Northwest Laboratory, Richland, WA.

Drewes, D. R. and J. M. Hales. 1979. Removal of Pollutants from Power Plant Plumes by Precipitation. Final report to the Electric Power Research Institute, Palo Al to, CA (Research Project 858) by Battelle, Pacific Northwest Laboratories, Richland, WA.

Scott, B. C. 1978. "Parameterization of Sulfate Removal by Precipitation." J. Appl. Meteor. 17:1375-1389.
Scott, B. C. and N. S. Laulainen. 1979. "On the Concentration of Sulfate in Precipitation." J. Appl. Meteor. 18:138-147.

Scott, W. D. and P. V. Hobbs. 1967. "The Formation of Sulfate in Water Droplets." J. Atmos. Sci. 24:54-57.

Tong, E. V., T. F. Lavery and F. Berland. 1976. "Regional and Local Aspects of Atmospheric Sulfates in the Northeast Quadrant of the United States." In Proceedings of the Third Symposium on TurbuTence, Diffusion and Air Quality, pp. 307-310, American MeteoroTogical Society, Boston, MA.

Wende11, L. L., D. C. Powe11 and R. L. Drake. 1976. "A Regional-Scale Model for Computing Deposition and Ground-Level Air Concentrations of $\mathrm{SO}_{2}$ and Sulfates from Elevated and Ground Sources." In Proceedings of the Third Symposium on Turbulence, Diffusion and Air Quality, pp. 318-329, American Meteorological Society, Boston, MA. 
A Generalized One-Dimensional Model of Reactive Pollutant Behavior, Including Dry Deposition, Precipitation Formation and Wet Removal

J. M. Hales (a)

A computer code has been developed that provides finite-difference approximations to solutions of a series of one-dimensional, time-variant equations corresponding to the conservation of atmospheric species. These equations take the form

$$
\frac{D C}{D t}=A 1 \frac{\partial^{2} c}{\partial z^{2}}+B 1 \frac{\partial C}{\partial z}+C l c+G
$$

where $c$ denotes species concentration, and $A 1, B 1, C l$, and $G$ are species-dependent variables that may vary with time, concentration, and location.

In its present form the computer code provides for:

- variable diffusion in height and in time

- generalized boundary conditions at both the bottom and top of the computational grid, allowing a versatile characterization of the deposition/resuspension process

- flexible vertical grid spacing

- the capability to describe cloud and precipitation phenomena

(a) This research was performed at the Meteorological Institute of Stockholm University in cooperation with MISU staff members. Drs. Lennart Granat, Henning Rodhe, and Hilding Sundqvist of MISU have contributed actively to this report.
- the versatile incorporation of aqueousphase and gaseous phase chemical conversion for multiple-component systems

- the capability to describe wet removal processes.

At present, the code has been tested only to a limited extent. The first test series addressed a comparison of the reactive scavenging of sulfur dioxide gas with the physical scavenging of sulfate aerosol. For the purposes of this test, nucleation was stipulated to be the sole mechanism of direct sulfate aerosol capture, and the aqueous-phase reaction

$$
\mathrm{SO}_{2}+\mathrm{O}_{3} \rightarrow \mathrm{SO}_{4}^{=}
$$

was specified as the sole $\mathrm{SO}_{2}$ conversion mechanism.

Results of the initial test are summarized in Figure 39, which depicts a storm system induced by orographic lifting with subsubsequent descent across a plateau. Precipitation intensity is indicated by the horizontal bar plots, and the computed cloud outline is given approximately by the idealized sketch. Numbers running across the schematic give computed rainwater sulfate concentrations in $\mu \mathrm{M} / \ell$ at the model times indicated. Values to the left of the slashes give sulfate concentrations arising from direct aerosol capture, while those to the right of the slashes correspond to the sulfate component contributed by reactive $\mathrm{SO}_{2}$ scavenging. The two rows of numbers are results that were obtained for two different assumptions regarding sulfur sulfate aerosolparticle sizes; the top row is based on the presumption of a homogeneous sulfate aerosol composed of $0.1-\mu$ particles, while the bottom pertains to $0.3-\mu$ particles.

Future plans call for documentation of the code for extended use and application for mechanistic studies within the Multistate Atmospheric Power Production Pollution Study (MAP3S) scavenging program. 


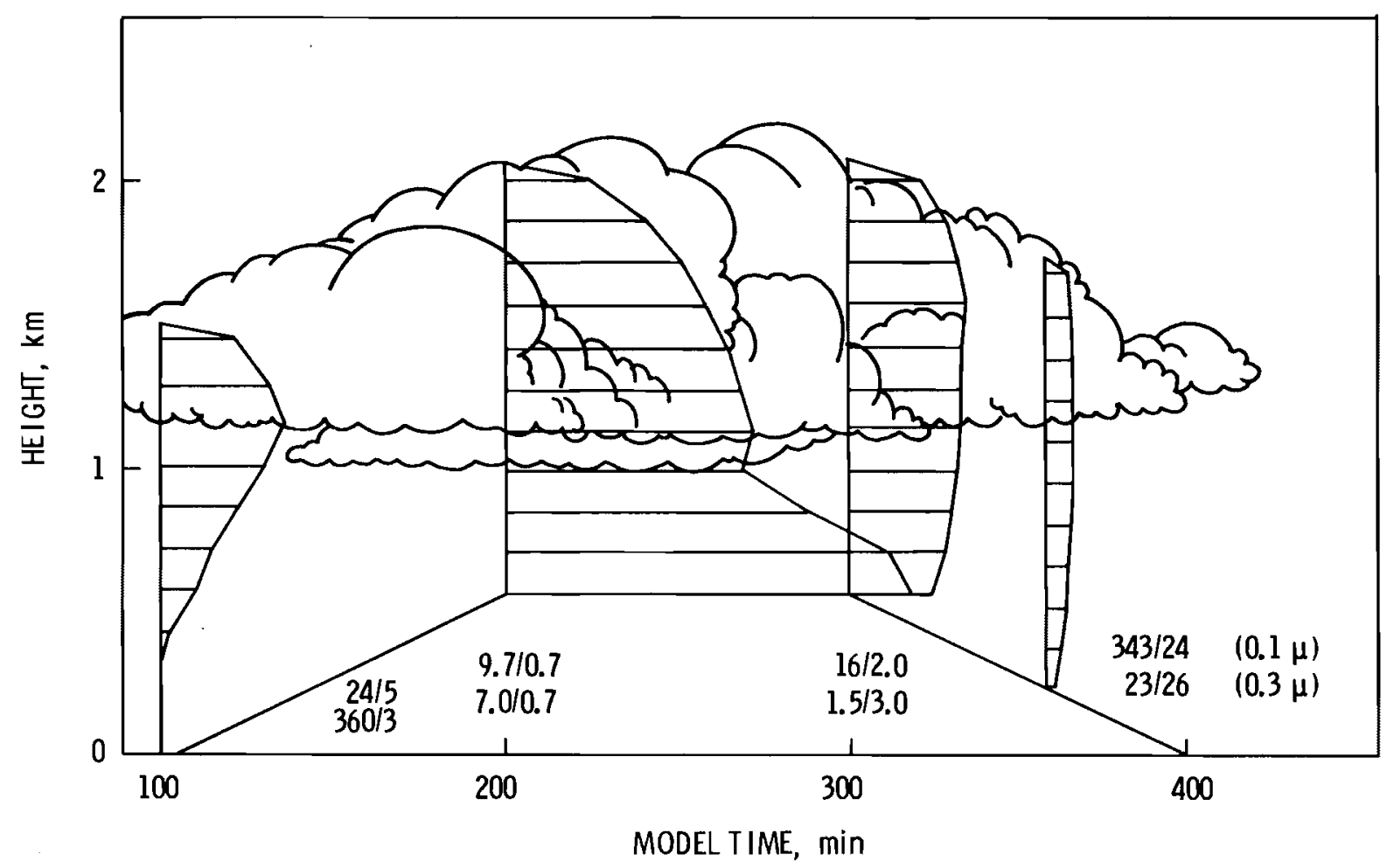

FIGURE 39. Schematic of Computed Results 


\section{- Aerosol and Trace Gas Transformations*}

Objectives of this study are:

- Understanding the behavior and implications of atmospheric pollutant transformation processes.

- Determining the importance of transformation processes in predicting removal rates, and in influencing weather and climate modifications.

- Studying pollutant transformations in power-plant and urban plumes in the Multistate Power Production Pollution Study (MAP3S) region through the use of field studies and diagnostic modeling.

Comparison Between Polluted and Clean Air Masses Over Lake Michigan

\section{A. J. Alkezweeny and N. S. Laulainen}

The Lake Michigan area offers a unique site to study and characterize aerosol and trace gases in clean and polluted air masses. clean air masses that move over lakes and sparsely populated areas in Canada are advected over Lake Michigan under the influence of north winds. In contrast, polluted air masses are associated with wind from the opposite direction. During the past several years, Pacific Northwest Laboratory (PNL) has been conducting field experiments in the Michigan area to characterize and investigate the formation of secondary pollutants. The study is a part of the Muttistate Atmospheric Power Production Pollution Study (MAP3S) initially supported by the Department of Energy (DOE) and most recently by the Environmental Protection Agency (EPA). Presented here are data collected during the surimers of 1976 and 1978 in a sampling program that consisted of airborne measurements of aerosol particle size distributions and chemical composition, light scattering and ozone. Figure 40 ilustrates the aircraft flight routes taken during these experiments.

Before we assess the meaning of the results of these experiments, we need to describe the meteorological conditions under which the data were collected. On August 21, 1976 the measurements were made over Lake Michigan at different altitudes and locations on east-to-west sampling routes. The wind was from the south; hence, industrial and urban pollutants from the Chicago-Gary area were advected over the

\footnotetext{
*See Foreword
}

aircraft sampling paths. On September 8, 1978 similar samples were taken over the lake across from Chicago under southwesterly winds.

On the other hand, August 29, 1976 and September 22, 1978 samples represent very clean background air masses as a result of the meteorological conditions prevalent before and during sampling. On August 27, 1976 the Lake Michigan area experienced a frontal passage at night associated with rain and shower activity and a shift in wind direction from the west to the northwest on August 28 and a northerly wind on August 29 . The measurements on August 29 were taken at different altitudes from about $130 \mathrm{~m}$ to $1300 \mathrm{~m}$ AGL. Similarly, the 2 days preceding the September 22, 1978 sampling were rainy. The samplings on both August 30, 1978 and September 22, 1978 were carried out while flying a $15-\mathrm{km}$ leg across the path of a tetroon at about $300 \mathrm{~m} \mathrm{AGL}$ altitude. The August 30 sampling period should have represented slightly polluted air.

Figure 41 shows the particle size distributions measured on August 21 and 29, 1976. The distributions are bimodal with one peak located between 0.1 to $1.0 \mu \mathrm{m}$ (fine particle mode) and another one at greater than $1.0 \mu \mathrm{m}$ (coarse particle mode). However, the distribution of the clean air aerosol is dominated by the coarse particle mode (August 29). On the other hand, the fine particle mode is more dominant in the polluted condition (August 21). There is also an indication that the concentration of aerosol particles in this mode increases with distance from a source that may be the result of gas to particle conversion. The particle size distributions for the August 21 samp7 ing period average over all altitudes at that location. 


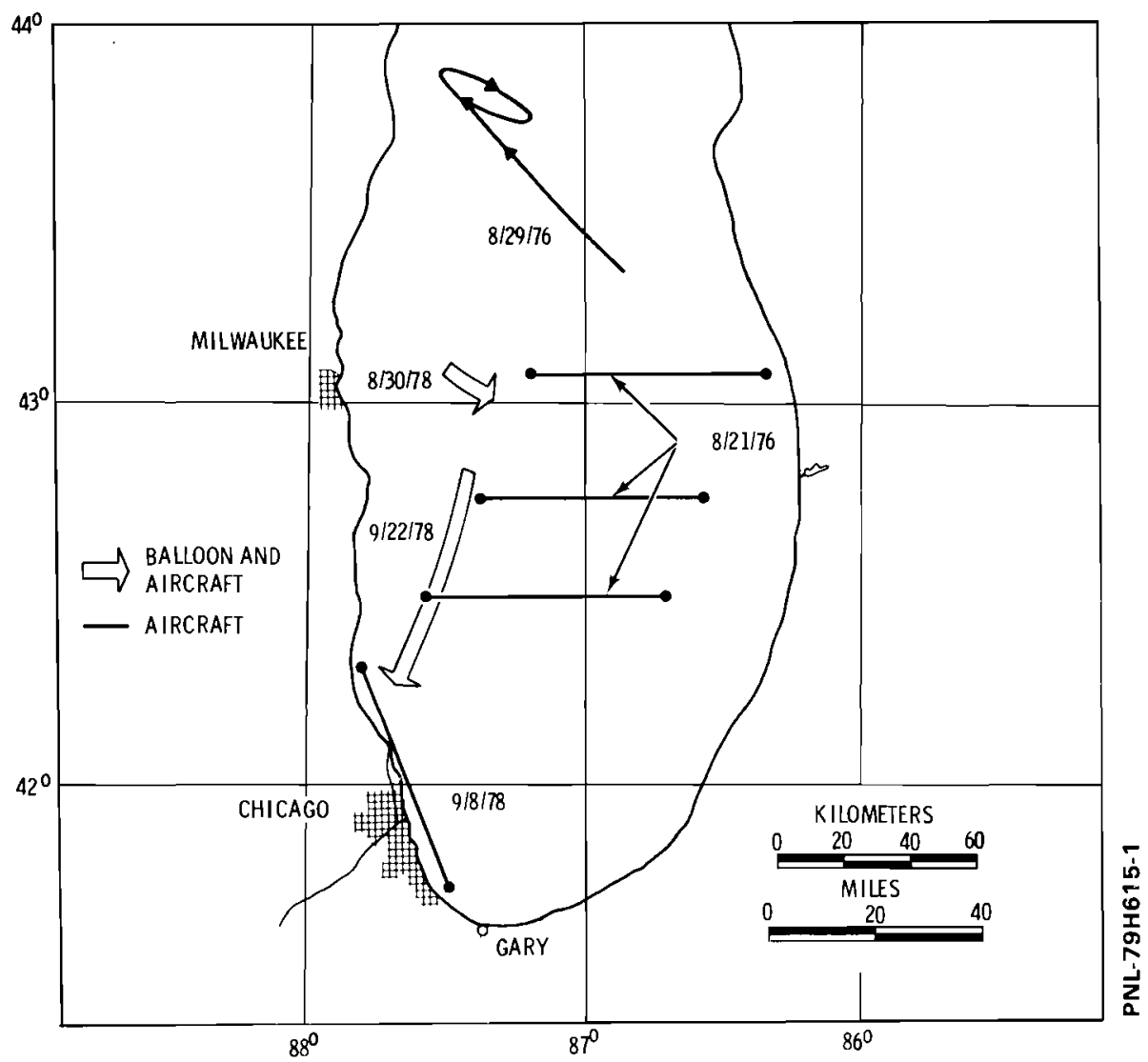

FIGURE 40. Map of Lake Michigan Showing Aircraft Sampling Routes During the Summers of 1976 and 1978

Table 8 shows the vertical profile of temperature, relative humidity, and light scattering ( $b_{a}$ refers to 1 ight scattering caused by aerosol alone) for August 29, 1976. As can be seen, $b_{a}$ is nearly constant with altitude until $b_{a}$ reaches the level of the temperature inversion, between 1100 and $1500 \mathrm{~m}$, where it drops off very sharply. Since the air above this level is very dry, it is possible that part of the sharp change in $b_{a}$ may have been caused by the drying out of the aerosol particles. The last column in the table shows the ratio of the total 1 ight scattering, $b_{t}$, to that caused by air molecules, $b_{r}$. The range of values is between 1.0350 to 1.0800 , which is close to the value 1.05 reported by Porch et al. (1970) for the cleanest day on Mount $01 y m p u s$, Washington.

Table 9 shows the concentrations of a few trace metals measured on the 2 days in 1976 . It is clear that the differences in measurements are more than an order of magnitude between clean and polluted air. The trace metals data measured on August 29 are comparable with those reported by Adams et al. (1977) for background aerosol on Chacaltaya Mountain in Bolivia. The sulfate concentration of $0.17 \mathrm{\mu g} / \mathrm{m}^{3}$ was the lowest value measured during our flight (see Table 10), a value within the range of concentration measured by Lawson and Winchester (1979) in remote South American sites. The lower nitrate concentration $\left(0.08 \mu \mathrm{g} / \mathrm{m}^{3}\right)$ was measured on the same day as the sulfate and is much lower than the $0.20 \mu \mathrm{g} / \mathrm{m}^{3}$ reported by Robinson and Robins (1970) for background aerosol. Corresponding to these low values of sulfate, nitrate and light scattering is an ozone level between 22 to $31 \mathrm{ppb}$, which is the lowest ozone concentration that we ever encountered during our sampling over Lake Michigan and over several rural areas in the northeast outside a plume. The data for August 21, 1976 and September 8, 1978 are typical of urban area pollutants, except that the nitrate values are on the high side; we had measured half of these values and lower on other days in the Chicago plume. 
AEROSOL SIZE DISTRIBUTION-VOLUME

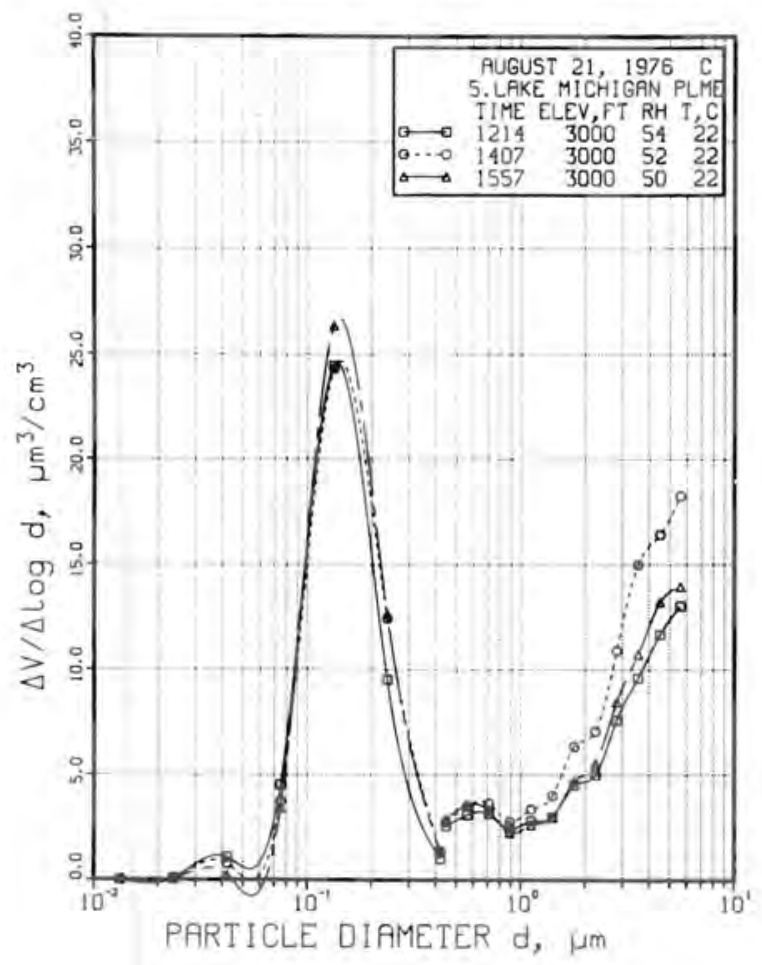

AEROSOL SIZE DISTRIBUTION-VOLUME

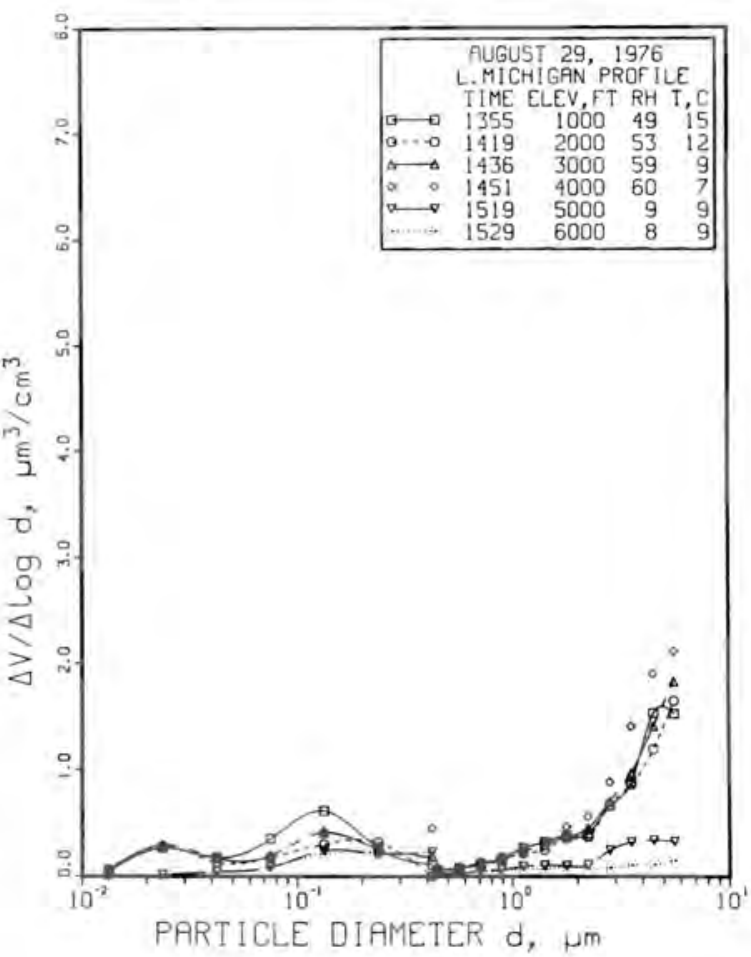

FIGURE 41. Aerosol Volume Distributions Measured on August 21 and 24, 1976 Over Lake Michigan

TABLE 8. Profiles of Temperature, Relative Humidity and Light Scattering over Lake Michigan on August 29, 1976

\begin{tabular}{|c|c|c|c|c|c|}
\hline Time, EDT & Alt., $m$ AGL & Temp ${ }^{\circ} \mathrm{C}$ & R.H. $\%$ & $\mathrm{~b}_{\mathrm{a}}$ & $b_{t} / b_{r}$ \\
\hline $1349-1413$ & 136 & 15 & 49 & 0.065 & 1.0675 \\
\hline $1415-1431$ & 450 & 12 & 53 & 0.057 & 1,0615 \\
\hline $1433-1446$ & 800 & 9 & 59 & 0.065 & 1.0729 \\
\hline $1448-1504$ & 1100 & 7 & 60 & 0.069 & 1,0800 \\
\hline $1507-1524$ & 1500 & 9 & 9 & 0.029 & 1.0350 \\
\hline $1526-1550$ & 1800 & 9 & 8 & 0.029 & 1.0370 \\
\hline
\end{tabular}

The data presented here demonstrate that background levels do exist even in the highly industrialized northwest of the United States.

\section{References}

Adams, F., R. Dams, L. Guzman, and J. W. Winchester. 1977. "Background Aerosol Composition on Chacaltaya Mountain, Bolivia." Atmos. Environ. 11:629-634. 
TABLE 9. Concentrations of Trace Metals in $\mathrm{ng} / \mathrm{m}^{3}$ Measured Over Lake Michigan

\begin{tabular}{lcc} 
& $\begin{array}{c}\text { September 21, } \\
1976\end{array}$ & $\begin{array}{c}\text { August 29, } \\
1976\end{array}$ \\
\cline { 2 - 3 } $\mathrm{Ca}$ & 662 & 79 \\
$\mathrm{Mn}$ & 32 & 1.7 \\
$\mathrm{Fe}$ & 590 & 54.9 \\
$\mathrm{~Pb}$ & 34 & 3.6 \\
$\mathrm{Zn}$ & 190 & $\mathrm{ND}(\mathrm{a})$
\end{tabular}

(a) ND: Not detected
Gas to Particle Conversion in Urban Plumes

\section{A. J. Alkezweeny}

The formation in the atmosphere of aerosol particles from the gaseous phase has received considerable attention in recent years. Emphasis has been placed on sulfate aerosol because of its association with adverse health effects, visibility degradation, and acid rain. Nitrate and organic aerosol particles are also important, but have received lesser consideration.

The conversion rates of sulfur dioxide to sulfate aerosol have been measured by several investigators, both in the atmosphere and in the laboratory. Results have shown a wide variation in the conversion rates. Even in urban plumes, within about $100 \mathrm{~km}$ of a source, the conversion rate variation is still very large, ranging from about 1.0 to $30 \% / h r$. Pacific Northwest Laboratory (PNL) has studied the problem of $\mathrm{SO}_{2}$ to sulfate conversion over the past several years in St. Louis, Missouri, and over Lake Michigan. The latter study has been a part of the Multistate Atmospheric Power Production Pollution Study (MAP3S) initially supported by the Department of Energy (DOE) and most recently by the Environmental Protection Agency. Summarized here are results of that study.

Robinson, E. and R. C. Robins. 1970. "Gas eous Nitrogen Compound Pollutants from Urban and Natural Sources." J. Air Poll. Cont. Ass. 20:303-306.

TABLE 10. The Ranges of Sulfate, Nitrate, Ozone and Light-Scattering Measurements During the Five Experiments over Lake Michigan

\begin{tabular}{|c|c|c|c|c|c|}
\hline Date & Alt. in $\mathrm{ACL}$ & $\underline{b_{a} 10^{-4} m^{-1}}$ & $\mathrm{SO}_{4} \mu \mathrm{g} / \mathrm{m}^{3}$ & $\mathrm{NO}_{3} \mu \mathrm{g} / \mathrm{m}^{3}$ & $\mathrm{O}_{3} \mathrm{ppb}$ \\
\hline $\begin{array}{l}\text { August } 29 \text {, } \\
1976\end{array}$ & 130 to 1800 & 0.051 & 0.20 & - & 22.6 to 30 \\
\hline $\begin{array}{l}\text { August 21, } \\
1976\end{array}$ & 130 & 2.3 & 35 & - & 80 to 112 \\
\hline $\begin{array}{l}\text { August } 30 \text {, } \\
1978\end{array}$ & 130 & 0.22 to 0.31 & 0.88 to 1.58 & 0.47 & 47 to 49 \\
\hline $\begin{array}{l}\text { September 8, } \\
1978\end{array}$ & 130 & 1.5 to 2.37 & 14 to 19 & $11.03,16.9$ & 155 to 198 \\
\hline $\begin{array}{l}\text { September } \\
22,1978\end{array}$ & 130 & 0.095 & 0.17 to 0.87 & $0.08,0.09$ & 30 to 31 \\
\hline
\end{tabular}


Earlier field experiments over Lake Michigan, reported by Alkezweeny et al. (1977), were aircraft flights conducted during the summer of 1976 in the Milwaukee plume. Results showed that for days with nearly identical meteorological conditions, conversion rates of $\mathrm{SO}_{2}$ to sulfate aerosol were quite different. For example, on one day the rate was close to zero; on another day the rate was about $7 \% / \mathrm{hr}$, even though on both days considerable photochemical reaction activities were present as was shown by the buildup of ozone. Similar results were also found when these measurements were repeated in the summer of 1978 in the Chicago and Gary plumes. Findings showed that large variations in the conversion rates are possible in urban plumes.

Miller and Alkezweeny (1979) examined the Milwaukee data and other data collected during the summer of 1977 using a chemical kinetics code devised to simulate the photochemical reactions bel ieved to have occurred during sampling. The model consisted of 53 reaction steps for irradiated $\mathrm{SO}_{2}-\mathrm{NO}_{\mathrm{X}}-$ hydrocarbon mixtures. The model predicted the observed ozone formation with good agreement between measured and calculated concentrations. However, the model failed to predict the wide variation in the conversion rates.

If we examine the data of 1976, 1977, and 1978 , we find that high conversion rates are associated with high aerosol loading. This observation and the failure of the photochemical smog model to predict the conversion rate suggest that the oxidation of sulfur dioxide might have taken place on the aerosol particles in the plumes. This assumption has received support in the past from several investigators but has not been verified from field experiments.

To solve the problem of photochemical reaction versus catalysis oxidation of $\mathrm{SO}_{2}$, several night flights were conducted downwind of Chicago and Gary during the month of June 1979. The nights were chosen so that the aerosol loading was similar to or higher than those found in the previous sampling days that were characterized by a high oxidation rate. Below is a description of one of these experiments.

The experiment was conducted on June 14 , 1979 during a flight initiated from Muskegon, Michigan, at 1730 CDT and headed directly toward Meigs airport in Chicago at an altitude of $800 \mathrm{~m} \mathrm{AGL}$. The temperature and relative humidity during the flight were $25^{\circ} \mathrm{C}$ and $45 \%$, respectively, and the wind was from the southwest. Therefore, we can consider the flight along the wind direction. The day was apparently active with photochemical activities and aerosol production as revealed by the recorded lightscattering and ozone data. Both ozone and light-scattering levels downwind of Chicago were much higher than those close by the city.

To determine the vertical profile of the wind speed and direction, several pilot balloons were released at the airport between 1920 and 2015 CDT. The wind speed and direction, estimated at $13 \mathrm{~m} / \mathrm{sec}$ and about $206^{\circ}$, were remarkably steady during this period and wind direction was nearly constant from near the surface to about $1900 \mathrm{~m} \mathrm{AGL}$. Using this wind speed and direction, the aircraft sampled the Chicago plume starting at 2230 CDT at constant altitude of about $475 \mathrm{~m}$ AGL. Each cross section was about $45 \mathrm{~km}$ perpendicular to the wind (see Figure 42). A total of 11 cross sections were made equally spaced between the west and east shores of the lake.

A few kilometers from the shore the air was quite turbulent; therefore, it can be assumed that the pollutants were well mixed. However, after that location the turbulence was damped out, and nearly laminar flow was established. Figure 43 shows the data collected during this flight. Each point is an average over each pass. As seen from the figure, the particle light scattering remained constant throughout the flight. The number of concentrations of total aerosol particles, as measured with a condensation nuclei counter (CNC), decreased with increasing distance from the city. Likewise, the total current measured by the Electrical Aerosol Analyzer (EAA), which is an indicator of particle concentration of sizes greater than $0.01 \mu \mathrm{m}$ in dia, also decreased downwind of the city. This behavior can be attributed to aerosol coagulation. Certainly this finding supports the idea that catalysis oxidation of $\mathrm{SO}_{2}$ in the atmosphere is unimportant, at least at a low relative humidity. For these flights the relative humidity was below $55 \%$. However, there is an indication from one flight that aerosol production may be significant under conditions of humidity greater than $80 \%$.

In conclusion, the results of the data collected during these experiments can be summarized as follows:

- The oxidation of $\mathrm{SO}_{2}$ to sulfate is dominated by photochemical reactions at low relative humidity. 


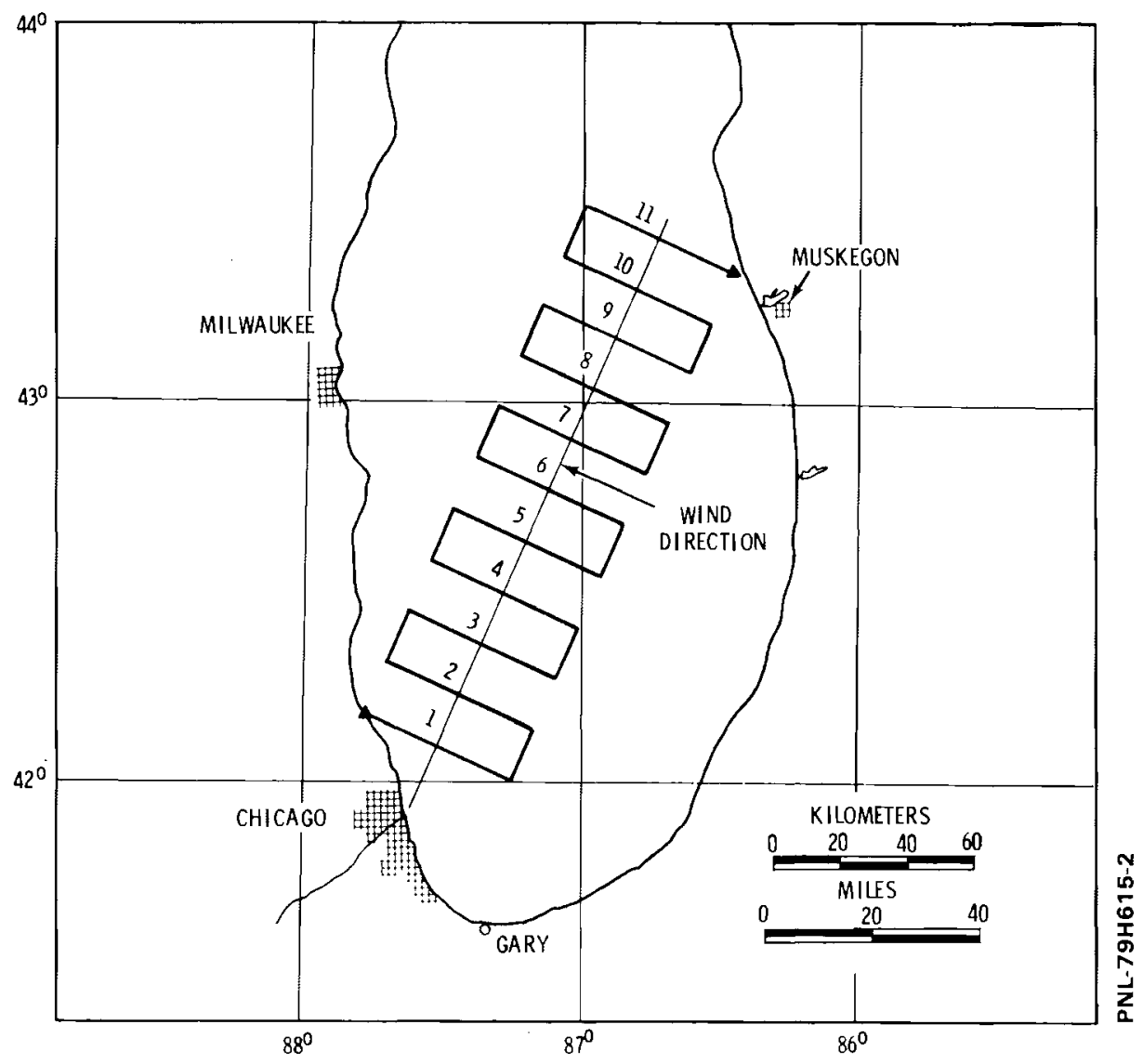

FIGURE 42. Map of Lake Michigan Showing the Aircraft Sampling Routes During June 14,1979

- There are some indications that catalysis oxidation at high humidity may be important.

- The oxidation rate during daylight is variable and cannot be explained by present photochemical models. A high oxidation rate seems to be associated with high aerosol loading or may be associated with the age of the air masses advected over the urban areas.

- Ozone is definitely formed in the urban plume downwind of the city.

\section{$\underline{\text { References }}$}

Al kezweeny, A. J., J. A. Young, R. N. Lee, K. M. Busness and J. M. Hales. 1977.

"Transport and Transformation of Pollutant in the Lake Michigan Area." Presented at the 4 th Joint Conference on Sensing of Environmental Pollutants, November 10, 1977, New Orleans, LA.
Miller, D. F. and A. J. Alkezweeny. 1979. "Aerosol Formation in Urban Plumes over Lake Michigan." Presented at the Conference on Aerosols, Anthropogenic and Natural--Sources and Transport, Sponsored by the New York Acadeny of Sciences and the Air Pollution Control Association, January 9-12, 1979, New York, NY.

The Impact of Fair-Weather Cumulus Clouds on Atmospheric Pollutants

\section{A. J. Alkezweeny}

Fair-weather cumulus clouds are nonprecipitating, detached, and dense white clouds formed by thermal convection in the atmosphere. They frequently appear during the warm season around midday, covering from a few percent to 70 to $80 \%$ of the sky. The clouds range in diameter from a few hundred meters to about $2 \mathrm{~km}$, and their depth is just about one or two times their diameter. 


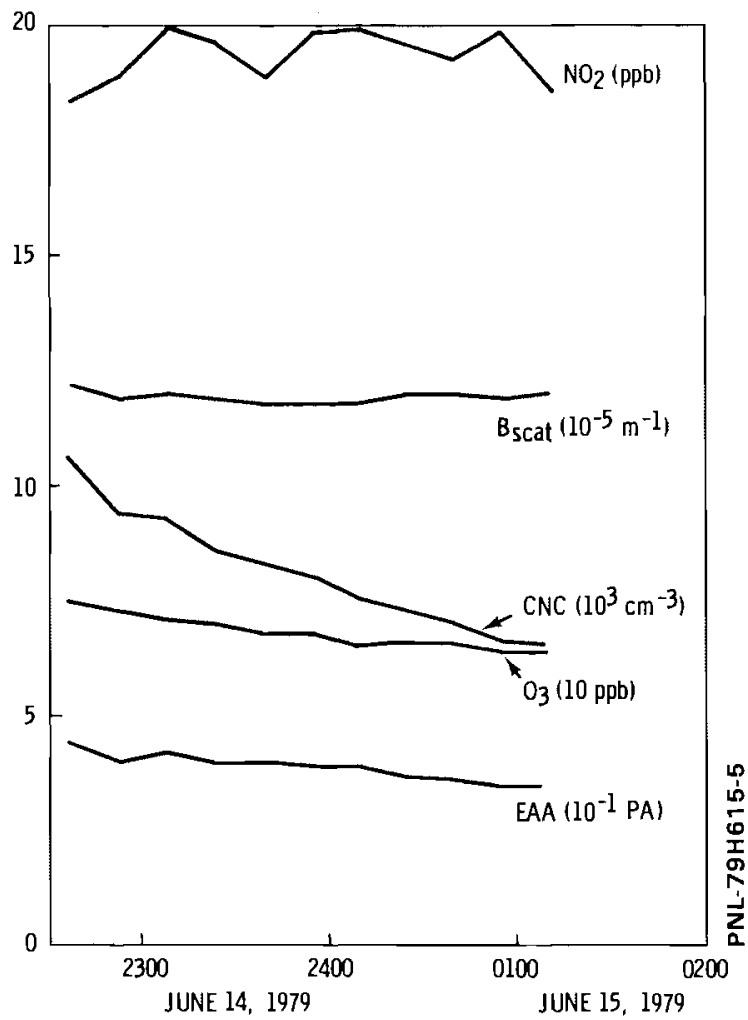

TIME EDT

FIGURE 43. Data Collected During the June 14, 1979 Night Flight Downwind of Chicago

Generally, their bases are located at about 1 to $2 \mathrm{~km}$ above the ground. Since these clouds undergo repeated cycles of condensation and evaporation involving airborne gases and aerosol particles, one would expect that these pollutants would undergo chemical and physical changes during these processes. These changes play a very important role in determining pollutant residence times and the impact of pollutants on man.

Aerosol particles in the size range roughly between 0.1 to $1.0 \mu \mathrm{m}$ have the longest residence time in the atmosphere. This is the range where most of the sulfate particle mass is normally found. The long residence time of aerosols in this size range will allow the sulfate to be accumulated and transported over long distances in the atmosphere. Thus, these aerosols contribute to visibility degradation and acid rain by being incorporated in rain through in-or below-cloud scavenging.
Even though removal of aerosol particles by precipitation or dry deposition is strongly dependent upon particle sizes, only few measurements of particles have been made. Reported data are incomplete and lack information about pertinent parameters. For instance, Twomey and Severynsen (1964) determined the size distribution of aerosol particles in a fog using diffusion batteries before and after bag formation. Results show that after $10 \mathrm{hr}$ the fog had removed most of the particles of radius less than $10^{-2} \mu \mathrm{m}$, with little change in the concentration of the larger particles. The particle size distribution after fog dissipation was not reported, however. In contrast, Harris and Morse (1968) obtained the size distribution of particles larger than $0.1 \mu \mathrm{m}$ in radius with a Royco Optical Counter in the presence of and during dissipation of fog in the Los Angeles area. Their results show that the concentration of particles below $1 \mu \mathrm{m}$ were somewhat higher after the fog evaporated and that the increase was most pronounced around $0.8 \mu \mathrm{m}$. Furthermore, a considerable decrease in the concentration of particles larger than $1 \mu \mathrm{m}$ was observed. Since the relative humidity decreased from $100 \%$ to $69 \%$ during the experiment, it is possible that the change in the relative humidity may explain the difference in the two size distributions, an explanation that has some support in Twomey's and Sverynsen's findings.

The above experiments did not give information on the concentration or the size of particles that remain airborne after fog dissipation. There is evidence that Aitken particles are generated by the evaporation of cloud droplets. For instance, Radke (1970) made a ircraft measurements around lee-wave and cap-wave clouds with a cloud condensation nuclei (CCN) counter operated at 0.5\% supersaturation. His results showed that the concentration of $\mathrm{CCN}$ in the air flowing out of the cloud was about three times larger than the concentration of CCN in the air flowing into the cloud. Since the supersaturation in his counter was $0.5 \%$ we can assume that a nominal concentration of particles of radius greater than $0.02 \mu \mathrm{m}$ was measured. We have made a few flights through a fair-weather cumulus cloud and found an increase in the concentration of condensation nuclei (CN) at the evaporating edges of the cloud. Since $\mathrm{CN}$ and $\mathrm{CCN}$ counters measure the total riumber of particles greater than a given particle size, it is possible that droplet evaporation may shift the particle size distribution to large sizes where more particles can be counted by the counter. 
Another important factor that may affect the sizes of aerosol particles after droplet evaporation is the presence of organic material in the air. Such surface-active material partially or completely encapsulates droplets and thus reduces their evaporation rate by as much as 100 times or more for the droplet size range normally found in clouds. Therefore, these droplets can remain in solution even in a subsaturated environment (relative humidity below $100 \%$ ). In fact, Braham (1977) found particles of sizes from several microns to $15 \mu \mathrm{m}$ in dia and in a concentration of about $1.0 / \mathrm{cm}$ between and below cloud base near St. Louis, Missouri.

Because aerosol particles are necessary for cloud formation and precipitation development, they may increase or decrease precipitation depending upon their size and chemical composition. Furthermore, an increase in aerosol particle concentration leads to an increase in the concentration of cloud droplets and, thus, has the effect of increasing the cloud albedo for the visible solar radiation (SMIC 1971).

In addition, a very important process that may be operative in the pollutant-cloud system is the oxidation of trace gases in the cloud droplets. Recently, great emphasis has been directed toward understanding the conversion of sulfur dioxide to sulfate in the liquid phase. However, outcomes of several theoretical studies and laboratory experiments have given conflicting results about the importance of the oxidation reaction in the atmosphere (see the summary of the International Conference on Sulfur in the Atmosphere in Atmospheric Environment, Volume 12, No. 1-3, 1978). Apparently, the oxidation rate in solution is determined by many things, including the amount of transition metal (e.g., iron, manganese, ozone, hydrogen peroxide, and ammonia).

Fair-weather cumulus clouds may play a very important role in the dispersion of pollutants. Gases and particles that are carried into the clouds by updrafts may well be injected above the mixing layer. This process has been a topic of conversation among atmospheric scientists for some time. Unfortunately, no detailed measurements have been carried out near clouds to shed light on this subject. The lack of data or planned experiments on the transport and modification of pollutants by cumulus clouds is very surprising since these clouds are formed during stagnating, anticyclonic weather conditions that are characterized by high accumulation of pollutants and poor visibility. Furthermore, many air pollution disasters such as those in Donora, 1948, Poza Rica, 1950, and in London, 1952, were associated with stagnation conditions.

It is clear from the above discussion that there is a need for field experiments to study the interaction between fairweather cumulus clouds and pollutants. The results should provide information that can be extrapolated to fogs, other nonprecipitating clouds or larger precipitating systems. A pilot experiment addressing this problem was conducted in the month of July, 1979, near Champagne, Illinois. The program is a part of the Central Illinois Rain Chemistry Experiment (CIRCE). Two aircraft were available for this study, the Pacific Northwest Laboratory (PNL) C-411 and DC-3. The C-411 was equipped with a nephelometer, an ozone monitor, and a high-volume sampler. Temperature, dew-point temperature, turbulence, standard aircraft parameters (altitude, air speed, etc.) and aircraft location (longitude, latitude) were also measured. The DC-3, with similar capability, had additional instrumentation to measure the concentration of $\mathrm{SO}_{2}, \mathrm{NO}_{\mathrm{x}}$, aerosol particles, and aerosol size distributions in the range of 0.01 to about $5.0 \mu \mathrm{m}$. Cloud droplet size distributions were also measured with an axially scattering spectrometer.

The flight plan was designed to thoroughly characterize the environment around and between the clouds. The aircraft sampled just below the cloud bases, between the clouds, and above the clouds as close to their tops as possible without touching them. Cloud penetrations were also made to determine droplet size distributions. The effect of the fair-weather cumulus clouds on the top of the boundary layer was also investigated. Vertical profiles of several state and pollution parameters were made between clouds at several locations that were characterized by different horizontal cloud separations. The data collected during this study are being analyzed and results will be reported later.

\section{References}

Braham, R. R., Jr. 1977. "Mesoscale Meteorology of Metropolitan Regions." Proc. of the Conf. on Metropolitan Environment, August 25-29, 1975, Syracuse, NY. USDA Forest Service Gen'7. Tech. Rpt. NE-25, 1977, Northeastern Forest Experiment Station, Forest Service, U.S. Department of Agriculture, 6816 Market St., Upper Darby, $\mathrm{PA}$. 
Harris, F. S., Jr., and F. L. Morse, Jr. 1968. "Simultaneous Multichannel Sizing, Counting, and Recording of Aerosol Size Distributions." Proc. Int. Conf, on Cloud Physics, August 26-30, 1968, Toronto, Canada.

Radke, L. F. 1970. "Field and Laboratory Measurements with an Improved Automatic Cloud Condensation Nucleus Counter." Proc. of the Conf. on Cloud Physics, August $24-2 \overline{6}$, 1979, Fort Collins, Co.

Study of Man's Inpact on Climate (SMIC). 1971. Inadvertent Climate Modification. The MIT Press, Cambridge, MA, 308 pp.

Twomey, S. and G. T. Severynsen. 1964. "Size Distribution of Natural Aerosol Below 0.1 Micron." J.Atmos. Sci. 21:558-568.
Relationship Among Secondary Pollutants

\section{A. J. Alkezweeny}

During the summer of 1978 several aircraft sampling missions were carried out over Lake Michigan by Pacific Northwest Laboratory (PNL) to monitor and study the formation of secondary pollutants such as ozone and sulfate. Ozone measurements were made with a Bendix ozone analyzer, and a MRI integrating nephelometer was used to determine the aerosol light-scattering at a wavelength of $0.525 \mu \mathrm{m}$. Aerosol particles were also collected on IPC filters at the rate of $1.4 \mathrm{~m}^{3} / \mathrm{min}$ and analyzed by $\mathrm{x}$-ray fluorescence for sulfur content.

Figure 44 shows the relationship between ozone and sulfate. The ozone values are

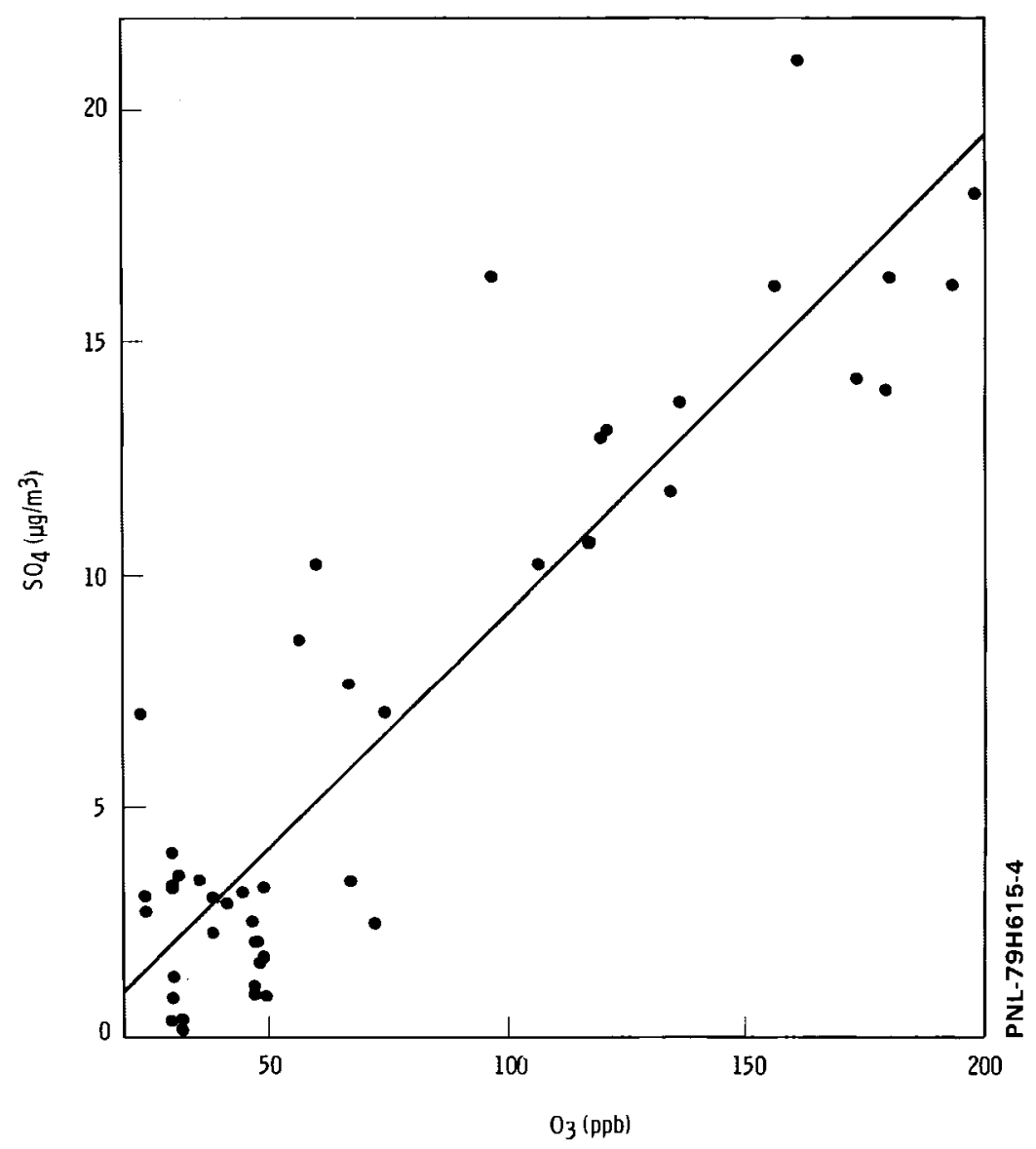

FIGURE 44. Relationship Between Sulfate and Ozone (Straight Line Represents the Best Fit) 
averages over the same sampling period. The data are fitted with a straight line using linear regression analys is on 47 pairs of data points. The best fit is described by the following equation,

$$
\mathrm{SO}_{4}=0.1020_{3}-1.03
$$

where $\mathrm{SO}_{4}$ and $\mathrm{O}_{3}$ are the concentration of sulfate in $\mu \mathrm{g} / \mathrm{m}^{3}$ and the concentration of ozone in ppb. The correlation coefficient between the two parameters is 0.9. Such high correlation suggests that sulfate particles in the atmosphere are formed by photochemical reaction. The data presented here were collected under low relative humidity conditions (below 75\%). Therefore, it is possible that catalysis of sulfur dioxide at high relative humidity may be important. Similar conclusions were also reached by Alkezweeny et al. (1977), Gillani et al. (1978) and Al kezweeny (1980).
A plot of the light scattering ( $B_{S C a t}$ ) versus sulfate particle concentration is shown in Figure 45 . The $B_{\text {Scat }}$ values are time-averaged over the same period of filter sampling times, and they represent the component of scattering as the result of aerosol alone. The correlation coefficient, calculated from 55 pairs of data points, is 0.94 . This high correlation demonstrates the strong contribution of sulfate to visibility degradation in the atmosphere. The linear regression of light scattering onto sulfate is:

$$
B_{\text {scat }}=0.11 \mathrm{SO}_{4}+0.13
$$

where $B_{\text {Scat }}$ is in units of $10^{-4} \mathrm{~m}^{-1}$ and $\mathrm{SO}_{4}$ is the concentration of sulfate in $\mu \mathrm{g} / \mathrm{m}^{3}$. The constants in the above equation are consistent with other reported data (see Pierson et al. 1979).

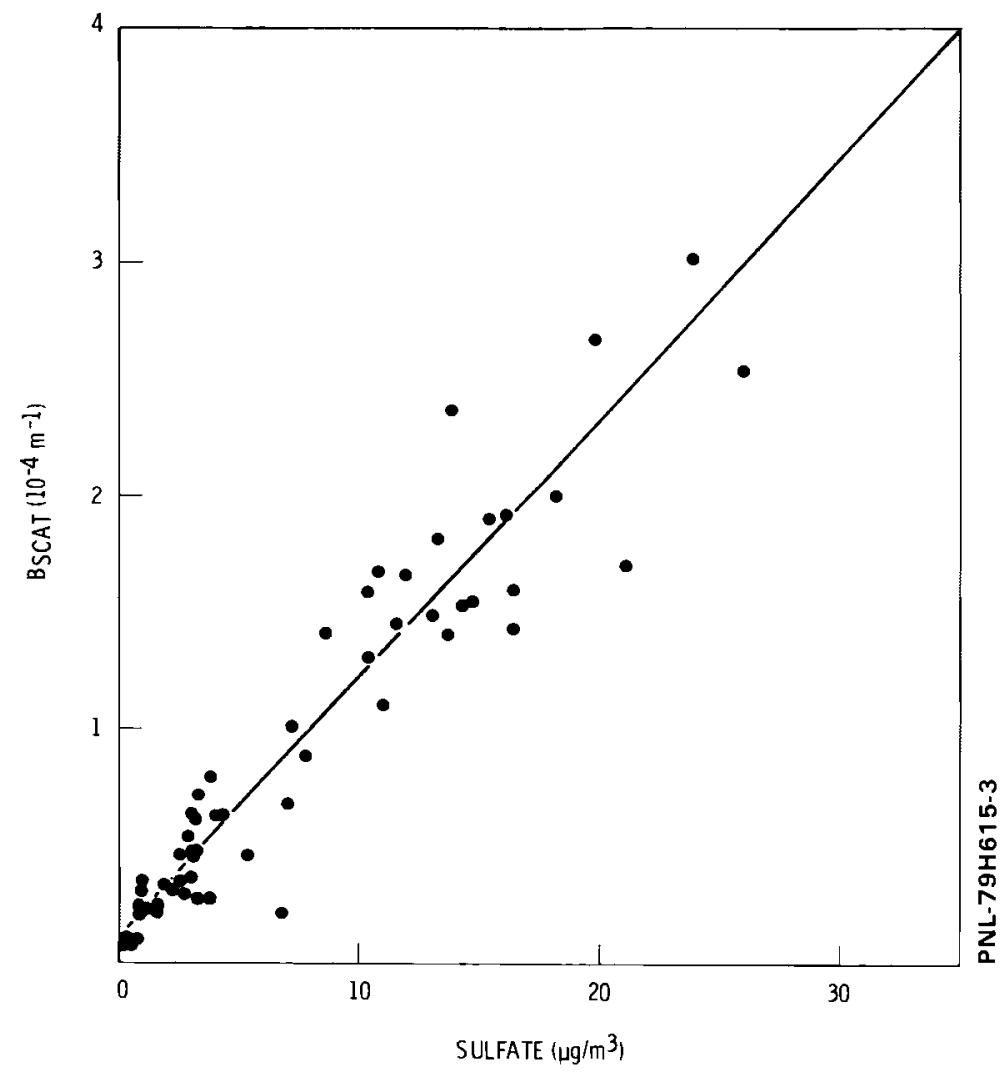

FIGURE 45. Relationship Between Sulfate and Bscat (Straight Line Represents the Best Fit) 


\section{References}

Al kezweeny, A. J. 1980. "Gas to Particle Conversion in Urban Plumes." In Pacific Northwest Laboratory Annual Report for 1979 to the DOE Assistant Secretary for Environment, Part 3, Atmospheric Sciences. PNL3300 PT3, Pacific Northwest Laboratory, Richland, WA.

Al kezweeny, A. J., J. A. Young, R. N. Lee, K. M. Busness and J. M. Hales. 1977. "Transport and Transformation of Pollutant in the Lake Michigan Area." Presented at the 4th Joint Conference on Sensing of Environmental Pollutants, November 10, 1977 , New Orleans, LA.

Gillani, N. V., R. B. Husar, J. D. Husar, D. E. Patterson and W. E. Wilson, Jr. 1978. "Project MISTT: Kinetics of Particulate Sulfur Formation in a Power Plant Plume Out to $300 \mathrm{~km} . "$ Atmos. Environ. 12:589-598,

Pierson, W. R., W. W. Brachaczek, T. J. Truex, J. W. Butler and T. J. Kormiski. 1979. "Ambient Sulfate Measurements on Allegheny Mountain and the Question of Atmospheric Sulfate in the Northeastern United States." Presented at the New York Academy of Sciences Conference on Aerosols: Anthropogenic and Natural Sources and Transport, January 9-12, 1979, New York, NY.

Measurement of Atmospheric Hydrogen Peroxide

\section{R. N. Lee}

Despite evidence of the significant role of hydrogen peroxide in photochemical smog chemistry (Demerjian, Kerr and Calvert 1974; Graede1, Farrow and Weber 1976) and potential contribution to sulfate aerosol production (Penkett et al. 1979), there have been very few reported measurements of $\mathrm{H}_{2} \mathrm{O}_{2}$ in the ambient atmosphere. Analytical deficiencies largely responsible for this void may have been overcome with the recent development of a chemiluminescent technique that has been applied to both integrated and real-time detection of $\mathrm{H}_{2} \mathrm{O}_{2}$ during moderate smog episodes in southern California (Kok et al. 1978a; Kok et a 1. 1978b). This technique utilizes the metal-catalyzed reaction of $\mathrm{H}_{2} \mathrm{O}_{2}$ with luminol for the quantitative determination of $\mathrm{H}_{2} \mathrm{O}_{2}$ in aqueous solution.

A system for the analysis of integrated samples of $\mathrm{H}_{2} \mathrm{O}_{2}$ [very similar to the system described by Kok et al. (1978b)] was constructed at the Muskegon (Michigan) Field
Laboratory during FY 1979. The system was used for samples acquired during urban plume flights over Lake Michigan and the Central Illinois Rain Chemistry Experiment (CIRCE) experiment in central Illinois during the summer of 1979. The analyzer unit was assembled from the following components:

- Technicon Proportioning Pump

- Glass Reaction Cell (spiral shape with mirrored wall constructed at BattelleColumbus)

- Hamamatsu R268 Photomultiplier Tube

- AID Model 513 Gas Chromatograph with Keithley A65 Electrometer

Reagent solutions, prepared from reagentgrade chemicals without further purification, were transported to the reaction cell through Teflon ${ }^{\circledR}$ tubing, with the exception of peristaltic pump tubing. The reaction cell was sealed in a light, tight, aluminum shield designed to accomodate the photomultiplier (PM) tube housing of a flame photometric detector from an AID Model 513 gas chromatograph. Chemiluminescent radiation, viewed by the PM tube without optical filtration, produced a photocurrent that was amplified by the electrometer of the AID chromatograph and displayed on strip-chart recorder output. Standards prepared immediately before use by serial dilution of stock $\mathrm{H}_{2} \mathrm{O}_{2}$ were run in sequence with samples and deionized water blanks to quantify sanlple response.

Hydrogen peroxide samples were collected by bubbling air at $1.3 \mathrm{l} / \mathrm{min}$ through $10 \mathrm{ml}$ of deionized water. Since there generally was a delay of at least 3 to $4 \mathrm{hr}$ between capture and analysis of samples, storage at subambient temperatures was utilized to minimize $\mathrm{H}_{2} \mathrm{O}_{2}$ decay. On the basis of the behavior of aged standards stored under identical conditions, the most concentrated ambient samples should have deteriorated by no more than about 50\% during storage. However, potential interferences by components of po1luted atmospheres such as sulfur dioxide (reported to be insignificant) have not been fully investigated. Samples collected in the Chicago plume during a severe stagnation episode in mid-July show decided disruption of the analyzer baseline as a result of some material in the collected sample. Our results, therefore, suggest the need for continued investigation of the analytical technique to establish its suitability for use in polluted atmospheres. 
Data collected during the summer of 1979 are summarized in Tables 11 and 12 . Concentrations reported for the CIRCE flights and

TABLE 11. Observed Concentrations Ranges of $\mathrm{H}_{2} \mathrm{O}_{2}$ During Summer 1979

\begin{tabular}{|c|c|}
\hline Sampling Locations & $\mathrm{H}_{2} \mathrm{O}_{2}, \mathrm{ppb}$ \\
\hline $\begin{array}{l}\text { Chicago Urban } \\
\text { Plume, } \\
\text { June } 1979\end{array}$ & 0.3 to 1.8 \\
\hline $\begin{array}{l}\text { CIRCE Flights, } \\
\text { July } 1979\end{array}$ & 0.5 to 1.7 \\
\hline $\begin{array}{l}\text { Muskegon, MI, } \\
\text { July 5, } 1979\end{array}$ & 1.0 to 1.7 \\
\hline
\end{tabular}

TABLE 12. Sequential Samples Collected at Muskegon County Airport During Period Characterized by Northerly Winds, July 5,1979

$\begin{array}{lcc}\text { Sampling Period } & & \mathrm{H}_{2} \mathrm{O}_{2}, \mathrm{ppb} \\ 1029 \text { to } 1120 \text { EDT } & & 1.7 \\ 1130 \text { to } 1230 & & 1.7 \\ 1231 \text { to } 1334 & & 1.5 \\ 1335 \text { to } 1454 & & 1.0\end{array}$

sequential samples collected at Muskegon on July 5, 1979 during a period of advection of unpolluted air should accurately reflect atmospheric $\mathrm{H}_{2} \mathrm{O}_{2}$ levels. Samples collected in polluted air over Lake Michigan were most subject to $\mathrm{H}_{2} \mathrm{O}_{2}$ decay during periods of prolonged storage and probable interference by material (or materials) in the urban plume. Calculated concentrations may, therfore, be an order of magnitude or more below actual concentration levels.

\section{References}

Demerjian, K. L., J. A. Kerr and J. G. Calvert. 1974. "The Mechanism of Photochemical Smog Formation." Advances in Envi- ronmental Science and Technology, J. A. Pitts and R. L. Metcalf, eds., Wiley, New York, NY, pp. 1-262.

Graedel, T. E., L. A. Farrow and T. A. Weber. 1976. "Kinetic Studies of the Photochemistry of the Urban Troposphere." Atmos. Environ. 10:1095.

Kok, G. L., K. R. Darnal1, A. M. Winer, J. N. Pitts, Jr. and B. W. Gay. 1978a. "Ambient Air Measurements of Hydrogen Peroxide in the California South Coast Air Basin." Environ. Science Technology. 12:1077.

Kok, G. L., T. P. Holler, M. B. Lopez, H. A. Nachtrieb and M. Yuan. 1978b. "Chemiluminescent Method for Determination of $\mathrm{Hy}-$ drogen Peroxide in the Ambient Atmosphere." Environ. Science Technology. 12:1072.

Penkett, S. A., B. M. R. Jones, K. A. Brice and A. E. J. Eggleton. 1979. "The Importance of Atmospheric 0zone and Hydrogen Peroxide in Oxidizing Sulfur Dioxide in Cloud and Rainwater." Atmos. Environ. 13:123.

Tests for the Evaluation of an Airborne Aerosol Sampling System and Filter Analys is Methodologies

R. N. Lee

Aerosol collection via high-volume filtration on-board an aircraft platform has been recognized as a difficult sampling problem. Difficulties relating to air volume measurement, leaks in the sampling lines and impaction of large particles on the inlet lines are potential problem areas. The high-volume sampling system on-board the Pacific Northwest Laboratory (PNL) DC-3 aircraft has undergone frequent modification to meet changing program requirements and to upgrade performance in regards to the above problems. A system with superior flow and volume measurement characteristics is now in place and is described by Arbuthnot and Hales in this Annual Report.

In order to appraise the quality of data derived from the use of this sampling system, a study has been initiated to evaluate all aspects of the data-generation scheme from aerosol collection through analysis. As the first step in this process, randomly selected quartz filters have been cut in half for analysis at both Brookhaven $\mathrm{Na}-$ tional Laboratory (BNL) and PNL. These samples include aircraft, surface and blank filters processed at the Muskegon (Michigan) Field Laboratory. Sections of filters to be analyzed by PNL were extracted with deionized 
water and extractants sent to the Hanford Precipitation Chemistry Laboratory for ion chromatographic analysis. Filter segments to be analyzed at BNL were sealed in individual plastic bags and mailed to BNL where they were processed with other filters analyzed at that laboratory. The resulting analytical data from both laboratories will provide a good comparison of the respective analytical procedures for the determination of airborne sulfate and nitrate and will be of particular interest when comparing data from collaborative field studies such as the Atmospheric Mass Balance Industrial Emitted and National Sulfur (AMBIENS) field study and the Central Illinois Ra in Chemistry Experiment (CIRCE).

During the summer of 1979 , the interlaboratory exchange of filter segments was expanded to include Lawrence Berkeley Laboratory ( $L B L)$. Surface samples obtained by $L B L$ were cut in quarters at LBL and the segments sent to the participating laboratories for sample work-up and analysis.

While the exchange of filter seginents will provide a data base for evaluating filter handling and analys is procedures, the identification of possible bias traceable to the airborne sampling system is being addressed by a second series of experiments. These tests currently in progress consist of the parallel exposure of three filters in the aircraft high-volume sampling system to ambient aerosol. In addition to quartz, Teflon ${ }^{\circledR}$-coated glass fiber, IPC and nylon membrane filters are among those being used for sample collection. Available from past studies are a limited number of tests involving parallel exposure of quartz and IPC filters during airborne sampling missions. These tests were run with an earlier version of the aircraft high-volume sampling system. Although the agreement between calculated sulfate concentrations from quartz (IC Analysis) and IPC (XRF analysis) filters was generally quite good, comparison is difficult since the low flow that could be achieved with the quartz filters on the old system resulted in different sampling intervals for the two filter materials. In order to yield optimum definition of sulfate profiles, two IPC filters were generally run sequentially with each quartz filter. Hence, quartz filters were relied upon to provide back-up sulfate data and an indication of the magnitude of nitrate aerosol concentration.

Tests now underway will restrict sampling to the same time interval.

Design of a High-Volume Air Sampling System for Aircraft Research

\section{A. Arbuthnot and J. M. Hales}

In the past, high-volume filter sampling practices aboard the Pacific Northwest Laboratory (PNL) DC-3 have been hampered by the rather cumbersonie configuration of the associated equipment and by the comparatively low flow rates provided by the conventional high-volume blowers that were installed onboard. This latter feature has been particularly troublesome because of the corresponding long time periods required to obtain measurable samples. Sulfate samples, for example, required at least 20 -min sampling times, even under rather polluted conditions.

A new high-volume filtering system was installed in the PNL DC-3 aircraft during the past year to overcome these difficulties. Shown schematically in Figure 46 , this system incorporates the following features:

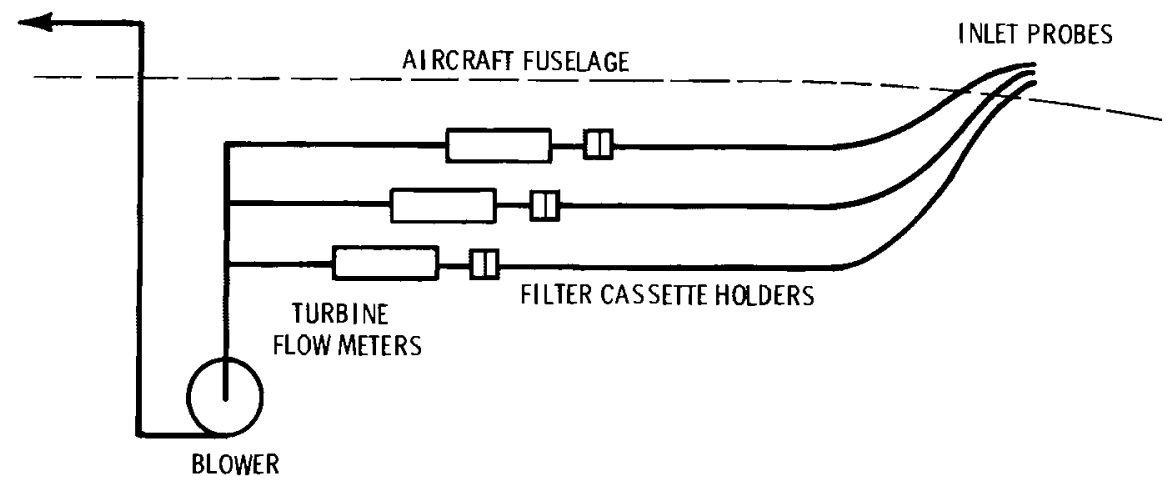

FIGURE 46. Schematic of PNL High-Volume Filter Sampling System 
- capability for simultaneous three-filter operation, with all filter lines driven by a common Paxton 2.5 hp 28 -vdc centrifugal blower

- continuous monitoring of flow rates in each sample 1 ine, using Cox turbine flowmeters, whose output signals are logged on the DC-3 data acquisition system

- convenient, rapid, and fail-sale filter mounting via clamp-type filter receptacles, which accept preloaded filter cassettes. Tandem filter-pack operation is possible
- sufficient flexibility to incorporate special sampling devices, such as cloudwater samplers when desired.

This new system triples the original flow capacity of the high-volume air sampling systems, thus lowering required sampling times by roughly one third. In addition, a significant improvement in measurement reliability and quality control has been achieved, which will be documented in quality assurance tests for the system currently in progress.

\section{- Research Aircraft Operations*}

Objectives of these operations are:

- Providing technical support in the form of research aircraft for on-going Multistate Power Production Pollution Study (MAP3S) programs.

- Providing aerial platforms for atmospheric sampling of aerosols and trace gases, for the release of special tracer materials, and for the measurement of radiative properties of the atmosphere.

Development of an In-Flight Calibrator for Sulfur Dioxide and $\mathrm{NO}_{\mathrm{x}}$ Monitoring Systems

K. M. Busness and J. M. Hales

Because of the adverse nature of aircraft operating environments, frequent calibration checks are essential for reliable operation of airborne sulfur dioxide and $\mathrm{NO}_{\mathrm{x}}$ instrumentation. In the past these checks usually have been performed while on the ground, using carry-on calibration equipment. Such checks are not totally satisfactory, however, because they cannot be performed with sufficient frequency, and they do not permit validation of the measurement equipment at operating altitudes under actual sampling conditions.

This situation has been improved during the past year by construction of an inflight calibrator for the Pacific iNorthwest Laboratory (PNL) DC-3 aircraft, which permits virtually instantaneous zero and span checks (for sulfur dioxide and nitrogen di-

*See Foreword oxide), and allows detailed, multipoint calibrations to be performed as wel1. Shown schematically in Figure 47 , this system uti1izes permeation-tube sources, which can be operated in three basic modes controlled by a remote switch:

- the sample mode, wherein the measurement instrumentation is sampling outside air

- the span mode, which supplies predetermined concentrations of nitrogen dioxide and sulfur dioxide to the respective analyzers

- the zero mode, which supplies zero gas to the analyzers.

The status of the calibration system is continually written on the magnetic-tape data-acquisition system so that these modes can be detected automatically in subsequent data analyses. It is important to note that positive-displacement, synchronous pumps are used as primary air movers, providing a constant volume of diluent air; thus, the system provides a constant concentration $(a)$ of

(a) As contrasted to mixing ratio. 


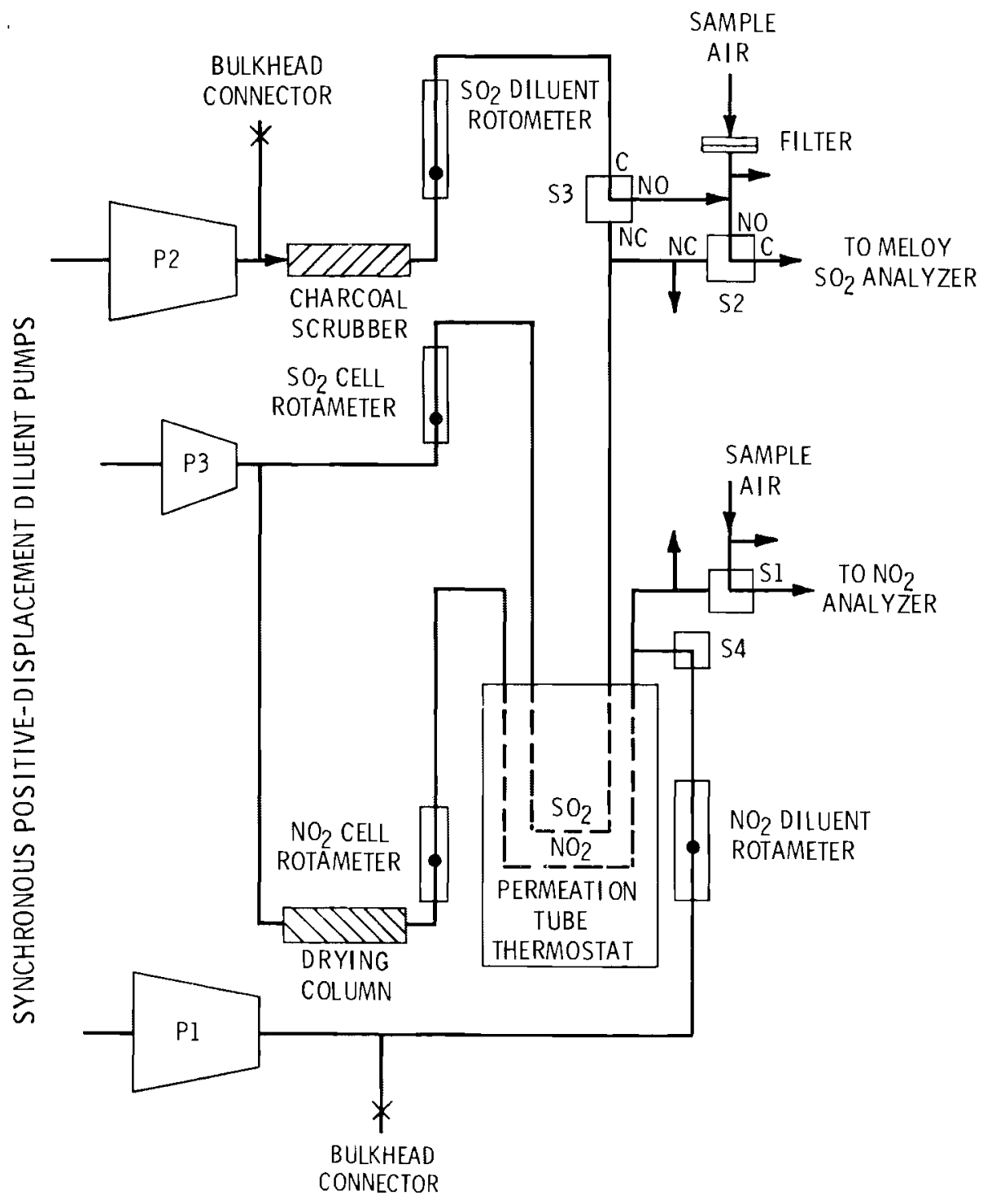

FIGURE 47. Schematic of In-Flight Calibrator Flow System

span gas, which is invariant with altitude. Time-response of the calibration system (after switching between modes) is of the order of 1 min; thus, span and zero checks can be obtained frequently during the course of a sampling flight.

Multipoint calibrations over an extended concentration range can be performed with the calibration system using an auxiliary air source and monitoring the diluent airflows with the rotameters. Owing to difficulties in obtaining reliable flow-rate measurements while airborne, multipoint calibrations are obtained only while the aircraft is on the ground. 


\section{- Multistate Power Production Pollution Study (MAP3S) Modeling Studies*}

Objectives of these studies are:

- Developing short- and long-range trajectory models that simulate the behavior of the atmosphere and its contaminants from the source of these contaminants to their receptors.

- Testing these assessment models for accuracy and sensitivity against field data collected in the Sulfate Regional Experiment (SURE) and the Multistate Atmospheric Power Production Pollution Study (MAP3S) field programs.

- Using these models to aid field investigators in planning experiments in the MAP3S program.

MAP3S Modeling: Annual Progress, FY 1979

D. J. McNaughton

\section{Introduction}

Presented here is a brief description of the Pacific Northwest Laboratory (PNL) modeling activities of the Multistate Atmospheric Power Production Pollution Study (MAP3S) program during FY 1979. Studies have been directed primarily toward developing capability in short-term regional model predictions over the Northeast and in model validation. Listed below are individual tasks and studies that have been accomplished during the fiscal year.

Short-Term Episode Predictions

- Investigation of Terrain-Involved Wind Shears Over the Northeast. Wind shear resulting from terrain variations or synoptic-scale meteorological systems can have significant impact on pollutant transport. This task was designed to study the impact of terrain-induced shear inregional model predictions that currently assume a 100 - to 1000-m-layeraverage interpolated wind field in predicting the fate of pollutant emissions. Initial model wind fields over the ivortheast MAP3S grid were analyzed using a mass conservative initialization model, actual wind profiles and smoothed terrain fields. Results indicated significant shear in the layer of winds currently used by the MAP3S model, but additional studies will be necessary to determine the degree of interaction of the wind shears, model results and observed air quality data.

*See Foreword
- A Synoptic Case Study of Elevated Layers of High Airborne Sulfate Concentration. Ta) A synoptic analysis was performed to identify the source and characteristics of an elevated layer of high airborne sulfate concentrations observed over southeast Wisconsin August 23 to 24, 1976. The setting of the episode was the interaction of a weak, dry cold front with a stagnating anticyclone over the eastern United States. Although several explanations of the layer formation were possible, it appears likely that the layers were formed as the top of a deep, mixed layer was lifted in a frontal zone and later became part of a subsidence inversion.

The analysis made use of synoptic meteorological data, aircraft samples from the MAP3S urban plume studies, and predictions of air parcel trajectories using an eight-layer trajectory model.

Model Validation and Sensitivity Testing

- Initial Comparisons of SURE/MAP3S Sulfur Oxide Observations with Long-Term Regional Model Predictions. Monthly sulfur dioxide and sulfate observations from the SURE intensive study periods and concurrent data from the MAP3S Precipitation Chemistry Network were compared to PNL regional pollutant transport model predictions, and sensitivity tests of subgridscale parameterizations were performed. Results are summarized in this Annual Report.

(a) McNaughton, D. J. and M. M. Orgi11, "A Synoptic Case Study of Elevated Layers of High Airborne Sulfate Concentration." To be published in Monthly Weather Review, 1980. 
- Emission Source Specification in a Regional Pol]utant Transport Model. Regional air pollutant modeling either using grid or trajectory models requires simulation of large numbers of emission sources and involves high computational expense. Sensitivity studies of emission source specifications, summarized in this Annual Report, indicate that approximations can be useful in minimizing the required resolution of emissions data in the model.

- Time Series Validation of the Long-Term PNL Regional Model. Work is in progress to perform a time series comparison of observed 24-hr average concentrations of airborne $\mathrm{SO}_{2}$ and $\mathrm{SO}_{4}$ to values predicted over a month by the long-term PNL regional model. The objective of the analysis is to determine the ability of the model to predict the correct position of trajectories using layer-average, interpolated wind fields. Results will hopefully show the impact of current wind field simplifications in the model and the synoptic situations under which improvement is required.

- Modeling Evidence of Included Transformation of Sulfur Dioxide to Sulfate. Concurrent analysis of a irborne $\mathrm{SO}_{2}$ and sulfate concentrations and sulfate concentrations in precipitation between observed data and model predictions indicated adequate predictions of airborne concentrations but under-predictions of sulfate in precipitation. Results summarized in this Annual Report show that increased sulfate formation in clouds may provide needed sulfate mass without disturbing air concentrations of sulfur oxides.

Initial Comparisons of SURE/MAP3S Sulfur 0xides 0bservation with Long-Term Regional Model Predictions

\section{J. McNaughton}

This article summarizes a paper (McNaughton 1980) that represents first efforts to verify a long-term regional model applicable for monthly or annual predictions of the transport and removal of airborne sulfur oxides. The model uses newly acquired data from the Electric Power Research Institute (EPRI) Sulfate Regional Experiment (SURE) (Perhac 1978) and the U.S. Department of Energy (DOE) Multistate Atmospheric Power Production Pollution Study (MAP3S) Precipitation Chemistry Network
(Dana 1979; MacCracken 1978). Presented here in tables and figures are monthly model predictions of ambient concentrations of sulfur dioxide and sulfate and total sulfur removed by precipitation scavenging, which are compared to observed data collected from the measurement networks in the northeast United States for August and 0ctober 1977.

Results of two study cases are presented where Case 1 is a base case for making predictions and Case 2 is a modification of the base case without near-source Gaussian dispersion and urban $\mathrm{SO}_{2}$ to $\mathrm{SO}_{4}^{=}$transformation rates which are subgrid-scale parameterizations. Model evaluation statistics for airborne sulfur oxide concentrations are presented in Table 13A. Base case predictions of $\mathrm{SO}_{4}$ deposition by precipitation are given in Table 13B. Predictive capabilities of the regional model and the sensitivities of the model to subgrid-scale parameterizations are best shown in Figures 48 and 49 which are plots of air concentrations of sulfur oxides to location on two cross sections.

Monthly Pacific Northwest Laboratory (PNL) model results show promising predictive capabilities for a long-term regional model based on initial comparisons with a new data base. Modeling of regional-scale sulfur oxide transport and removal can be made more efficient by eliminating some subgrid-scale influences. Evaluation of the model with concurrent analysis of three parameters, $\mathrm{SO}_{2}$ and $\mathrm{SO}_{4}=$ concentrations and total sulfur removed by wet processes, suggests that a study of two transformation and precipitation scavenging regimes, incloud and subcloud, may be necessary to predict scavenging and precipitation acidity.

\section{References}

Dana, M. Terry, ed. 1979. The MAP3S Precipitation Chemistry Network: Second Periodic Summary Report (July 1977-June 1978). PNL2829, Pacific Northwest Laboratory, Richland, WA.

MacCracken, M. C. 1978. The Multistate Atmospheric Power Production Study. DOE/ EV-0008/1, NTIS, Department of Commerce, Springfield, VA.

McNaughton, D. J. 1980. "Initial Comparisons of SURE/MAP3S Sulfur 0xides Observation with Long-Term Regional Model Predictions." Atmos. Environ. 14.

Perhac, R. M. 1978. "Sulfate Regional Experiment in the Northeastern U.S.: The SURE Program." Atmos. Environ. 12:641-648. 
TABLE 13A. Summary of Model Evaluation Statistics

\begin{tabular}{|c|c|c|c|c|c|c|c|c|}
\hline \multirow[b]{3}{*}{ Comparison Statistics } & \multicolumn{4}{|c|}{ Ambient $\mathrm{SO}_{4}{ }^{2}$ Concentration } & \multicolumn{4}{|c|}{ Ambient $\mathrm{SO}_{2}$ Concentration } \\
\hline & \multicolumn{2}{|c|}{ August 1977} & \multicolumn{2}{|c|}{ October 1977} & \multicolumn{2}{|c|}{ August 1977} & \multicolumn{2}{|c|}{ October 1977} \\
\hline & Case 1 & Case 2 & Case 1 & $\overline{\text { Case 2 }}$ & Case 1 & Case 2 & Case 1 & Case 2 \\
\hline $\begin{array}{l}\text { Mean Observed Concentration } \\
\left(\mu \mathrm{g} \mathrm{m}^{-3}\right)\end{array}$ & 10.25 & 10.25 & 6.24 & 6.24 & 14.97 & 14.97 & 21.70 & 21.70 \\
\hline 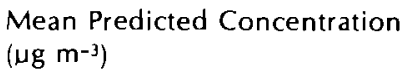 & 7.93 & 5.73 & 6.17 & 4.46 & 12.82 & 13.29 & 13.68 & 12.92 \\
\hline $\begin{array}{l}\text { Correlation of Observed to } \\
\text { Predicted Concentration }\end{array}$ & 0.61 & 0.65 & 0.51 & 0.59 & 0.59 & 0.56 & 0.72 & 0.76 \\
\hline Variance in Observed Data & 3.41 & 3.41 & 1.82 & 1.82 & 54.75 & 54.75 & $155.41^{(a)}$ & 155.41 \\
\hline Variance in Predicted Data & 9.04 & 20.29 & 1.96 & 1.66 & 45.54 & 44.66 & 54.48 & 39.96 \\
\hline $\begin{array}{l}\text { Maximum Observed } \\
\text { Concentration }\left(\mathrm{\mu g} / \mathrm{m}^{3}\right)\end{array}$ & 14.6 & 14.6 & 8.92 & 8.92 & 30.13 & 30.13 & 69.17 & 69.17 \\
\hline $\begin{array}{l}\text { Maximum Predicted } \\
\text { Concentration at Monitoring } \\
\text { Sites }\left(\mu \mathrm{g} / \mathrm{m}^{3}\right)\end{array}$ & 21.31 & 14.9 & 12.60 & 7.31 & 28.27 & 25.20 & 36.94 & 45.69 \\
\hline $\begin{array}{l}\text { Frequency of Concentrations } \\
\text { Within a Factor of }(\%):\end{array}$ & 78 & 97 & 97 & 89 & 82 & 78 & 65 & 62 \\
\hline 3 & 91 & 77 & 99 & 99 & 95 & 86 & 89 & 89 \\
\hline$>3$ & 100 & 100 & 100 & 100 & 100 & 100 & 100 & 100 \\
\hline
\end{tabular}

\footnotetext{
$\overline{(a)}$ Apparent bias by a local source influence at Johnstown, PA
} 
TABLE 13B. Monthly Wet Deposition of Sulfur (as $\mathrm{SO}_{4}^{\bar{F}}$ )

\begin{tabular}{|c|c|c|c|c|}
\hline \multirow[b]{3}{*}{ Data Sites } & \multicolumn{4}{|c|}{ August 1977} \\
\hline & \multirow[b]{2}{*}{ Precipitation, $\mathrm{cm}$} & \multicolumn{3}{|c|}{ Monthly Deposition $\left(\mathrm{gm}^{-2}\right)$} \\
\hline & & Observed & Predicted & Ratio \\
\hline Whiteface Mountain, NY & 16.32 & 0.50 & 0.40 & 0.81 \\
\hline State College, PA & 9.10 & 0.42 & 0.28 & 0.68 \\
\hline Charlottesville, VA & 2.68 & 0.13 & 0.04 & 0.31 \\
\hline Ithaca, NY & 8.97 & 0.44 & 0.31 & 0.69 \\
\hline
\end{tabular}

October 1977

\begin{tabular}{|c|c|c|c|c|}
\hline \multirow[b]{3}{*}{ Data Sites } & \\
\hline & \multirow[b]{2}{*}{ Precipitation, $\mathrm{cm}$} & \multicolumn{3}{|c|}{ Monthly Deposition $\left(\mathrm{gm}^{-2}\right)$} \\
\hline & & Observed & Predicted & Ratio \\
\hline Whiteface Mountain, NY & 19.94 & 0.28 & 0.11 & 0.38 \\
\hline State College, PA & 15.63 & 0.35 & 0.12 & 0.34 \\
\hline Charlottesville, VA & 5.33 & 0.06 & 0.03 & 0.45 \\
\hline Ithaca, NY & - & - & - & - \\
\hline
\end{tabular}



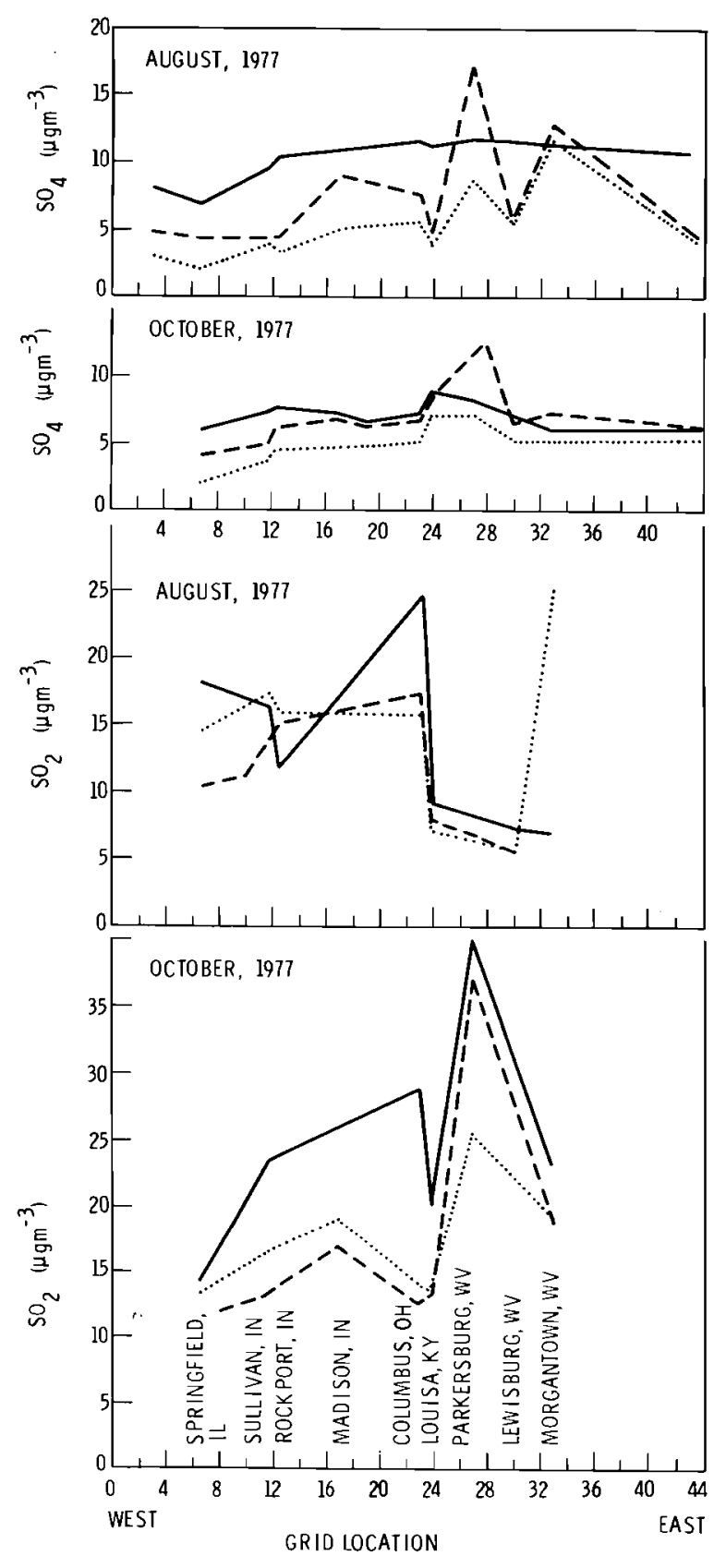

OBSERVED

- - CASE 1

CASE 2

FIGURE 48. Cross Sections of $\mathrm{SO}_{2}$ and $\mathrm{SO}_{\overline{4}}^{\overline{4}}$ Predicted and Observed Concentrations (East-West)
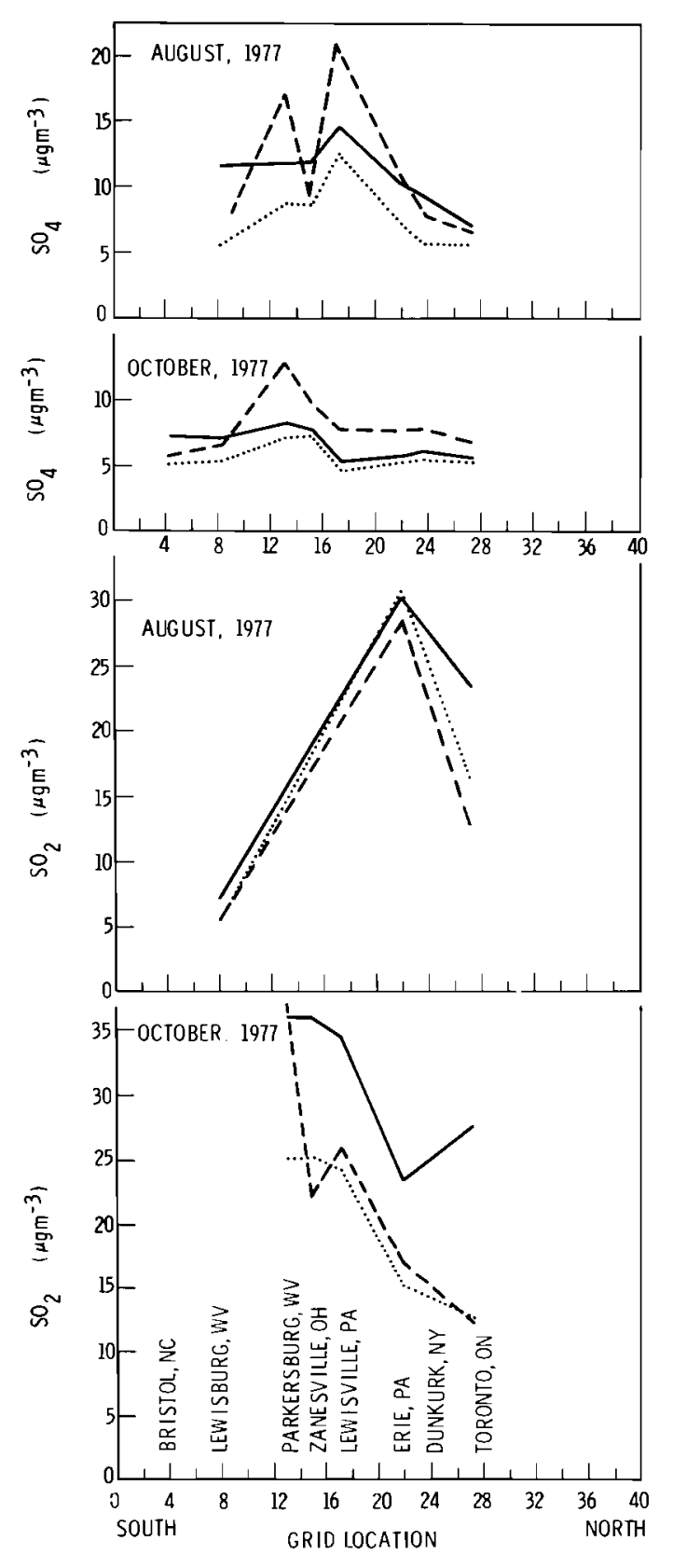

- 0 B SERVED $\quad---$ CASE $1 \quad$........... CASE 2

FIGURE 49. Cross Sections of $\mathrm{SO}_{2}$ and $\mathrm{SO}_{\overline{4}}^{\overline{\bar{P}} \text { Predicted }}$ and Observed Concentrations (North-South) 
Emission Source Specification in a Regional Pollutant Transport Model

D. J. McNaughton

\section{Introduction}

Modeling of regional air pollutant transport, transformation, and removal presents the problem of analysis of inputs, processes and desired results over a range of spatial and temporal scales. Model sensitivity tests are presented to investigate bounding model complexity and computational expense while assuring prediction of main parameter effects and interactions. The analys is compares model results for source specification alternatives to base case results and an observed data set including sulfur dioxide and sulfur sulfate air concentrations and the concentration of sulfur oxides in precipitation.

\section{Study Cases}

Three types of emission source specifications were tested in the Pacific Northwest Laboratory (PNL) regional transport model (Powell et a1. 1979) and simulations were compared to observations and results of base case simulations (McNaughton 1980):

- Base Case--Emissions and source locations were derived from data of the U.S. Environmental Protection Agency (EPA 1976), the U.S. Federal Power Commission (FPC 1976), and the Ontario Ministry of the Environment. Sixty-three individual sources used as input are a collection of local groups of power plants and urban sources. The point inventory represents approximately $65 \%$ of actual $\mathrm{SO}_{2}$ emissions on the computational grid. The base case was tested to determine how many sources are required to identify major patterns in pollutant concentration fields.

- Emission Rate Sensitivity Cases--Forty of the 63 base case sources were selected at random and emission rates were changed $\pm 15 \%$ or $\pm 30 \%$ to study the impact of emission rate variability.

- Source Location Sensitivity Cases--A single source group with total emissions of approximately $7 \times 10^{5} \mathrm{t} \mathrm{yr}^{-1}$ was studied to investigate the sensitivity of the model to combining point sources and to errors in source locations.

- Emissions Averaging Case--Total actual emissions on the calculational grid were distributed over land areas using a point-source grid to study spatial averaging of emissions.

Results

Results of the analysis were:

- Initial comparisons of predictions to observations are given by McNaughton (1980) for the base case (summary statistics are found in Table 14A,B). The base case simulations were further analyzed to determine, in light of the limited emissions inventory used, whether results included the dominant sulfur oxide patterns in Figure 50. The main concentration patterns appear to be determined by major source groups or areas as indicated by the level and location of concentration peaks and the correlation coefficients. Overall levels of $\mathrm{SO}_{2}, \mathrm{SO}_{4}$ and aqueous sulfur sulfate $\left(\mathrm{ASO}_{4}{ }_{4}\right.$ ) increase uniformly with the increased $\mathrm{SO}_{2}$ levels increasing more rapidly possibly because the monitors are sited near sources of $\mathrm{SO}_{2}$, the primary emission.

- Results of the emission rate sensitivity test (Table 14A,B) indicated a slight sensitivity in the $\mathrm{SO}_{2}$ maximum and a change range of $\mathrm{SO}_{4}=$ concentrations with little impact on other statistics. Sulfur dioxide air concentration maxima are generally associated with single sources or local source complexes and will generally show an immediate response to increases in $\mathrm{SO}_{2}$ emissions. Sulfate concentration patterns appear to be set by mean distributions emissions.

- Results from the source location tests indicate that source location errors or source combinations within one grid radius have very little impact on mean monthly concentrations levels and patterns but do have an impact on maximum local concentrations in the prevailing wind direction (Table 15). The single source specification appears to move the $\mathrm{SO}_{2}$ maximum values closer to the source without significantly changing $\mathrm{SO}_{4}=$ concentrations.

- Gridding emissions improves prediction of aqueous $\mathrm{SO}_{4}$ and mean levels of airborne $\mathrm{SO}_{4}=$ over the base case as a result of the increase in emissions over the grid from 65 to $100 \%$ (Table 14A,B, Case 3a). Maximum airborne $\mathrm{SO}_{4}^{=}$concentrations are overpredicted by a greater extent in the vicinity of large sources. Sulfur dioxide concentrations are overpredicted both in the mean and extremes. Patterns of $\mathrm{SO}_{2}$ 
TABLE 14A. Summary of Model Evaluation Statistics

\begin{tabular}{|c|c|c|c|c|c|c|c|c|}
\hline \multirow[b]{3}{*}{ Comparison Statistics } & \multicolumn{4}{|c|}{$\mathrm{SO}_{2}$} & \multicolumn{4}{|c|}{$\mathrm{SO}_{4}$} \\
\hline & \multicolumn{4}{|c|}{ Case $^{(a)}$} & \multicolumn{4}{|c|}{ Case $^{(a)}$} \\
\hline & 1 & 2 & $3 a$ & $3 b$ & 1 & 2 & $3 a$ & $3 b$ \\
\hline \multicolumn{9}{|l|}{ Mean Observed ${ }^{(b)}$} \\
\hline Concentration $\left(\mu \mathrm{g} \mathrm{m}^{-3}\right)$ & 14.94 & 14.94 & 14.94 & 14.94 & 10.25 & 10.25 & 10.25 & 10.25 \\
\hline \multicolumn{9}{|l|}{ Mean Predicted } \\
\hline Concentration $\left(\mu \mathrm{g} \mathrm{m}^{-3}\right)$ & 13.29 & 13.57 & 19.15 & 17.78 & 5.73 & 5.86 & 7.99 & 7.95 \\
\hline $\begin{array}{l}\text { Correlation of Observed to } \\
\text { Predicted Concentration }\end{array}$ & 0.56 & 0.56 & 0.47 & 0.47 & 0.65 & 0.64 & 0.64 & 0.64 \\
\hline Variance in Observed Data & 54.75 & 54.75 & 54.75 & 54.75 & 3.41 & 3.41 & 3.41 & 3.41 \\
\hline Variance in Predicted Data & 44.66 & 49.79 & 75.07 & 51.20 & 20.29 & 14.79 & 15.58 & 11.03 \\
\hline $\begin{array}{l}\text { Maximum Observed } \\
\text { Concentration }\left(\mu \mathrm{g} \mathrm{m}^{-3}\right)\end{array}$ & 30.1 & 30.1 & 30.1 & 30.1 & 14.6 & 14.6 & 14.6 & 14.6 \\
\hline \multicolumn{8}{|l|}{ Maximum Predicted } & 15.5 \\
\hline \multicolumn{9}{|l|}{$\begin{array}{l}\text { Frequency of Concentrations } \\
\text { Within a Factor of }(\%) \text { : }\end{array}$} \\
\hline 2 & 78 & 78 & 82 & 86 & 59 & 59 & 81 & 81 \\
\hline 3 & 86 & 86 & 90 & 86 & 77 & 83 & 96 & 97 \\
\hline
\end{tabular}

TABLE 14B. Ratios of Predicted to Observed (C)

Concentration of Sulfate in Rainwater (\%)

\begin{tabular}{lccccc}
\multicolumn{1}{c}{ Station } & \multicolumn{4}{c}{Case$^{(a)}$} \\
\cline { 2 - 6 } Whiteface Mt., NY & & $\frac{1}{81}$ & $\frac{2}{84}$ & $\frac{3 \mathrm{a}}{85}$ & $\frac{3 \mathrm{~b}}{}$ \\
Ithaca, NY & 69 & 67 & 78 & 78 \\
State College, PA & 72 & 71 & 78 & 78 \\
Charlottesville, VA & 31 & 32 & 44 & 44 \\
Mean & 63 & 63 & 71 & 71
\end{tabular}

(a) Case 1 - Base Case

2 - Emission Rate Sensitivity Test

3 a,b, - 70 Point-Gridded Emissions Tests

(b) Sulfate Regional Experiment (SURE) Data

(c) Dana 1979 


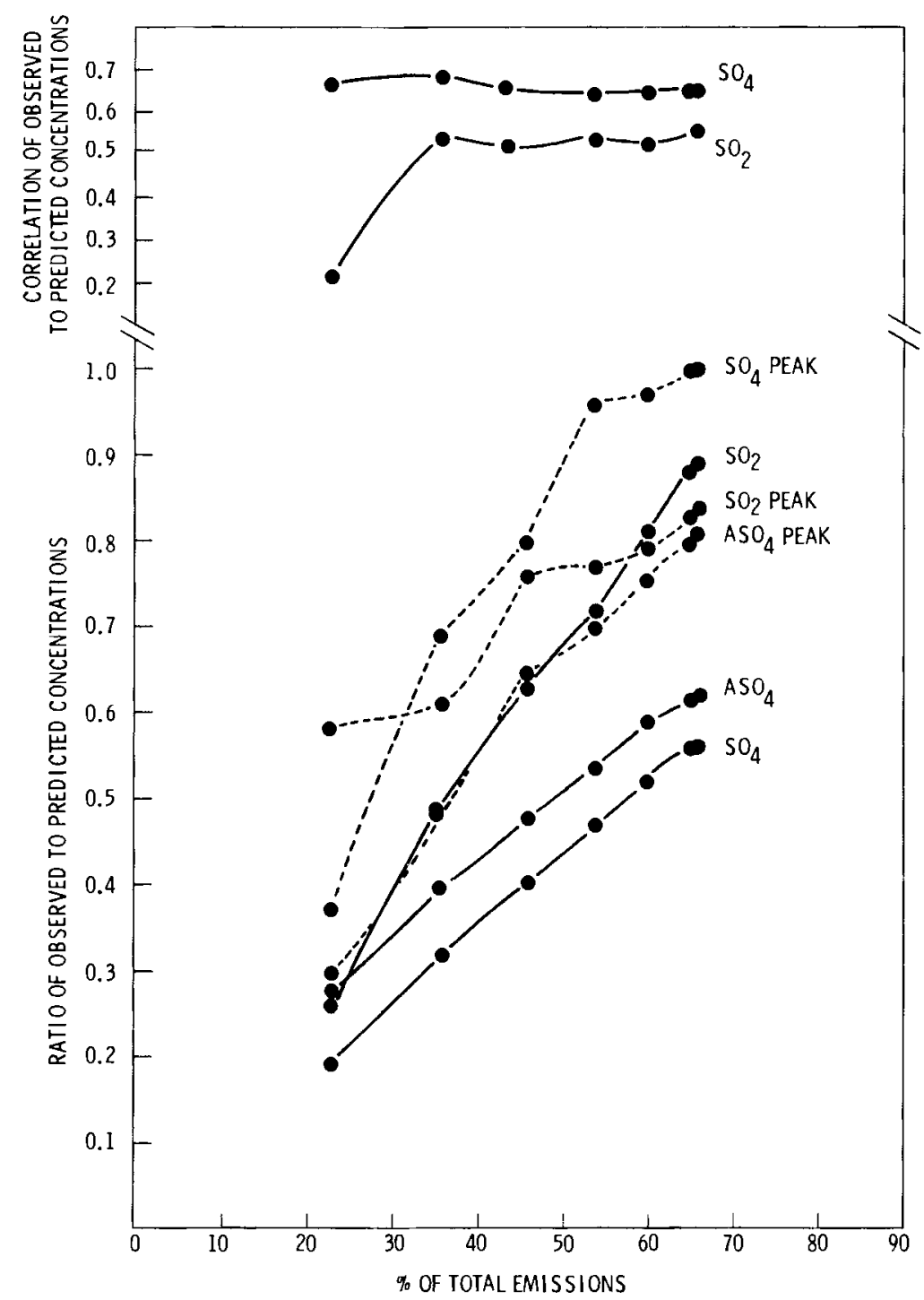

FIGURE 50. Correlation Coefficients and Ratios of Predicted to Observed Mean and Peak Concentrations (Sulfur Dioxide- $\mathrm{SO}_{2}$, Sulfate- $\mathrm{SO}_{4}^{-}$, Aqueous Sulfate- $\left.\mathrm{ASO}_{\overline{4}}\right)$

concentrations show agreement with the base case and observations, but results are deformed by local maximum concentrations near the grid-points. Further tests (Case 3b) modified calculations to try to eliminate the deformation of $\mathrm{SO}_{2}$ patterns near gridpoints and to predict only regional concentrations by not allowing diffusion from the sources during the first hour of transport to contribute to concentrations. Results indicated an additional improvement in predictions.

\section{Implications}

Successful long-term predictions of $\mathrm{SO}_{2}$, $\mathrm{SO}_{4}$, and aqueous $\mathrm{SO}_{4}^{=}$can be made with a less refined emissions inventory provided it is recognized that peak concentrations of $\mathrm{SO}_{2}$ are in general a smaller-scale phenomenon. Spatial averaging of emissions in grid or trajectory models does not appear to significantly disturb predicted monthly concentrations. The sensitivity of the model to local concentration peaks, especially in the 
TABLE 15. Maximum Air Concentrations $\left(\mu \mathrm{g} \mathrm{m}^{-3}\right)$ of $\mathrm{SO}_{2}$ and $\mathrm{SO}_{4}^{=}$near Northeast Ohio

\begin{tabular}{|c|c|c|c|c|}
\hline \multirow[t]{2}{*}{ Pollutant } & Station & \multirow[t]{2}{*}{$\begin{array}{c}\text { Total Observed } \\
\text { Air Concentrations } \\
\end{array}$} & \multicolumn{2}{|c|}{$\begin{array}{l}\text { Predicted Contribution } \\
\text { by Northeast Ohio } \\
\text { Sources Modeled As: }\end{array}$} \\
\hline & & & 1 Point & 3 Points \\
\hline \multirow[t]{2}{*}{$\mathrm{SO}_{2}$} & Erie, $P A^{(a)}$ & 30.13 & 7.22 & 7.53 \\
\hline & Warren, PA(b) & 22.27 & 4.88 & 4.41 \\
\hline \multirow[t]{2}{*}{$\mathrm{SO}_{4}=$} & Erie, PA & 10.22 & 0.96 & 0.99 \\
\hline & Warren, $\mathrm{PA}$ & 12.64 & 0.80 & 0.82 \\
\hline
\end{tabular}

(a) Approximately $175 \mathrm{~km}$ from the source (downwind)

(b) Approximately $275 \mathrm{~km}$ from the source (downwind)

primary pollutant, $\mathrm{SO}_{2}$, suggests that shortterm modeling would be more sensitive to spatial emissions averaging.

\section{References}

Dana, M. T., ed. 1979. The MAP3S Precipitation Chemistry Network: Second Periodic Summary Report (JuTy 1977-June 1978). PNL2829, Pacific Northwest Laboratory, Rich1and, WA.

MciNaughton, D. J. 1980. "Initial Comparisons of SURE/MAP3S Sulfur Oxide Observations with Long-Term Regional Model Predictions." Atmos. Environ. 14.

Powe11, D. C., D. J. McNaughton, L. L. Wendeli and R. L. Drake. 1979. A Variable Trajectory Model for Regional Assessments of Air Pollution from Sulfur Compounds. PNL2734, Pacific Northwest Laboratory, Richland, WA.

U.S. Environmental Protection Agency. 1976. 1973 National Emissions Report. EPA-450/ 2-75-007.

U.S. Federal Power Commission. 1976. Steam Electric Plant Air and Water Quality Control Data, 1973. FPC-S-253.
A Study of HTO Plume Washdown in an EightLayer Computer Model

W. E. Davis

Past work by Dana and Davis (1979) pointed out that a plume of tritiated water vapor, HTO, released in the lower troposphere and encountering a front could be washed down. A theoretical presentation was made linked with a number of vertical velocities showing the net vertical velocity of HTO expected in a typical warm or cold front. Dana and Davis's work was based on earlier results by Hales (1972a, 1972b) who presented theoretical work on the redistribution of a plume by a reversible gas process.

The model used for the case study here was a modified version of an eight-layer diabatic transport model developed by Davis and Wendell (1976). The modification in their model was in the calculation of net removal. A net vertical velocity, Wnet, was calculated based on the vertical motion encountered in the frontal system, W front, and the vertical motion caused by plume washdown, W washdown:

$$
w_{\text {net }}=w_{\text {front }}+w_{\text {washdown }}
$$


The $W$ front was calculated by diabatic motions accompanying the air parcel where the W washdown was calculated with respect to the HTO. When the integrated vertical movement indicated that the changes should be made in the layer the air parcel was in, a change in the layer was made as well as a change in the potential temperature of the HTO to the new layer's potential temperature. The latter change was necessary since the HTO in cases of precipitation would not follow the air parcel motions.

A short case study was made for April 1 to 15,1974 , based on a plume leaving St.
Louis, Missouri. Hourly releases were made and a time step of one hour was used in the advection step. Hourly precipitation was used to calculate washdown.

Results of comparing air concentrations of HTO with and without plume washdown were somewhat surprising in that very little if any differences in air concentrations could be detected close in to the source. At greater distances (see Figures 51 and 52), differences as great as an order of magnitude occurred in the calculation of surface air concentrations of HTO.

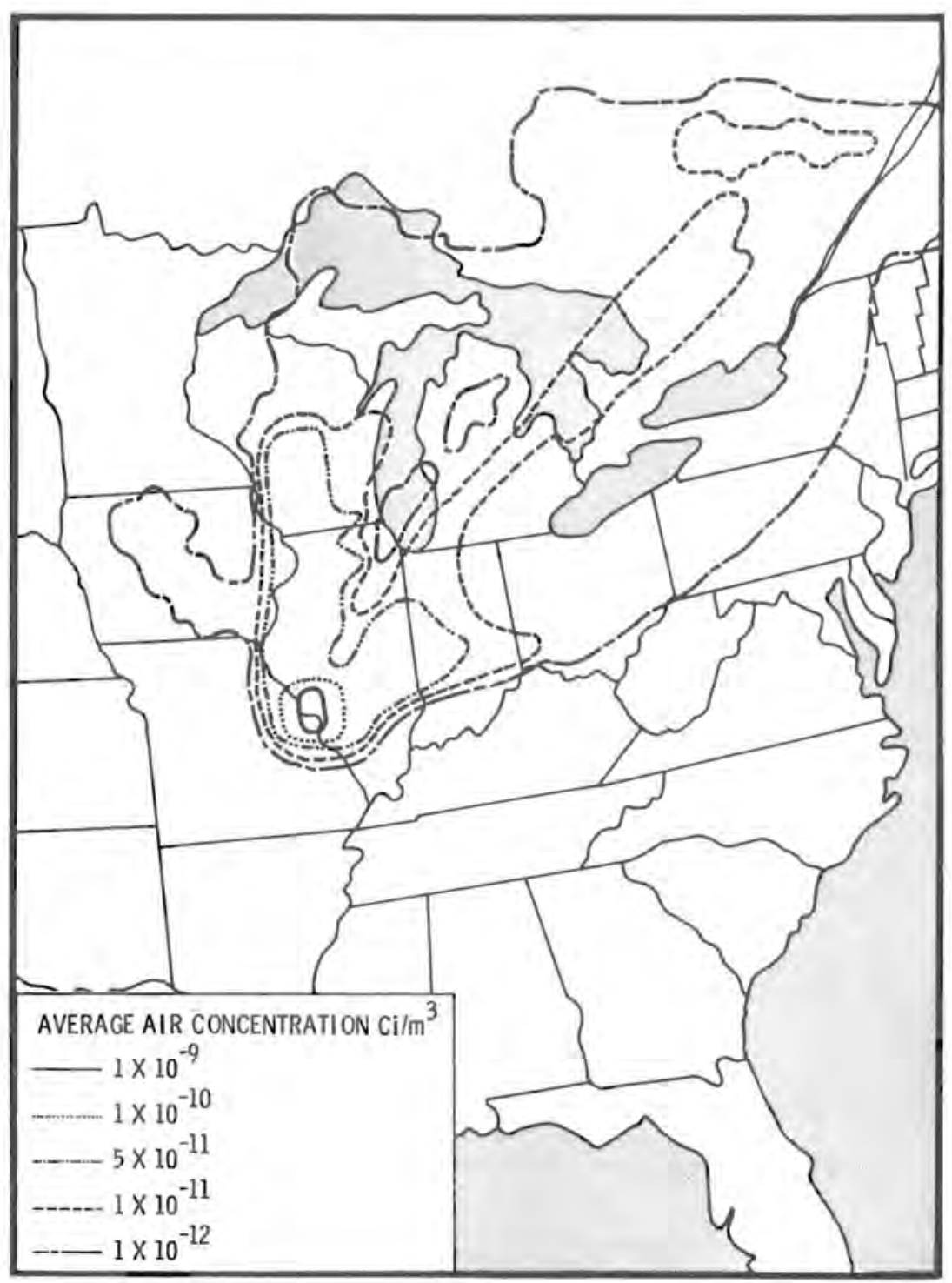

FIGURE 51. Average Air Concentrations $\mathrm{Ci} / \mathrm{m}^{3}$ With No Plume Washdown 


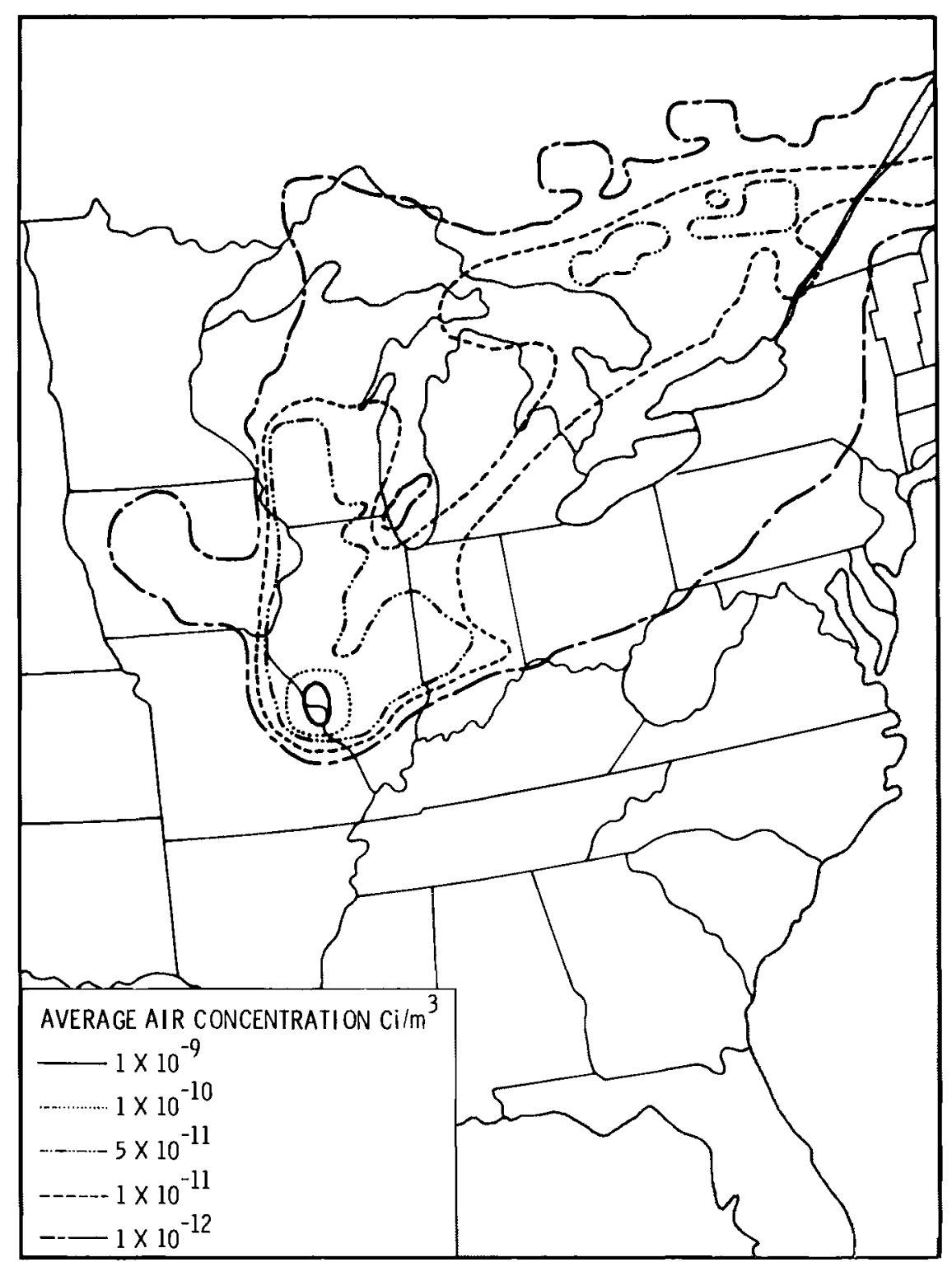

FIGURE 52. Average Air Concentrations $\mathrm{Ci} / \mathrm{m}^{3}$ With Plume Washdown

The conclusion of this study is that significant differences are predicted by the model for air concentrations. Further work should be done on the model to determine why there were no significant differences near the source.

\section{References}

Dana, M. Terry and W. E. Davis. 1979. "Redistribution of a Layer of HTO by Rainfall." In Pacific Northwest Laboratory Annual Re- port for 1978 to the DOE Assistant Secretary for Environment, Part 3, Atmospheric Sciences. PNL-2850 PT3, Pacific Northwest Laboratory, Richland, WA.

Davis, W. E. and L. L. Wendel1. 1976.

"Some Effects of Isentropic Vertical Motion Simulation in a Regional Scale Quasi Lagrangian Air Quality Model." Preprint from the Third Symposium on Atmospheric Turbulence Diffusion and Air Quality, October 19-22, 1976, Raleigh, NC. 
Hales, J. M. 1972a. "Fundamentals of the Theory of Gas Scavenging by Rain." Atmos. Environ. 6:635-659.

Hales, J. M. 1972b. Scavenging of Gaseous Tritium Compounds by Rain. BNWL-1659, Pacific Northwest Laboratory, Richland, WA.

A Method of Initialization of Wind Fields Over A Region for the Primitive Forecast Equations

C. H. Huang and R. L. Drake

\section{Introduction}

In numerical prediction, errors may grow rapidly in the initial stages of integration. This error growth can arise from imperfect initial conditions as a result of observational errors or improper data analysis, and from deficiencies in the forecasting model. Thus, one of the essential requirements for producing accurate predictions is to obtain high-quality initial conditions.

There are two basic approaches for generating initial conditions for forecasting models: static and dynamic initialization (Bengtsson 1975). Static initialization methods are based on the balance equation and the w-equation (Haltiner 1971) or on variational techniques (Haltiner, Sasaki and Baker 1976); dynamic initialization methods are based on the prognostic dynamic equations. Dynamic initialization consists of the following steps (Miyakoda, Strickler and Cheludzinaki 1978): 1) static initialization is used to obtain balanced wind fields, and 2) these balanced wind fields are used to generate dynamic initialization through the use of an iterative Eulerbackward scheme applied to the dynamic equations. Using the dynamically determined initial fields allows the dynamic equations to be used in a predictive mode. However, when new data are inserted into the predictive equations, a numerical "shock" may occur in the dynamic model. Thus, the procedure of dynamic initialization must be reapplied to the system.

As we have noted, there are two major techniques used to generate balanced winds: the balance equation approach and the use of variational techniques. In order to avoid the creation of fictitious data, Nitta (1969) and Nitta and Hovermale (1969) used idealized atmospheric data obtained from an extended forecast based on the National Meteorological Center (NMC) model. They then used geopotential heights to obtain the rotational components of the wind field from the balance equation. However, we feel that this indirect method of arriving at rotational wind fields is ineffective because the accuracy of the fields is strongly dependent on proper specification of geopotential heights and boundary conditions. This proper specification is often difficult to realize.

Haltiner, Sasaki and Baker (1976) used a variation approach to obtain balanced wind fields. However, Liu and Goodin (1976) have observed that the wind fields computed by this method often differ significantly from data recorded by observational stations. These differences are the result of the strong dependence of the computed fields on the Lagrangian multipliers $(\lambda)$, which tend to smooth the wind fields too severely in data-poor areas. Variational methods may also be too time-consuming since one has to solve a Poisson equation for the multipliers, $\lambda$.

In the current study, a direct method developed by Huang and Drake (1979) is used to obtain a three-dimensional, mass-consistent wind field over the northeastern United States and southeastern Canada. We feel this model is more flexible and efficient than the other balanced wind field models because of the use of a terrain-following coordinate system and the rapidity of convergence of the numerical scheme. This model can also be used to update prediction models (the insertion of new data into the dynamic equations) with greater ease and with the creation of fewer instabilities than the other wind field schemes. The relationships and differences between the present method and the indirect methods are illustrated in Figure 53 .

\section{Wind Field Interpolation Scheme}

A wind field interpolation scheme developed by Barnes (1964) is used to transfer wind data from observations stations to grid points of the domain of interest. This interpolation scheme uses the techniques of surface-fitting and weighted averages. For wind fields the Barnes scheme is expressed in the following manner:

$$
v(x, y)=\frac{\sum_{i=1}^{n} v_{i}(x, y) \exp \left[-y_{i}^{2} / 4 k\right]}{\sum_{i=1}^{n} \exp \left[-y_{i}^{2} / 4 k\right]},
$$




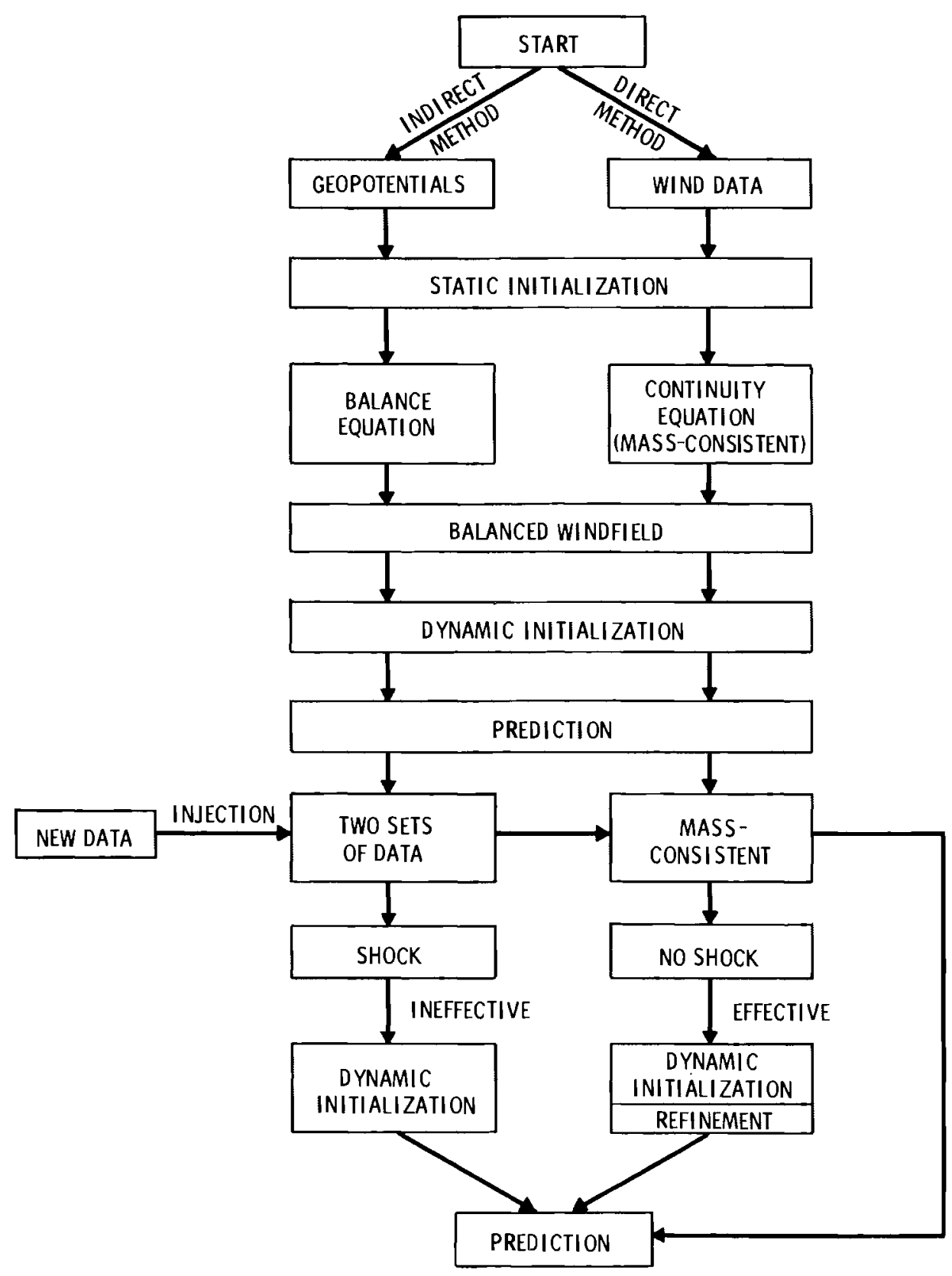

FIGURE 53. Methods of Initialization for Primitive Forecast Equations

where $n$ is the number of observing stations, $v_{i}$ the wind at station $i, y_{i}$ the distance between the station $i$ and a grid point, and $k$ a weighting factor. The value of $k$ depends on the density of the data and can be estimated from

$$
\frac{\mathrm{R}^{2}}{4 \mathrm{k}}=-\ln \varepsilon \equiv E \text {, }
$$

where $R$ is the radius of influence of the weighting factor. In general, $R$ should be chosen greater than $\bar{d}$, the average distance between data points at the observing sites. Once the radius of influence and $E$ (the degree of influence of data points within the radius $R$ ) are specified, the parameter $k$ can be evaluated from Equation (2). The wind speed at each grid point can then be inter- 
polated from the surrounding observed data by Equation (1). The choice of $E$ and $R$ may be somewhat arbitrary, but they are dependent upon the terrain in the domain of computation, the location of the observation stations, and the representativeness and quality of data collected at the stations. The wind field generated by this objective analys is scheme serves as initial data for use in the wind field model.

\section{The Wind Field Model}

A generalized, direct method for the adjustment of wind fields was developed by Huang and Drake (1979). This technique computes mass-consistent wind fields over complex terrain in a terrain-following coordinate system using a "modified" Newton's method (Huang and Nickerson 1974). Because the technique is a direct method, computational time is shorter than for the indirect variational techniques of Sasaki (1958) and Sherman (1978). Software requirements of the present model are also less than the indirect methods.

The choice of a particular conformal coordinate system may be immaterial. However, for the solution of the continuity equation for a divergence wind field we used the well-known sigma coordinate system. For this system, the defining difference equation for the "modified" Newton method is given by

$$
u_{\alpha}^{n+1}(i, j, k)=u_{\alpha}^{n}(i, j, k)-w_{\alpha} \frac{f^{n}}{\left(\frac{\partial f}{\partial u_{\alpha}}\right)_{i, j, k}^{n}},
$$

where $\alpha=1,2,3$ represent the velocity components at the $i, j, k$ grid point and $n$ represents the $n$th iterate. The vertical coordinate is given in terms of

$$
\sigma=\frac{z-z_{S}(x, y)}{H(x, y)-z_{S}(x, y)},
$$

where $H(x, y)$ is the height of the upper boundary of the computational doma in above the terrain and $z_{s}(x, y)$ is the terrain elevation above some reference level. The dependent variables in Equation (3) are defined by

$$
\begin{aligned}
f & =\frac{\partial u_{1}}{\partial x}+\frac{\partial u_{2}}{\partial y}+\frac{\partial u_{3}}{\partial \sigma}, \\
u_{1} & =\left(H-z_{s}\right) \tilde{u}_{1}, \\
u_{2} & =\left(H-z_{s}\right) \tilde{u}_{2}, \\
u_{3} & =\left(H-z_{s}\right) \dot{\sigma},
\end{aligned}
$$

where $\left(u_{1}^{\tilde{1}}, \tilde{u_{2}}, \dot{\sigma}\right)$ are the velocity components in the $(x, y, \sigma)$ system, $f$ the divergent wind field, $\omega_{\alpha}$ a relaxation factor, and $\partial f / \partial u_{\alpha}$ the Fréchet derivative of $f$. The boundary conditions corresponding to Equations (3) and (5) are

$$
\begin{aligned}
& \sigma=1, \text { and } \dot{\sigma}=0 \text { at the upper boundary, } \\
& \sigma=\dot{\sigma}=0 \quad \text { at the lower boundary. }
\end{aligned}
$$

The use of a o-coordinate in place of a $z$-coordinate permits an easier specification of wind fields over complex terrain. The iterative solution of Equation (3) over the doma in of integration produces the adjusted wind field that can be used in the initialization of primitive forecast models.

Case Study: Northeastern United States and Southeastern Canada

The wind field model described in the previous section was applied to a specific flow field over the portion of northeastern United States and southeastern Canada shown within the heavy-faced boundary in Figure 54 . This boundary outlines the MAP3S (Multistate Atmospheric Power Production Pollution Study of the Department of Energy/ Environmental Protection Agency) computational domain that extends approximately $2400 \mathrm{~km}$ along the abscissa and $1360 \mathrm{~km}$ along the ordinate. The horizontal grid consists of $12 \times 8$ squares with an average length and width of $170 \mathrm{~km}$; the actual size varies with latitude. This particular grid length (or width) is equal to half the length of the AMMC northern hemisphere grid, shown by dotted 1 ines outside the MAP3S domain in Figure 54. The upper-air National Weather Service stations and the smoothed terrain elevation contours are also shown in Figrue 54. The vertical grid used in the wind field computations consists of five, equally spaced levels in the $\sigma$-coordinate system, with the top boundary defined by $H(x, y)=3 \mathrm{~km}$.

The example wind field calculations were carried out for August 1, 1977 at $0000 z$ time. The wind data at each station shown in Figure 54 were linearly interpolated to each o-surface in the vertical and were horizontally (constant o-surfaces) interpolated using Equations (1) and (2). Figure 55 shows a plot of the vertically-interpolated data corresponding to the upper-air stations at level $2(\sigma=0.25)$, while Figure 56 gives the horizontally interpolated initial wind field on the same level.

The adjusted wind field at level 2 after the 50th iteration of Equation (3) is shown in Figure 57. Although the general flow 


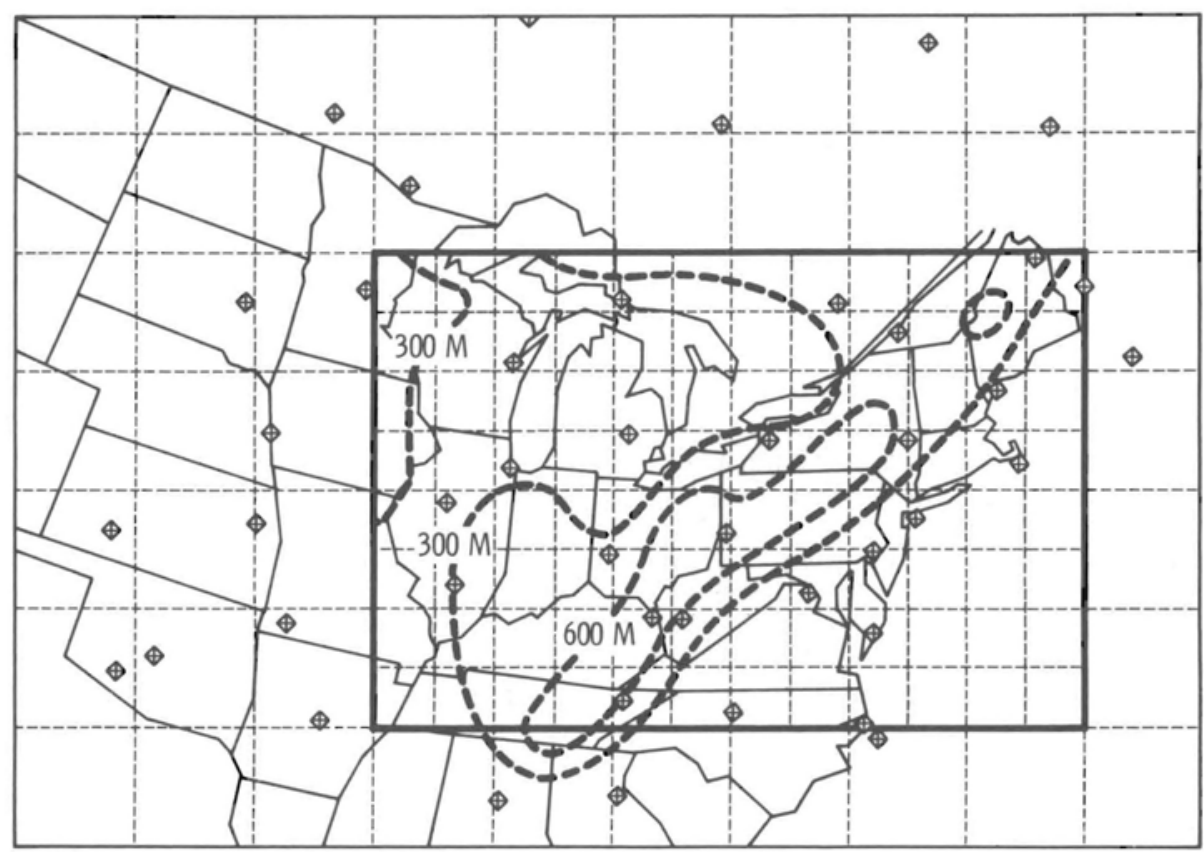

FIGURE 54. NMC Grid System, MAP3S Grid System, Wind Stations ( $\oplus$ ), and Terrain Elevation (----) Over the Domain of Computation

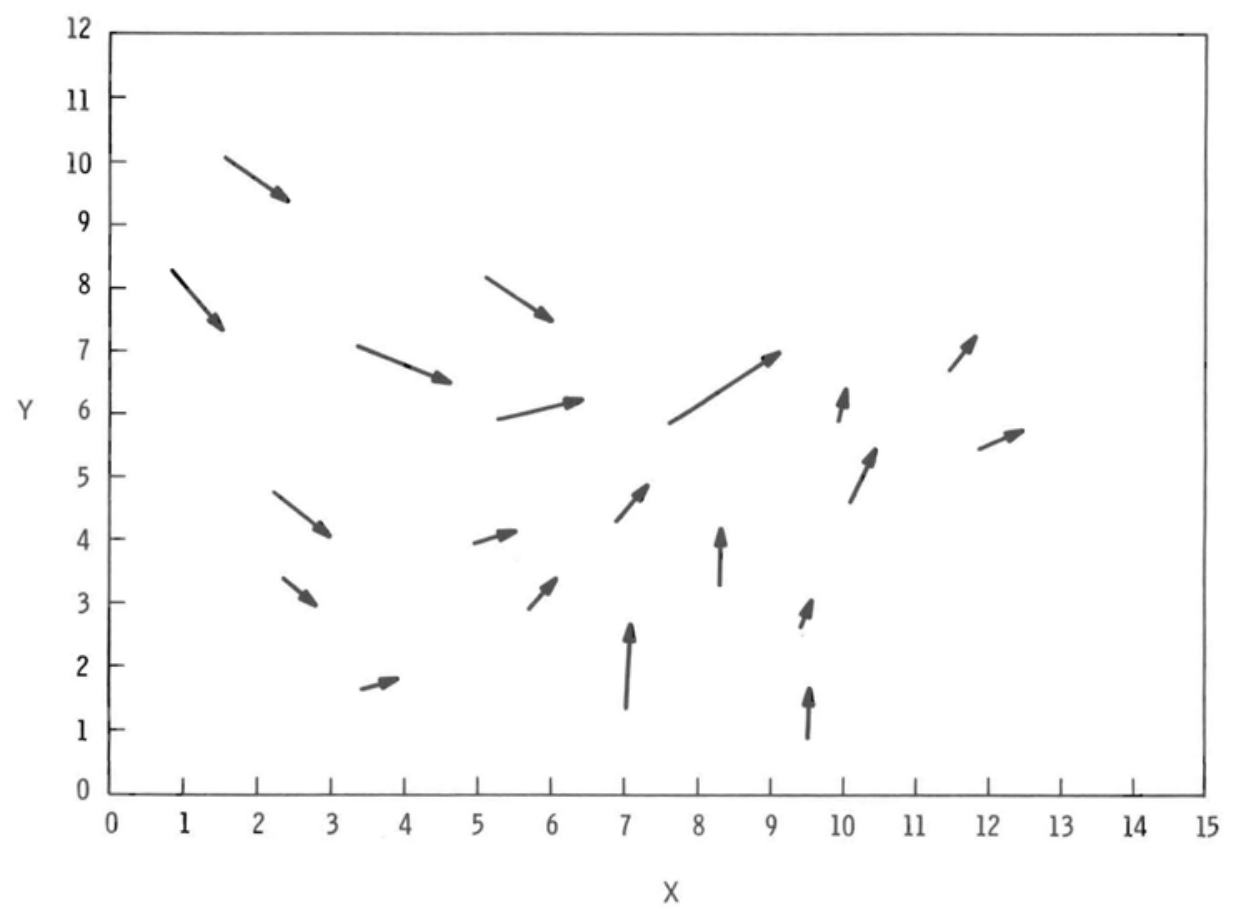

FIGURE 55. Initial Wind Data Obtained from Upper-Air Soundings at Level Two, $\alpha=0.25$ 


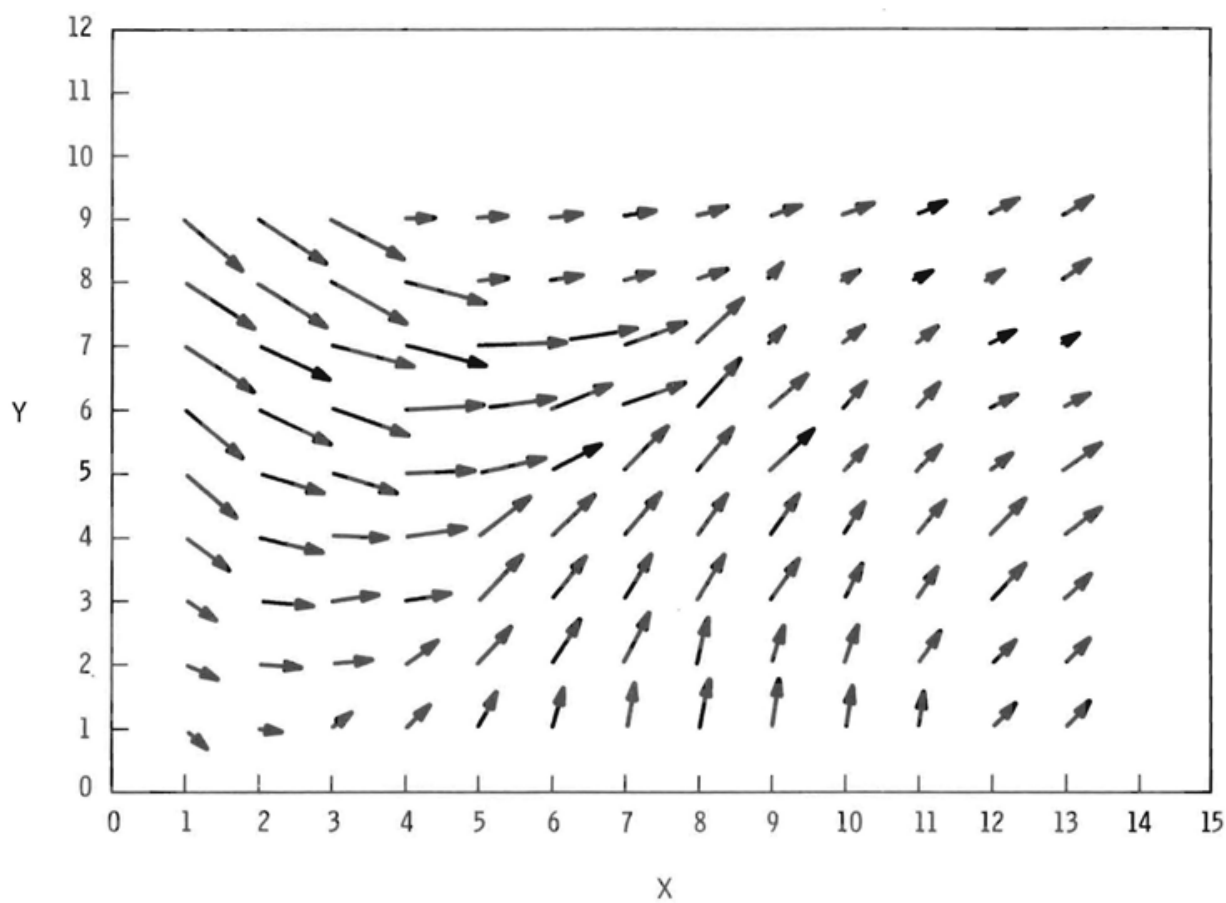

FIGURE 56. Objective Wind Field Corresponding to Figure 55

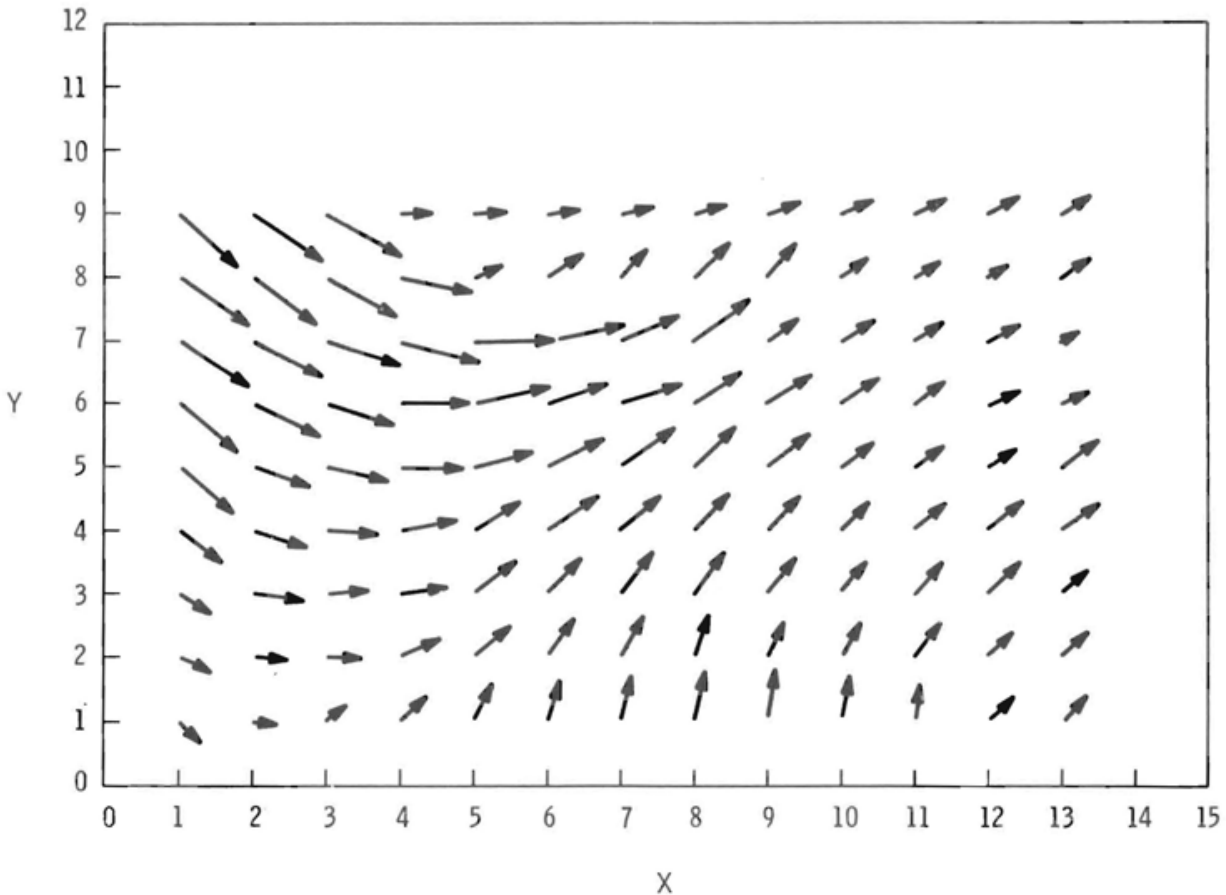

FIGURE 57. Mass-Consistent Wind Field Corresponding to Figure 56 
characteristics are similar in Figures 56 and 57, the field in Figure 57 conserves mass and is much smoother. The smoothness of the wind field in Figure 57 compared to Figure 56 can be seen in the neighborhood of grid point $(8,7)$ and along a trajectory starting from grid point $(9,1)$. Similar smoothing of wind fields off the southeastern United States was obtained by Endlich (1967). For the present example we demonstrated that our direct method removed the spurious divergence contained in the original wind field; our calculations reduced the maximum divergence by a factor of $10^{-13}$.

\section{Conclusions}

In the present study we use a direct method of obtaining mass-consistent wind fields that can be used to initialize primitive forecast equations. This method is simpler and more effective than indirect methods based on the balance equation and the w-equation, or certain variational methods. Using the direct method for initialization and reinitialization of dynamic equations also reduces induced instabilities as compared with the current indirect methods. The direct method is especially suited for use in mesoscale and regional modeling over data-sparse regions.

\section{Acknowledgment}

The authors thank D. J. McNaughton of Pacific Northwest Laboratory for his assistance in retrieving the wind data from a magnetic tape.

\section{References}

Barnes, S. L. 1964. "A Technique for Maximizing Details in Numerical Weather Map Analysis." J. Appl. Meteor. 3:396-409.

Bengtsson, L. 1975. "Four-Dimensional Assimilation of Meteorological Observations." GARP Publication Series No. 15, Joint Organizing Committee.

Endlich, R. M. 1976. "An Iterative Method for Altering the Kinematic Properties of Wind Fields." J. Appl. Meteor. 6:837-844.

Haltiner, G. J. 1971. Numerical Weather Prediction. Wiley, New York, NY.

Haltiner, G. J., Y. K. Sasaki and L. H. Baker. 1976. "A Variational Procedure for Obtaining Global Balanced Winds." The GARP Programme on Numerical Experimentation.

Rep. 11. Proceedings of the JOC Study Group
Conference on Four-Dimensional Data Assimi1ation, pp. 189-223, November 17-21, 1975, Paris.

Huang, C. H. and E. C. Nickerson. 1974. "Stratified Flow Over Non-Uniform Surface Conditions: Mixing Length Model." Boundary Layer Meteorology. 5:395-417.

Huang, C. H. and R. L. Drake. 1979. "A Direct Method of Adjusting Wind Field Over Complex Terrain." Fourteenth Conference on Agriculture and Forest Meteorology and Fourth Conference on Biometeorology, pp. 102-104, April 2-6, 1979, Mínneapolís, MN.

Liu, C. and W. Goodin. 1976. "An Iterative Algorithm for Objective Wind Field Analysis." Monthly Weather Rev. 194.

Miyakoda, K., R. F. Strickler and J. Cheludzinaki. 1978. "Initialization for the Primitive Forecast Equation." Monthly Weather Rev. 97:652-658.

Nitta, T. 1969. "Supplement to the Experimental Forecasts from Different Initial

Data." Meteor. Soc. Jap. 47:407-410.

Nitta, T. and J. B. Hovermale. 1969. "A Technique of Objective Analysis and Initialization for the Primitive Forecast Equation." Mon. Weather Rev. 97:652-658.

Sasaki, Y. 1958. "An Objective Analysis Based on the Variational Method." J. Meteor. Soc. Japan. 36:77-88.

Sherman, C. 1978. "A Mass-Consistent Model for Wind Fields Over Complex Terrain." $\mathrm{J}$. App1. Meteor. 17(3):312-319.

Back Trajectories Using an Eight-Layer Diabatic Model

\section{W. E. Davis}

Davis and Wendel1 (1976) performed a study of vertical transport with an eightlayer diabatic model that operated on the calculation of forward trajectories based on isentropic considerations. With increasing interest in explaining acid rain, back trajectories in the model could identify probable source regions for pollutants in rain water. Davis and Wendell's technique for calculating forward trajectories was reversed to calculate back trajectories in an attempt to identify source regions in a case study. However, when the trajectory technique was modified to run back 
trajectories, it failed. The method failed because the back trajectories indicated that the parcel being tracked had "grounded out," which meant that the potential temperature of the parcel was less than the potential temperature in the lowest layer of the model. For this reason, a new technique was needed if back trajectories in the vicinity of frontal storms were to be constructed. Such a technique is described here.

The new model uses the same basic framework as deveToped by Davis and Wendel1 (1976) a)though an alteration has been made in the model to avoid the errors that originated when using the model in the back-trajectory mode. Basically the model consists of eight layers using gridded wind, temperature and mixing ratio of fields to calculate the horizontal and vertical movement. The model also includes an estimate of the diurnal variations of temperature within a layer.

A test for a near-frontal situation was made in the original mode with the resuTt that the model transported an air parcel from the cold sector into the warm sector where the model terminated the trajectory because the parcel had "grounded out." This "grounding out" occurred because the model used bilinear interpolations of winds at four grid points in the same layer (Figure 58). The dashed lines in Figure 58 indicate the back trajectory using all four winds in the layer for computation, whereas the dotted line indicates using only the

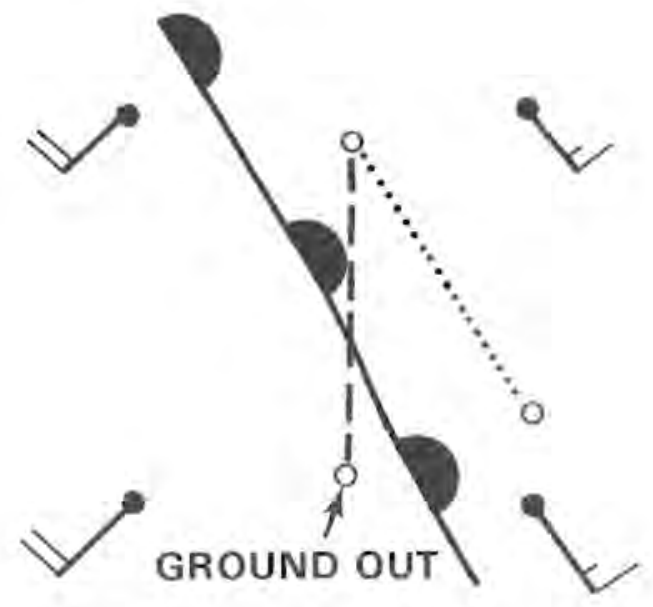

FIGURE 58. Back Trajectories in a Near-Frontal Situation (Dotfed Line Indicates What Trajectory Should Look Like; Dashed Line Shows Calculated Trajectory) winds from Tayers with the same potential temperature. Davis and Wendell also used a stairstep approach whereby the transport winds were used from the layer in which the parcel was embedded. As the parcel changed layers, Davis and Wende11 used the new layer to calculate new wind speeds.

In the new approach, layer winds used to transport the parcels are calculated separately from the grid points that have potential temperatures closest to that of the parcel. This technique means that in a steeply sloped isentropic surface that all four winds could potentially be in different 1ayers. If no such layer exists at one or more of the corner winds, the remaining winds are used (Figure 59). Figure 59 shows the difference between the two techniques. only two wind speeds are used in this case to calculate the back trajectory.

The model has been used in three studies, one by McNaughton and Orgill(a) for back trajectories with no vertical motions from a region of elevated high sulfates (Figure 60), the second for an acid rain case, August 27, 1977. The result of the second study compared favorably with a hand analysis for the same time period. The third test (Figure 61) was run in the vicinity of

(a) McNaughton, D. J. and M, M. Orgill, "A Synoptic Case Study of Elevated Layers of High Airborne Sulfate Concentrations." To be published in Monthiy Weather Review, 1980.

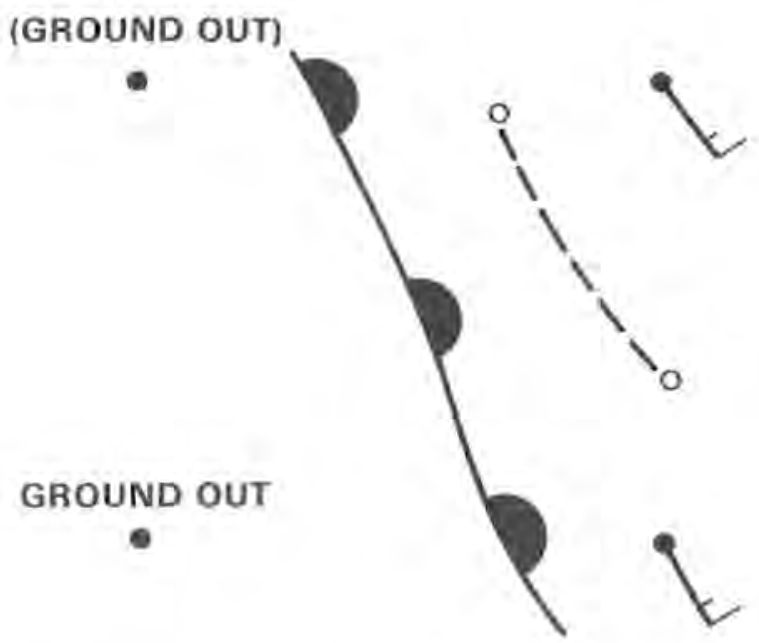

FGURE 59. Calculated Back Trajectory Using Updated Model (Dashed Line Shows Calculated Trajectory) 


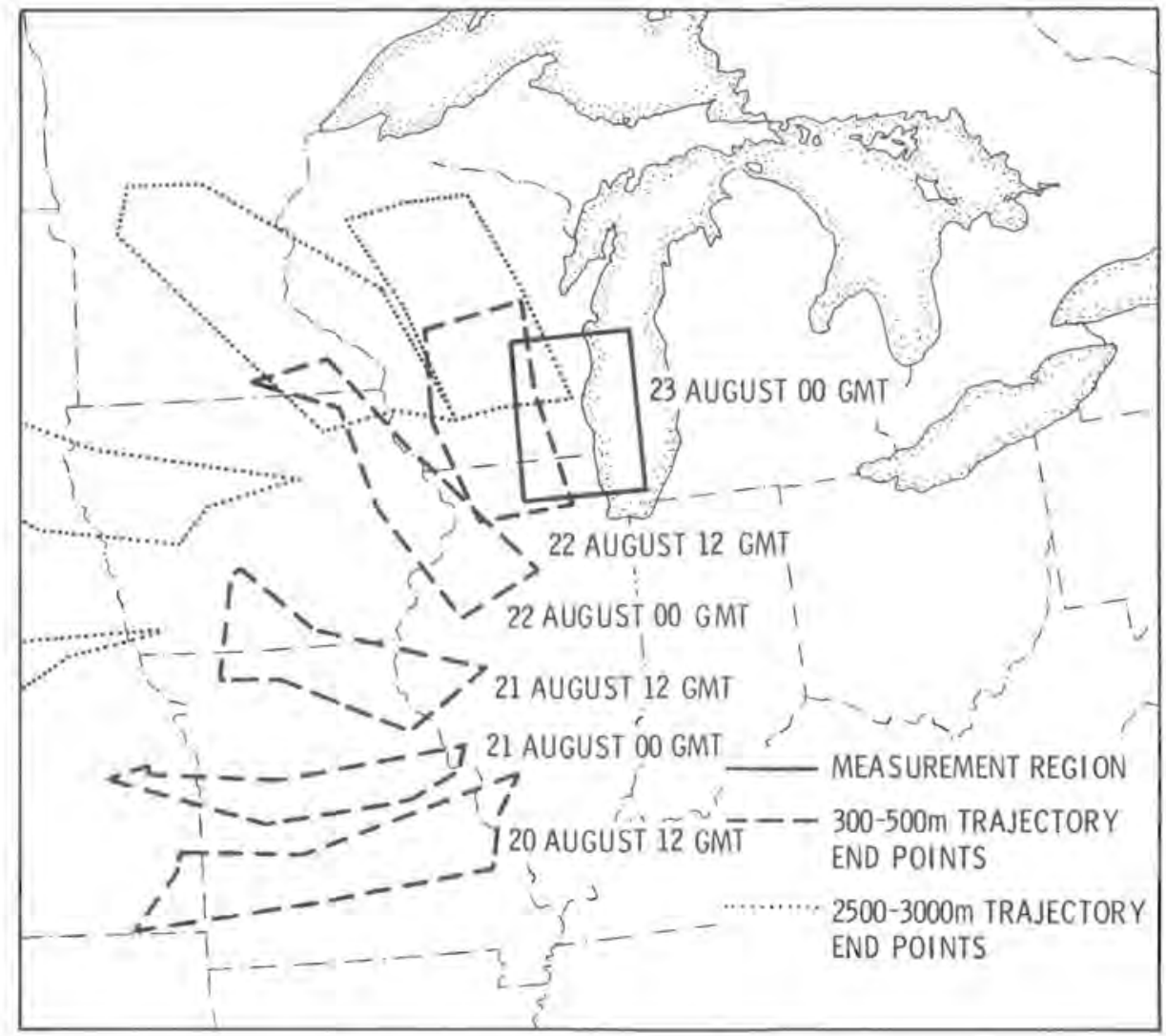

FIGURE 60. Constant Level Back Trajectories

a cold front with vertical motions. No problems were encountered with trajectories "grounding out".

However, many other problems exist in tracking back trajectories of pollutants to sources. One of these, wind shear with height, can be seen in Figure 60 . A singlelayer back-trajectory model does not include vertical wind shear. Another problem is mixing-along-the-path. When following back trajectories, the diurnal variation of vertical mixing can redistribute the pollutant over a large extent of the lower troposphere. This redistribution because of mixing over several layers can cause severe complications. If one were to track each layer over which the pollutant is redistributed, the number of trajectories required to encompass the ensemble would become large. This is especially true for more than one cycle of mixing. An example of this is where redistribution over all eight layers of the model causes an increase from an original eight back trajectories to 64 back trajectories.

\section{Reference}

Davis, W. E, and L. L. Wende11. 1976. "Some Effects of Isentropic Vertical Motion Simulation in a Regional Scale QuasiLagrangian Air Quality Model." Presented at the Third Symposium on Atmospheric Turbutence Diffusion and Air Quality, October 19-22, 1976, Raleigh, NC. 


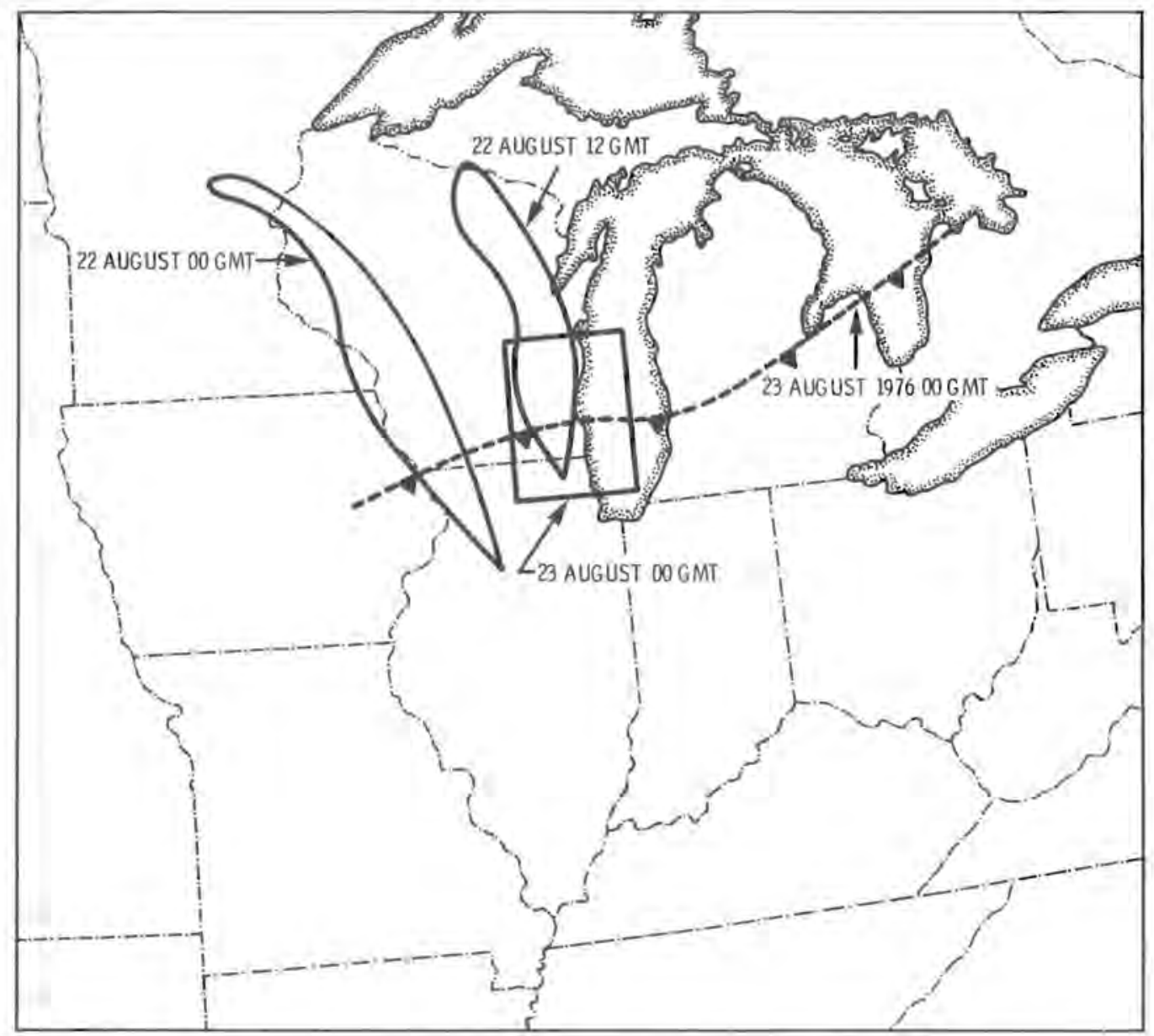

FIGURE 61. Back Trajectories with Vertical Motions, The original starting points were in the second layer (300 to $500 \mathrm{~m}$ above surface)

Modeling Evidence of Incloud Transformation of Sulfur Dioxide to Sulfate

\section{J. McNaughton and B. C. Scott}

\section{Introduction}

Early tests (McNaughton 1980) of a regional model describing the transformation, transport and removal of pollutants indicated satisfactory concentration predictions of airborne sulfur oxides, but levels of sulfur in precipitation were underpredicted. Results of simulations are presented that test the hypothesis that an enhanced incloud aqueous-phase transformation of sulfur dioxide to sulfate might increase the prediction of the precipitation concentrations of sulfate without detrimental1y affecting the predicted airborne concentrations of sulfur.

\section{Background}

The Model. Predictions over the northeast United States were made with a regional transport model (Powel1 et a1. 1979). Concentration calculations were made hourly for grid elements approximately $35-\mathrm{km}$ square using mass conservation equations for sulfur dioxide and sulfur sulfate coupled through a linear transformation term. Other terms in the equations allowed for caiculation of wet and dry removal.

Results are presented for two cases. Case 1 is identical to Case 2 except that Case 1 includes an incloud $\mathrm{SO}_{2}$ to $\mathrm{SO}_{4}=$ transformation rate of $10 \% \mathrm{~h}^{-1}$ during precipitation events. The chemical transformation rate for Case 2 is taken 0 be $2 \% \mathrm{~h}^{-1}$ during the day and $0.25 \% \mathrm{~h}^{-1}$ a night (McNaughton 
1980). Simulations used an emissions inventory consisting of $65 \%$ of expected $\mathrm{SO}_{2}$ emissions on the grid, which is thought to represent major features of sulfur oxide patterns (McNaughton 1979).

Initial Results. Case 2 simulations indicated satisfactory predictions of air concentrations of sulfur oxides but deficiencies in sulfur removed by precipitation. A weak inverse relationship between precipitation amount and airborne $\mathrm{SO}_{4}=$ concentration was also predicted to exist although such a relationship was not evident in the observed air concentration data. Thus, concentration results were obtained in which $\mathrm{SO}_{x}$ removal by precipitation as indicated by $\mathrm{S}_{4}=$ concentration in the precipitation was underpredicted but the net removal of $\mathrm{SO}_{4}$ aerosols seemed to be overpredicted. Simultaneously, airborne $\mathrm{SO}_{\mathrm{x}}$ concentrations were satisfactorily predicted. One way to increase sulfur in the precipitation without further overpredicting subcloud scavenging and without simultaneous disturbance to the air concentration fields was to introduce more mass incloud by advection or incloud transformation. The results of the test of incloud transformation follow.

Incloud Transformation. Scott and LauTainen (1979) reviewed characterizations of sulfur oxides in cloud environments to study incloud conversion and precipitation scavenging. They propose that incloud oxidation rates of $\mathrm{SO}_{2}$ must be on the order of $10 \% \mathrm{~h}^{-1}$ in order for the sulfur produced by aqueous-phase conversion to exceed the sulfur input from subcloud sulfate aerosols. This incloud conversion rate of $10 \%$ of $h^{-1}$ for $\mathrm{SO}_{2}$ was tested to supplement the sulfate mass available for scavenging.

\section{Results}

Monthly average air concentrations and deposition for $\mathrm{SO}_{2}$ and $\mathrm{SO}_{4}$ were simulated for August and 0ctober 1977.

The desired effect of increasing precipitation sulfur is shown by increases of approximately a factor of 2 in $\mathrm{SO}_{4}$ removed by precipitation. Table 16 compares observed and predicted values of sulfur deposition with base case underprediction and the changes produced by considering incloud transformation of $\mathrm{SO}_{2}$ (Case 1). Case 1 predictions are slightly too large if the limited emissions inventory is considered indicating that a slightly smaller transformation rate is required.

Table 17 depicts the impact of incloud transformation modifications through the use

TABLE 16. Monthly Wet Deposition of Sulfur (as $\mathrm{SO}_{4}^{=}$in $\mathrm{gm}^{-2} \mathrm{hr}^{-1}$ )

\begin{tabular}{|c|c|c|c|c|c|c|}
\hline \multirow[b]{2}{*}{ Station } & \multicolumn{3}{|c|}{ August 1977} & \multicolumn{3}{|c|}{ October 1977} \\
\hline & Observed $(a)$ & Case 1 & Case 2 & Observed & Case 1 & Case 2 \\
\hline Whiteface, NY & 5.96 & 6.90 & 4.83 & 3.45 & 2.03 & 1.30 \\
\hline State College, PA & 5.35 & 6.71 & 3.67 & 4.28 & 4.34 & 1.47 \\
\hline Charlottesville, VA & 5.02 & 6.92 & 3.41 & 0.69 & 0.66 & 0.31 \\
\hline Ithaca, NY & 1.56 & 0.59 & 0.49 & - & - & - \\
\hline Mean $\left(\frac{\text { Predicted }}{\text { Observed }}\right)$ & & 1.04 & 0.62 & & 0.85 & 0.39 \\
\hline
\end{tabular}

(a) Multistate Atmospheric Power Production Pollution Study (MAP3S) Precipitation Chemistry Network data 
TABLE 17. Summary of Model Evaluation Statistics

\begin{tabular}{|c|c|c|c|c|c|c|c|c|}
\hline \multirow[b]{3}{*}{ Comparison Statistics } & \multicolumn{4}{|c|}{ Ambient $\mathrm{SO}_{4}^{\bar{z}}$ Concentration } & \multicolumn{4}{|c|}{ Ambient $\mathrm{SO}_{2}$ Concentration } \\
\hline & \multicolumn{2}{|c|}{ August 1977} & \multicolumn{2}{|c|}{ October 1977} & \multicolumn{2}{|c|}{ August 1977} & \multicolumn{2}{|c|}{ October 1977} \\
\hline & Case 1 & Case 2 & Case 1 & Case 2 & Case 1 & Case 2 & Case 1 & Case 2 \\
\hline Mean Observed ${ }^{(a)}$ & & & & & & & & \\
\hline Concentration $\left(\mu \mathrm{g} \mathrm{m}^{-3}\right)$ & 10.25 & 10.25 & 6.24 & 6.24 & 14.97 & 14.97 & 21.70 & 21.70 \\
\hline $\begin{array}{l}\text { Mean Predicted } \\
\text { Concentration }\left(\mu \mathrm{g} \mathrm{m}^{-3}\right)\end{array}$ & 8.09 & 5.73 & 5.74 & 4.46 & 11.56 & 1329 & 1185 & 1292 \\
\hline $\begin{array}{l}\text { Correlation of Observed to } \\
\text { Predicted Concentration }\end{array}$ & 0.65 & 0.65 & 0.39 & 0.59 & 0.57 & 0.56 & 0.75 & 0.76 \\
\hline Variance in Observed Data & 3.41 & 3.41 & 1.82 & 1.82 & 54.75 & 54.75 & 155.41 & 155.41 \\
\hline Variance in Predicted Data & 20.52 & 20.29 & 2.58 & 1.66 & 38.92 & 44.66 & 39.54 & 39.96 \\
\hline $\begin{array}{l}\text { Maximum Observed } \\
\text { Concentration }\left(\mathrm{\mu g} / \mathrm{m}^{3}\right)\end{array}$ & 14.6 & 14.6 & 8.92 & 8.92 & 30.13 & 30.13 & 69.17 & 69.17 \\
\hline $\begin{array}{l}\text { Maximum Predicted } \\
\text { Concentration at Monitoring } \\
\text { Sites }\left(\mathrm{\mu g} / \mathrm{m}^{3}\right)\end{array}$ & 21.83 & 14.9 & 8.74 & 7.31 & 23.35 & 25.20 & 23.99 & 45.69 \\
\hline $\begin{array}{l}\text { Frequency of Concentrations } \\
\text { Within a Factor of }(\%) \text { : }\end{array}$ & & & & & & & & \\
\hline 2 & 70 & 59 & 100 & 89 & 73 & 78 & 62 & 62 \\
\hline 3 & 88 & 77 & 100 & 99 & 90 & 86 & 79 & 89 \\
\hline
\end{tabular}

of model evaluation statistics. Results show the most significant changes between cases are the increase in the maximum $\mathrm{SO}_{\overline{4}}$ concentration in August and the change in the correlation between observed and predicted $\mathrm{SO}_{4}=$ values in 0ctober. Each effect is caused by an overprediction of $\mathrm{SO}_{4} \overline{\text { in the }}$ area of maximum $\mathrm{SO}_{2}$ emissions.

Data in the tables illustrate differences between August and October results indicating the need for different responses to convective storms or large-scale synoptic storms.

\section{Conclusions}

Simulating enhanced incloud transformation of $\mathrm{SO}_{2}$ to $\mathrm{SO}_{4}$ appears to be a means for reducing the discrepancy between model predictions and observations; that is, significant increases in sulfur oxide concentrations in precipitation can be produced without drastically changing ground-level air concentrations of $\mathrm{SO}_{\mathrm{X}}$. Initial tests suggest that an incloud conversion rate of $10 \% \mathrm{~h}^{-1}$ may be close to the proper magnitude, but in general, slightly overpredicts water and air concentrations of $\mathrm{SO}_{\mathrm{x}}$.

\section{References}

Mcivaughton, D. J. 1979. "Emission Source Specification in a Regional Pollutant Transport Mode1." Presented at the World Meteorological Organization Symposium on Long-Range Transport of Pollutants, Sophia, Bulgaria.

McNaughton, D. J. 1980. "Initial Comparisons of SURE/MAP3S Sulfur 0xide Observations with Long-Term Regional Model Predictions." Atmos. Environ. 14.

Powe 11, D. C., D. J. McNaughton, L. L. Wendell and R. L. Drake. 1979. A Variable Trajectory Model for Regional Assessments of Air Pollution from Sulfur Compounds. PNL-2734, Pacific Northwest Laboratory, Richland, WA.

Scott, B. C. and N. S. Laulainen. 1979. "On the Concentration of Sulfate in Precipitation." J.Appl. Meteor. 18:138-147. 

Fission and Fusion 


\section{FISSION AND FUSION}

- Air Pollution Dry Deposition: Radioisotopes as Particles and Volatiles

- Particle Resuspension and Translocation

- Fallout Rates and Mechanisms

- ALE Climatology

The major pollutants of concern from the nuclear energy industry are long-lived particles (i.e., plutonium and other radionuclides) and waste heat and water vapor from power-plant cooling systems. Since these pollutants may affect living species and local and regional climate in an adverse manner, field, laboratory and theoretical investigations of their fate are very important to human welfare.

Research activities at PNL include studies of atmospheric diffusion and deposition of material on the earth's surface, resuspension of particulate matter, and the regional and global transport of material. Transport studies include the modeling of vertical diffusion and deposition, the determination of the effect of wind speed on resuspension rates and the study of the vertical temperature structure. 


\section{- Air Pollution Dry Deposition: Radioisotopes as Particles and Volatiles}

Objectives of this study are:

- Developing an experimental basis for models predicting removal of airborne particles and gases by dry deposition onto outdoor surfaces.

- Developing predictive models accounting for the influence of particle size, gas characteristics, wind velocity, deposition surface, and other variables on deposition rates.

- Determining deposition rates using dual tracer techniques in the field and in a wind tunnel in the laboratory.

Literature Ranges of Particle Dry Deposition Velocities

\section{G. A. Sehmel}

\section{Introduction}

The dry deposition velocity is used to describe mass transfer across the airsurface interface in atmospheric diffusion and transport models. This deposition velocity is defined as the ratio of the deposition flux per unit area divided by the airborne pollutant concentration per unit volume at some height above the deposition surface.

Independent measurements of particle dry deposition velocities have been reported in the literature for many field experiments. However, there have been limited crosscomparisons between results. Consequently, a comparison between field results is made here for experimental results in which the particle diameter range is indicated.

\section{Experimental Field Results}

During FY 1979 experimental dry deposition velocities for many materials and various deposition surfaces were summarized by Sehmel(a) who listed reported deposition velocities for different materials as a function of particle diameter. The range of experimental deposition velocities for each field experiment was presented rather than

(a) "Deposition and Resuspension Processes." PNL-SA-6746, accepted for publication as Chapter 12 in Atmospheric Sciences and Power Production, Darryl Randerson, ed. (in press 1979). an "average" deposition velocity. This range is critical in emphasizing the experimental uncertainties in many field dry deposition experiments and in our ability to predict dry deposition mass transfer rates. The deposition velocities reported range over five orders of magnitude from a minimum of $10^{-3} \mathrm{~cm} / \mathrm{sec}$ to $180 \mathrm{~cm} / \mathrm{sec}$.

Since few measurements for deposition to water surfaces have been made, Sehmel listed the literature results of deposition to land surfaces as a function of particle diameter. These particle deposition velocity data are organized graphically in Figure 1. The reference numbers refer to references given in Sehmel (1979). The ranges of deposition velocities for each set of experimental conditions are shown as a function of particle diameter range. The dashed lines are for field experiments determined with polydispersed aerosols. In contrast, the solid 1 ines are data obtained with much narrower size distributions. In general, the data show the following:

- the deposition velocities in any individual experiment range over several orders of magnitude,

- a minimum deposition velocity exists and is approximately $10^{-2} \mathrm{~cm} / \mathrm{sec}$ for particle diameters in the range of 0.1 to $1 \mu \mathrm{m}$ dia.

Generalizing from these early field experiments has been 1 imited in that experimental variables have not been adequately controlled, $i . e$. , often the particle size distribution has either not been known or reported. Since deposition velocities are a function of particle diameter, most fielddetermined mass transfer data should be interpreted with qualification when generalization is attempted. 


.




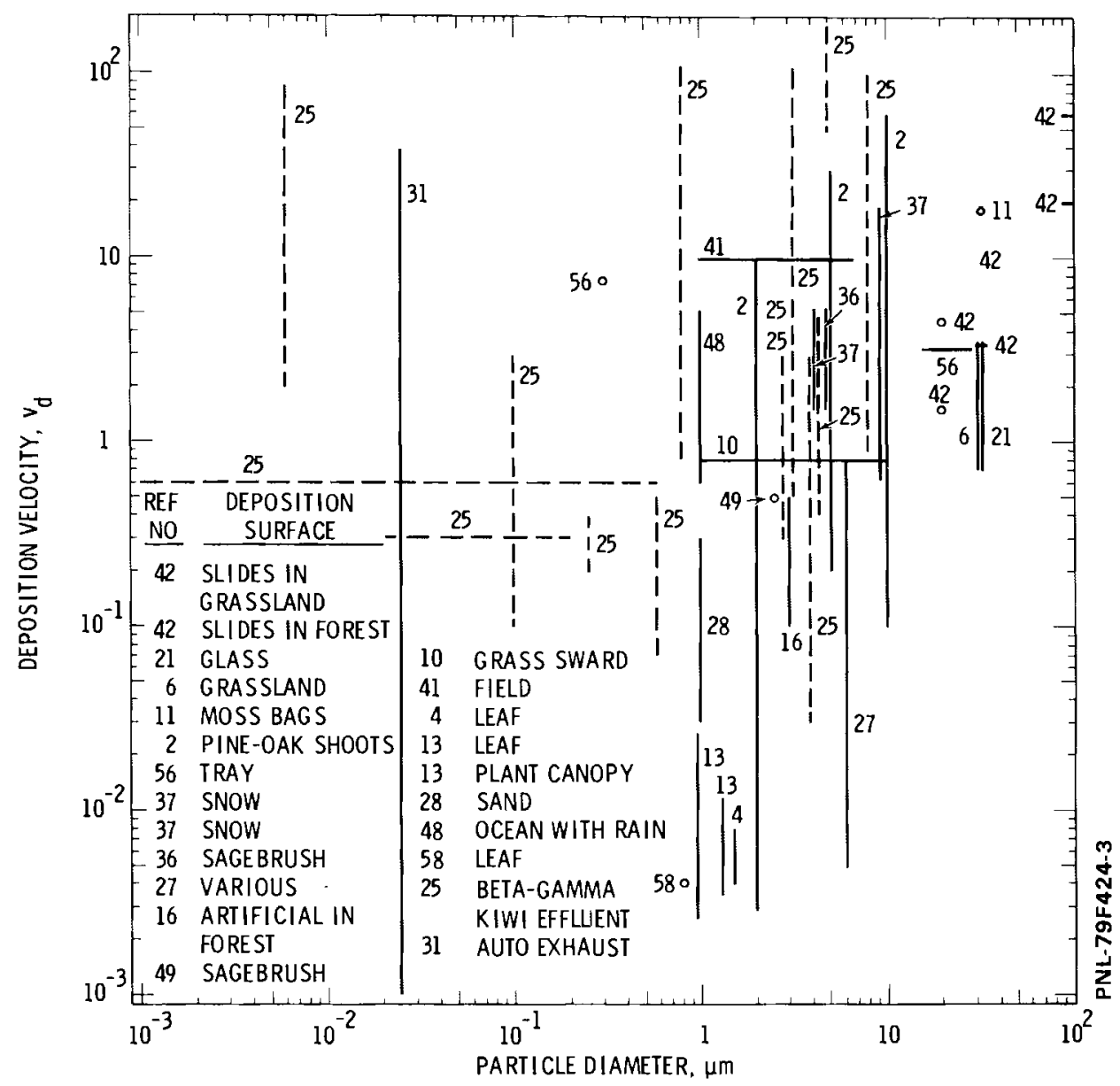

FIGURE 1. Particle Dry Deposition Velocities Measured in the Field

\section{Predictive Model}

Dry deposition velocities determined in these reported early field experiments encompass the range also predicted by Sehmel and Hodgson's empirical model (1980) based upon wind tunnel measurements of dry deposition velocities for monodispersed particles. In addition, Sehmel and Hodgson's model predictions indicate a minimum of about $10^{-2} \mathrm{~cm} /$ sec for particle diameters in the range of 0.1 to $1 \mu \mathrm{m}$. Thus, for predictive generalizations, Sehmel and Hodgson's deposition velocity predictions are recommended for use. These predictions are a function of particle diameter, friction velocity, aerodynamic surface roughness and particle density.

\section{References}

Sehme1, G. A. 1979. "Model Predictions and A Summary of Dry Deposition Velocity Data." Presented at and to be included in the proceedings of the Second Life Sciences Symposium on Potential Environmental and Health Consequences of Atmospheric Sulfur Deposition, October 14-18, 1979, Gatlinburg, TN.

Sehmel, G. A. and W. H. Hodgson. 1980. "A Model for Predicting Dry Deposition of Particles and Gases to Environmental Surfaces." In Implications of the Clean Air Act Amendments of 1977 and Energy Considerations for Air Pollution Control. Vol. 76, American Institute of Chemical Engineers, New York, NY. 
Literature Ranges of Dry Deposition Velocities for Gases

G. A. Sehmel

\section{Introduction}

Independent measurements of dry deposition velocities for gases have been reported in the literature for many experiments. These measurements have not been generalized but have been summarized by Sehmel. (a) The reported ranges of deposition velocities for 16 different gases are shown in Table 1. The range of deposition velocities is at least one order of magnitude for each gas. For nitrogen oxides ( $\mathrm{NO}$ and $\mathrm{NO}_{\mathrm{X}}$ ), the range is actually from minus to positive numbers. For all gases other than krypton, the range of deposition velocities is from $10^{-4}$ to $7.5 \mathrm{~cm} / \mathrm{sec}$. For $\mathrm{Kr}$ the maximum deposition rate is seven orders of magnitude lower, $2.3 \times 10^{-11} \mathrm{~cm} / \mathrm{sec}$.

\section{Iodine and Sulfur Dioxide}

Deposition velocities for iodine and sulfur dioxide have been studied extensively

(a) "Deposition and Resuspension Processes." PNL-SA-6746, accepted for publication as Chapter 12 in Atmospheric Sciences and Power Production, Darryl Randerson, ed. (in press 1979).

TABLE 1. Summary of Deposition Velocity Ranges for Gases

\begin{tabular}{lll}
$\begin{array}{c}\text { Depositing } \\
\mathrm{Gas}\end{array}$ & & $\begin{array}{c}\text { Deposition Velocity } \\
\text { Range, cm/sec }\end{array}$ \\
\cline { 1 - 1 } $\mathrm{SO}_{2}$ & & 0.04 to 7.5 \\
$\mathrm{I}_{2}$ & & 0.02 to 26 \\
$\mathrm{HF}$ & & 1.6 to 3.7 \\
$\mathrm{ThB}$ & & 0.08 to 2.6 \\
Flourides & & 0.3 to 2.4 \\
$\mathrm{Cl}_{2}$ & & 1.8 to 2.1 \\
$\mathrm{O}_{3}$ & & 0.002 to 2.0 \\
$\mathrm{NO}_{2}$ & & 1.9 \\
$\mathrm{NO}$ & & Minus to 0.9 \\
$\mathrm{PAN}_{\mathrm{NO}}$ & & 0.8 \\
$\mathrm{H}_{2} \mathrm{~S}$ & & Minus to 0.5 \\
$\mathrm{CO}$ & 0.015 to 0.38 \\
$\left(\mathrm{CH}_{3}\right)_{2} \mathrm{~S}$ & & 0.3 \\
$\mathrm{CH}_{3} \mathrm{l}$ & 0.064 to 0.28 \\
$\mathrm{Kr}$ & $10^{-4}$ to $10^{-2}$ \\
& $2.3 \times 10^{-11}$ max.
\end{tabular}

since those gases could be effluents from nuclear and nonnuclear industries, respectively. Even though $\mathrm{I}_{2}$ and $\mathrm{SO}_{2}$ have been studied extensively, their deposition velocities are so widely scattered that they cannot be confidently predicted. The deposition velocity of $I_{2}$ ranges three orders of magnitude, from 0.02 to $26 \mathrm{~cm} / \mathrm{sec}$; the deposition velocity of $\mathrm{SO}_{2}$ ranges two orders of magnitude, from 0.04 to $7.5 \mathrm{~cm} / \mathrm{sec}$.

The deposition velocity data for $I_{2}$ and $\mathrm{SO}_{2}$ are further organized in Figures 2 and 3 . Reference numbers in these figures refer to references given in Sehmel (1979). In each figure, data have been organized or ranked according to the maximum deposition velocity reported in each experiment. Commonly, deposition velocities are a function of experimental conditions and show a wide range even for the same types of deposition surfaces. This wide range is most evident for grass and water surfaces. Although a $1 \mathrm{~cm} / \mathrm{sec}$ deposition velocity is often assumed for gases, Figures 2 and 3 show that $1 \mathrm{~cm} / \mathrm{sec}$ for $\mathrm{I}_{2}$ and $\mathrm{SO}_{2}$ may have an uncertainty range from about $10^{-1}$ to $10 \mathrm{~cm} / \mathrm{sec}$. In addition, maximum $\mathrm{SO}_{2}$ deposition velocities determined for laboratory conditions are less than for some experimental conditions measured in the field. As an example, the deposition velocities reported over St. Louis (Figure 3) are greater than any of the maximum rates shown within the figure. 0bviously, there is much yet to be learned to adequately interpret these data and to develop more precise and accurate predictive deposition velocity models for gases.

\section{Atmospheric Stability}

There is some indication that the deposition velocities for gases may depend on atmospheric stability (Bunch 1968). Whelpdale and Shaw (1974) have also shown a dependency on atmospheric stability. They report that the deposition velocities to grass and snow for neutral conditions are greater than for stable conditions. In contrast, the deposition velocity to a water surface for a neutral atmosphere is greater than for a stable atmosphere.

\section{Conclusions}

Generalization of these summarized results is confounded by the wide deposition velocity ranges that have been measured. Possibly ordering the data with respect to more recent versus older data might decrease the data ranges. Nevertheless, at present we must conclude that dry deposition velocities for gases cannot be accurately predicted. Even 

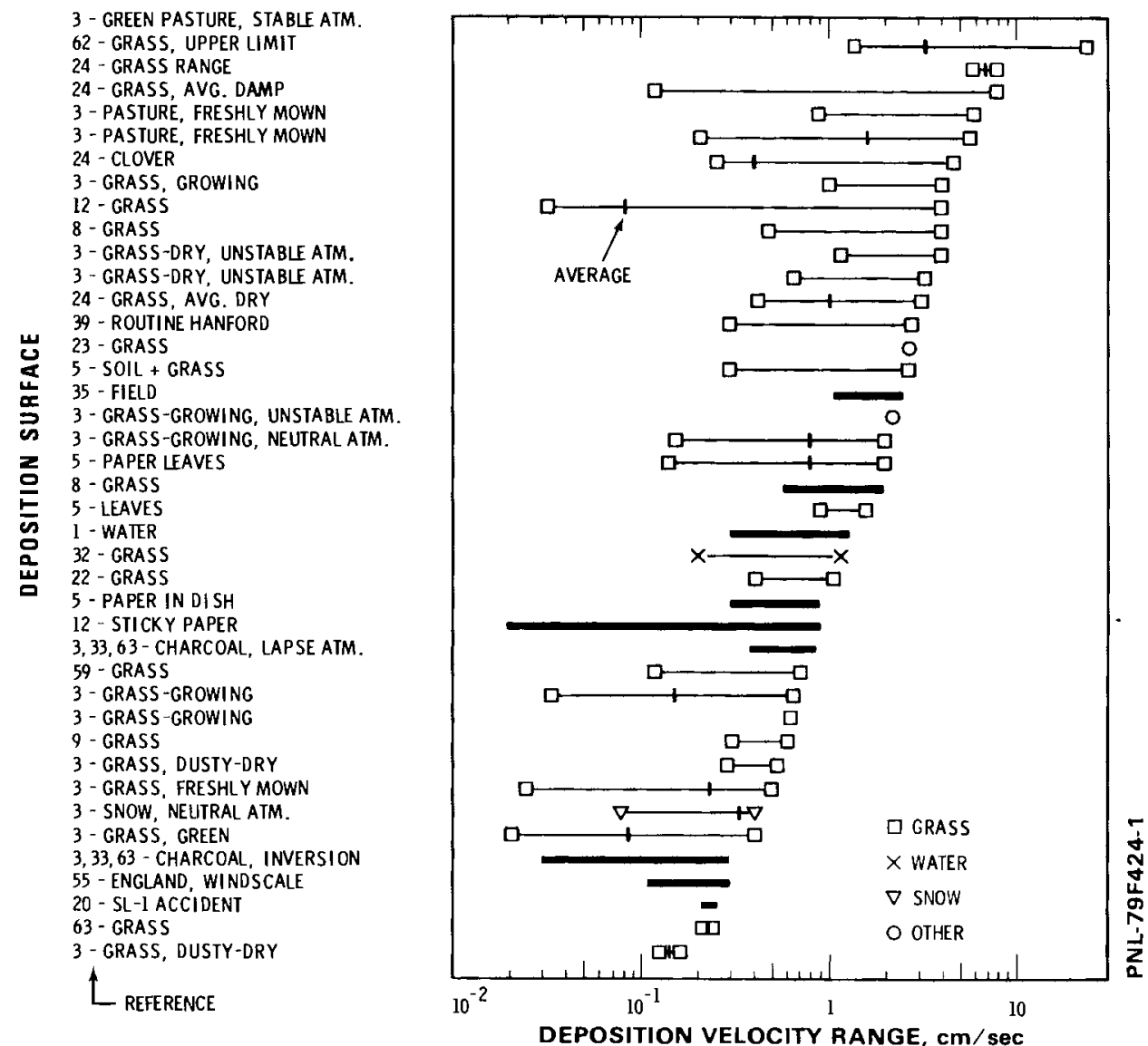

FIGURE 2. lodine Deposition Velocity Summary

for $\mathrm{I}_{2}$ and $\mathrm{SO}_{2}$, which have been investigated most extensively, the deposition velocity range is two to three orders of magnitude. Thus, the often quoted deposition velocity of $1 \mathrm{~cm} / \mathrm{sec}$ must currently bear the caveat that the uncertainty is probably at least plus or minus one order of magnitude. $0 \mathrm{~b}$ viously, considerable research is yet needed to accurately predict or to generalize dry deposition removal rates for gases.

\section{References}

Bunch, D. F., ed. 1968. Controlled Environmental Radioiodine Tests, Progress Report
Number Three. ID0-12063, Idaho Operations Office, U.S. Atomic Energy Commission, NTIS.

Sehme1, G. A. 1979. "Model Predictions and A Summary of Dry Deposition Velocity Data." Presented at and to be included in the proceedings of the Second Life Sciences Symposium on Potential Environmental and Health Consequences of Atmospheric Sulfur Deposition, October 14-18, 1080, Gatlinburg, TN.

Whelpdale, D. M. and R. W. Shaw. 1974.

"Sulphur Dioxide Removal by Turbulent Transfer Over Grass, Snow, and Water Surfaces." Tellus XXVI. I(2):196-204. 

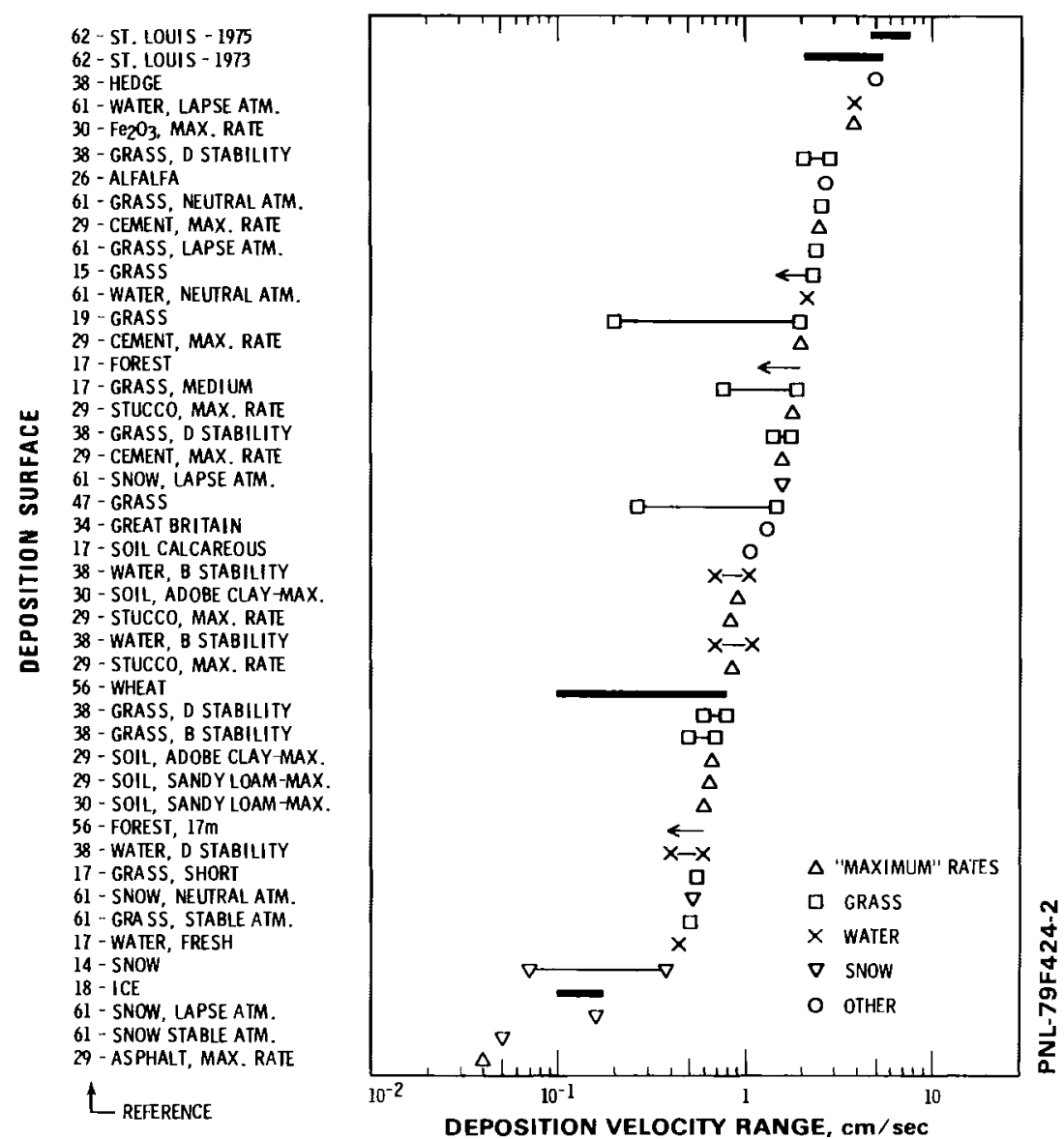

FIGURE 3. Sulfur Dioxide Deposition Velocity Summary

Equipment for Dual Tracer Dry Deposition Measurements

G. A. Sehmel and W. H. Hodgson

\section{Experiment}

An experimental technique is being developed to measure the dry deposition of particles and gases over complex terrain. During initial developments, a dual tracer of 1 ithium-traced particles and sulfur hexafluoride gas was used. Airborne lithium in the form of a lithium stearate tracer is sensed in real time by a flame ionization detector. Airborne concentrations of depositing lithium particles are then referenced to measured concentrations of nondepositing $\mathrm{SF}_{6}$ gas.

Initially, the $\mathrm{SF}_{6}$ gas was to be measured in real time using a Lovelock (1975) detec- tor. However, after extensive development of the $\mathrm{SF}_{6}$ tracer conc:st using the Lovelock literature reference, he conclusion was that the Lovelock de', ctor as published/improved does not wort. Consequently, the Lovelock detector cilcept was discarded and commercial $\mathrm{SF}_{6}$ det: :tors were purchased. Al though $\mathrm{SF}_{6}$ meas'; ements are not real-time with our detector. measurements can be made every 2 min. It $s$ now anticipated that a $2-\min \mathrm{SF}_{6}$ sampliry period will be satisfactory when compal, to sampling times required to accumsate statistically significant 1 ithium tricer particle measurements for field conc ions.

Lithium Par icie Detector Calibration. Six Tithium pirtice detectors were calibrated after c(nsicrable sensitivity adjustments were mact. Tise lithium particle detectors were calibicted with both monodispersed as well as poljuisperset particles. 
Instrument response as a function of particle diameter was measured using monodispersed aerosols. Each instrument has its own calibration curve, but all instruments show the same general maximum response as a function of particle diameter. Results of instrument response are shown in Figure 4 .

Instrument response for each particle diameter is illustrated as a ratio of instrument response to response calculated from an isokinetic filter sample of the air stream. The maximum instrument response is about $20 \%$ of the isokinetic airborne concentration. This maximum occurs for a particle diameter of about $1 \mu \mathrm{m}$. For particle diameters below about $0.3 \mu \mathrm{m}$ and above about $2 \mu \mathrm{m}$, the 1 ithium detector response decreases over one order of magnitude. For particle diameters less than $0.2 \mu \mathrm{m}$, detector response decreases two orders of magnitude from the maximum response. Thus, these calibration curves show these lithium detectors are most responsive to particle diameters in the range of about 0.3 to $2 \mu \mathrm{m}$ in dia.

Particle Generation. In field experiments large numbers of 1 ithium-traced particles will be required to measure particle

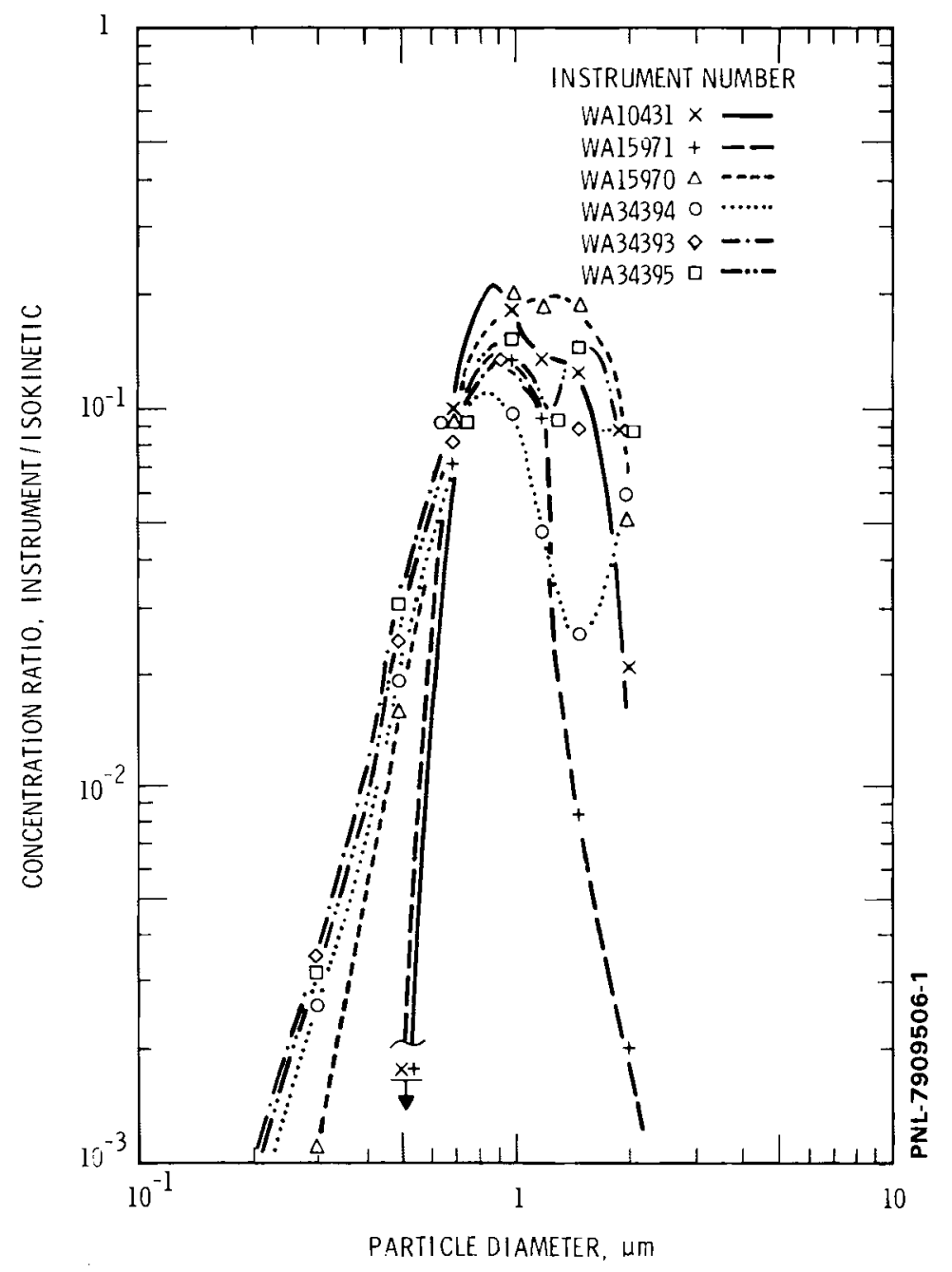

FIGURE 4. Instrument Concentration Ratio as a Function of Monodispersed Particle Diameter 
concentrations at significant downwind distances. For other than laboratory conditions, monodispersed particles cannot be generated in sufficient quantities for use. The proposed field particle-generation technique is to use pressurized spray nozzles (model 1711 Astrospray) to generate polydispersed aerosols with particle diameters in the range for which the 1 ithium detectors are most responsive.

Detector responses were determined for 1 ithium stearate particles generated with the spray nozzle. Results are shown in Figure 5. Shown are airborne concentrations measured by the 1ithium particle detectors normalized to an average airborne concentration of 2000 particles $/ \mathrm{cm}^{3}$. These norma 1 ized airborne concentrations are shown as a function of the lithium stearate concentration in solution as well as spray nozzle air pressure. Instrument responses are nearly independent of both the $1 \mathrm{ithium}$ stearate con- centration in solution as well as nozzle air pressure between 45 and 75 psi.

\section{Conclusions}

The maximum response of the airborne lithium particle detector for a particle diameter of about $1 \mu \mathrm{m}$ is very encouraging and essential for proposed dual tracer deposition velocity field measurements. the concept behind these experiments is that we will measure only the minimum particle dry deposition velocity over various complex terrains. This predicted minimum deposition velocity occurs for particle diameters in the range of about 0.1 to $1 \mu \mathrm{m}$, which approximates the response range of the 1 ithium particle detectors.

Satisfactory operating ranges for lithiumtraced particle generation have now been determined. We are currently preparing to generate particles under field conditions and

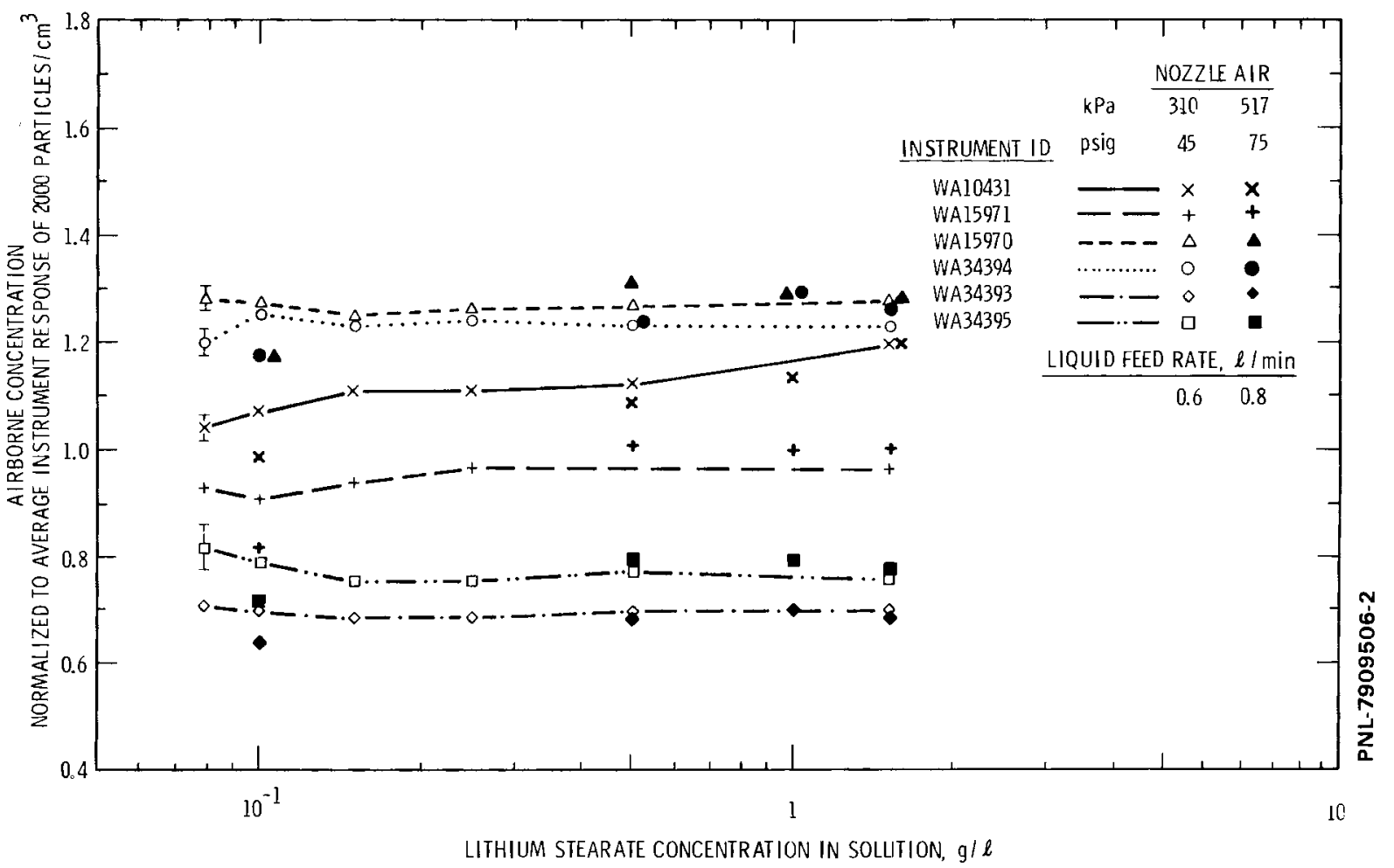

FIGURE 5. Normalized Instrument Concentration Response for Polydispersed Particles (Methyl Alcohol Solution in Model 1711 Astrospray Nozzle) 
to measure particles downwind from the generation site. After sufficient testing has been done to determine airborne concentrations of ambient background lithium particles as well as required tracer particle generation rates, dry deposition experimentation will begin using depositing lithium-traced particles and nondepositing $\mathrm{SF}_{6}$ gas.

\section{Reference}

Lovelock, J. E. 1975. "Solute Switching and Detection by Synchronous Demodulation in Gas Chromatography." J. Chrom. 112:29-36.

\section{- Particle Resuspension and Translocation}

Objectives of this study are:

- Investigating particle resuspension rates and air concentrations as functions of atmospheric stresses, local soil-working stresses, particle variables and surface variables.

- Developing an experimental resuspension data base to aid in establishing surface contamination limits to assure adequate public protection from hazardous materials.

- Factoring time-varying resuspension rates into models describing delivery of surface contaminants to man.

Literature Ranges of Wind and Mechanically Caused Resuspension Factors

\section{G. A. Sehme1}

\section{Introduction}

One method of estimating the potential airborne concentration of particles to which a person is subjected while in a contaminated area is to use a resuspension factor. The resuspension factor is defined as the airborne pollutant concentration per unit air volume at or near breathing height divided by the pollutant surface contamination per unit area in which the person is living or working. The resuspension factor has units of $\mathrm{m}^{-1}$.

Resuspension factors have been reported in the literature for various experiments. These data were tabulated in a review by Sehme1. (a) However, there have been limited cross-comparisons between these tabulated

(a) "Deposition and Resuspension Processes." PNL-SA-6746, accepted for publication as Chapter 12 in Atmospheric Sciences and Power Production, Darryl Randerson, ed. (in press 1979). results. Usually the main comment regarding these results is that there is variation of several orders of magnitude between results. The purpose here is to show in graphical form all these resuspension factor data.

Resuspension factors are shown in Figure 6 for both mechanically and wind-caused resuspension. Resuspension factors for mechanically caused resuspension are shown in the upper portion of the figure, and resuspension factors for wind stresses are shown in the lower portion. In both cases the data have been ranked in terms of descending order of the maximum resuspension factor reported for each experiment. In addition, the resuspension factor range for each experiment is shown by a horizontal line with vertical end marks. If only a single resuspension factor is reported, this datum is shown as an open circle.

Several conclusions can be drawn from this figure. These include:

- The figure does not correlate, rather only shows a graphical representation from maximum to minimum reported resuspension factors. 


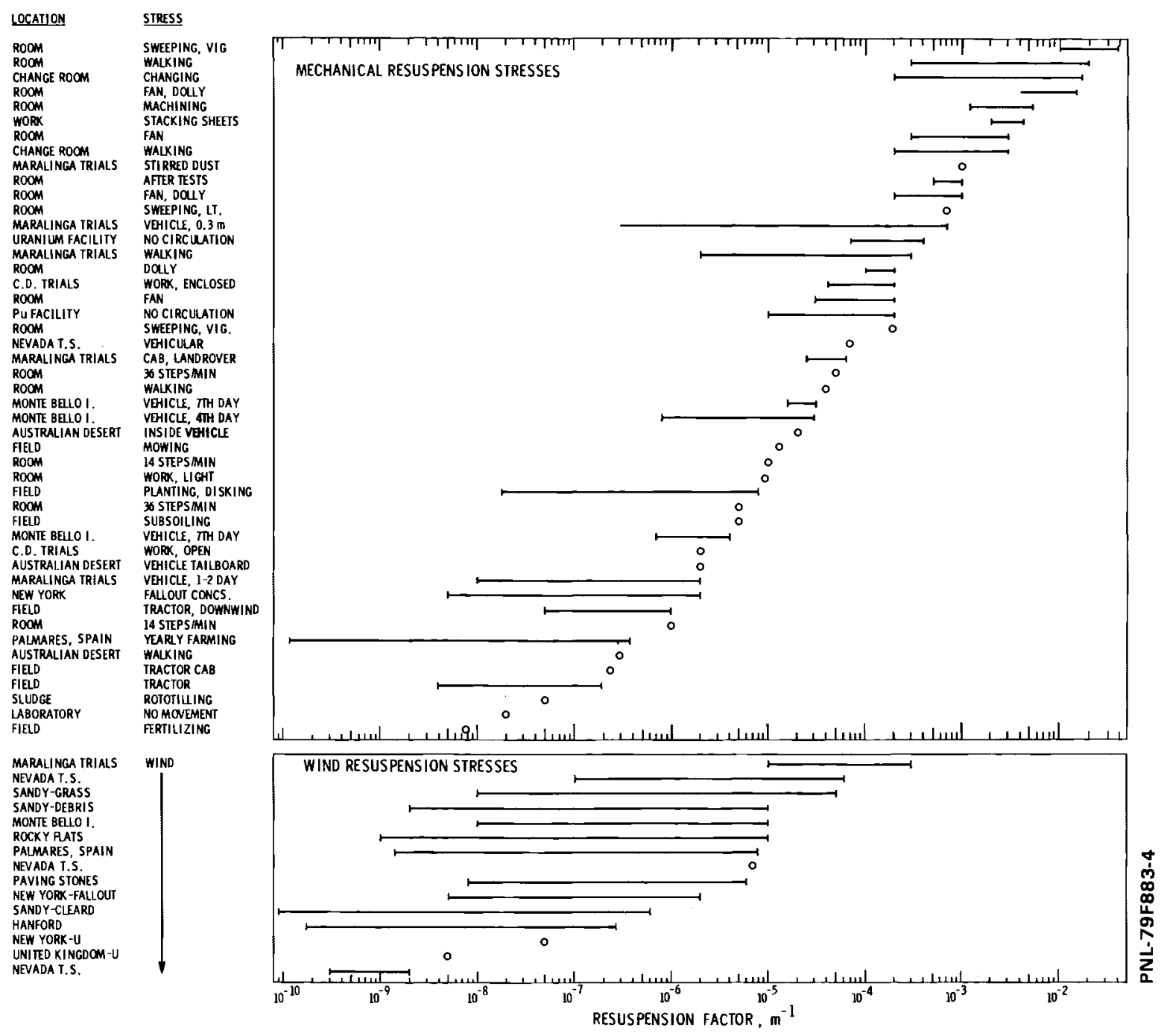

FIGURE. 6. Resuspension Factor Ranges from Mechanical and Wind Resuspension Stresses

- The range of resuspension factors within some individual experiments can be over several orders of magnitude.

- Mechanically caused resuspension factors range over nine orders of magnitude from $10^{-10}$ to over $10^{-2} \mathrm{~m}^{-1}$.

- Wind-caused resuspension factors range over seven orders of magnitude from $10^{-10}$ to $10^{-3} \mathrm{~m}^{-1}$.

- The maximum resuspension factors were caused by mechanical stresses.
- The minimum reported resuspension factor is $10^{-10} \mathrm{~m}^{-1}$ for both wind and mechanically caused resuspension stresses.

\section{Conclusions}

In utilizing this figure for predictive purposes, I recommend, if possible, locating a similar stress and situation comparable to the one being studied. If this is not possible, I recommend, at least, using a resuspension factor range for sensitivity studies rather than using only a single "average" resuspension factor. Obviously, inspection 
of this figure shows that our ability to accurately predict airborne concentrations from either mechanically or wind-caused resuspension stresses is extremely poor. Much research is yet needed to adequately understand resuspension processes and to accurately predict airborne concentrations arising from surface contamination.

Wind-Caused Particle Resuspension Rates at Two Sites

\section{G. A. Sehme1}

\section{Introduction}

Wind stresses can resuspend pollutant particles from contaminated surfaces and transport these particles downwind. However, one of the conclusions of a recent 1 iterature review by Sehmel(a) is that particle resuspension rates cannot be accurately predicted. In addition, literature results are inconsistent in quantifying the so-called weathering half-time. The weathering half-time describes the rate at which airborne pollutant concentrations decrease with time over a surface-contaminated area. Early literature suggested that the halftime might be as low as 35 to 40 days. Also, the literature review indicated unknowns including the effects of pollutant particle diameter and vegetation cover upon resuspension characteristics.

Experimental resuspension rates presented here are expanding our knowledge about windcaused resuspension rates as a function of wind speed, contaminated site, pollutant particle size and the validity of weathering half-time measured over several years.

\section{Experimental}

Wind-caused resuspension rates are being investigated at two Hanford area sites using inert calcium molybdate tracer particles as pollutant simulants. At both study sites the calcium molybdate tracers were originally sprayed uniformly as suspensions around centrally located air sampling towers. On each tower are three sets of wind-vaneoriented air sampling systems, including a particle cascade impactor (Sehmel 1973), for

(a) "Deposition and Resuspension Processes." PNL-SA-6746, accepted for publication as Chapter 12 in Atmospheric Sciences and Power Production, Darryl Randerson, ed. (in press 1979). sampling resuspended tracer as a function of sampling height. Each set of a ir samplers are turned on automatically for different wind speed increments in order to determine the effects of increasing wind speed on particle resuspension rates. Collected samples are analyzed for molybdenum by $X$-ray fluorescence.

At a site near U-pond in the 200 west area, submicrometer calcium molybdate tracer particles were sprayed in a circular area $23 \mathrm{~m}$ in radius. At a site near the Horn Rapids dam area, an average 6- $\mu m-d i a$ calcium molybdate tracer was sprayed in a circular area $30 \mathrm{~m}$ in radius. The average molybdenum surface contamination level initially deposited was $0.62 \mathrm{~g} / \mathrm{m}^{2}$ for the submicron site and $3.4 \mathrm{~g} / \mathrm{m}^{2}$ at the $6-\mu \mathrm{m}$ site.

Resuspension rates were calculated from the integrated flux per unit width passing through each centrally located sampling tower, the sampling duration and the total radial tracer source per unit width. For the calculations, the total vertical resuspension flux per unit width from the edge to center of the tracer source was assumed equal to the vertically integrated horizontal flux per unit width passing through each centrally located air sampling tower. Horizontal fluxes through the towers were calculated using air sampling data collected at five sampling heights $(0.3,0.9,1.8,3$ and $6.1 \mathrm{~m}$ ) at the submicrometer tracer source and seven sampling heights $(0.3,1,2,3,6$, 9 , and $12 \mathrm{~m}$ ) at the 6 - $\mu \mathrm{m}$ tracer source.

\section{Results}

Calculated resuspension rates for the two sites are shown in Figures 7 and 8 . The horizontal line with limit marks through each data point corresponds to either the time duration over which each experiment was conducted or the wind speed limits for each increment sampled. Resuspension rates ranged from $10^{-13}$ to over $10^{-7}$ fraction resuspended/sec.

Submicrometer Tracer Source. For the submicrometer tracer site, resuspension rates are shown in Figure 7 for wind speed increments after March 1974 of 4.5 to $5.4,5.4$ to 6.7 , and 6.9 to $9.4 \mathrm{~m} / \mathrm{sec}$. In general, resuspension rates at each wind speed remained constant over the total time period. However, there is an apparent seasonal change in resuspension in rates. The seasonal variation is not explicit since each experimental time period was determined in part by the occurrence of sufficient desired winds during that particular season. Nevertheless, 

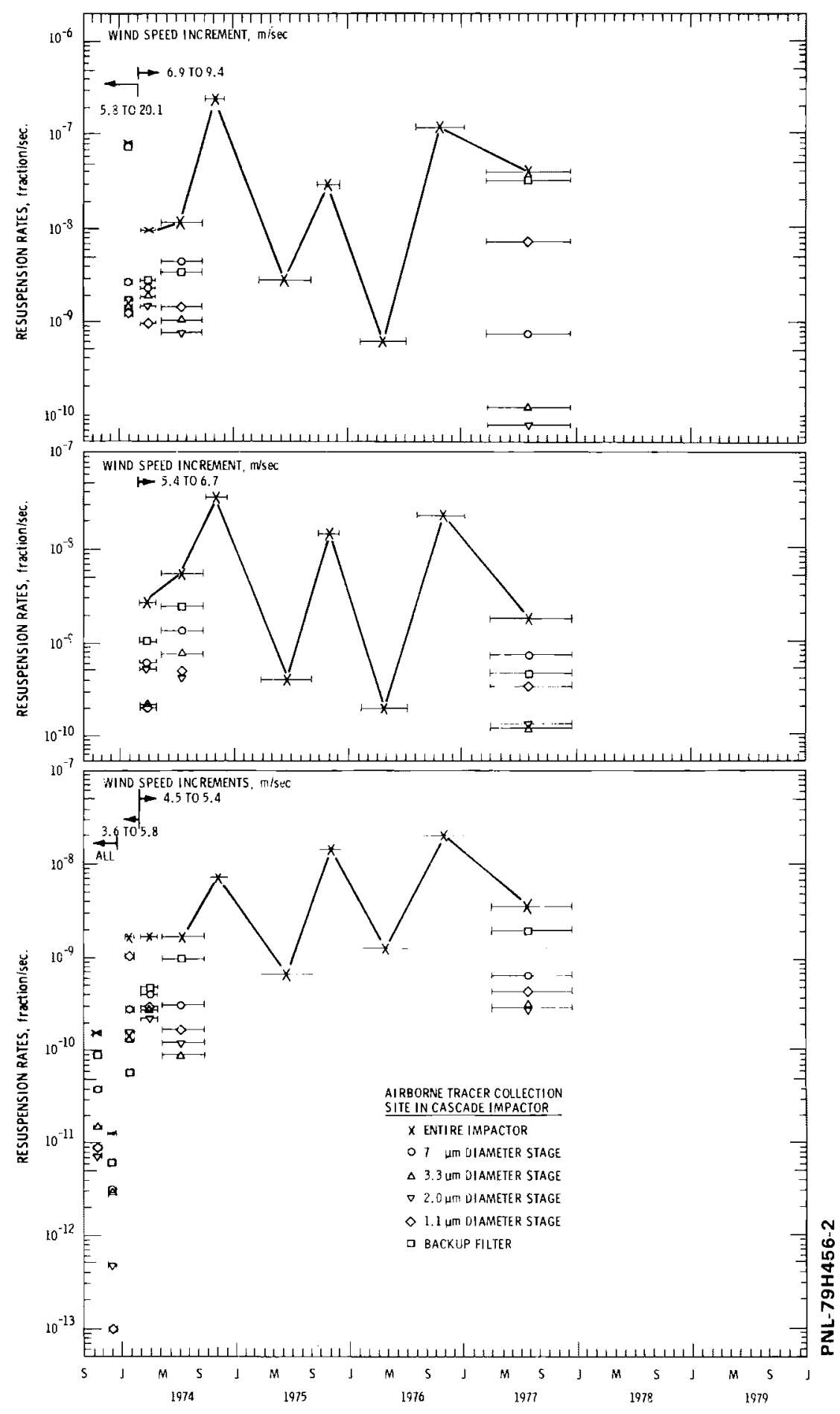

SAMPLING PERIOD, MONTH AND YEAR

FIGURE 7. Resuspension Rates as a Function of Year, Wind Speed Increment and Apparent Airborne Particle Diameter at the Submicrometer Tracer Site 


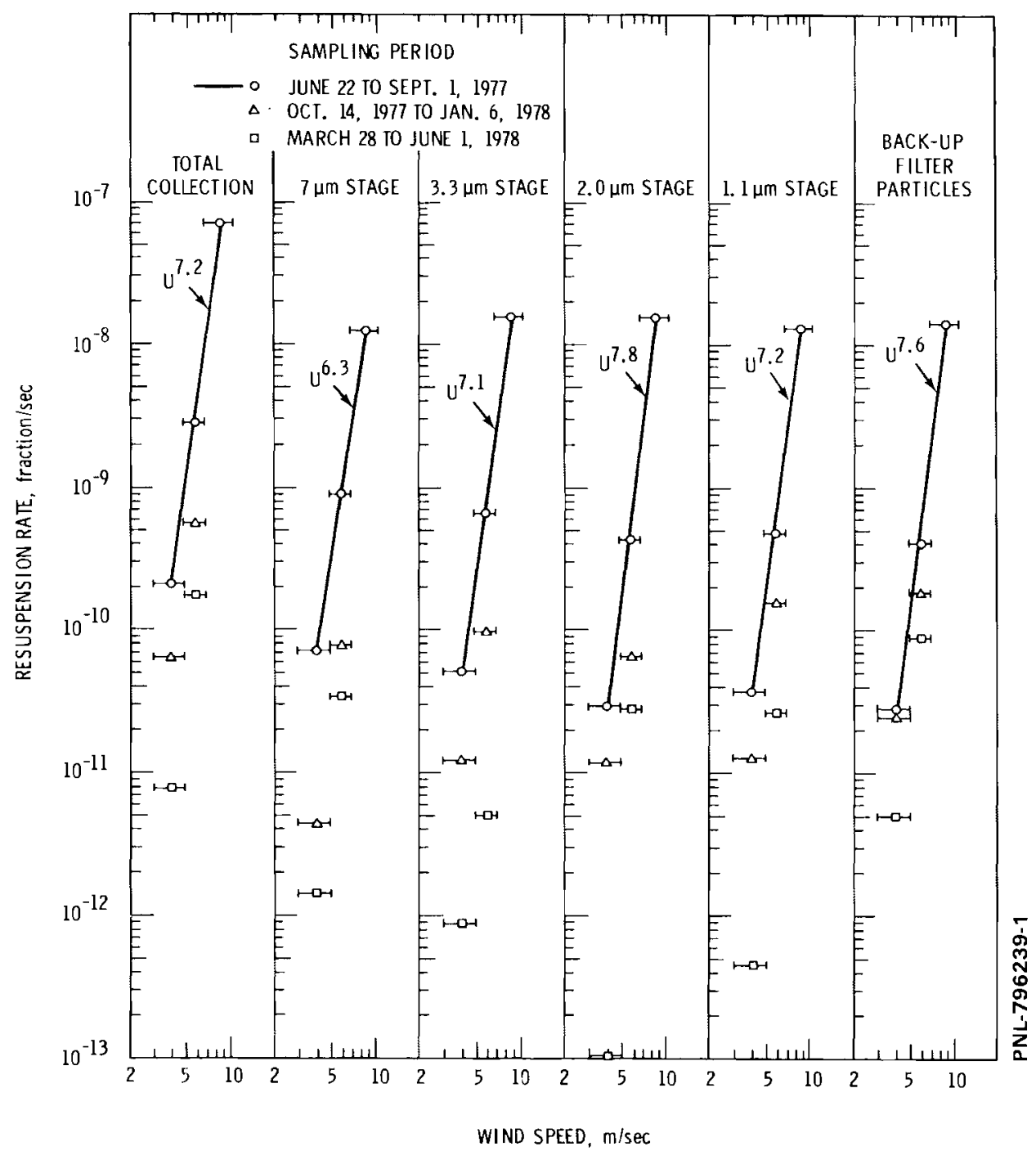

FIGURE 8. Tracer Resuspension Rates as a Function of Particle Diameter, Wind Speed Increments, and Average Wind Speed, $U$, at the Six-Micrometer Site

resuspension rates appear to be higher during the autumn than in the spring and summer.

Most resuspension rates were calculated from the entire sample collected in each cascade particle impactor. In some cases, each stage of the cascade particle impactor was analyzed separately for tracer content. For both cases, resuspension rates were calculated assuming the tracer source strength was independent of particle diameter. Resuspension rates indicate tracer was resuspended or was attached to all host particle sizes characterized by sampling with cascade particle impactors. In addition, tracer continued to be resuspended attached to all particle sizes throughout the duration of the experimental results.

A resuspension rate wind speed dependency was calculated from the data obtained from the entire impactor collection. For this calculation, each resuspension rate was normalized to the respective resuspension rate measured for the 4.5 to $5.4 \mathrm{~m} / \mathrm{sec}$ wind speed increment. Using this procedure, a least 
squares fit of the data indicates resuspension rates increased with wind speed raised to the 3.4 power.

Six-Micrometer Tracer Source. For the 6- $\mu \mathrm{m}$ tracer source, resuspension rates are shown in Figure 8 for wind speed increments of 3 to 5,5 to 7 , and 7 to $11 \mathrm{~m} / \mathrm{sec}$. Resuspension rates were calculated from the entire particle cascade impactor collection and also as a function of the collection site within the cascade particle impactor.

Resuspension rates increased with wind speed raised to the 3.5 to 13.8 power. For the time period shown, resuspension rates were decreasing with time.

\section{Conclusions}

Wind-caused resuspension rates are shown for two study sites. For one site, resuspension rates tended to remain constant with time. At the second site, resuspension rates were decreasing with increasing time. Since these experiments are continuing, longterm changes in these resuspension rates will be determined. Long-term resuspension effects are needed for environmental assessments of surface-contaminated areas. Previously, some credit could have been given for decreased resuspension with time. This potential credit is now questionable in light of the resusperision results shown here, and thus, assessment studies must al so consider the data presented here.

Al though nominal submicrometer and $6-\mu \mathrm{m}$ tracer particles were sprayed as resuspension sources, each source would have a tracer particle size distribution. This distribution is reflected in calculated resuspension rates for each stage of the cascade impactor. Each resuspension rate was calculated based on the total source concentration rather than the source concentration as a function of the tracer particle size distribution after deposition and weathering. Still to be determined is an initial experimental relationship between the tracer size distribution on the ground versus the tracer size distribution as resuspended on host particles. Once these relationships and measurement techniques between airborne versus ground contamination per gram of each soil size are estab1ished, possibly an improved basis rather than total contaminant level will be available to help establish permissible surface contamination levels.

\section{Reference}

Sehme1, G. A. 1973. "An Evaluation of a High-Volume Cascade Particle Impactor System." In Proc. of the Second Joint Conference on Sensing of Environmental Pollutants. Instrument SOC. of Amer., Washington, DC, December 10-12, 1973, pp. 109-115.

Airborne Plutonium Transported During Southwesterly Winds Near the Hanford Prosser Barricade(a)

\section{G. A. Sehme1}

\section{Introduction}

Airborne plutonium could result from resuspension of nuclear-weapons-testing stratospheric fallout deposition. To determine this possible resuspension at the Hanford site, two field experiments between Apri1 12 to June 29, 1976 and August 12, 1976 to January 11,1977 were conducted near the Prosser Barricade in the Hanford area (see Figure 9 ) about 19 to $22 \mathrm{~km}$ southeast $\left(140^{\circ}\right.$ to $160^{\circ}$ )(b) of the fuel-processing areas. The primary objective of these experiments was to determine if stratospheric fallout resuspension was reflected by airborne plutonium concentrations increasing with increasing wind speed.

A secondary objective was to confirm the source of the airborne plutonium by determining the plutonium-240 isotopic content or the plutonium-240/plutonium-239 mass ratio. Stratospheric fallout can be identified by the ratio of $240 \mathrm{Pu}$ to other plutonium isotopes in surface soils. Worldwide fallout (Krey et a1. 1976) ${ }^{240} \mathrm{Pu} /{ }^{239} \mathrm{Pu}$ mass ratios average $0.18 \pm 0.01$. These results are given with one standard deviation precision. Some variation in the fallout $240 \mathrm{Pu} / 239 \mathrm{Pu}$ mass ratios is shown for data obtained in Washington state. At Puyallup, Washington, the $240 \mathrm{Pu} / 239 \mathrm{Pu}$ mass ratio in January 1971 was $0.182 \pm 0.004$. The $240 \mathrm{Pu}$ and $239 \mathrm{Pu}$ isotopic contents were $13.82 \pm 0.05$ and $84.45 \pm$ 0.05 , atom percent, respectively, for a forest fire smoke plume sampled near Mt. St. Helens, Washington (Sehmel and Orgi11 1978)

(a) PNL-SA-7839, presented at the American Nuclear Society National Meeting, November 11 to 16, 1979, San Francisco, CA.

(b) North is $0^{\circ}$; angles are measured clockwise from $0^{\circ}$. 


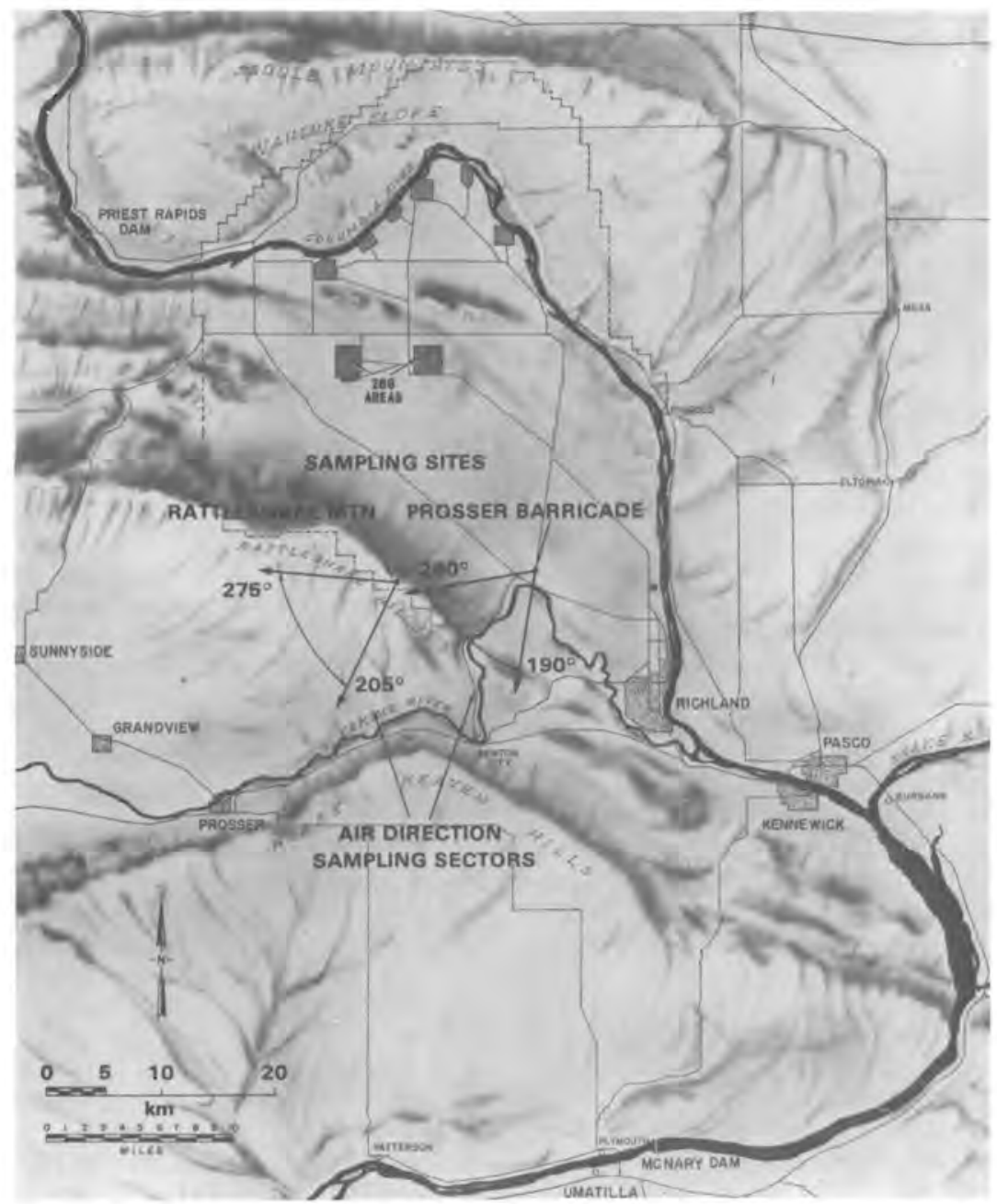

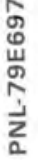

FIGURE 9. Sampling Locations on Hanford Site

on June 9, 1975. The ${ }^{240} \mathrm{Pu} /{ }^{239} \mathrm{Pu}$ mass ratio was thus 0.16. Sampling was also conducted during June 30 to November 17, 1978 (Sehme1 1979a) near the top of Rattlesnake Mountain, which is the western boundary of the Hanford area and the highest mountain within the 10cal area. The elevation of the sampling site was $1075 \mathrm{~m}$, which was approximately $875 \mathrm{~m}$ above the 200 Area plateau (200-m elevation) of the Hanford site. The Rattlesnake Mountain sampling site is approximately $17 \mathrm{~km}$ south of the Hanford 200 fuel processing areas, and $12 \mathrm{~km}$ from the Prosser Barricade. At this site, samples were collected as a function of wind speed and wind direction between $205^{\circ}$ and $275^{\circ}$. For seven samples collected within particle cascade impactors (a) during June 30 to November 17 , 1978 , the $240 \mathrm{Pu} /{ }^{239} \mathrm{Pu}$ ratios ranged from $0.152 \pm 0.010$ to $0.229 \pm 0.024$. For all particles collected in the seven cyclone preseparators, the mass ratio was $0.102 \pm 0.008$. In comparison to fallout, Hanford productiongrade plutonium (ERDA 1977) has an average $240 \mathrm{Pu}$ composition of 6.3 atom percent and an average ${ }^{240} \mathrm{Pu} /{ }^{239} \mathrm{Pu}$ mass ratio of 0.067 .

\section{Experiment}

Airborne particles transported during southwesterly winds were sampled with

(a) Model 230CP cyclone preseparator, Sierra Instrument Co., Carmel Valley, CA. 
particle cascade impactor systems (Sehmel 1978) shown in Figure 10 . The particle cascade impactor(a) for sampling respirable particles was attached to a rotating cow1, allowing simultaneous sampling of larger nonrespirable particles. Particles entering the 15-cm-dia cylindrical sampler inlet of the cowl either settled on the cowl floor or were drawn up into the impactor. In this report, particles settling within the cowl are called "large" cowl-collected particles. The sum of all particles collected on the cascade impactor collection surfaces plus backup filter are called "small" particles. "Sma11" particles entering the particle cascade impactor were separated into nominal aerodynamic diameter ranges of $7,3.3,2.0$ and $1.1 \mu \mathrm{m}$, which are impactor stage $50 \%$ cutoff diameters for unit-density spheres. Remaining airborne particles were collected on

(a) Model 65-100 High-Volume Sampler Head, Anderson 2000, Inc., Atlanta, GA. an impactor backup filter which was attached to the high-volume samplers. Unless stated separately, plutonium collected on the backup filter is included in the cascade impactor small particle sample. Some nonrespirable versus respirable particle size classification occurs in this sampling system since nonrespirable particles tend to be removed by gravity settling within the cowl. Particles that pass through the cowl and are collected on the last three cascade impactor fiberglass impaction stages and on the backup filter are often called respirable.

The high-volume sampler was activated only if the wind at a height of $1.5 \mathrm{~m}$ was blowing from off-site towards the Hanford area from $190^{\circ}$ to $260^{\circ}$. Small particles were sampled within particle cascade impactors for wind speed increments from 3 to 5 , 5 to 7 , and 7 to $11 \mathrm{~m} / \mathrm{sec}$ measured at a height of $1.5 \mathrm{~m}$. In addition, since the cowl inlet was always open, all southwest
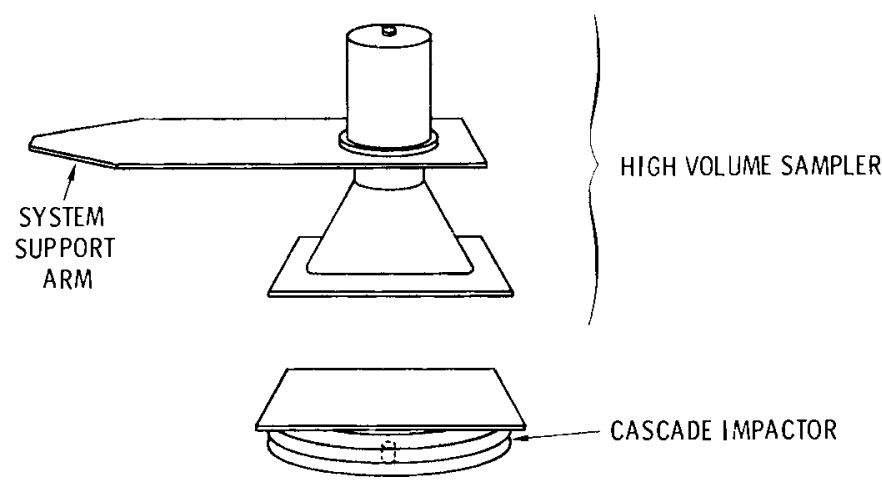

SPINDLE EXTENSION

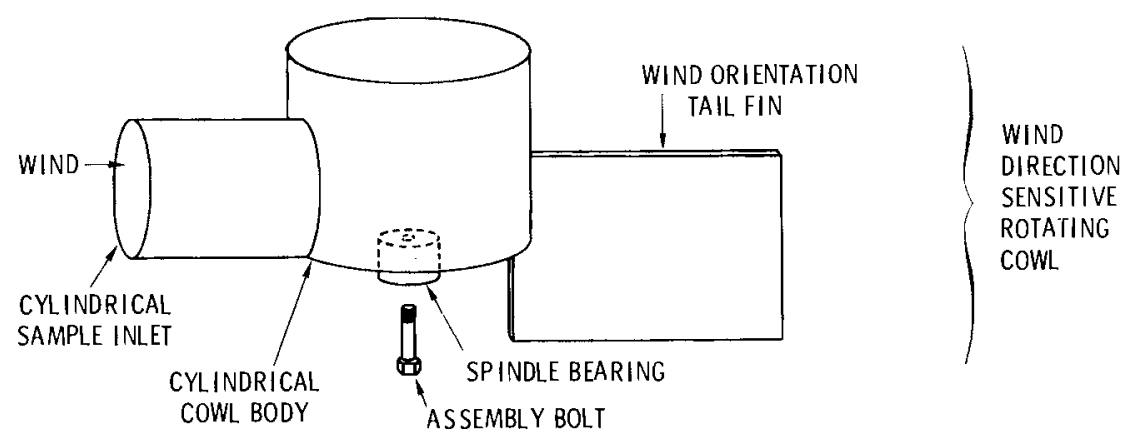

FIGURE 10. Sampling Systems: A Wind Direction-Oriented Cowl for Collecting

"Large" Particles by Gravity Settling and a Particle Cascade Impactor for

Collecting the Remaining Particles Called "Small" in this Article 
winds were continuously sampled for large particles within the particle inertial collection sampling cowl. Small particles also entered the inlet, but the collection was minimal within the cowl because their gravity settling velocity is low.

Airborne solids were collected during April 12 to June 29, 1976 and August 12, 1976 to January 11, 1977 within cowl particle cascade impactor systems located at heights of $0.3,2.0$ and $5.8 \mathrm{~m}$ above ground.

After collected samples were equilibrated with low humidity air and weighed, selected samples were combined for plutonium analysis in order to increase the radiochemical sensitivity. Plutonium analyses were performed by a commercial lab(a) using total dissolution followed by electrodeposition onto a platinum disc for alpha spectroscopy. After the plutonium content was determined, the platinum discs were returned to Pacific Northwest Laboratory for analysis of the plutonium isotopic content. Selected samples of both airborne smali and large particles were analyzed for the plutonium isotopic content.

Subsequently to investigating transport during southwesterly winds, further information on the isotopic conposition of airborne plutonium was obtained at a Horn Rapids sampling site which is $1.4 \mathrm{~km}$ south $\left(176^{\circ}\right)$ of the Prosser Barricade. During May 11 to July 2, 1979, airborne solids were collected continuously for all wind directions at the Horn Rapids as well as the Rattlesnake Mountain site. Massive (Mitchel1, Henry and Henderson 1978) volume air samplers were operated at a flow rate of $11 \mathrm{~m}^{3} / \mathrm{min}$. These samplers have two cascade impactor stages followed by an electrostatic precipitator. The first impactor stage was coated with silicone grease to minimize particle bouncethrough. The calculated $50 \%$ cut-off diameter of the second impactor stage was $2.1 \mu \mathrm{m}$. Particles collected on the electrostatic precipitator plates were removed and analyzed at the Pacific Northwest Laboratory (PNL) for plutonium isotopic composition.

\section{Results}

Results from three experimental time perjods are discussed. Plutonium transport during southwesterly winds was measured at the Prosser Barricade site for two time periods in 1976 to 1977. In 1979, plutonium trans-

(a) LFE Environmental Analys is Laboratory, 230 Wright Avenue, Richmond, CA. port during all wind directions was measured at the Horn Rapids site.

In the first experiment, airborne 239-240Pu concentrations were measured (Sehmel 1978; Sehmel 1977) near the Prosser Barricade during April 12 to June 29, 1976. For this experiment, 239-240 Pu isotopic analyses were made for only large particle samples. The sampling experiment was repeated (Sehmel 1979b) from August 12, 1976 to January 11, 1977 to confirm results from this initial experiment. Results will be discussed for both time periods; however, the second experiment will be discussed in more detail since 239-240 Pu isotopic analyses were made for both small and large particle samples.

April 12 to June 29, 1976. Airborne $239-240 \mathrm{Pu}$ concentrations, $\mu \mathrm{C} i / \mathrm{cm}^{3}$, on small particles, and airborne 239-240 Pu fluxes in $\mathrm{\mu C} /\left(\mathrm{m}^{2}\right.$ day), on large particles were determined (see Figure 11 and Table 2). Data are shown in Figure 11 for plutonium collection on the 3 plus $7 \mu \mathrm{m} 50 \%$ cut-off impactor stages, 1 plus $2 \mu \mathrm{m} \mathrm{50 \%} \mathrm{cut-off} \mathrm{impactor}$ stages, and the backup filter. The range of each wind speed increment is shown by a horizontal line through each data point. The vertical lines show the one sigma limits, corresponding to the radiochemical counting statistics. Also shown are 1 ines, calculated by least squares, through the data points. The wind speed dependency is shown as an exponent on the wind speed velocity, $(U)$, measured at the $1.5-\mathrm{m}$ height. Airborne $239-240 \mathrm{Pu}$ concentrations ranged from about $10^{-18}$ to $10^{-16} \mathrm{\mu C} / \mathrm{m}^{3}$. Airborne $239-240 \mathrm{Pu}$ concentrations increased as powers of wind speed, $(U): U^{0.8}$ to 7.8 .

The concentration of 239-240 Pu per gram of airborne solids was also determined. For small particles, $239-240 \mathrm{Pu}$ concentrations ranged from $6.0 \times 10^{-8}$ to $1.7 \times 10^{-6} \mu \mathrm{Ci} / \mathrm{g}$ with an average of $4.0 \times 10^{-7} \mu \mathrm{Ci} / \mathrm{g}$ of airborne solids. For large particles, the 239-240 Pu concentrations ranged from $1.3 \times 10^{-7}$ to $2.1 \times 10^{-7} \mu \mathrm{Ci} / \mathrm{g}$.

In addition, the isotopic plutonium compositions on large cowl-collected particles were determined. The $240 \mathrm{Pu}$ isotopic composition in atom percent was $6.10 \pm 0.02$ at a $0.3-\mathrm{m}$ sampling height; $6.31 \pm 0.02$ at $2 \mathrm{~m}$; and $6.28 \pm 0.03$ at $5.8 \mathrm{~m}$ while the $240 \mathrm{Pu} /$ $2{ }^{39} \mathrm{Pu}$ mass ratios were $0.065,0.068$ and 0.067 , respectively.

August 12, 1976 to January 11, 1977. Airborne plutonium concentrations, $\mu \mathrm{Ci} / \mathrm{cm}^{3}$, and concentrations of total airborne solid 


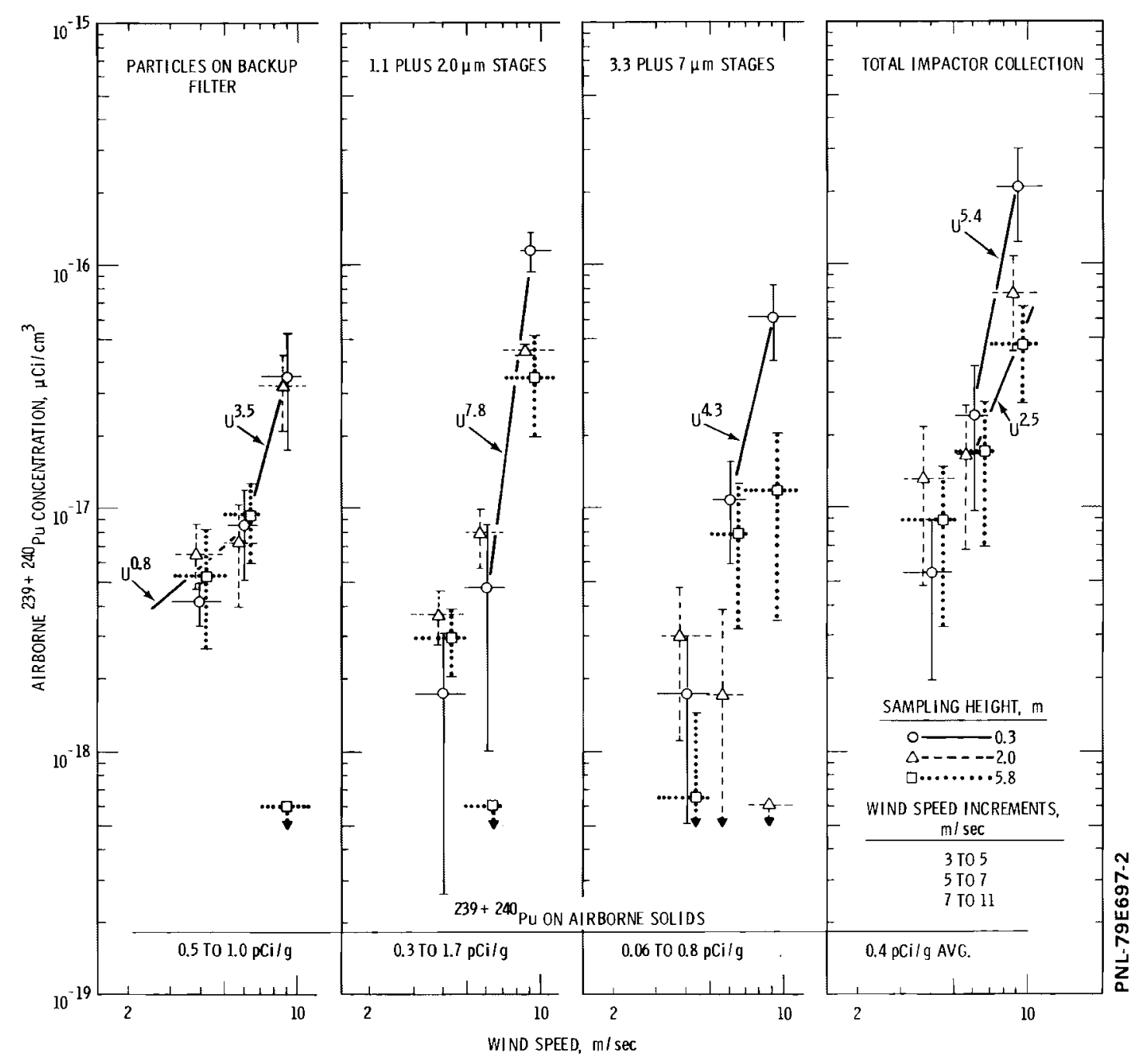

FIGURE 11. Airborne Plutoriium -239, -240 Concentrations near the Prosser Barricade at Hanford from April 12 to June 29,1976 when Sampling with $190^{\circ}$ to $260^{\circ}$ Winds Measured at the $1.5-\mathrm{m}$ Height

particles, $\mu \mathrm{g} / \mathrm{m}^{3}$, are shown in Figure 12 . Data are shown separately for each sampling height of $0.3,2.0$ and $5.8 \mathrm{~m}$. Airborne concentrations ranged from $4 \times 10^{-18}$ up to a maximum of $2 \times 10^{-16} \mu \mathrm{Ci} / \mathrm{cm}^{3}$. This maximum concentration is $0.3 \%$ of the 168-hr maximum permissible concentration guidance level (ERDA 1977; Code of Federal Regulations) of $6 \times 10^{-14} \mu \mathrm{C} / \mathrm{cm}^{3}$.

At the lowest sampling height of $0.3 \mathrm{~m}$, the airborne 239-240 Pu concentrations were nearly constant at about $5 \times 10^{-17} \mu \mathrm{Ci} / \mathrm{m}^{3}$ for all wind speeds. Although the plutonium concentration remained constant, the bottom portion of the figure shows that the airborne dust loading increased with the 2.1 power of wind speed.

In contrast to concentrations at the $0.3-m$ height, plutonium concentrations at the 2-m and 5.8-m heights increased with increasing wind speed. Airborne concentrations for the 2-m sampling height are shown in the central section of the figure. Airborne plutonium concentrations were $4.6 \times 10^{-18} \mu \mathrm{Ci} / \mathrm{cm}^{3}$ for the $3-$ to $5-\mathrm{m} / \mathrm{sec}$ wind speed increment. At this lowest wind speed increment, the airborne plutonium concentration at the $2-m$ height was one order 
TABLE 2. Plutonium-239, -240 Transport on Large Particles During Southwesterly Winds near the Prosser Barricade on the Hanford Project from April 12, 1976 to June 29, 1976

\begin{tabular}{|c|c|c|c|c|}
\hline \multirow{3}{*}{$\begin{array}{l}\text { Sampling } \\
\text { Height, } m \\
\end{array}$} & & & \multicolumn{2}{|c|}{$\begin{array}{c}\text { Airborne Pu Large Particle } \\
\text { Flux, } \mu \mathrm{Ci} /\left(\mathrm{m}^{2} \text { day }\right)\end{array}$} \\
\hline & \multicolumn{2}{|c|}{$\begin{array}{l}\text { Pu on Airborne } \\
\text { Solids }\end{array}$} & \multirow{2}{*}{$\begin{array}{l}\text { Only for } 190^{\circ} \\
\text { to } 260^{\circ} \mathrm{Winds} \\
3 \text { to } 11 \mathrm{~m} / \mathrm{sec}\end{array}$} & \multirow{2}{*}{$\begin{array}{r}\text { For Total } \\
\text { Field Time }\end{array}$} \\
\hline & $\mathrm{dpm} / \mathrm{g}$ & $\mu \mathrm{Ci} / \mathrm{g}$ & & \\
\hline 0.3 & 0.29 & $1.3 \times 10^{-7}$ & $3.9 \times 10^{-6}$ & $6.0 \times 10^{-7}$ \\
\hline 2 & 0.46 & $2.1 \times 10^{-7}$ & $4.0 \times 10^{-6}$ & $8.3 \times 10^{-7}$ \\
\hline 5.8 & 0.32 & $1.5 \times 10^{-7}$ & $1.4 \times 10^{-6}$ & $2.8 \times 10^{-7}$ \\
\hline
\end{tabular}

of magnitude less than the plutonium concentration at the lower height of $0.3 \mathrm{~m}$ for al 1 wind speeds. As a possible explanation of the data, a decrease in airborne plutonium concentration with height would be expected for a local resuspension source.

In contrast, for the highest wind speed increment of 7 to $11 \mathrm{~m} / \mathrm{sec}$, the airborne plutonium concentration at the 2-m sampling height is about four times greater than that at the $0.3-\mathrm{m}$ height. This increased airborne plutonium concentration with height at high winds resuspension results are dominated by some upwind source(s).

At the 2-m sampling height, airborne plutonium concentrations increased with the 4.8 power of wind speed, while the airborne solids concentration increased with the 3.0 power of wind speed. For the highest point sampled $(5.8 \mathrm{~m})$, both the airborne plutonium and airborne solids concentrations increased with the wind speed to the 2.7 to 2.8 power.

Airborne plutonium concentrations, $\mu \mathrm{Cj} / \mathrm{g}$, of airborne material and the isotopic $240 \mathrm{Pu}$ concentration were also determined. In Figure 13 , both the $239-240 \mathrm{Pu} \mu \mathrm{Ci} / \mathrm{g}$ and the atom percent of $240 \mathrm{Pu}$ are shown at each sampling height as a function of wind speed. For the lowest sampling elevation level of $0.3 \mathrm{~m}$, the plutonium concentration, $\mu \mathrm{C} / \mathrm{g}$, on airborne soil decreased with speed to the negative 2.3 power. The underlying cause of this concentration decrease with increasing wind speed is unknown. A possible explanation for this concentration decrease could include either locally uncontaminated soil being resuspended at higher wind speeds or uncontaminated soils being transported from upwind. In contrast, at a sampling height of $2.0 \mathrm{~m}$, the plutonium concentration on the airborne soil increased with the 1.8 power of wind speed. This relationship might be explained by a resuspension process proportional to $U^{3}$ and a subsequent airborne plume dilution proportional to $U^{-1}$. Thus, the exponent 2 is nearly equal to the experimental exponent of 1.8 .

A third $\mu \mathrm{C} i / g$ concentration pattern is shown by the data from the highest sampling level of $5.8 \mathrm{~m}$. For this height, the concentration was nearly constant for the lowest and highest wind speed increments with a maximum concentration occurring at the middle wind speed increment. The reason for this maximum is unknown. However, a maximum might have also occurred for the intermediate wind speed at the $2.0-m$ height.

The $240 \mathrm{Pu}$ isotopic content in atom percent was determined for each of five samples collected within cascade impactors including the backup filter. As shown in the lower portion of Figure 13, the $240 \mathrm{Pu}$ atom percent ranged from 5.6 to 8.1 . The one sigma limits for the atom percents are shown by the vertical bars. However, for two samples, the bars are within the drawn data symbol. For these samples, the $240 \mathrm{Pu} / 239 \mathrm{Pu}$ mass ratio ranged from 0.060 to 0.089 .

For large cowl-collected particles, 239-240 Pu concentrations in $\mu \mathrm{Ci} / \mathrm{g}$ and fluxes in $\mu \mathrm{Ci} /\left(\mathrm{m}^{2}\right.$ day) are shown in Table 3 . The plutonium concentration per gram associated with these large particles was less than that associated with small particles. The $240 \mathrm{Pu}$ atom percent ranged from 5.6 to

8.1 for small particles; for large particles the percentage was similar, 6.6 to 6.8 . The $240 \mathrm{Pu}$ atom percent at the $2-\mathrm{m}$ height was $6.8 \pm 0.1$ and at the $5.8-\mathrm{m}$ height was 

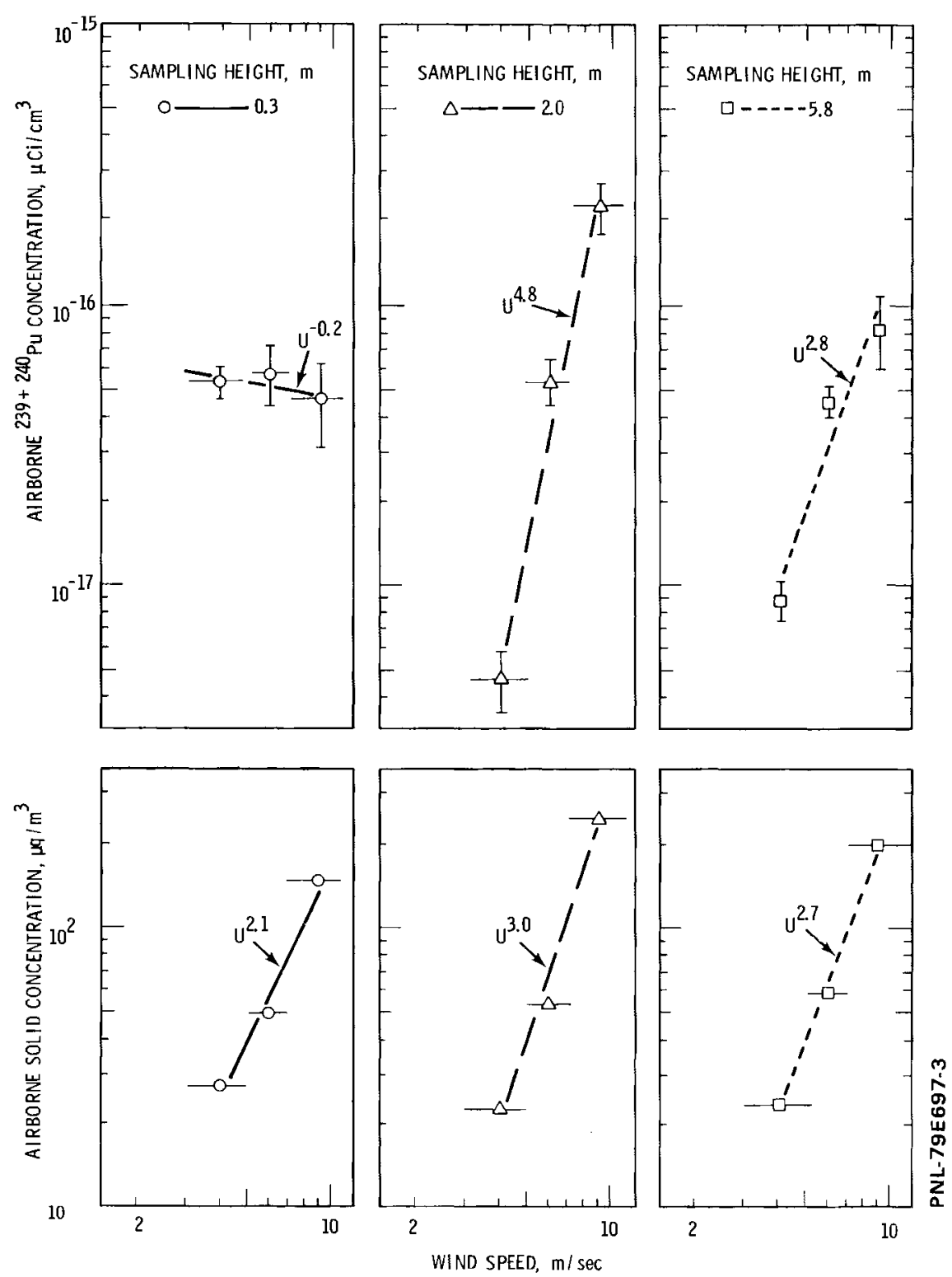

FIGURE 12. Airborne Plutonium -239, -240 Concentrations and Soil Loadings for Total Samples Collected Within Particle Cascade Impactors and Backup Filters near the Prosser Barricade at Hanford from August 12, 1976 to January 11,1977 when Sampling with $190^{\circ}$ to $260^{\circ}$ Winds Measured at the 1.5- $\mathrm{m}$ Height

$6.6 \pm 0.1$. The ${ }^{240} \mathrm{Pu} / 239 \mathrm{Pu}$ mass ratios were 0.074 and 0.071 , respectively.

The relative plutonium transport on large cowl collected versus small particles was not directly measured, since the cowl inlet was open and large particles could be trapped within the cowl at all winds between $190^{\circ}$ to $260^{\circ}$. The direct measurement would have required closure of the cowl inlet during the nonsampling periods. Nevertheless, an estimate was made for the relative 

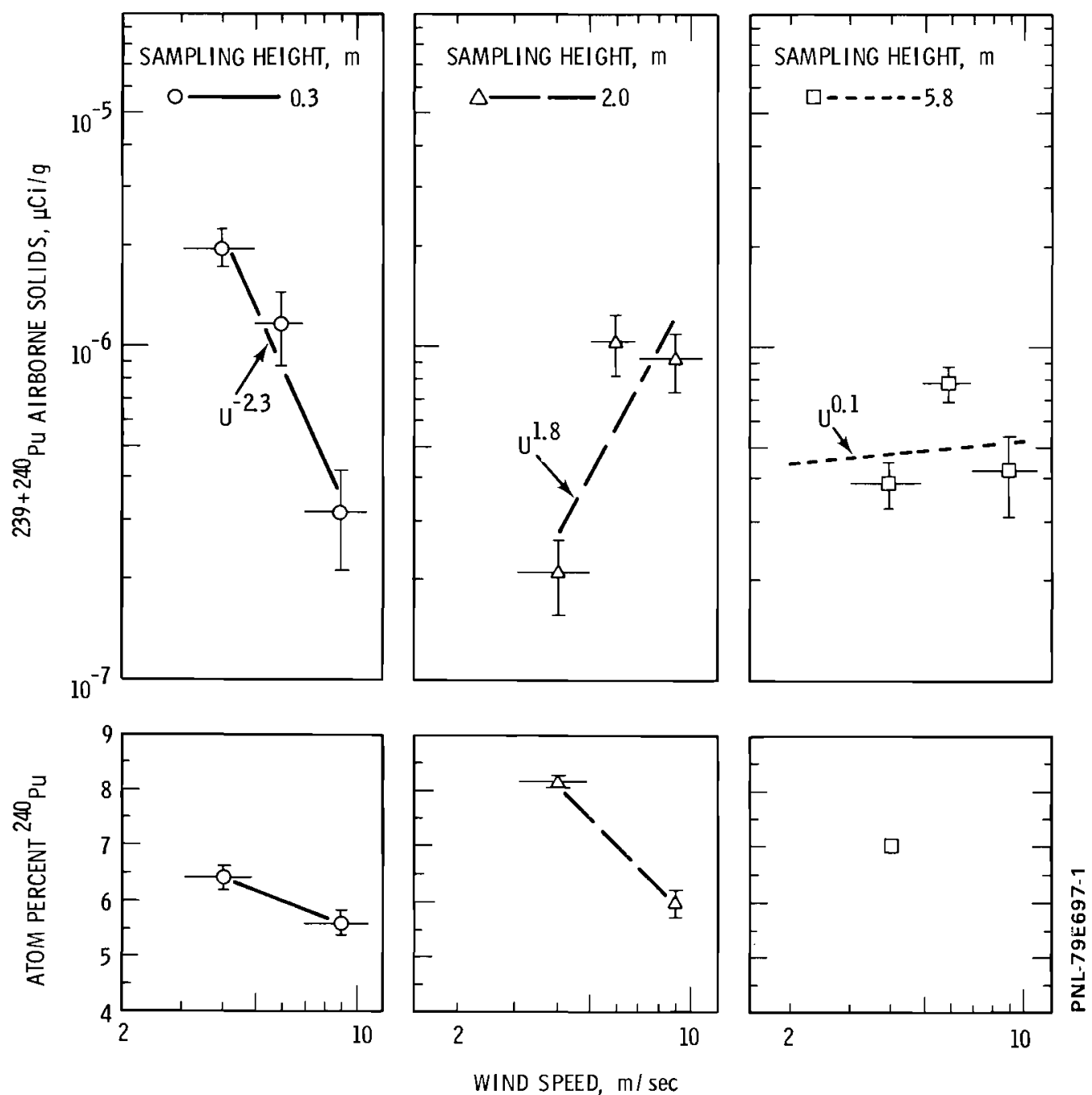

FIGURE 13. Plutonium -239,-240 Concentrations on Airborne Soil and Plutonium - 240 Isotopic Content for Total Samples Collected Within Particle Cascade Impactors and Backup Filters near the Prosser Barricade at Hanford from August 12, 1976 to January 11, 1977 when Sampling with $190^{\circ}$ to $260^{\circ}$ Winds Measured at the $1.5-\mathrm{m}$ Height

plutonium transport on small and large particles. The calculations assume that the air velocity was uniform for all sampling heights, that anisokinetic sampling corrections for small particles be negligible and that large particles be collected only between 3 to $11 \mathrm{~m} / \mathrm{sec}$ winds for wind directions between $190^{\circ}$ and $260^{\circ}$. A constant wind speed with height was assumed only as an approximation of changes with height which occur at different atmospheric stabilities.
To make a relative comparison of the fluxes on sma11 and large particles, the average small particle concentration was multiplied by the average wind speed, $4.6 \mathrm{~m} / \mathrm{sec}$, to get the average flux of small particles. The average flux of small particles and the flux of large particles were then compared to determine the percentage of plutonium transported on small particles. These calculations suggest that from 96 to 99\% of the plutonium was transported on small particles. 
TABLE 3. Plutonium-239, -240 Transport on Large Particles During Southwesterly Winds near the Prosser Barricade on the Hanford Project from August 12, 1976 to June 11, 1977

\begin{tabular}{|c|c|c|c|c|}
\hline \multirow{3}{*}{$\begin{array}{l}\text { Sampling } \\
\text { Height, m }\end{array}$} & & & \multicolumn{2}{|c|}{$\begin{array}{c}\text { Airborne Pu Large Particle } \\
\text { Flux, } \mu \mathrm{Ci} /\left(\mathrm{m}^{2} \text { day }\right)\end{array}$} \\
\hline & \multicolumn{2}{|c|}{$\begin{array}{l}\text { Pu on Airborne } \\
\text { Solids } \\
\end{array}$} & $\begin{array}{l}\text { Only for } 190^{\circ} \\
\text { to } 260^{\circ} \text { Winds }\end{array}$ & For Total \\
\hline & $\mathrm{dpm} / \mathrm{g}$ & $\mu \mathrm{Ci} / \mathrm{g}$ & 3 to $11 \mathrm{~m} / \mathrm{sec}$ & Field Time \\
\hline 0.1 & 0.22 & $1.0 \times 10^{-7}$ & $1.56 \times 10^{-7}$ & $1.30 \times 10^{-8}$ \\
\hline 2 & 0.23 & $1.1 \times 10^{-7}$ & $1.89 \times 10^{-7}$ & $1.57 \times 10^{-8}$ \\
\hline 5.8 & 0.39 & $1.8 \times 10^{-7}$ & $3.38 \times 10^{-7}$ & $2.82 \times 10^{-8}$ \\
\hline
\end{tabular}

Airborne plutonium fluxes, $\mu \mathrm{Ci} /\left(\mathrm{m}^{2}\right.$ day), for these large particles were calculated for two time periods. Horizontal flux calculations were made both for the total time that winds were simultaneously between 3 and $11 \mathrm{~m} / \mathrm{sec}$ and with wind direction between $190^{\circ}$ and $260^{\circ}$ and also for the total time that cowl air samplers were in the field. When the shorter period $(3$ to $11 \mathrm{~m} / \mathrm{sec}$ and $190^{\circ}$ to $260^{\circ}$ winds) was used, horizontal plutonium fluxes ranging from $1.6 \times 10^{-7}$ to $3.3 \times 10^{-7}$ to $10^{-7} \mu \mathrm{Ci} /\left(\mathrm{m}^{2}\right.$ day $)$ were calculated.

\section{Analysis}

Plutonium-239, -240 was transported during southwesterly winds on both small and large particles, i.e., including transport on both respirable and nonrespirable particles. Although maximum airborne concentrations were far below the 168-hr maximum permissible concentration guidance (ERDA 1977; Code of Federal Regulations) levels $(0.3 \%)$, possible sources of this airborne plutonium are of interest. In considering possible sources, both $240 \mathrm{pu}$ isotopic ratios and meteorological airflow patterns will be considered.

Plutonium-240. Plutonium-240 isotopic content and $240 \mathrm{Pu} / 239 \mathrm{Pu}$ mass ratios can be used to "fingerprint" the plutonium source as being principally from nuclear weapons testing stratospheric fallout or from production-grade plutonium. The worldwide fallout level for the $239 \mathrm{Pu} / 240 \mathrm{Pu}$ mass ratio is $0.18 \pm 0.01$. An average production grade (ERDA 1977) $240 \mathrm{Pu}$ atom percent is 6.3. For the Prosser Barricade samples, the maximum observed $240 \mathrm{pu}$ concentration is 8.1 atom percent (see Table 4 for a summary of $240 \mathrm{Pu}$ atom percents and Table 5 for a summary of $240 \mathrm{Pu} / 239 \mathrm{Pu}$ mass ratios). The $240 \mathrm{Pu} / 239 \mathrm{Pu}$ mass ratios from 0.060 to 0.089 are about one-half that of 0.18 for worldwide fallout.

These percentages will be used to estimate the fraction of fallout, Fo, in the Prosser Barricade sample. The maximum fallout fraction is calculated form the maximum observed $240 \mathrm{Pu}$ atom percent of 8.1 at the Prosser Barricade and the fallout of 13.8 at Mt. St. Helens, Washington:

$$
(13.8)(F 0)+(6.3)(1-F 0)=8.1 .
$$

The estimated fraction of fallout in the Prosser Barricade 8.1 atom percent plutonium240 sample is 0.24 . Similarly, the estimated fraction of fallout in this sample is al so 0.24 when using the $240 \mathrm{pu} / 239 \mathrm{pu}$ mass ratio of 0.182 at Puyallup, Washington, an assumed $239-240 \mathrm{Pu}$ isotopic content of $90 \%$, and a calculated $240 \mathrm{Pu}$ isotopic composition of 13.9 atom percent. For the other Prosser Barricade samples with $240 \mathrm{Pu}$ atom percentages less than 8.1 , the estimated fallout contribution to the total observed plutonium is even less than 0.24 .

Entirely different results were obtained from the Horn Rapids airborne sample. The $240 \mathrm{Pu}$ and $239 \mathrm{Pu}$ isotopic composition were $17.3 \pm 0.1$ and $81.3 \pm 0.1$ atom percent, respectively. The $240 \mathrm{Pu} /{ }^{239} \mathrm{Pu}$ mass ratio was $0.213 \pm 0.002$. These data are similar to fallout. Fallout was simultaneously measured at Rattlesnake Mountain where the ${ }^{240} \mathrm{Pu}$ and $2{ }^{39} \mathrm{Pu}$ isotopic compositions were $14.43 \pm 0.08$ and $83.35 \pm 0.09$ a tom percent, respectively. The $240 \mathrm{Pu} / 239 \mathrm{Pu}$ mass ratio was $0.173 \pm 0.001$. 
TABLE 4. Prosser Barricade Plutonium-240 Isotopic Content Summary

\begin{tabular}{|c|c|c|c|c|}
\hline \multirow[b]{3}{*}{$\begin{array}{l}\text { Sampling } \\
\text { Height, } m\end{array}$} & \multirow{3}{*}{$\begin{array}{l}\text { Wind Speed } \\
\text { Sampling } \\
\text { Increment, } \\
\mathrm{m} / \mathrm{sec}\end{array}$} & \multicolumn{3}{|c|}{ Atom Percent } \\
\hline & & \multicolumn{2}{|c|}{$\begin{array}{l}\text { Large Particles } \\
\text { Collected in Cowls }\end{array}$} & $\begin{array}{c}\text { Small Particles } \\
\text { Collected in Cascade } \\
\text { Impactor }\end{array}$ \\
\hline & & $\begin{array}{l}12 \text { April to } \\
29 \text { June } 1976\end{array}$ & $\begin{array}{l}12 \text { August } 1976 \text { to } \\
11 \text { January } 1977\end{array}$ & $\begin{array}{c}12 \text { August } 1976 \text { to } \\
11 \text { January } 1977\end{array}$ \\
\hline \multirow[t]{3}{*}{0.3} & All & $6.10 \pm 0.02$ & NA & NA \\
\hline & 3 to 5 & $\mathrm{NA}(\mathrm{a})$ & NA & $6.4 \pm 0.2$ \\
\hline & 7 to 11 & NA & NA & $5.6 \pm 0.2$ \\
\hline \multirow[t]{3}{*}{2.0} & All & $6.31 \pm 0.02$ & $6.85 \pm 0.09$ & NA \\
\hline & 3 to 5 & NA & $\mathrm{NA}$ & $8.1 \pm 0.1$ \\
\hline & 7 to 11 & NA & NA & $6.0 \pm 0.2$ \\
\hline \multirow[t]{2}{*}{5.8} & All & $6.28 \pm 0.03$ & $6.6 \pm 0.1$ & NA \\
\hline & 3 to 5 & NA & $\mathrm{NA}$ & $7.0+0.01$ \\
\hline
\end{tabular}

(a) NA: Not analyzed

TABLE 5. Prosser Barricade Plutonium-240/Plutonium-239 Mass Ratio Summary

\begin{tabular}{|c|c|c|c|c|}
\hline \multirow[b]{3}{*}{$\begin{array}{l}\text { Sampling } \\
\text { Height, } m\end{array}$} & \multirow{3}{*}{$\begin{array}{c}\text { Wind Speed } \\
\text { Sampling } \\
\text { Increment, } \\
\mathrm{m} / \mathrm{sec}\end{array}$} & \multicolumn{3}{|c|}{ Plutonium-240/Plutonium-239 Mass Ratio } \\
\hline & & \multicolumn{2}{|c|}{$\begin{array}{c}\text { Large Particles } \\
\text { Collected in Cowls }\end{array}$} & $\begin{array}{c}\text { Small Particles } \\
\text { Collected in Cascade } \\
\text { Impactor } \\
\end{array}$ \\
\hline & & $\begin{array}{l}12 \text { April to } \\
29 \text { June } 1976\end{array}$ & $\begin{array}{l}12 \text { August } 1976 \text { to } \\
11 \text { January } 1977\end{array}$ & $\begin{array}{c}12 \text { August } 1976 \text { to } \\
11 \text { January } 1977\end{array}$ \\
\hline \multirow[t]{3}{*}{0.3} & All & 0.065 & NA & NA \\
\hline & 3 to 5 & $N A(a)$ & NA & 0.069 \\
\hline & 7 to 11 & NA & NA & 0.060 \\
\hline \multirow[t]{3}{*}{2.0} & All & 0.068 & 0.074 & NA \\
\hline & 3 to 5 & NA & NA & 0.089 \\
\hline & 7 to 11 & NA & NA & 0.063 \\
\hline \multirow[t]{2}{*}{5.8} & All & 0.067 & 0.071 & NA \\
\hline & 3 to 5 & $\mathrm{NA}$ & NA & 0.076 \\
\hline
\end{tabular}

(a) NA: Not analyzed 
Wind Direction. The significant difference in the isotopic composition at the Prosser Barricade and Horn Rapids sites may be a function of the wind field patterns. Although southwesterly winds were sampled at the Prosser Barricade, synoptic-scale southwest winds can entrain air flowing southeasterly along the side of Rattlesnake Mountain. often, this southeasterly flowing air tends to mix with and to follow the motion of the southwesterly wind approaching the Hanford Area from offsite. Although the location of this entrainment is a function of the meteorology occurring, mixing can occur within the region near the Prosser Barricade. Since the Horn Rapids site is $1.4 \mathrm{~km}$ south of the Prosser Barricade, the possibility exists that 1) most entrained air is transported at locations near or north of the Prosser Barricade, 2) little entrained air flows near ground level across the Horn Rapids sampling site, and 3) the entrained air carried Hanford-produced plutonium from onsite. A1though these possibilities exist and might explain the differences between the Prosser Barricade and Horn Rapids isotopic compositions, the source of the production-type plutonium collected at the Prosser Barricade is yet to be identified.

\section{Conclusions}

Plutonium was transported during southwesterly winds during the two study periods at the Prosser Barricade. Airborne 239-240 Pu concentrations varied as powers of wind speed $(U): U^{-0.2}$ to $U^{7.8}$. The airborne solids content ranged from $6 \times 10^{-8}$ to $1.7 \times 10^{-6} \mu \mathrm{Ci} / \mathrm{g}$. The $240 \mathrm{Pu}$ isotopic content ranged from 5.6 to 8.1 atom percent and the $240 \mathrm{Pu} / 239 \mathrm{Pu}$ mass ratio ranged from 0.065 to 0.089 . The estimated fraction of stratospheric fallout plutonium in these samples was less than 0.24 . The remaining airborne plutonium was probably of Hanford origin. Airborne plutonium probably represents resuspension of plutonium from undetermined sites by mechanisms and events not clear at present.

An increasing airborne plutonium concentration with increasing wind speed might be expected for an upwind resuspension source(s). However, the geographical source(s) location was not investigated in this study. More research is planned to determine relationships between airborne and any surface concentrations. Although airborne plutonium was measurable after filtering larger air volumes, the maximum calculated airborne 239-240 $\mathrm{Pu}$ concentration of $2 \times 10^{-16} \mu \mathrm{Ci} / \mathrm{cm}^{3}$ is $0.3 \%$ of the
$6 \times 10^{-14} \mu \mathrm{Ci} / \mathrm{cm}^{3} 168-\mathrm{hr}$ maximum permissible concentration guidance level (Code of Federal Regulations).

\section{References}

Code of Federal Regulations, 10 CFR Part 20, Appendix B, Table II.

ERDA. 1977. Alternatives for Long-Term Management of Defense High-Level Radioactive Waste, Hanford Reservations. ERDA 77-44, p. 3.8, Energy Research and Development Administration, Washington, DC.

ERDA, Manual of Operation. March 1977. Chapter 0524, "Standards for Radiation Protection," Appendix A, Table II. U.S. Energy Research and Development Administration.

Krey, P.W., E. P. Hardy, C. Pachucki, R. Rourke, J. Coluzza, and W. K. Benson. 1976. "Mass Isotopic Composition of Global Fallout Plutonium in Soi1." In Transuranic Nuclides in the Environment, pp. 671-678, International Atomic Energy Agency, Vienna, Austria.

Mitche11, R. I, W. M. Henry and N. C. Henderson. 1978. Fabrication Optimization and Evaluation of a Massive Volume Air Sampler of Sized Respirable Particulate Matter. EPA-600/4-78-031, Nationa1 Technical Information Service, Springfield, VA.

Sehmel, G. A. 1977. "Plutonium Concentrations in Airborne Soil at Rocky Flats and Hanford." In Airborne Radioactivity, pp. 81-101, selected papers from the 1979 ANS Winter Meeting, San Francisco, CA, November 29-December 2, 1977, American Nuclear Society, Inc., LaGrange Park, IL.

Sehme1, G. A. 1978. "Offsite Plutonium Resuspension Near Hanford." In Pacific Northwest Laboratory Annual Report for 1978 to the DOE Assistant Secretary for Environment. PNL-2500-3, pp. 2.4 to 2.5, Pacific Northwest Laboratory, Richland, WA.

Sehme1, G. A. 1979a. "Airborne Plutonium and Americium Concentrations Measured from the Top of Rattlesnake Mountain." In Pacific Northwest Laboratory Annual Report for 1978 to the DOE Assistant Secretary for Environment. PNL-2580 PT3, pp. 2.4-2.7, Pacific Northwest Laboratory, Richland, WA.

Sehme1, G. A. 1979b. "Plutonium Resuspension." In Pacific Northwest Laboratory Annual Report for 1978 to the DOE Assistant Secretary for the Environment, Part 3, Atnospheric Sciences. PNL-2850 PT3, pp. 2.7-2.11, Pacific Northwest Laboratory, Richland, WA. 
Sehme1, G. A. and M. M. Orgill. 1978. "Plutonium Concentrations in Forest Fire Smoke P1umes." In Pacific Northwest Laboratory Annual Report for 1977 to the DOE Assistant
Secretary for Environment, Part 3, Atmospheric Sciences. PNL-2500 PT3, p. 2.44, Pacific Northwest Laboratory, Richland, WA.

\section{- Fallout Rates and Mechanisms}

Objectives of this study are:

- Measuring radionuclide concentrations at Barrow, Alaska, and Richland, Washington, for the assessment of the hazard to the environment presented by future radionuclide releases.

- Determining the physical and chemical forms of airborne radionuclides, their deposition rates, and iodine- 131 concentrations in grass and milk.

- Calculating the rates of atmospheric mixing of radionuclides.

Atmospheric Radionuclide Concentrations at Richland, Washington and Barrow, Alaska

J. A. Young and C. W. Thomas

\section{Long-Term Concentration Variations}

Nuclear Weapons-Produced Radionuclides. Concentrations of a wide spectrum of radionuclides have been measured bimonthly at Richland, Washington $\left(46^{\circ} \mathrm{N}, 119^{\circ} \mathrm{W}\right)$ since 1961 and monthly at Barrow, Alaska (71\%, $\left.157^{\circ} \mathrm{W}\right)$ since 1964 . Since the end of atmospheric nuclear testing by the United States and Russia in 1962, radionuclides have been released into the atmosphere primarily as a result of atmospheric tests by France (which discontinued testing in 1971) and by the People's Republic of China. The

Chinese have conducted about 25 atmospheric nuclear tests at a rate of one or two a year since 1964. Primarily because of Chinese nuclear tests, the decrease in atmospheric concentrations of nuclear weapons radionuclides has been slow since about 1966. The yearly average concentrations of zirconium-95, cesium-137, plutonium-238, plutonium-239 and americium-241 at Richland in disintegrations per minute per $10^{3}$ standard cubic meters (SCM) since 1962 are shown in Figure 14 (before 1968 only the sum of the $95 \mathrm{Zr}$ and niobium-95 concentrations was measured). The peak in the $238 \mathrm{Pu}$ concentration that occurred around 1966 resulted from the burnup of a SNAP-9A nuclear power

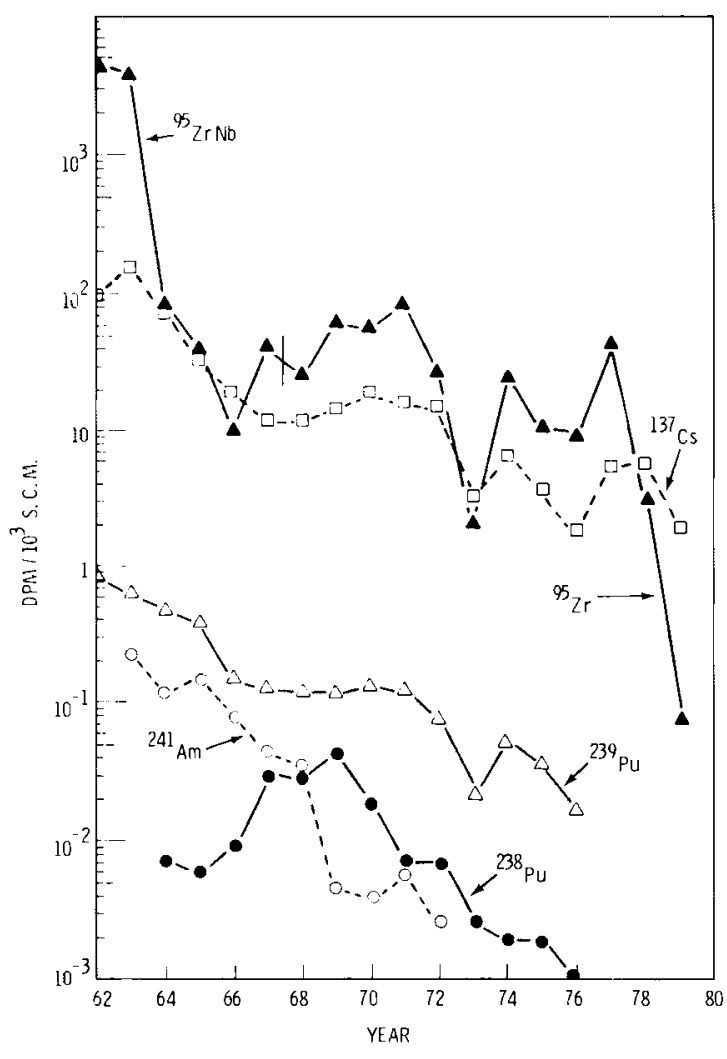

FIGURE 14. Average Yearly Radionuclide Concentrations at Richland, Washington 
generator in the upper atmosphere following the failure of a navigational satellite to achieve a stable orbit. The concentrations of other medium-to-long-1ived (weeks to years) radionuclides have shown about the same change with time as ${ }^{95} \mathrm{Zr},{ }^{137} \mathrm{Cs},{ }^{239} \mathrm{Pu}$ and ${ }^{241} \mathrm{Am}$.

The Chinese conducted only two small (less than 20 kilotons) tests in 1978 and have not yet conducted any in 1979. As a result, the concentrations of nuclear weapons radionuclides, especially those with short half-lives, have decreased in 1978 and 1979. However, the concentrations are still considerably higher than those that have resulted or would be expected to result from releases by nuclear power reactors. It has been estimated that in 1978 the radiation dose to the population from nuclear weapons radionuclides was 20 or 30 times that from reactor releases (Marx 1979). If the Chinese continue their past schedule of testing, they would be expected to conduct a test in the near future that would cause concentrations to rise.

Beryllium-7 and Sodium-22. The radionucl ides beryl1ium-7 (53d) and sodium-22 $(2.6 y)$ are produced by spallation reactions of cosmic rays with atmospheric gases. Their production rates increase by about three orders of magnitude between ground level and the lower stratosphere. However, ${ }^{22} \mathrm{Na}$ is also produced by nuclear weapons tests. Large-scale atmospheric testing by the United States and Russia in 1961 and 1962 caused the ${ }^{22} \mathrm{Na}$ concentrations at Rich1 and to rise to a maximum in 1963 (Figure 15). The concentrations at Richland and Barrow decreased rapidly unt il 1966, but have decreased only slowly since that time, presumably because of atmospheric testing by the Chinese. The continued slow decrease in the ${ }^{22} \mathrm{Na}$ concentrations indicates that an appreciable fraction of the $22 \mathrm{Na}$ in the atmosphere is still of nuclear weapons origin.

Berryllium-7 was not produced in significant quantities by nuclear weapons tests, but its yearly average concentrations have still changed with time (Figure 16). The production rates of cosmogenic radionuclides would be expected to vary inversely with sunspot number since the high magnetic fields associated with sunspots tend to shield the earth from intergalactic cosmic rays. Beryllium-7 concentrations at Rich1 and and Barrow appear to show the expected inverse correlation with sunspot number, except at Richland before about 1968. One would have expected, based on sunspot num-

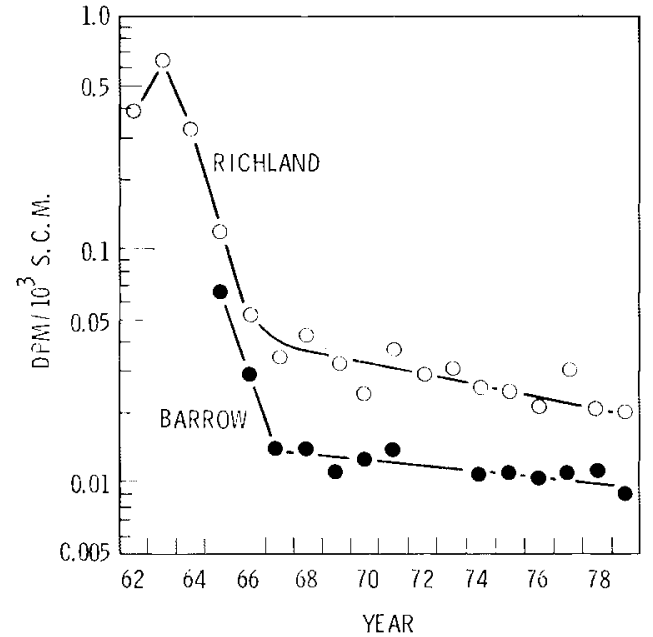

FIGURE 15. Yearly Average ${ }^{22} \mathrm{Na}$ Concentrations

ber, that the ${ }^{7}$ Be concentration would have increased at Richland in going back in time from 1968 to 1964. The reason for the continuing decrease of ${ }^{7} \mathrm{Be}$ is not clear and needs further investigation. Before 1968 , ${ }^{7} \mathrm{Be}$ was measured with a $\mathrm{NaI}(\mathrm{Tl})$ detector, whereas a $\mathrm{Ge}(\mathrm{L} i)$ detector has been used since. Thus, there was a greater uncertainty in the earlier data, but we do not feel that this could have produced a bias in the results.

\section{Seasonal Variations}

Nuclear Weapons Radionuclides. The concentrations of nuctear weapons radionuclides and natural radionuclides have shown pronounced seasonal variations, but the seasonal variations have shown considerable differences between Richland and Barrow and between radionuclides of different sources. In addition to the seasonal variations, there have been fairly large short-term fluctuations that have presumably resulted from variations in meteorological processes such as precipitation scavenging. Therefore, the radionuclide concentrations were averaged over several years to provide a clearer picture of the average seasonal variations. The average concentrations of $137 \mathrm{Cs}$ for each month at Richland and Barrow during the period from 1967 through 1978 are shown in Figure 17. The seasonal variations of other medium to long-lived nuclear weapons radionuclides were very similar to those of ${ }^{137} \mathrm{Cs}$, al though the concentrations of $95 \mathrm{Zr}$ (65d) and ruthenium-103 (40d) peaked slightly earlier in the year than did the 


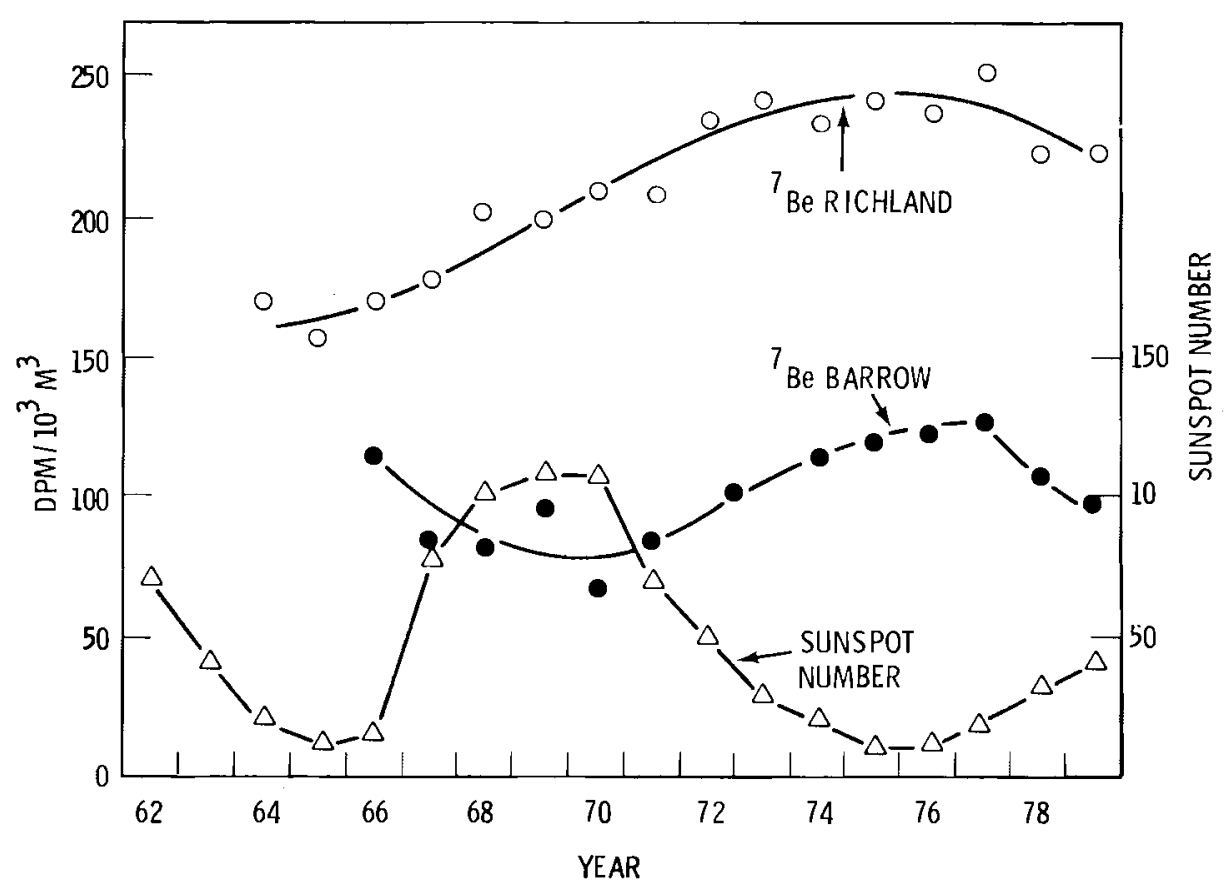

FIGURE 16. 'Be Concentration and Sunspot Number Versus Year (Sunspot Number from K. D. Wood. 1972. Nature. 240:91-93)

${ }^{137} \mathrm{Cs}$ concentrations, presumably because of the radioactive decay of ${ }^{35} \mathrm{Zr}$ and $10{ }^{3} \mathrm{Ru}$.

The ${ }^{137} \mathrm{Cs}$ concentrations increased to a maximum in March and then decreased to a minimum in August at Barrow. However, the concentrations did not reach a maximum until June and a minimum until December at Richland. The spring maximums were presumably the result of the spring maximum in the rate of transport of radionuclides from the stratosphere into the troposphere through the tropopause gap region. The prominence of the spring peak indicates that the majority of the medium to long-lived radionuclides measured at Richland and Barrow during this period had been injected into the stratosphere and later transported into the troposphere, even though the Chinese conducted several tests that injected debris primarily into the troposphere.

At all times of the year the concentrations of the nuclear weapons radionuclides were appreciably higher at Richland than at Barrow. The decrease in the concentrations at Barrow between March and August could be the result of a decrease in the rate of transport of radionuclides from middle to high latitudes resulting from the decrease in the rate of meridional mixing that occurs at this time. Radionuclides attached to aerosols have a relatively short residence time in the troposphere ( 3 to $4 \mathrm{wk}$ ); therefore, the concentrations would begin to decrease rapidly when the source strerigth was decreased. In the fall, the rate of meridional mixing increases again, which would tend to increase the concentrations at high latitudes and accelerate the decrease at middle latitudes.

Beryllium-7 and Sodium-22. The seasonal variations of the cosmogenic radionuclides ${ }^{7} \mathrm{Be}$ and ${ }^{22} \mathrm{Na}$ were very similar to those of the nuclear weapons radionuclides (Figures 18 and 19). The large spring maximums indicate that the majority of the ${ }^{7} \mathrm{Be}$ and $22 \mathrm{Na}$ measured at Richland and Barrow was produced in the stratosphere. However, the differences between the ${ }^{7} \mathrm{Be}$ and ${ }^{2} 2 \mathrm{Na}$ concentrations at Richland and those at Barrow 


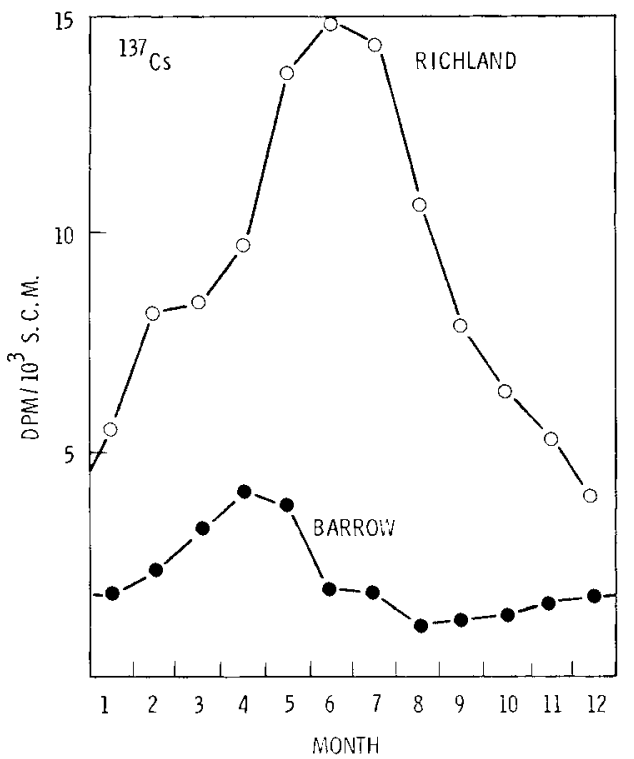

FIGURE 17. Average Monthly ${ }^{137} \mathrm{Cs}$ Concentration Since 1967

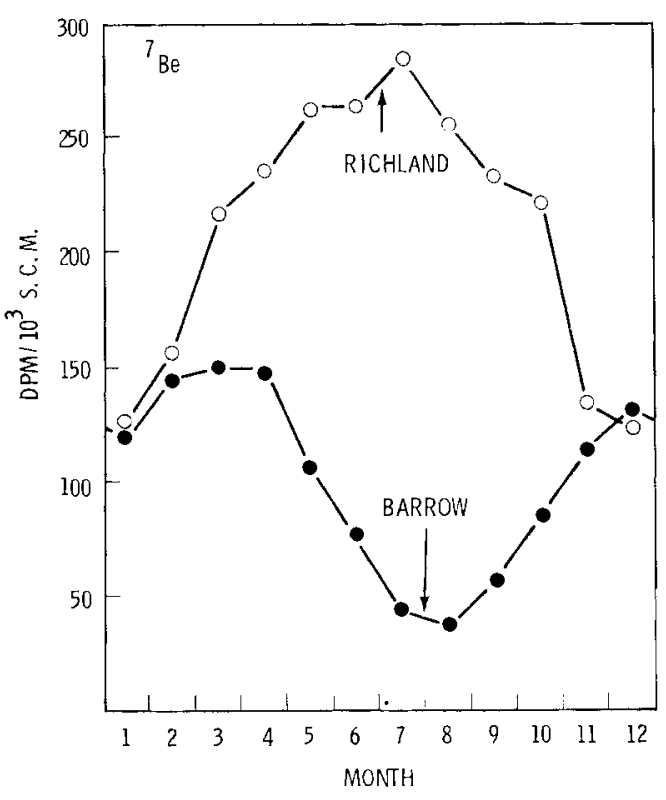

FIGURE 18. Average Monthly ${ }^{7} \mathrm{Be}$ Concentrations from 1964 Through 1978

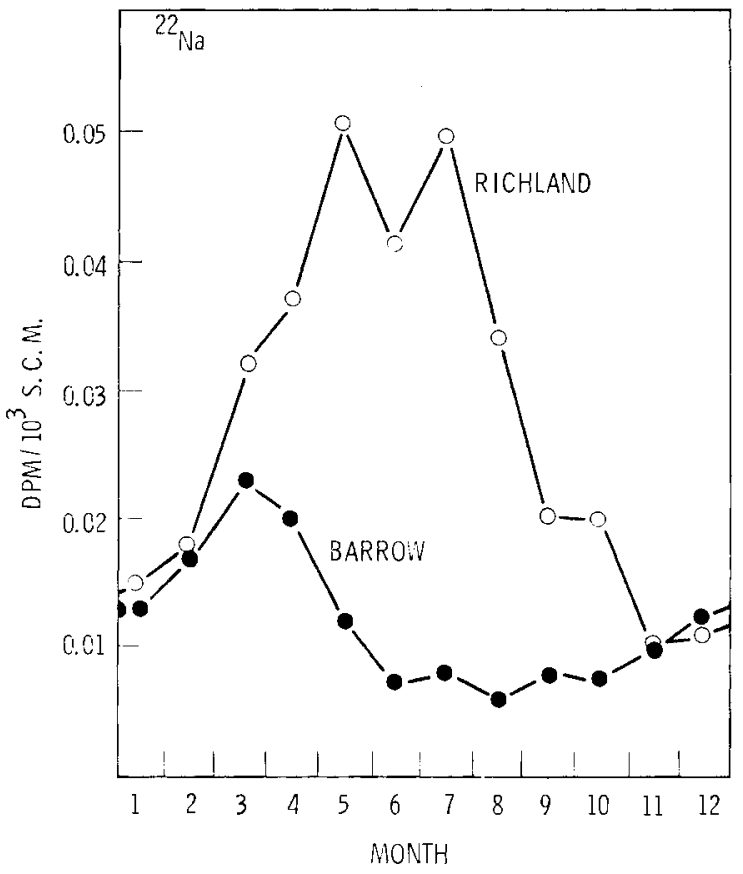

FIGURE 19. Average ${ }^{22} \mathrm{Na}$ Concentrations at Richland and Barrow from 1967 Through 1978

were considerably smaller than was the case for nuclear weapons radionuclides. The average ratio of the Richland to the Barrow concentration was 2.1 for ${ }^{7} \mathrm{Be}, 2.4$ for $22 \mathrm{Na}$, and about 4 for the nuclear weapons radionuclides. Tropospheric production of ${ }^{7} \mathrm{Be}$ and ${ }^{22} \mathrm{Na}$ may have decreased the difference in the concentrations between Richland and Barrow.

There were some differences between the seasonal variations of ${ }^{7} \mathrm{Be},{ }^{22} \mathrm{Na}$, and the nuclear weapons radionuclides. At Richland the concentrations of the nuclear weapons radionuclides increased somewhat earlier in the spring than did the ${ }^{7} \mathrm{Be}$ concentrations, but the opposite was true at Barrow. The net result was that the ${ }^{7}$ Be variations were appreciably farther out of phase between Richland and Barrow than were the nuclear weapons radionuclides. The $22 \mathrm{Na}$ seasonal variations seemed to be between those of

${ }^{7} \mathrm{Be}$ and the nuclear weapons radionuclides, 
presumably because ${ }^{22} \mathrm{Na}$ is produced both by nuclear weapons and cosmic rays.

Lead-210. Radon $(222 \mathrm{Rn})$ is a radioactive gas produced in crustal material by the uranium decay chain with a 3.8 day halflife. After the formation of radon, the gas diffuses into the atmosphere where it decays through a series of daughter radionuclides until stable lead-210 is produced. The only daughter radionuclide with a long half-life in this series is $210 \mathrm{~Pb}(22 y)$. Its concentrations have shown large seasonal variations at Richland and Barrow, but these variations have been considerably out of phase with those of ${ }^{7} \mathrm{Be},{ }^{22} \mathrm{Na}$ and the nuclear weapons radionuclides (especially at Richland). The $210 \mathrm{~Pb}$ concentrations increased to a maximum in January and decreased to a minimum in May at Richland, but did not reach a maximum until February and a minimum until June at Barrow (Figure 20). The concentrations averaged on 1 y $20 \%$ higher at Richland than at Barrow.

Short-lived Radionuclides from Chinese Nuclear Tests. The People's Republic of China conducted a small (less than $20 \mathrm{kilo-}$ ton) atmospheric nuclear test on December 14, 1978. Debris from this test was first detected at Richland in a sample collected from 1105 to 1412 on December 22, 1978. The radionuclide concentrations measured at Richland following this test were considerably lower than those that were measured following some of the previous Chinese tests (Table 6).

A fairly large fraction of the radionuclides from the December 1978 test were associated with relatively large particles, but the size distribution was somewhat smaller than that measured following several previous tests. The percentages of several radionuclides associated with particles larger than 1.3 microns in diameter are reported in Table 7 for the tests for which size distributions were measured. These were all tests that injected debris primar-

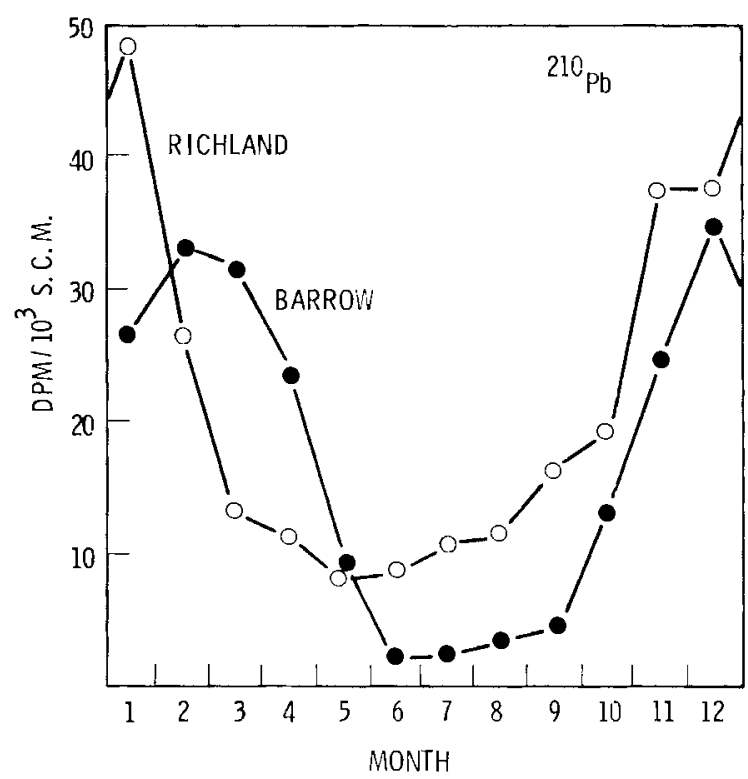

FIGURE 20. Average 210pb Concentrations at Richland and Barrow from 1975 Through 1978

ily into the troposphere. The size distribution of debris that has been injected into the stratosphere and later transported into the troposphere is typically much smaller, more like that of cosmogenic ${ }^{7} \mathrm{Be}$ (Table 7).

The physical and chemical forms of iodine-131 produced by the December 1978 test were measured using a special ${ }^{131}$ I sampler. We found that $52 \%$ of the ${ }^{131}$ I was associated with particulates, $43 \%$ was in gaseous organic forms, and only $5 \%$ was in inorganic gaseous forms. The relative concentrations of I3II in the different forms have varied considerably between different nuclear tests (see Table 8).

\section{Reference}

Marx, J. L. 1979. "Low-Level Radiation: Just How Bad is It?" Science. 204:160-164. 
TABLE 6. Maximum Radionuclide Concentrations Measured at Richland, Washington Following Chinese Nuclear Tests

\begin{tabular}{|c|c|c|c|c|c|c|c|c|}
\hline \multirow[b]{2}{*}{ Date of Test } & \multicolumn{8}{|c|}{ Concentration in $\mathrm{dpm} / 10^{3} \mathrm{~m}^{3}$} \\
\hline & ${ }^{95} \mathrm{Zr}$ & ${ }_{99}^{990}$ & ${ }_{131}(a)$ & ${ }^{132} \mathrm{Te}$ & ${ }^{140} \mathrm{Ba}$ & ${ }^{141} \mathrm{Ce}$ & ${ }^{237} \mathrm{U}$ & ${ }^{239} \mathrm{~Np}$ \\
\hline $\begin{array}{l}\text { December } 14, \\
1978\end{array}$ & 2.6 & 120 & 179 & 573 & 343 & 88 & 10.6 & 1,840 \\
\hline $\begin{array}{l}\text { March 15, } \\
1978\end{array}$ & 113 & 2470 & 2750 & 7980 & 2230 & 557 & NM & 10,100 \\
\hline $\begin{array}{l}\text { September } 17 \text {, } \\
1977\end{array}$ & 162 & 359 & 317 & 182 & 383 & 195 & 65.6 & 1100 \\
\hline $\begin{array}{l}\text { September } 26 \text {, } \\
1976\end{array}$ & $N M^{(b)}$ & 8200 & 1460 & 3300 & 3500 & 600 & 170 & 80,000 \\
\hline $\begin{array}{l}\text { June } 26, \\
1973\end{array}$ & 8.5 & 173 & 56 & 156 & 80.5 & 18.0 & 328 & 2040 \\
\hline $\begin{array}{l}\text { March 18, } \\
1972\end{array}$ & 430 & 3680 & 303 & NM & 87 & 213 & 4140 & 74,100 \\
\hline $\begin{array}{l}\text { January } 7, \\
1972\end{array}$ & 47 & 421 & 102 & $N M$ & 123 & 58 & 4.5 & 406 \\
\hline
\end{tabular}

TABLE 7. Radionuclide Size Distributions Measured at Richland, Washington Following Chinese Nuclear Tests

\begin{tabular}{|c|c|c|c|c|c|c|c|c|c|}
\hline \multirow[b]{2}{*}{ Date of Test } & \multicolumn{9}{|c|}{$\begin{array}{l}\text { Percent Associated with Particles Greater } \\
\text { Than } 1.3 \text { Microns in Diameter }\end{array}$} \\
\hline & ${ }^{95} \mathrm{Zr}$ & ${ }^{99} \mathrm{Mo}$ & 131 & ${ }^{132} \mathrm{Te}$ & ${ }^{140} \mathrm{Ba}$ & ${ }^{141} \mathrm{Ce}$ & ${ }^{237} \mathrm{U}$ & ${ }^{239} \mathrm{~Np}$ & ${ }^{7} \mathrm{Be}$ \\
\hline $\begin{array}{l}\text { December } 14, \\
1978\end{array}$ & $N M(a)$ & NM & 41 & 43 & 19 & 37 & $N M$ & NM & 6 \\
\hline $\begin{array}{l}\text { March 15, } \\
1978\end{array}$ & 51 & 64 & 50 & 60 & 52 & 59 & $N M$ & 63 & 15 \\
\hline $\begin{array}{l}\text { September } 17 \\
1977\end{array}$ & 62 & 84 & 66 & 81 & 73 & 79 & $N M$ & 91 & 20 \\
\hline $\begin{array}{l}\text { September } 26 \text {, } \\
1976\end{array}$ & 77 & 74 & 62 & 63 & 58 & 66 & 74 & 76 & 20 \\
\hline $\begin{array}{l}\text { June } 26 \text {, } \\
1973\end{array}$ & 71 & 88 & 51 & 75 & 84 & 79 & 80 & 77 & NM \\
\hline
\end{tabular}

(a) Not measured 
TABLE 8. Relative Concentrations of "31 in Different Chemical and Physical Forms Measured at Richland, Washington Following Chinese Nuclear Tests

\begin{tabular}{|c|c|c|c|}
\hline \multirow[b]{2}{*}{ Date of Test } & \multicolumn{3}{|c|}{ Percentage in Each Form } \\
\hline & Particulate & $\begin{array}{c}\text { Gaseous } \\
\text { (Organic) } \\
\end{array}$ & $\begin{array}{c}\text { Gaseous } \\
\text { (Inorganic) }\end{array}$ \\
\hline $\begin{array}{l}\text { December } 18 \\
1978\end{array}$ & 52 & 43 & 5 \\
\hline $\begin{array}{l}\text { March 15, } \\
1978\end{array}$ & 80 & 8 & 12 \\
\hline $\begin{array}{l}\text { September 17, } \\
1977\end{array}$ & 76 & 11 & 13 \\
\hline $\begin{array}{l}\text { September } 26 \text {, } \\
1975\end{array}$ & 76 & 10 & 14 \\
\hline $\begin{array}{l}\text { June } 26, \\
1973\end{array}$ & 17 & 38 & 45 \\
\hline
\end{tabular}

\section{- Arid Lands Ecology (ALE) Climatology}

Objectives of this study are:

- Operating the temperature and precipitation network on the Arid Lands Ecology (ALE) reserve at Hanford.

- Issuing daily and monthly summaries of data from the network.

- Analyzing climatological data from the network, such as cross-correlations between daily and monthly temperature stations.

Correlations of Extreme Air Temperatures at $30 \mathrm{~cm}$ and $120 \mathrm{~cm}$ on the $\overline{A L E}$ Reserve, Hanford

\section{J. M. Thorp}

Monthly maximum and minimum temperatures at $30 \mathrm{~cm}$ above ground have been measured at 26 sites on the Arid Lands Ecology (ALE) Reserve of the Hanford Project since 1971. These measurements are made from mercuryin-glass maximum/minimum thermometers. At six of these sites, recording thermograpis provide continuous temperature data at $120 \mathrm{~cm}$ above ground.
Rain, snow, deep dust or washout have occasionally prevented scientists from reaching one or more of the remote sites on the scheduled monthly basis. To make estimates of such missing data or to provide temperature estimates at $30 \mathrm{~cm}$ for times other than those when the monthly extremes occur, the $30-\mathrm{cm}$ and $120-\mathrm{cm}$, monthly extreme temperatures from the rat.tlesnake Springs station (Tha? . ... Meteorology Station) for $\because . \quad$ Sey: ber 1971 to May 1979 have

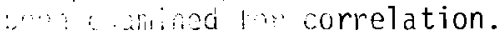


The correlation coefficient, $r$, is 0.9963 , which indicates a cTose correlation (perfect correlation when $r= \pm 1.0$ ) between the temperatures at $30 \mathrm{~cm}$ and those at $120 \mathrm{~cm}$. The coefficient of determination, $r^{2}$, equals 0.9926 , which means that $99 \%$ of the variance in $30-\mathrm{cm}$ extreme temperatures can be explained by differences in the $120-\mathrm{cm}$ extreme temperature values for the same month. Calculations have been made on a sample size of 149 data points. These points are plotted in Figure 21 and the regression curve is drawn in. The $\gamma$-intercept shows that, on the average, extreme monthiy temperatures at $30 \mathrm{~cm}$ are slightly more than $2^{\circ} \mathrm{F}$ colder than at $120 \mathrm{~cm}$ for the Rattlesnake Springs site. The regression equation,

$T_{30}\left({ }_{\mathrm{cm}}^{\circ} \mathrm{F}\right)=1.06 \mathrm{~T}_{120}\left({ }_{\mathrm{cm}}^{\circ} \mathrm{F}\right)-2.26$; wi11 provide statistically reliable estimates of daily temperature at $30 \mathrm{~cm}$ at this site.
Daily temperature records for periods of 3 to 8 yr have been made at or near seven other sites within the ALE Reserve. The, site elevations range from $210 \mathrm{~m}$ (MSL) (a) at Ratt7esnake Springs to $1075 \mathrm{~m}$ (MSL) at the Rattlesnake Mountain Observatory. The $30-\mathrm{cm}$ and $120-\mathrm{cm}$ temperature data from these seven stations will be compared at a later date.

\section{Reference}

Thorp, J. M. and W. T. Hinds, 1977, Microclimates of the Arid Lands Ecology Reserve, 1968-1975. BNWL-SA-6231, p. 5, Pacific Northwest Laboratory, Richland, WA.

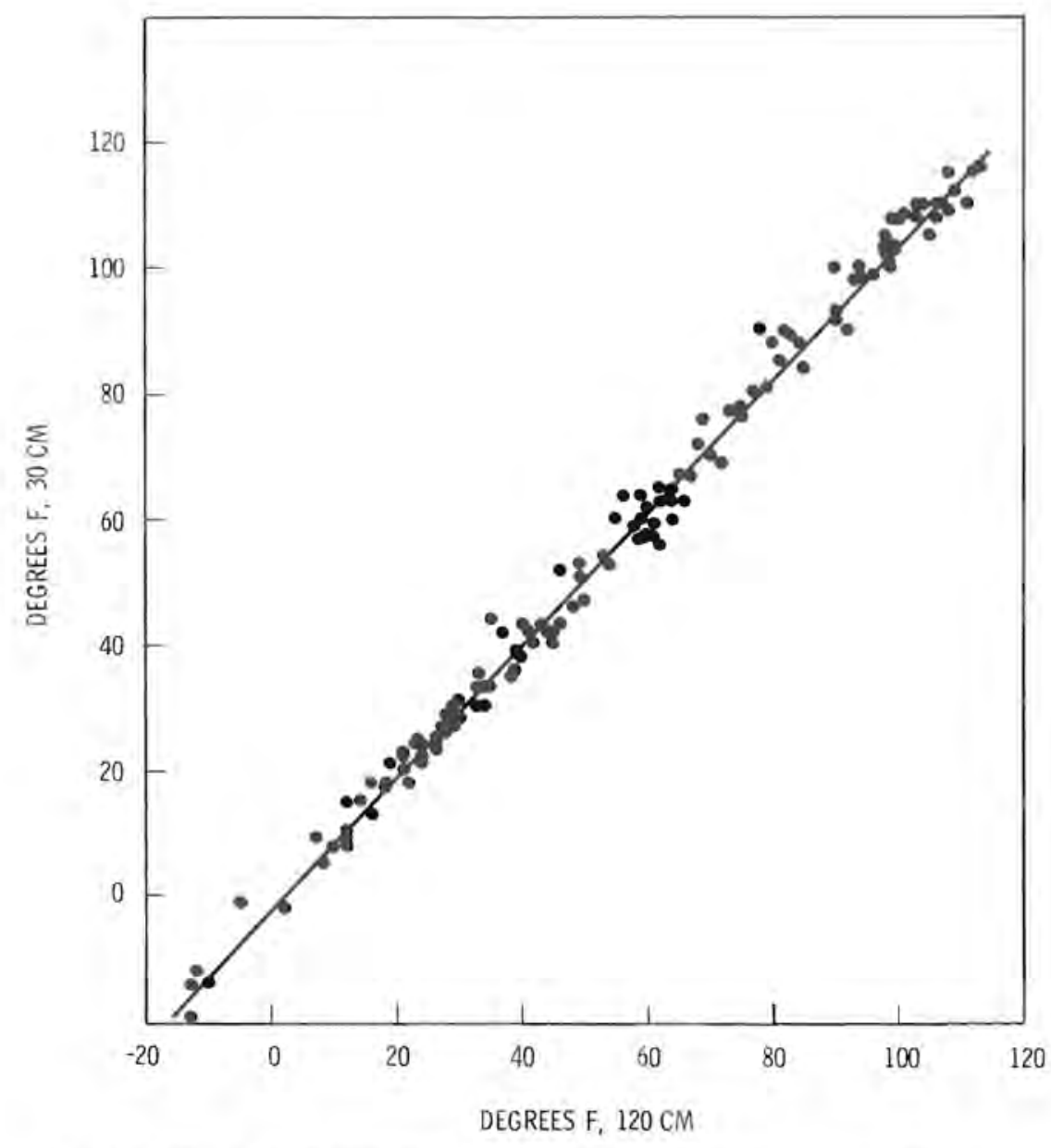

FIGURE 21. Thirty-Centimeter Monthly Extreme Temperature Versus-120-cm Monthly Extreme Temperature at Rattlesnake Springs, 1971-1979 


\section{- Atmospheric Boundary Layer Studies}

Objectives of these studies are:

- Investigating the meteorological characteristics of the planetary boundary layer that pertain to pollutant transport and dry removal.

- Analyzing the transport and diffusion of pollutants in complex terrain, particularly in the Geysers Geothermal Area of California.

- Constructing simple models for the prediction of the depth, speed and direction of gravity-controlled drainage flows and pollutant dispersion within these flows.

Comparative Study of the Hanford Dispersion Model

\section{J. G. Droppo}

Documented here is a comparison of the Hanford atmospheric dispersion model with recently compiled dispersion data bases.

The Hanford Model for computing atmospheric dispersion as documented in Heteorology and Atomic Energy (MAE) (1968, p. 141) has been historically used for dispersion estimates at Hanford. Since this model was based on dispersion tests at Hanford, the model has been promulgated as the best relationship for predicting dispersion at Hanford.

Only the Model formulations for stable atmospheric conditions were based on onsite Hanford studies; the equations for neutral and unstable conditions noted in MAE were Sutton's original dispersion relationships, which were in use at Hanford at the time MAE was compiled. However, many of the environmental and accident analyses at Hanford in recent years have used the Pasquil1Gifford formulations for neutral and unstable conditions in place of the older Sutton equations.

The original formulations of the Hanford Model parameters for lateral and vertical dispersion under stable conditions were made separately. Comparisons of these components are considered separately here. The lateral comparisons are between observed and measured values of sigma-y for a number of data sets. The vertical comparisons are between predicted and measured normalized crosswind integrated concentrations (CWIC). CWICs contain only vertical dispersion parameters.

The data base for the comparisons includes the original data used in the model formulation, and additionally, Hanford Green Glow, Prairie Grass, and NRTS data. References to sources of these data are in Horst, Doran and Nickola (1979).

Figure 22 shows a comparison of measured and computed sigma-y $\left(\sigma_{y}\right)$ values. The computed value for $\sigma_{y}$ is determined from

$$
\sigma_{y}^{2}=A t-\frac{A^{2}}{2\left(\sigma_{\theta} \bar{u}\right)^{2}}\left\{1-\exp \left[\frac{2\left(\sigma_{\theta} \bar{u}\right)^{2} t}{A}\right]\right\}
$$

where $t$ is travel time, $\bar{u}$ the wind velocity, $\sigma_{\theta}$ the standard deviation of wind direction, and $A$ a constant evaluated from the empirically determined relationship

$$
A=13.0+232 \sigma_{\theta} \bar{u}
$$

Figure 23 is a comparison of predicted and normalized crosswind concentrations (CWIC). Since CWICs are a function of $\sigma_{z}$ values alone, they provide a basis for evaluating the vertical dispersion predictions by the Hanford Model. In the Hanford Model, $\sigma_{z}$ is computed from

$$
\sigma_{z}^{2}=a\left[1-\exp \left(-k^{2} t^{2}\right)\right]+b t
$$

The values of $a, k$, and $b$ depend on stability. In evaluating these plots, note that factors such as different sampling times and calibration methods will contribute to the scatter between different data sets. In addition, different sites may not have the same dispersion characteristics. The agreement between the predicted and measured lateral dispersion values shows that the predicted Hanford Model lateral dispersion values are reasonable. Some variations between data sets are the result of the factors noted above. For sigma-y values on the order of $1 \mathrm{~m}$, the Prairie Grass data suggest a tendency for the Hanford Model to 


\section{HANFORD MODEL COMPARISON}

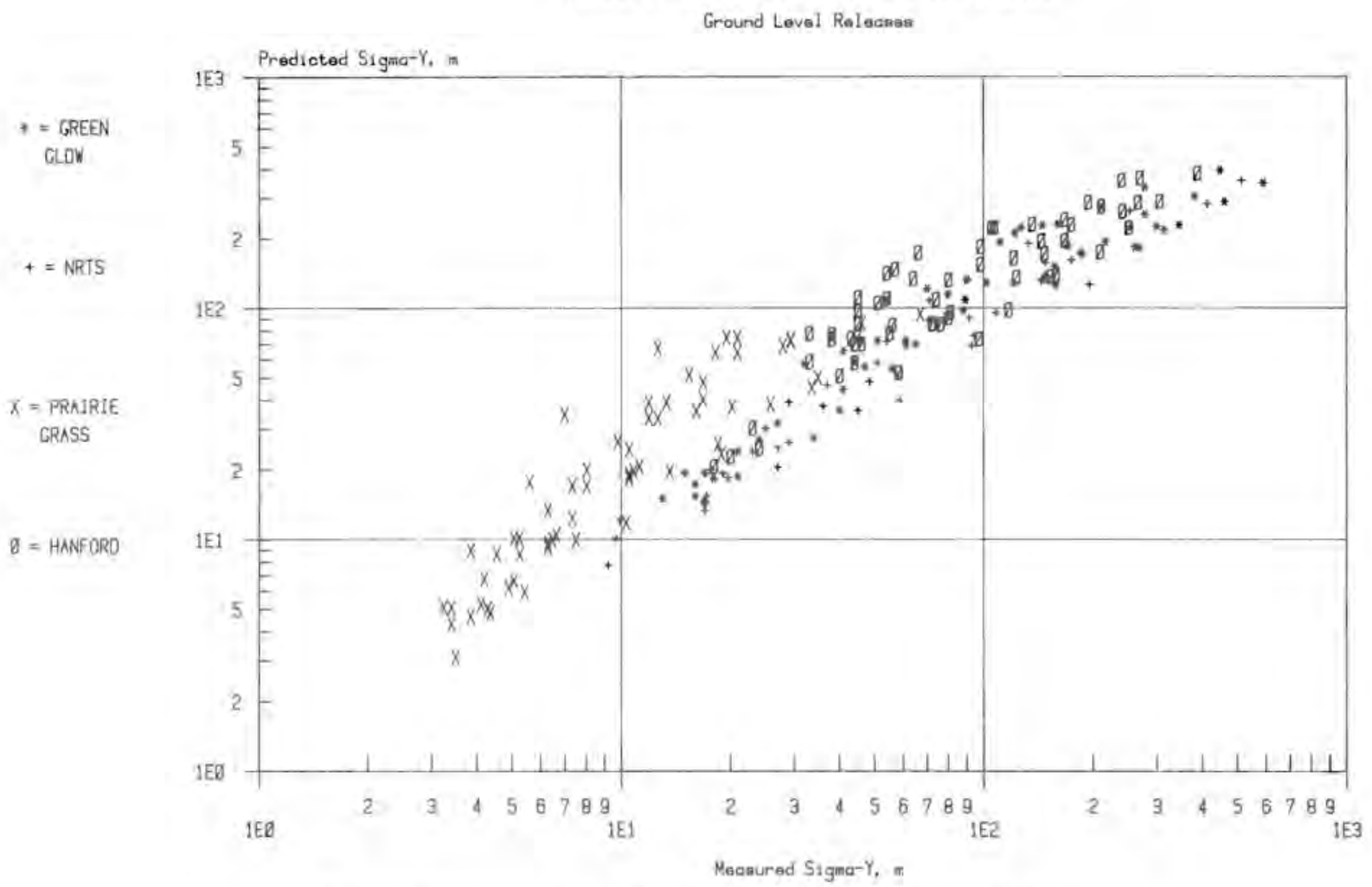

FIGURE 22. Comparison of Predicted and Measured Sigma-y Values

overpredict sigma-y values. This tendency to overpredict for relatively close distances is not borne out by the other data sets that have a better fit between predicted and measured values.

The vertical dispersion parameters agree only for the higher values of CWICs in Figure 23. This plot indicates that the Hanford Model for vertical dispersion is quite conservative; that is, the extent of vertical dilution is progressively underestimated at greater downwind distances. The extent of the conservatism may be overemphasized for the Green Glow data in this plot as a result of a possible over-estimate of the appropriate source terms. There is a possibility that significant deposition of larger tracer particles may have occurred, which means that the normalized crosswind integrated concentrations will tend to be lower than they should be to reflect dispersion alone.

The conclusion that the Hanford Model is conservative when extended beyond its original short range is indicated by all the other data sets plotted on Figure 23. However, the degree of conservatism is not as great as suggested by the Green GTow data.

Several additional comparisons beyond the current scope could be made to check the degree of conservatism of the Hanford Model. These involve a procedure for normalization of CWIC values to eliminate the effect of source term uncertainties and allow comparisons of the predicted and observed rates of change of dispersion.

At the distances typically used in peak value accident analyses, the overestimates in the lateral are nearly balanced by underestimates in the vertical dispersion parameters. In terms of these predicted air concentrations, the Hanford Model provides as accurate a fit with field results as can be expected in any model. The original Hanford Model was based on a much smaller data base for shorter ranges than used in these comparisons. Revision or replacement of the methodology of computing dispersion is indicated by these comparisons with the larger data base. 


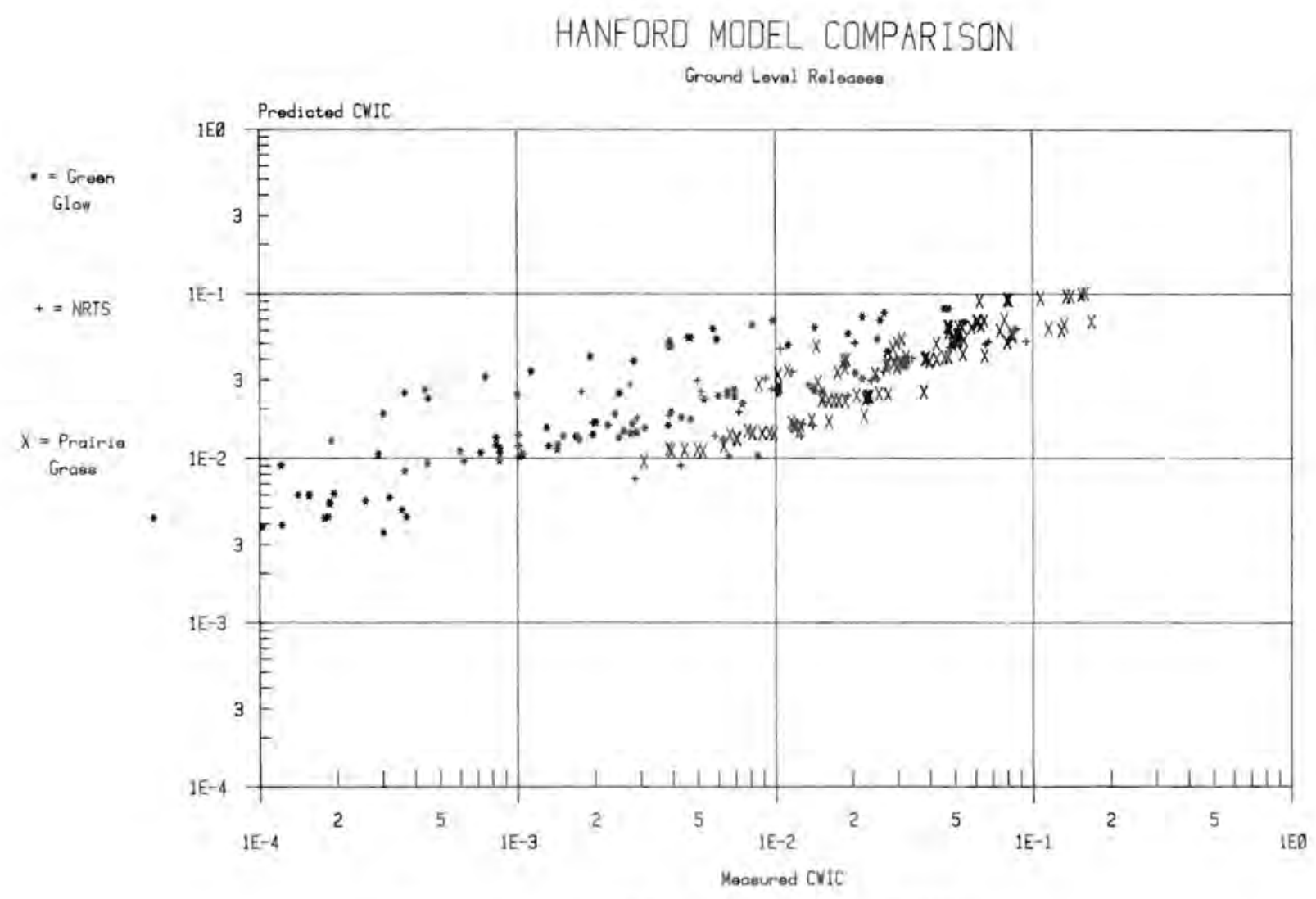

FIGURE 23. Comparison of Predicted and Measured CWIC

References

Horst, T. W., J. G. Doran, and P. W. Nickola.

1979. Evaluation of Empirical Atmospheric
Diffusion Data. NUREG/CR-0798, PiNL-2599, Nuclear Regulatory Commission, Richisand, WA.

Slade, D. H., ed. 1968. Meteorology and Energy. 1968. TID24190, USAEC, Office of Information Services. 
Oil Shale 



\section{OIL SHALE}

\section{- Oil Shale Fugitive Air Emissions}

\section{- DOE/RL Special Studies}

The primary oil shale regions of the country are in the Rocky Mountain West where any airborne pollutants will be emitted, transported, transformed and deposited over very complex terrain under meteorological conditions that are, at best, extremely complicated. This complexity dictates the development of a set of complex models and innovative field techniques.

PNL has assessed the future research needs in this area and has formulated an experimental design for atmospheric transport studies over the oil shale region. Other activities include:

- the development of wind field models for complex terrain

- the development of a tracer technique to measure dry deposition of pollutants over complex areas

- insolation and turbidity measurements over rough topography

- aerosol and visibility measurements

- deposition measurements of ambient airborne soil. 



\section{- Oil Shale Fugitive Air Emissions}

Objectives of this study are:

- Evaluating fugitive airborne particulate and gaseous emissions from the present and future oil shale activities.

- Investigating emissions from mining, transportation, material handling, crushing, retorting, and spent shale disposal sites.

- Identifying and classifying pollutants such as carbon monoxide, hydrogen sulfide, oxides of nitrogen, ozone, sulfur dioxide, hydrocarbons, and suspended particles.

Assessment of Research Needs in the $0 i 1$ Shale Industry

G. B. Parker

Introduction

Interest in commercial extraction of oil from shale has varied over the years. Presently, increasing demand for liquid fuels, decreasing petroleum supplies and increased fuel costs have again focused attention on the development of oil shale resources. Large-scale commercial development of the oil shale regions in the three-state area of Colorado, Wyoming, and Utah will result in a decline of the general air quality of the region. There are approximately 10 active commercial development sites in the region. These sites include federal lease tracts in Colorado ( $\mathrm{C}-\mathrm{a}$ and $\mathrm{C}-\mathrm{b}$ ) and Utah (U-a and $U-b)$, and in addition, private and stateleased developments scattered throughout the region.

Recognizing that oil shale development will cause air degradation, the industry and developers have over the past several years conducted air quality monitoring operations. Associated environmental impact studies have been required by the federal government on the federal lease tracts and/or by the states in which the developments are taking place. These studies have been evaluated and recommendations have been made for further studies to better assess the overall impact of a fully developed oil shale industry in the three-state area.
Genera 1

A number of processes have been proposed by the developers for extracting (retorting) oil from the shale. These processes are: 1) above-ground retorting, 2) modified insitu retorting, and 3 ) true in-situ retorting. Field developnent of these processes is in effect, yet no commercial-scale retorting has been demonstrated.

Emissions will arise from several activities during oil shale processing and any shale oil upgrading operations. These emissions include sulfur dioxide, hydrogen sulfide, oxides of nitrogen, carbon monoxide, hydrocarbons, ozone, polycyclic organic matter, particulates and unspecified trace elements.

Generally, above-ground retorting operations themselves do not involve significant atmospheric emissions; gaseous, liquid, and solid streams leaving the retort can be handled by downstream systems before reaching an atmosphere interface. However, features inherent in above-ground retorting methods influence the nature and magnitude of uncontrolled emissions such as those from the spent shale pile.

A modified in-situ and a true in-situ plant would be expected to produce uncontrolled emissions also since large quantities of gas are produced and vented, untreated, to the atmosphere. A certain amount of mining is required for both modified and true insitu retorting, and the associated 
uncontrolled mobile equipment and dust emissions would be similar to those associated with the mining for above-ground retorting.

\section{Air Quality Assessment Programs}

Complete environmental baseline reports have been issued by the oil shale developers on federal lease tracts ( $C-a, C-b, U-a, U-b)$, and environmental impact statements have been completed for two other developments, Colony Development Co. and Development Engineering, Inc., both in Colorado. Environmental monitoring studies by other developers are underway, but data was not readily available.

In all studies completed, the reports issued include descriptions of 1 ) the area meteorology and existing air quality, 2) several months of baseline data for the $\mathrm{Na}-$ tional Ambient Air Quality (NAAQ) criteria pollutants, and 3) model ing efforts to determine the transport of pollutants to assess the impact on air quality from commercial operations.

The studies show that the three-state region has one of the highest frequencies of inversions anywhere in the United States. Prevailing winds in the region are southwesterly with surface winds variable, being strong, spatial, diurnal and seasonal. The rugged terrain of the area causes turbulence within the boundary layer. Topography influences the mountain-valley system, which results in differential heating and cooling.

There are very few man-caused emissions in the oil shale areas, mainly because of the sparse population of the region. However, measurements during the studies indicated levels of ozone, and nonmethane hydrocarbons sometimes exceeded the primary NAAQ standards. A significant amount of haze has also been observed in valley regions.

The high levels of nonmethane hydrocarbons were later attributed to natural sources such as sagebrush. The source of ozone was attributed to the upper air mass from western urban regions or from stratospheric injection of ozone associated with the passage of storm fronts.

A variety of models were used in the environmental studies to determine ambient concentrations of pollutants from plant operations. These included Gaussian plume, gradient wind (APSIM), up-valley (APAX), EPA C7M3D, PTMTM and EPA C9M3D terrain models.
Evaluation of Environmental Programs

The programs instituted on the federal oil shale lease tracts did not answer the question, "What will be the environmental impact if the extensive oil shale resources of Colorado, Utah and Wyoming are developed?" Lack of integration of the data made it difficult to assess the environmental effects of an oil shale industry over the entire three-state region. There was little coordination of efforts among the lease-holders with a nonuniform data acquisition system. In other words, the data acquired have no realistic and practical use unless reworked.

Also, the meteorological data from the federal lease tracts to be used in modeling were not sufficient. No upper-air studies were conducted; the only data acquired were from two levels at a single site on each tract. In fact, a study for the Colony Development Corporation demonstrated difficulty in describing transport and diffusion of pollutants over complex terrain even when upper-air studies were conducted.

In all oil shale programs reviewed there were limitations in modeling efforts to predict air quality and environmental impact. These models used basic Gaussian equations in one form or another. Modeling efforts ranged from 1) simple applications estimating ground-level pollutant concentrations using meteorological data collected at a site not necessarily at the same geographic location as the plant site, to 2) complex studies simulating long- and short-term concentrations using data from tracer studies to predict influences of area topography and local meteorological data collected onsite. There are, however, limitations in these modeling studies, caused by using the following:

- strictly a Gaussian approach

- nonsite-specific meteorology

- inaccurate representative plant emission inventory data.

Research Needs and Requirements

The following research areas are required to fill the gaps identified in the evaluation of the developers' environmental programs. The studies below need to be integrated into a program for the entire region.

- A systematic study is required to characterize the particulates, gases and 
vapors in the air and deposited in water and on surfaces. Methods need to be developed to sample and analyze pollutants using the most sensitive instrumentation. This study should be done before site operations begin and after processsing of the shale is initiated.

- The physical transport and deposition of particulates, gases, and vapors need to be assessed. Such research should address 1) the applicability of existing information on transport phenomena to the oil shale development programs and 2) the need to provide additional information and develop improved predictive techniques for monitoring (especially) on a regional basis. Close cooperation with other research efforts, notably those addressing characterization of pollutants and ecology effects, will be required. This study will include field experiments such as tracer studies to assess dispersion and resuspension of pollutants applicable to complex terrain, and physical and chemical transformation and interaction of pollutants during transport.

- Also needed are 1) estimates of the air quality expected in the different regions likely to be developed, 2) evaluations of the need for pollution control under different levels of development or different combinations of technologies, and 3) determinations of suitable monitoring programs.

Al1 of the above research work should be put together in an integrated program involving a coordinated effort between scientists and engineers qualified to perform work on the various tasks. The research should be done over several years including the periods preceding development of an area to establish baseline data, during site preparation and construction, and after shale oil production is initiated. This research will provide answers for regulatory agencies, the public and the operators. concerned with the total environmental impact of an oil shale industry.

\section{Reference}

Parker, G. B. 1979. Review of Air Quality Assessment Studies and Definitions of Some Research Needs for the Emerging 0il Shale Technology. PNL-2910, Pacific Northwest Laboratory, Richland, WA.
Basis and Design of Atmospheric Transport Studies Proposed for the 0 il Shale Region

G. A. Sehme1

\section{Introduction}

Development of the $0 i 1$ shale industry must be encouraged with validated fugitive source and airborne plume depletion models directed toward predicting possible consequences of the developing industry. As an example, consider possible future litigation about the environmental impact of the $0 i 1$ shale industry. Based on existing knowledge and baseline measurements, the litigation could possibly be biased depending on the litigants' desires and locations at which air samples were collected. Questions could be raised such as:

- Were the baseline and subsequent air concentrations measured at the same locations during similar meteorological conditions?

- Are the monitoring sites truly representative of the area, or are the monitoring sites biased, either high or low, including dependency upon the proximity to roads, sources and location of the sites within the variable local airflow patterns?

- Can downwind concentrations be predicted from validated models?

- What are the confidence limits for those predictions?

Data are needed to answer such questions.

\section{Modeling Needs}

Presentiy, there is some information concerning ambient air concentrations of pollutants in the oil shale regions of Colorado and Utah. These baseline data have been acquired to fulfill lease requirements. Although extensive documentation covers these baseline studies, the prime results of the studies are that airborne particulates, nonmethane hydrocarbons, and oxidants concentrations have exceeded national ambient air quality standards (NAAQS).

Predictive transport models need to be developed/validated to describe air pollutant transport in the oil shale region. For 
example, the baseline results for sulfur dioxide and hydrogen sulfide in one study made for a prototype oil shale leasing program (C-b Shale 0 il Venture, Environmental Baseline Program Final Report, November 1974 through October 1976) points out the need for pollution transport models.

During the study, $\mathrm{SO}_{2}$ and $\mathrm{H}_{2} \mathrm{~S}$ were winddependent for measured airborne concentrations. As shown in Figure 1 for the three sampling stations along the Piceance Creek in Colorado 0 il Shale Tract C-b, maximum airborne concentrations occurred during nonprevailing wind directions. Apparently, valley plume entrapment occurred for these pollutants. When the valley was flushed by winds parallel to the valley axis, pollutants were transported to air sampling sites.

It is obvious that data from more than five Tract $C-b$ air quality sampling stations (data from three of these stations are illustrated in Figure 1) are needed to develop either predictive or site-specific transport models for the oil shale industry. Although additional analysis of existing baseline data is in progress by others, the potential development of either site-specific or

PNL-79H456-1

STATION 21

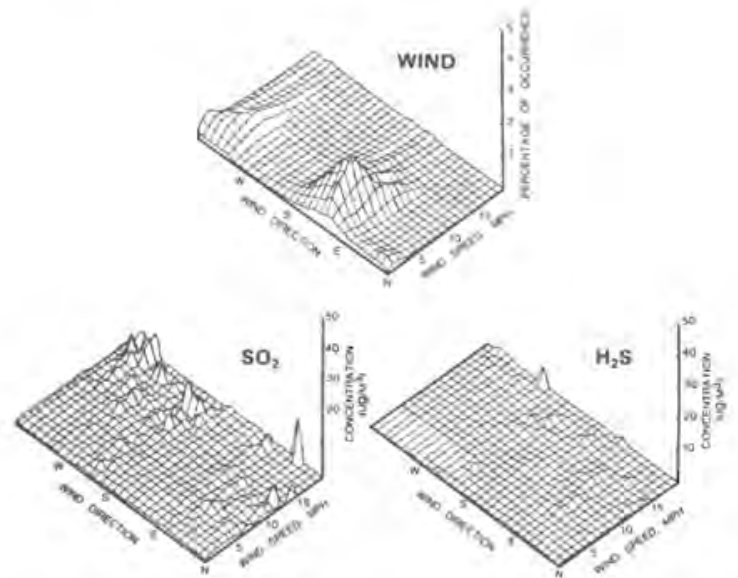

STATION 24

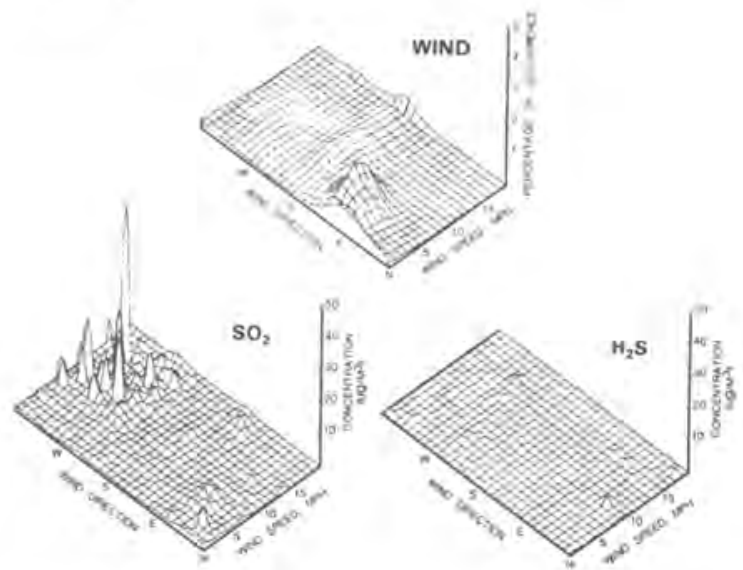

FIGURE 1. Tract C-b Air Quality Data 
general predictive fugitive emissions transport models from these data is optimistic. However, needed for model development are validation data (fugitive emissions, transformation during transport and plume depletion) for all phases of the oil shale industry. These phases include baseline data, construction of sites and their operation, and data about long-term effects after processing sites are deactivated.

Air monitoring stations for use in model development must be located at oil shale sites that adequately represent airborne pollutant concentrations in an area rather than at sites selected only because of current electrical power availability. That is, each selected sampling site should be selected based on proven relationships between airborne concentrations measured at that site compared to air concentrations throughout the adjacent region.

In addition, air monitoring site selection for model development requires that sites be responsive to and distinguish between emissions from the oil shale industry and those from local vehicular activity, including sportsman activity, vacation travel and other causes. Predictive emission and transport models must be developed from data bases that consider natural occurrences exceeding the NAAQS, while accurately predicting the air quality impact from an active oil shale industry. Data are needed for development of site-specific models, for determination of site-specific model predictive sensitivity and for the confidence intervals of predicted airborne concentrations that might be allowable based on the sensitivity analysis.

\section{Predictive Model Accuracy Estimates}

Approximately $6 \%$ of the United States' $0 i 1$ shale reserves are in the relatively rich Green River formation that lies within the complex terrain of Colorado, Utah and wyoming. Too few data. related to complex terrain models exist to base even a scientific judgment of the tentative accuracy estimates of predicted downwind airborne concentrations. In fact, the accuracy estimates of complex terrain models should show greater uncertainty than those for flat terrain models.

Accuracy estimates (Crawford et al. 1978) for flat terrain transport models are shown in Table 1. As the table shows, for a continuous release of emissions using a highly instrumented meteorological array, ground centerline concentrations can be predicted within only $\pm 20 \%$ for distances less than
$20 \mathrm{~km}$. This is the case even using the best existing predictive models to calculate the field conditions for which the models were developed. For other flat terrain conditions predictive accuracies are even much less. On a monthly or seasonal basis for downwind distances from 10 to $100 \mathrm{~km}$, the tentative accuracy estimate is a factor of \pm 4 . By analogy to general predictive models over flat terrain, the tentative accuracy estimates of complex terrain transport models that predict downwind airborne concentrations may be much greater than can be accommodated by a viable oil shale industry.

Predictive model accuracy requirements are also influenced by current/future regulations. At present, the prevention of significant deterioration (PSD) regulations allow only a small increment of airborne pollutants.

For particulates, the increment is as low as $5 \mathrm{\mu g} / \mathrm{m}^{3}$. This value seems unrealistic when model accuracies are considered. To demonstrate this unrealism, consider simple assumed conditions: a predictive model accuracy of $20 \%$ (the best even for flat terrain) and a "pristine" area particulate ambient concentration of $25 \mathrm{\mu g} / \mathrm{m}^{3}$ (a low numerical value). Thus, the uncertainty in predicting downwind transport of ambient "pristine" particulates is $5 \mathrm{\mu g} / \mathrm{m}^{3}(20 \%$ of $\left.25 \mu \mathrm{g} / \mathrm{m}^{3}\right)$. This uncertainty of $5 \mu \mathrm{g} / \mathrm{m}^{3}$ is the allowable increment. However, for fugitive emissions in complex terrain, the uncertainty is even larger than $5 \mathrm{\mu g} / \mathrm{m}^{3}$. This inability to accurately predict downwind airborne concentrations might hinder the development of the oil shale industry, even if it were in flat terrain.

\section{Experimental}

Currently, field experiments are being designed by Pacific Northwest Laboratory (PNL) to answer some of the unknowns previously discussed. Both ambient airborne pollutants and tracers will be measured in the oil shale region of Colorado beginning in the spring of 1980 . For gaseous pollutants, initially the distribution of ambient $\mathrm{SO}_{2}$ collected in liquid impingers will be investigated. Subsequent7y, depending on the availability of gas sampling and meteorological instrumentation as well as datalogging equipment, airborne gaseous pollutants will also be measured at one or two air sampling stations. The principal experimental technique for development of sitespecific models will be with multiple tracers with sulfur hexafluoride gas as the prime tracer. 
TABLE 1. Accuracy of Model Predictions

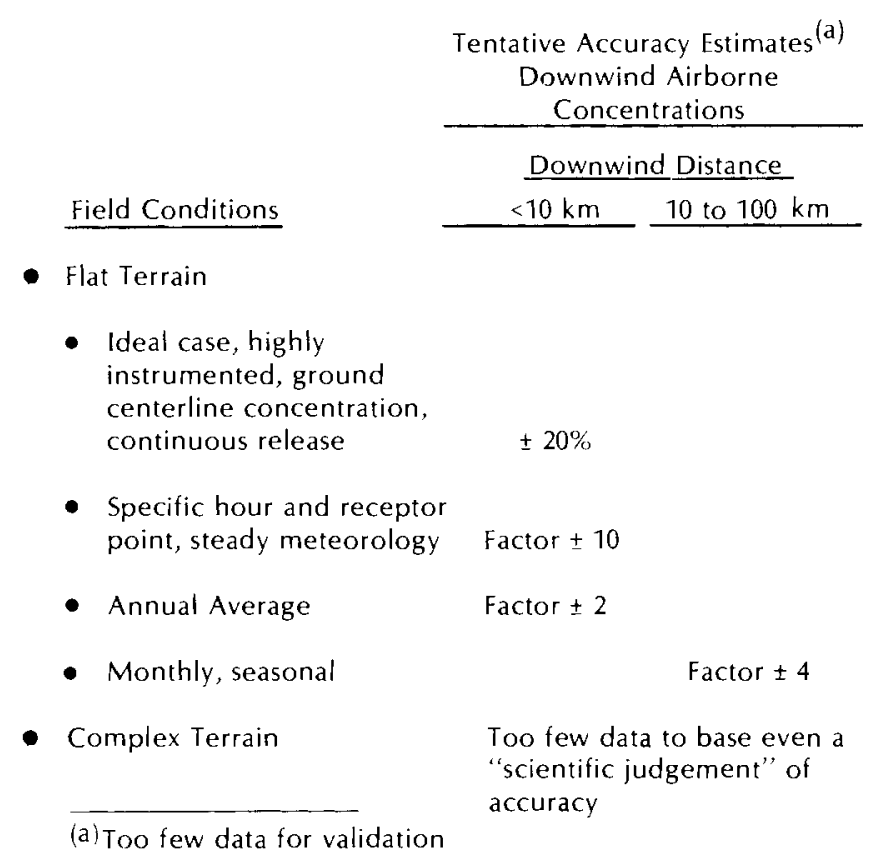

The experimental tracer technique being developed releases multiple tracers from proposed single or multiple emission sites. After airborne transport, the tracer concentrations will be measured downwind at multiple sampling sites activated by radio control signal. Each sampling site will consist of a radio receiver, a stepping switch for activating and deactivating a series of selected air sampling pumps, and air sampling bags and impingers for collecting or concentrating airborne pollutants. At present, equipment for 32 radio-controlled sampling stations are being assembled at PNL. Each station is battery-operated for ease of sampling station placement at any remote site, that is, from valley floor level up to mountain-top height. For ground- or towerbased operations, these stations can be located at any distance as long as there is a line of sight between the radio signal transmitter and signal receivers. During investigations of plume mixing on a regional scale, an airplane-mounted radio signal transmitter will possibly be used to activate receivers placed throughout the oil shale region. When radio transmission from an airplane is used, downwind plume mixing of selected elemental tracers for each source can be readily investigated.

Downwind $\mathrm{SF}_{6}$ samples will be collected in Tedlar bags at each of the radio-controlled air sampling stations. Air sampling will be a function of sampling time depending on the meteorology occurring, and sampling site locations will be adjusted to determine downwind flow characteristics for the $S_{6}$ gas simulant of fugitive emissions.

Once apparent optimum sampling site locations are determined, simultaneous releases of both nondepositing $\mathrm{SF}_{6}$ gas and depositing lithium stearate particles will be made. Real-time measurements of downwind airborne lithium particle concentrations will be measured at six sampling sites. The relative concentration decrease, lithium particle compared to $\mathrm{SF}_{6}$ gas, will be used as a basis for determining site-specific plume depletion transport models for particles. Transport and plume depletion will be investigated during all meteorological conditions as limited by the duration of each field 
experiment. Depending on experimental results, the experimental protocol in the field will be adjusted as deemed advisable based on the data collected.

\section{Conclusions}

It is anticipated that the investigations at selected sites will depend on the level of current or proposed oil shale activity. Possibly, a radio-controlled station will be located at each site at which baseline data were obtained. Such a comparison might allow more profitable use of the baseline data.

Since great uncertainty is inherent in current predictive techniques for airborne pollutant transport and plume depletion, predictive models need adaptation to or development on a site-specific basis. Because of the potentially rapid expansion of the oil shale industry to meet national energy requirements, we may have the time to develop site-specific, predictive models for complex terrain rather than accurate, general, validated models.

Tracer field experiments using many airsampling stations will be required to adequately describe and validate/adjust models to predict fugitive emissions, transport, and downwind plume depletion within the oil shale region. In addition, on a regional basis, models to predict the enhanced total or joint concentrations caused by plume mixing from several sources need to be developed and validated.

\section{References}

C-b Shale $0 i 1$ Venture (Ashland 0il, Inc. Occidental 0 il Shale, Inc.). November 1974 through October 1976. U.S. Dept. of Interior Prototype 0 il Shale Leasing Program, 0 il Shale Tract C-b, Environmental Baseline Final Report: Vol. III, Meteorology Air Quality, and Noise. Submitted to: $\mathrm{Mr}$. Peter A. RutTedge, Area 0il Shale Supervisor, Conservation Division, U.S. Geological Survey, Grand Junction, C0, pp. 30, 63, 134-135.

Hoffman, F. 0., ed. 1978. "Atmospheric Transport of Radionuclides." In Proceedings of a Workshop on the Evaluation of Models Used for the Environmental Assessment of Radionuclide Releases, September 6-9, 1977, Gatlinbutg, TN. CONF-770901, available from National Technical Information Service, U.S. Dept. of Commerce, Springfield, VA, pp. 1112.

\section{- DOE/RL Special Studies}

Objectives of these studies are:

- Collecting data from an airborne platform on scattering extinction coefficients, relative humidity, sulfate and trace metals over mountainous terrain in the Northwest.

- Analyzing seasonal, weekly and daily variations in spectral turbidity coefficients at Hanford.

- Examining differential turbidity effects of measured insolation between the Rattlesnake Observatory and the Hanford Meteorological Station.

Aerosol, Trace Elements and Visibility Measurements in Mountainous Terrain

M. M. Orgill, N. S. Laulainen, D. R. Drewes and R. N. Lee

This study was a continuation of an initial effort to collect data on the relationship between aerosols, trace elements, and visibility in mountainous terrain (Orgill, Drewes and Garcia 1979a; Orgill et al. 1979b). Data on scattering-extinction coefficient, relative humidity, sulfate and trace elements were collected in seven locations in or near mountainous terrain in the states of Washington, Oregon, and Idaho during the month of June 1978. During September 1978 similar data, including that related to ozone, was obtained at five additional locations. These data were obtained by an instrumented Cessna 411 fitying between $300 \mathrm{~m}(1000 \mathrm{ft})$ to $610 \mathrm{~m}(2000 \mathrm{ft})$ 
above the terrain east of the urban areas of Seattle and Portland.

The sampling data were obtained by three principal instruments: an integrating nephelometer, a high-volume filter sampler and an ozone analyzer. Data from the integrating nephelometer, ozone analyzer and temperature-dew-point probes were recorded automatically on a DAS 32 Data Acquisition system. The integrating nephelometer measures the scattering extinction coefficient

$$
b=b_{s p}+b_{s g}
$$

where $b_{s p}$ represents the component caused by light-scattering by aerosol and bsg represents the Rayleigh scattering as a result of gaseous air. Koschmieder's formula relates the total extinction coefficient, $b_{t}$, and meteorological range, $L_{v}$, by the simple formula

$$
L_{v}=\frac{3.9}{b_{t}}
$$

The other two components of the total extinction coefficient bt are: 1) $b_{a p}, a b-$ sorption as a result of particles, and 2) bag, absorption as a result of gases. In most haze conditions the se absorption components are considered much smaller than the scattering components. Therefore, Equation (2) is normally used as

$$
L_{v}=\frac{3.9}{b} \text {. }
$$

This relationship has been generally verified by comparing simultaneous measurements of both variables $L_{v}$ and $b$ at a site. However, the constant in the formula can vary from 1 to 4.4 as a result of the ambient relative humidity and other factors. Meteorological range is also approximately equal to the prevailing visibility $(a)$ when an observer is looking at prominent dark objects.

Sampling procedures and analysis for trace elements, sulfate, and ozone are discussed in Orgill, Drewes and Garcia (1979) and Orgill et a1. (1979). The concentration of anthropogenic trace elements such as lead, titanium, calcium, vanadium, nickel, zinc, chromium and arsenic were below $1 \mathrm{\mu g} / \mathrm{m}^{-3}$ for

(a) Prevailing visibility is defined as the greatest visibility that is attained or surpassed around at least half of the horizon circle, but not necessarily in continuous sections (Huschke 1959). all sampling flights. However, some concentrations of titanium, calcium and chromium were on the same order of magnitude or larger for similar trace elements in the San Francisco Bay area. Crustal trace elements such as iron, aluminum, silicon, potassium and calcium were often above $1 \mathrm{\mu g} / \mathrm{m}^{-3}$.

One of the chemical species suspected of increasing optical haze in regions distant from primary sources is sulfur, and particularly sulfate. Figure 2 shows the range of total sulfur and sulfate for all sample flights as determined from analysis of IPC and quartz filters. Generally, the levels of total sulfur and sulfate were below $1 \mathrm{\mu g} / \mathrm{m}^{-3}$ and $3 \mathrm{\mu g} / \mathrm{m}^{-3}$ respectively, except for sample Flights 2,6 and 9 .

Sample Flights 2 and 9 (and 8) were conducted over the Cascade foothills and valleys east of the Tacoma-Seattle-Everett-Bellingham urban areas. Flights 8 and 9 were flown over the same area on the same day, but Flight 9 was $152 \mathrm{~m}(500 \mathrm{ft})$ higher than Flight 8 at approximately $610 \mathrm{~m}(\sim 2000 \mathrm{ft}$ ) above the terrain and was flown in the afternoon. The weather and wind conditions for these days were favorable for haze formation, but the winds were light and variable and most of the visual haze was located near the coastal regions. Sample Flight 6 was taken in the Columbia Gorge during westerly winds. Apparently, the higher sulfur and sulfate concentrations were, in part, the result of pollutants being transported down the Gorge from the Portland metropolitan area.

Figure 3 represents the range of the total scattering extinction coefficient, relative humidity and ozone for all sample flights. Also included is the minimum meteorological range estimated from Equation (3). The bottom part of Figure 3 shows the approximate elevation range of each flight, general weather conditions, and the average prevailing visibility that existed at the nearest National Weather Service (NWS) weather stations.

Generally, the minimum meteorological range corresponded with visual observations taken during the sample flights. Flight visibility was generally good for all flights but was degradated by degrees of haze on sample Flights 2, 4, 6, 8 and 9 . A comparison of Figures 2 and 3 shows that the sample flights with higher sulfate concentrations were also the same five flights exhibiting the lower meteorological ranges. In addition, some of the higher relative humidities were observed on these flights. 


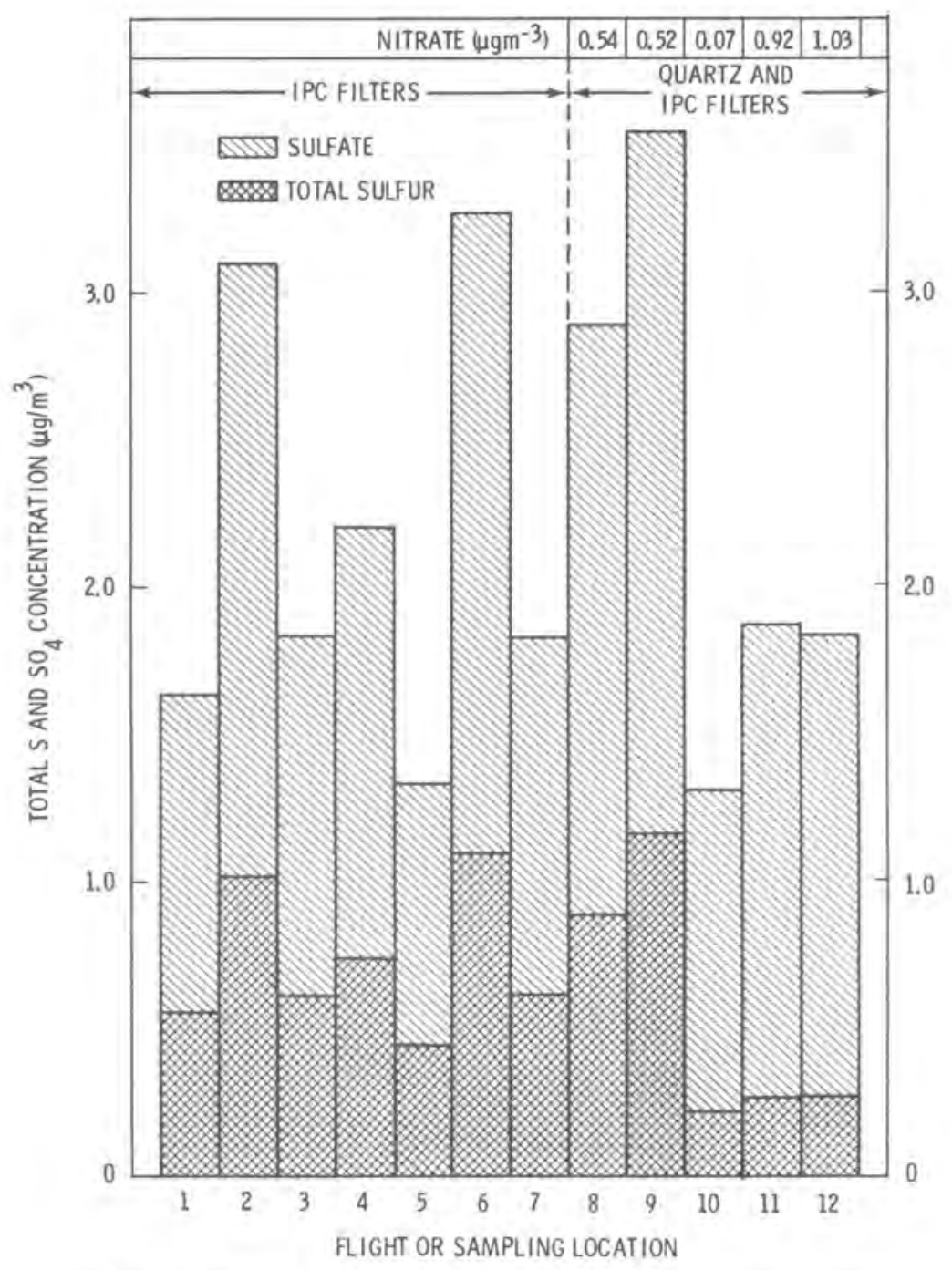

FiGURE 2. Total Sulfur, Sulfate and Nitrate Concentrations $\left(\mu \mathrm{g} / \mathrm{m}^{-3}\right)$ from Ambient Air Samples During the Twelve Sampling Flights

Sample Flights 3 and 4, taken over Snoqualmie Pass and Kittitas Valley on different days, were somewhat different in relation to the presence of sulfate and visual quality. Both flights showed about the same concentration of sulfate (Figure 2), but the meteorological ranges were quite different. A comparison of the trace element concentrations from these two flights showed that air samples from Flight 4 had 3 to 13 times more abundance in elements iron, potassium, calcium, manganese and titanium than Flight 3. Apparently, these other airborne materials as well as sulfate contributed to the slight visual haze that decreased the visual quality for that sampling period. The origin of this haze is not known, but since the winds were from the west it is suspected that material came from the Seattle-Tacoma metropolitan area.

The range of ozone concentrations for the sample flights varied from about 14 to $40 \mathrm{ppb}$ and were essentially background concentration values. Some of the higher ozone peaks were shown to be correlated with some of the higher values of scattering extinction coefficient and relative humidity. Some of the lowest concentrations of ozone were found in principal valleys such as the Sagit-Sauk River Valley and the Cowlitz River Valley. The Columbia River Gorge had concentrations ranging from 25 to $40 \mathrm{ppb}$.

These 12 sampling flights are not representative of the wide range of visual 

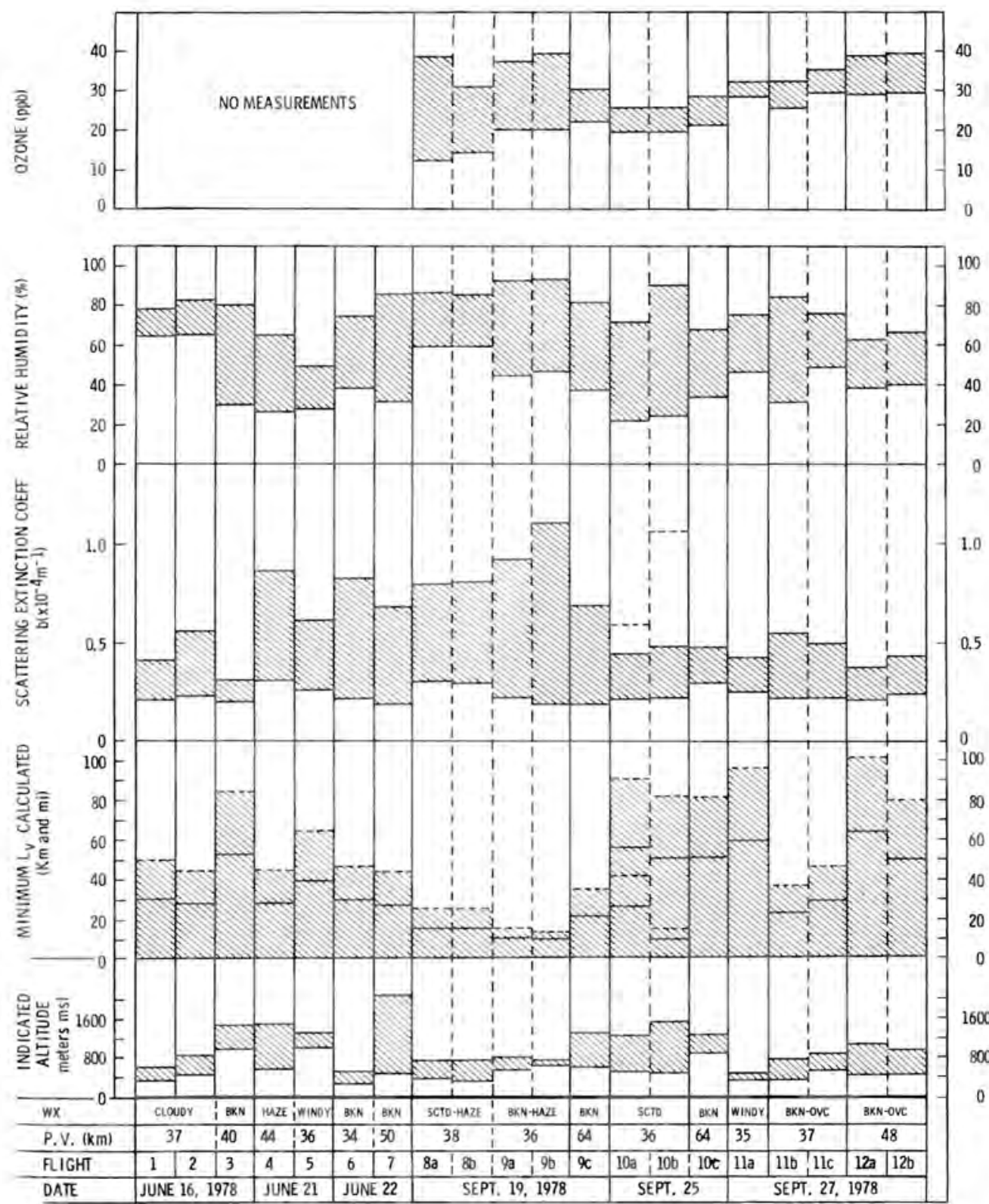

FIGURE 3." Range of Maximum and Minimum Values (1-min Averages) of Ozone, Relative Humidity, Total Scattering Coefficient and Indicated Altitude for the 12 Sampling Flights. The minimum meteorological range as calculated from total scattering coefficient, Equation 3 and relative humidity (P.V. = average prevailing visibility; $w x=$ general weather conditions).

conditions that can exist in mountainous regions. Days with poor visual quality were not sampled and should be a task set aside for future sampling work. Data from the oil shale tracts of Colorado and Utah and of the various geothermal sites would be of interest.

\section{References}

Huschke, R. E., ed. 1959. Glossary of Meteorology. American Meteorological Society, Boston, MA. 
Orgill, M. M., D. R. Drewes and S. R. Garcia. 1979. "Aerosol and Visibility Measurements in Mountainous Terrain." In Pacific Northwest Laboratory Annual Report for 1978 to the DOE Assistant Secretary for Environment, Part 3, Atmospheric Sciences. PNL-2850 PT3, pp. 3.3-3.6, Pacific Northwest Laboratory, Richland, WA.

Orgill, M. M., N. S. Laulainen, D. R. Drewes and R. N. Lee. 1979. "Aerosol, Trace Elements, and Visibility Measurements in Mountainous Terrain." Proceedings of 25th Annual Technical Meeting, Institute of Environmental Science, pp. 278-286, Seattle, WA.

Hanford Turbidity During 1979

N. S. Laulainen

Emission scenarios have been developed for the Federal Region 10 (Wilfert et al. 1979) that project, among other things, atmospheric sulfate and total suspended particulate (TSP) burdens and visibility deterioration in Class I areas in 1990 as a result of added industrial and energy production. In particular, the 500-MWe, coalfired power plant nearing completion at Boardman, Oregon, may be expected to increase sulfate and particulate burdens in the Lower Columbia Basin and, hence, may alter the visibility and turbidities of the region.

A program to document turbidity variations at Hanford in Federal Region 10 has been in place since July 1974 (Laulainen 1978) with the following objectives:

- to establish an atmospheric turbidity data base from which trends, if any, may be sought;

- to examine haze variability with respect to particulate sources and synoptic meteorological events and conditions;

- to study the redistribution of solar radiation caused by atmospheric aerosol.

Previous reports (Laulainen 1978; Laulainen et a1. 1979) have discussed the observational procedures and various results of experiments. In these studies turbidities showed definite seasonal variations, with maxima and minima occurring at regular times of the year. Attempts to fit the turbidity data to annual and biannual harmonic terms were only of limited usefulness (Laulainen 1978). Haze and turbidity variations appear to be closely related to synop- tic meteorological patterns that govern the rate at which atmospheric aerosols, frequently of local origin, accumulate in the resident air mass. Stagnant air masses, for example, allow the accumulation of smoke and haze in the Lower Columbia Basin leading to rather high turbidities until a frontal passage brings in a clean air mass with low turbidities. Summarized here are turbidity measurements at Hanford during FY 1979.

The 1979 turbidity data are shown in Figure 4 along with those from 1977, 1978 and last quarter of 1976. It is remarkable that the 1979 turbidities exhibit the same kinds of seasonal variations as do those for the previous years, except possibly for a phase difference of 1 to 2 wk in the maxima. Most of the maxima are associated with periods of air mass stagnation. Sources of smoke and dust are most pronounced in the spring, mid-July to mid-August and September to October and appear to be related primarily to agricultural activity, such as tilling and planting, crop harvesting, and field-burning in the Basin region. Occasionally, windstorms will cause corisiderable increases in turbidity through suspension of dust. Turbidity measurements during these periods are not always made because of cloudiness that is often associated with such events.

The magnitude of the turbidity excursions plays an important role in reduction of the intensity of the direct solar beam. At the wavelength for the data shown in Figure 4 $(547.7 \mathrm{~nm})$, turbidity minima correspond to aerosol optical depths of 0.03 to 0.04 , which results in a reduction of the direct beam of 3 to $4 \%$ for a zenith sun, whereas turbidity maxima rarely exceed optical depths of 0.22 , which corresponds to a $20 \%$ reduction. For comparison, molecular or Rayleigh scattering optical depth is 0.1 or a $10 \%$ beam reduction. The minimum turbidity values are also consistent with the best estimates of stratospheric aerosol depths of 0.015 to 0.020 (Russe11, Livingston and Uthe 1979).

The wavelength dependence of turbidity is also an important factor in accounting for the redistribution of solar radiation by atmospheric aerosols. Changes in the wavelength dependence reflect changes in the aerosol size distributions. Spectral turbidities can be approximated by a simple power law of the form $\tau \sim \lambda \alpha$ where $\tau$ is the optical depth of turbidity, $\lambda$ is the wavelength and $\alpha$ is the power law exponent (Middleton 1968). Seasonal variability of the wavelength exponent is shown in Figure 5 . A 


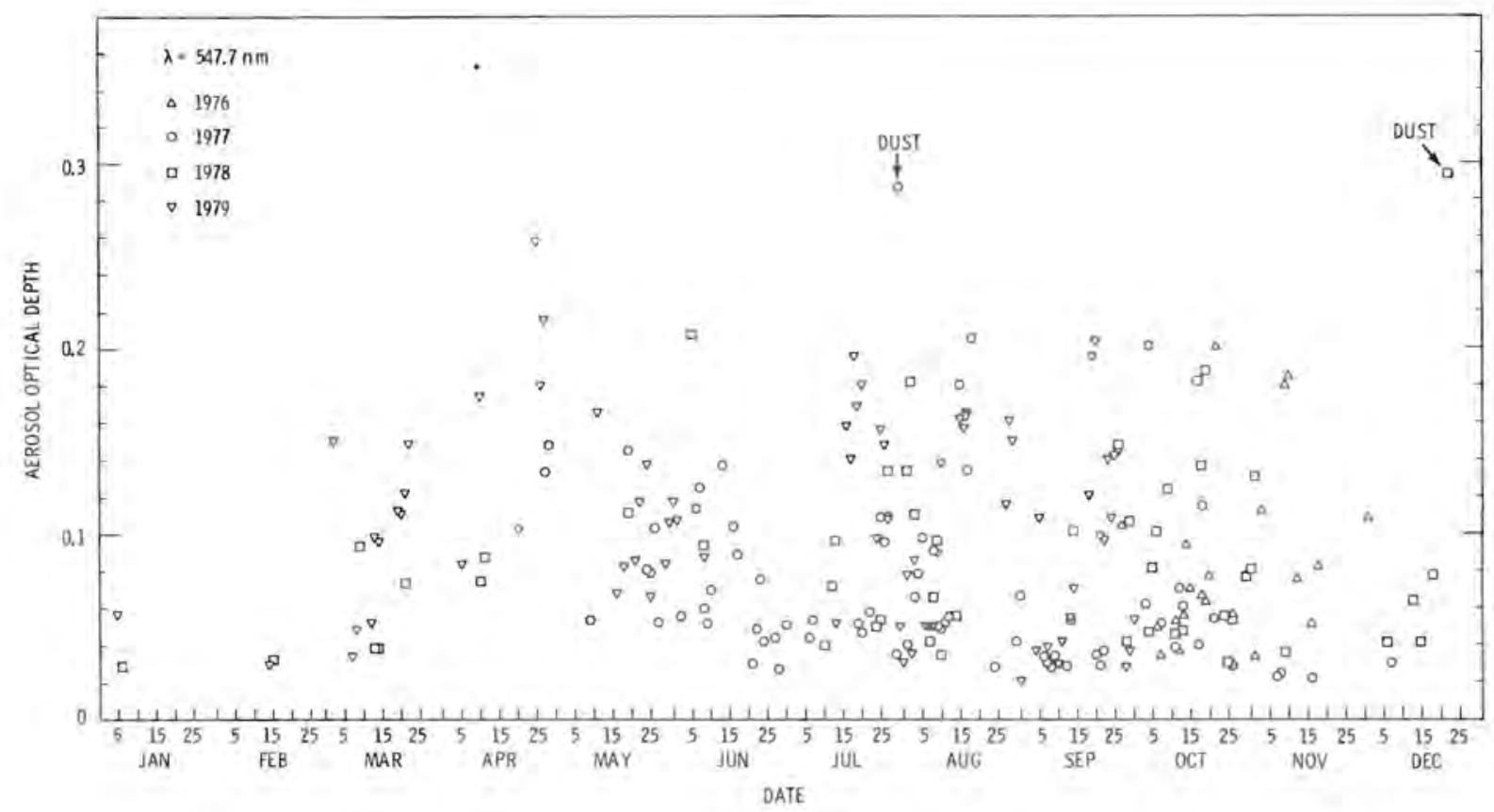

FIGURE 4. Hanford Turbidity Data from 1979, 1978, 1977 and the Last Quarter of 1976

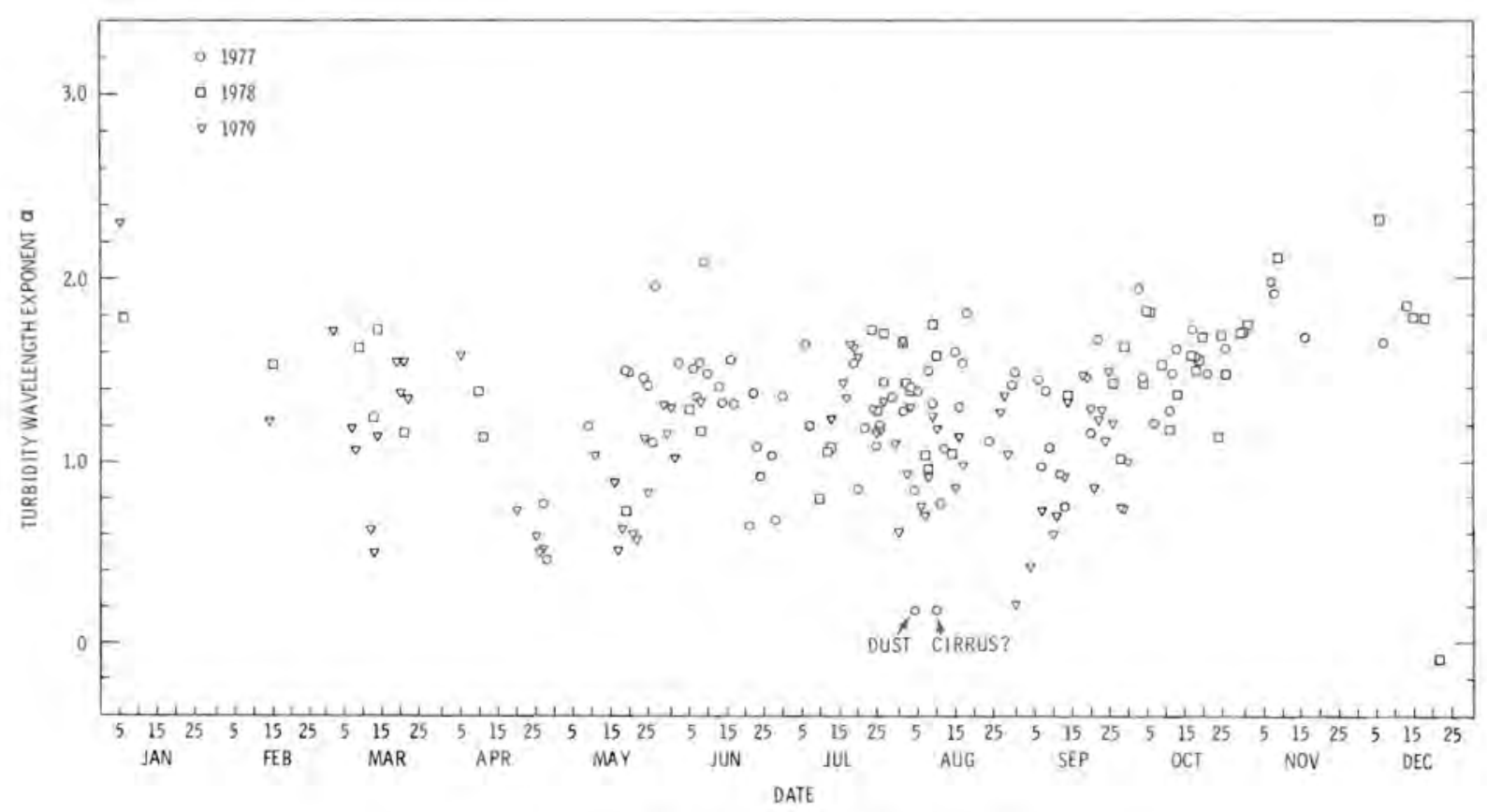

FIGURE 5. Hanford Seasonal Variability Data of Wavelength Exponent, $\alpha$ 
value of $\alpha=0$ corresponds to neutral extinction of the wavelength by large particles, such as dust and fog; a value of $\alpha=2$ corresponds to very fine particles. The values of $\alpha$ are largely confined to the region $0.5 \leqslant \alpha \leqslant 1.8$ with an average near $\alpha=1.3$. Seasonal variations in $\alpha$ are not as pronounced as in the turbidity data.

Since the turbidity observations extend back to July 1974, it should be possible to extract any time trends in the data, particularly any changes in the frequency of hazy days and in the magnitude of the annual mean turbidities. Several problems need to be addressed before these time trends can be sought. First of all, two different sunphotometers were used to obtain the turbidity data since 1974, each having a different set of wavelength selection filters. The first unit was used from July 1974 through October 1976, while the second unit was used from 0ctober 1976 to the present. The effective wavelengths are $557.8 \mathrm{~nm}$ and $547.8 \mathrm{~nm}$, for the first and second sunphotometers, respectively. Hence, the turbidities would have to be adjusted to a common wavelength for proper registration of the time sequence. Another important problem is readily apparent from an inspection of Figure 4. The observations are clustered around times of the year when clear skies (or at least when the line-of-sight to the sun is cloud-free) prevail. Consequently, simple averaging schemes will tend to give undue weight to certain times of the year. The magnitude of the bias towards clear skies and high-pressure meteorological conditions is at this point unknown, since cloudy days can either be hazy or not, depending upon a variety of factors. Appropriate statistical procedures need to be evaluated to deal with these problems. Results of the examination for time trends in atmospheric turbidity will be the subject of a later report.

\section{References}

Laulainen, N. S. 1978. "Turbidity Variations at Hanford Since July 1974." In Pacific Northwest Laboratory Annual Report for 1977 to the DOE Assistant Secretary for Environment, Part 3, Atmospheric Sciences. PNL-2500 PT3, pp. 3.1-3.3, Pacific Northwest Laboratory, Richland, WA.

Laulainen, N. S., E. W. Kleckner, J. J. Michalsky and J. M. Thorp. 1979. "Insolation and Turbidity Measurements at Hanford." In Pacific Northwest Laboratory AnnuaY Report for 1978 to the DOE Assistant Secretary for Environment, Part 3, Atmospheric Sciences. PNL-2850 PT3, pp. 3.6-3.10, Pacific Northwest Laboratory, Richland, WA.

Middleton, W. E. 1968. Vision Through the Atmosphere. University of Toronto Press, Toronto, Canada.

Russe11, P. B., J. M. Livingston and E. E. Uthe. 1979. "Aerosol-Induced Albedo Change: Measurement and Modeling of an Incident." J. Atmos. Sciences. 36:1587-1608.

Wilfert, G. L., M. A. Beckwith, C. E. Cowan and G. R. Keizur. 1979. Regional Issue Identification and Assessment (RIIA). Volume 1: An Analysis of the Trendlong MidMid Scenario for Federal Region 10. PNLRAP-36, Pacific Northwest Laboratory, Richland, WA.

\section{Differential Turbidity at Hanford}

N. S. Laulainen, E. W. Kleckner, J. J. Michalsky and G. M. Stokes

Experiments continued in FY 1979 to examine differential turbidity effects on insolation as measured at the earth's surface. These experiments are primarily intended to provide means for interpreting insolationdata assessment studies. These data are also valuable for inferring aerosol radiative or optical effects, which is an important consideration in evaluating inadvertent climate modification and visibility degradation as a result of aerosols. The experiments are characterized by frequent, nearly simultaneous observations at the Rattlesnake Mounta in Observatory (RMO) and the Hanford Meteorological Station (HMS) and take advantage of the nearly $1-\mathrm{km}$ altitude difference between these two observing sites (Laulainen et al. 1979).

The instrumentation is similar to that used in the earlier experiments (Laulainen et al. 1979). Because of calibration problems, the portable field pyranometers were discontinued and replaced at the RMO site by an Eppley PSP pyranometer and a siliconcell pyranometer with a rotating shadow band. Direct solar measurements were continued with 10-channel sunphotometers, the MASP unit (RMO only) and an Eppley NIP pyrheliometer (HMS only). A regular program of washing the dome of the MASP unit at the RMO site was initiated because of difficulties in maintaining precise and reliable calibration factors necessary for interpreting the direct measurements. 
Considerable effort has gone into procedures to rehabilitate direct solar data from the MASP unit before the dome-washing program. This rehabilitation is not yet complete; hence, summarized here are only differential turbidities obtained from the 1978 to 1979 sunphotometer data. In addition to the two sites mentioned above, a third site, located at the southeastern base of Rattlesnake Mountain and near the gate to the Arid Land Ecology (ALE) Reserve, was used on some occasions. The difference between the aerosol optical depths measured at either the ALE or the HMS sites and the RMO site is related to the average extinction coefficient of the aerosol contained in the layer between these sites, respectively. Turbidity and extinction data obtained during 4 days in 1978 and 6 days in 1979 are shown in Table 2 along with comment on sky conditions. Visibilities, as reported at HMS, were all greater than $25 \mathrm{~km}$ (the maximum value reported) for the days listed.

Inspection of Table 2 shows that in all but two cases, the turbidity difference be- tween HMS and RMO is positive, although in three cases the differences are quite small ( $₹ 0.01)$. Since the uncertainty in the individual turbidity values is about 0.005 to 0.010 , turbidity differences that are less than 0.010 may not be significantly different from zero. In particular, for the days August 7, 1978, October 30, 1978, and September 18, 1979, the average aerosol extinction coefficient is roughly one third to one times that resulting from molecular or Rayleigh scattering $\left(0.12 \times 10^{-4} \mathrm{~m}^{-1}\right.$ at $\lambda=547.7 \mathrm{~nm}$ ). Observations of atmospheric transparency for these days indicated none to very little haze in the layer between the RMO and HMS sites. Consequently, the contribution haze from aerosols above RMO were of some significance, especially for the September 18, 1979 day. Subvisual cirrus may have contributed to the measured turbidities also.

For the other days, except July 31, 1979 and August 2, 1979, when negative differences were observed, turbidity differences were large enough to produce average

TABLE 2. Aerosol Optical Depth Turbidity at $547.7 \mathrm{~nm}$ Wavelength at RMO, HMS and the Base of Rattlesnake Mountain (ALE)

\begin{tabular}{|c|c|c|c|c|c|c|}
\hline \multirow[b]{2}{*}{ Date } & \multicolumn{3}{|c|}{ Aerosol Optical Depth } & \multirow{2}{*}{$\begin{array}{c}\text { Difference } \\
\Delta \tau\end{array}$} & \multirow{2}{*}{$\begin{array}{c}\text { Average Aerosol } \\
\text { Extinction } \\
\text { Coefficient(b) } \\
\left(10^{-4} \mathrm{~m}^{-1}\right)\end{array}$} & \multirow[b]{2}{*}{ Sky Conditions } \\
\hline & $\tau(\mathrm{HMS})$ & $\tau(\mathrm{ALE})$ & $\tau(\mathrm{RMO})$ & & & \\
\hline July 13,1978 & 0.097 & 0.098 & 0.074 & 0.024 & 0.281 & Clear, light Haze \\
\hline August 7,1978 & 0.042 & 0.042 & 0.034 & 0.008 & 0.09 & Clear \\
\hline October 30,1978 & 0.040 & 0.033 & 0.033 & 0.003 & 0.03 & Some Cirrus (0.2) \\
\hline December 18, 1978 & 0.078 & 0.086 & 0.035 & 0.047 & 0.54 & $\begin{array}{l}\text { Clear, Light Haze, } \\
\text { Smoke }\end{array}$ \\
\hline April 26, 1979 & 0.166 & 0.156 & 0.137 & 0.024 & 0.28 & Clear, Haze, Smoke \\
\hline July 26, 1979 & 0.126 & 0.103 & 0.703 & 0.020 & 0.23 & Clear, Haze, Smoke \\
\hline July 31, 1979 & 0.036 & - & 0.054 & - & - & Clear \\
\hline August 2, 1979 & 0.036 & - & 0.060 & - & - & Clear \\
\hline September 5, 1979 & 0.109 & - & 0.034 & 0.075 & 0.86 & $\begin{array}{l}\text { Cirrus, Altocumulus } \\
(0.1) \text {, Light Haze }\end{array}$ \\
\hline September 18, 1979 & 0.121 & - & 0.117 & 0.004 & 0.05 & Clear, Haze, Smoke \\
\hline
\end{tabular}

\footnotetext{
(a) Difference $=1 / 2[\tau(\mathrm{HMS})+\tau(\mathrm{ALE})]-\tau(\mathrm{RMO})$ when data from both sites available; otherwise difference $=$ $\tau$ (HMS) - $\tau$ (RMO).

(b) Average Extinction Coefficient $=\Delta \tau /[\mathrm{h}(\mathrm{RMO})-\mathrm{h}(\mathrm{HMS})]$
} 
aerosol extinction coefficients between 2 and 8 times Rayleigh scattering. Data for the December 18, 1978 and September 5, 1979 dates indicate that most of the aerosol was confined to the layer below the RMO site, while on the remaining dates, the aerosol was distributed to altitudes higher than the RMO site. An explanation for the anomalous negative turbidity differences is not apparent, although horizontal inhomogeneity of the aerosol could account for the discrepancy (RMO is $25 \mathrm{~km}$ south of HMS).

This study has shown that nearly simultaneous measurements of the direct solar beam from stationary sites that are separated in altitude can be used to monitor the incremental optical depth arising from aero- sols in the intervening layer. Once appropriate calibration procedures have been established for the MASP unit, the direct solar data can be used to document on a routine basis aerosol variations in the first kilometer between HMS and RMO.

\section{Reference}

Laulainen, N. S., E. W. Kleckner, J. J. Michalsky and J. M. Thorp. 1979. "Insolation and Turbidity Measurements at Hanford." In Pacific Northwest Laboratory Annual Report for 1978 to the DOE Assistant Secretary for Environment, Part 3, Atmospheric Sciences PNL-2850 PT3, pp. 3.6-3.10, Pacific Northwest Laboratory, Richland, WA. 


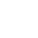




\section{Publications and Presentations}



PUBLICATIONS AND PRESENTATIONS

\section{PUBLICATIONS}

Berkowitz, C. M 1979. "The Use of the Cray-1 in Simulating Hail Growth." In Proceedings, Scientific Computer Information Exchange Meeting. Sponsored by U.S. Department of Energy, September 12-13, 1979, Livermore, CA.

Berkowitz, C. M. and N. S. Laulainen. 1979. "The Use of Standard Surface Weather observations to Evaluate Solar Insolation in the Pacific Northwest." In Proceedings of Solar '79--Northwest, pp. 195-197, sponsored by the U.S. Department of Energy, August 10-12, 1979, Seattle, WA.

Dana, M. T. 1979. The MAP3S Precipitation Chemistry Network: Second Periodic Summary Report (July 1977-June 1978). PNL-2829, Pacific Northwest Laboratory, Richland, WA.

Doran, J. C. 1979. "Sensitivity of Particle Deposition to Changes in Deposition Velocity." Atmos. Environ. 13:1269-1273.

Droppo, J. G. 1978. "Book Review: Forest Microclimatology." Bu11. of Am. Meteor. Society. November 1978.

Droppo, J. G. 1979. "The Removal of Air Pollutants by Vegetation Canopies." Symposium on Forest Meteorology (World Meteorological Organization). 527:159.

Droppo, J. G. and J. C. Doran. 1979. "Measurements of Surface Layer Turbulent Ozone Flux Processes. " Preprints of the Fourth Symposium on Turbulence, Diffusion and Air Pollution, Reno, NV, American Meteorological Society, Boston, MA.

Eadie, W. J. and W. E. Davis. 1979. The Development of a National Interregiona 7 Transport Matrix for Respirable Particulates. PNL-RAP-37, Pacific Northwest Laboratory, Richland, WA.

Haies, J. M. 1979. Ammonia. National Academy of Sciences, University Park Press, Baltimore.

Hales, J. M. 1979. "How the Air Cleans Itself." In Proceedings of the British Sulfur Symposium, Society of Chemical Industry, May 1979, London.

Hales, J. M. 1979. "Precipitation Scavenging of Urban Pollutants by Convective Storm Systems:" J.Appl. Meteor. 18(3):294-316.
Hales, J. M. 1979. "Regional Scale Deposition of Sulfur Dioxide by Precipitation Scavenging." Atmos. Environ. 13(8):11211132.

Hales, J. M. and D. R. Drewes. 1979. "Solubility of Ammonia in Water at Low Concentrations." Atmos. Environ. 13(8):1133-1147.

Horst, T. W. 1979. "Lagrangian Similarity Modeling of Vertical Diffusion from a GroundLevel Source." J. Appl. Meteor. 18:733-740.

Horst, T. W. 1979. "The Annual-Average Effect of the Deposition-Resuspension Process on Airborne Contamination Near the Surface." Atmos. Environ. 13:791-796.

Huang, C. H. 1979. "A Theory of Dispersion in Turbulent Shear Flow." Atmos. Environ. $13: 453-463$

Laulainen, N. S. 1979. "Comprehensive Study of Drift from Mechanical Draft Cooling Towers." In Meteorological Effects of Thermal Energy Releases (METER) Program Annual Progress Report October 1977 to September 1978. ORNL/TM-6867, Oak Ridge National Laboratory, Oak Ridge, TN.

Laulainen, N. S. 1979. "Drift from Mechanical Draft Cooling Towers." In Proceedings of 1979 Annual Technical Meeting of the Institute of Environmental Sciences, pp. 347353, Apri1 30-May 2, 1979, Seatt1e, WA.

Laulainen, N. S., R. 0. Webb, K. R. Wilber and S. L. Ulanski. 1979. Comprehensive Study of Drift from Mechanical Draft Cooling Towers. Final Report. PNL-3083, Pacific Northwest Laboratory, Richland, WA.

McNaughton, D. J. and C. M. Berkowitz. 1979. "Overview of Research Activities in the Dispersion of Dense Gases." Proceedings, Symposium Schwere Gas, Sponsored by BattelleFrankfurt, September 3-4, 1979, Frankfurt, Germany.

Nickola, P. W. 1979. "Field Measurements of the Benefits of Increased Stack Height." J. Appl. Meteor. 18(10).

Orgi11, M. M., N. S. Laulainen, D. R. Drewes and R. N. Lee. 1979. "Aeroso1, Trace Elements and Visibility Measurements in Mountainous Terrain." In Proceedings of 25 th Annual Technical Meeting, Institute of Environmental Sciences, pp. 278-286; Seattle, WA. 
Parker, G. B. 1979. Review of Air Quality As sessment Studies and Definitions of Some Research Needs for the Emerging 0il Shale Technology. PNL-2910, Pacific Northwest Laboratory, Richland, WA.

Powe 1 1, D. C., D. J. McNaughton, L. L. Wendell and R. L. Orake. 1979. A Variable Trajectory Model for Regional Assessment of Air Pollution from Sulfur Compounds. PNL2734, Pacific Northwest Laboratory, Rich1 and, WA.

Scott, B. C. 1979. "Wet Removal Processes." In The Multistate Atmospheric Power Production PolTution Study - MAP3S, Progress Report for FY 1977 and FY 1978. DOE/EV-0040, U.S. Department of Energy, Assistant Secretary for Environment, Office of Health and Environment Research.

Scott, B. C. 1979. "Wet Removal Rates for $\mathrm{SO}_{2}$ Gas and $\mathrm{SO}_{4}$ Aerosol" (Appendix A). In Impacts of Air Pollutants on Wilderness Areas of Northern Minnesota. Environmental Research Laboratory - Duluth, Office of Research and Development, U.S. Environmental Protection Agency, Duluth, MN.

Sehmel, G. A. 1978. "Airborne Plutonium239 and Americium-241 Transport Heasured from the 125-m Hanford Meteorological Tower." In Selected Environmental Plutonium Research Reports of the NAEG, eds., M. G. White and P. B. Dunaway, NVO-192, available NTIS, pp. 707-722, June 1978 (Report distributed August 1979).

Young, J. A. and C. W. Thomas. 1979. "Aerosol Deposition Velocities on the Pacific and Atlantic Oceans Calculated from ${ }^{7}$ Be Measurements." Presented at the Conference on Natural Radioactive Isotopes of Beryllium in the Environment, October 1-2, 1979, Yale University.

\section{PATENT}

Sehme], G. A. 1979. Isokinetic Air Sampler, U.S. Patent No. 4,159,635.

\section{PRESENTATIONS}

Berkowitz, C. M. 1979. "Hailstone Development." PNL-SA-7699, presented at the Meteorology Seminar Series, San Jose State University, September 13, 1979, San Jose, CA.

Childs, J. T. and M. M. Orgi1l. 1979. "Case Study of a Severe Convective Storm in the Pacific Northwest." PNL-SA-7998, presented at the 26th Annual Pacific Northwest
American Geophysical Union Meeting, September 17-19, 1979, Bend OR.

Dana, M. Terry. 1979. "Overview of Wet Deposition and Scavenging." PNL-SA-8072, presented at the Oak Ridge National Laboratory Symposium on Potential Environmental and Health Effects of Atmospheric Sulfur Deposition, October 14-18, 1979, Gatl inburg, TN.

Dana, M. Terry. 1979. "Regional Precipitation Chemistry Measurements in the MAP3S." PNL-SA-7391, presented at the 22nd Conference of the International Association for Great Lakes Research, May 1-3, 1979, Rochester, NY.

Dana, M. Terry. 1979. "SO Versus Sulfate Wet Deposition in the Eastern U.S." PNL-SA7674 , presented at the CACGP Symposium on the Budget and Cycles of Trace Gases and Aerosols in the Atmosphere, August 12-18, 1979, Boulder, CO.

Dana, M. Terry and W. E. Davis. 1979. "Redistribution of a Layer of HTO by Rainfal1." PNL-SA-7461, presented at the 25th Annual Technical Meeting, Institute of Environmental Sciences, April 29-May 2, 1979, Seattle, WA.

Davis, W. E. 1979. "Comparison of the Results of an Eight-Layer Model Versus a Single-Layer Model for a Short-Term Assessment." PNL-SA-7546, presented at the World Meteorological Organization Symposium on the Long-Range Transport of Pollutants and Its Relation to the General Circulation, October 1979, Sophia, Bulgaria.

Davis, W. E. 1979. "The Effect of Using Time-Averaged Precipitation for the Estimation of Wet Deposition in a Regional Scale Model." PNL-SA-6996, presented at the Fourth Symposium on Turbulence, Diffusion and Air Pollution of the American Meteorological Society, January 15-18, 1979, Reno, NV.

Davis, W. E. and W. J. Eadie. 1979. "A New Regional Scale Assessment Method Based on Regional Assessments at Regularly Spaced Grid Points." PNL-SA-7589, presented at the PNWIS-APCA Conference, November 7-9, 1979, Edmonton, Alberta, Canada.

Davis, W. E. and W. J. Eadie. 1979. "The Use of Time-Averaged Precipitation for Wet Removal in a Regional Air Pollution Assessment Model." PNL-SA-7658, presented at the Tenth International Technical Meting on Air Pollution Modeling and Its Application, October 21-iNovember 4, 1979, Rome, Italy. 
Droppo, J. G. 1979. "Experimental Techniques for Dry Deposition Measurements." PNLSA-8080, presented at the Symposium on Potential Environmental and Health Effects of Atmospheric Sulfur Deposition, October 14-18, 1979, Gatl inburg, TN.

Droppo, J. G. 1979. "Field Determinations of HVdc Ozone Production Rates." PNL-SA7520 , presented at the Summer Meeting of the Institute of Electrical and Electronics Engineers, Inc., Vancouver, BC, Canada.

Droppo, J. G. and J. C. Doran. 1979. "Dry Deposition of Air Pollutants." PNL-SA-7477, presented at the 1979 Proceedings of the 25 th Annual Technical Meeting of the Institute of Environmental Sciences, Seattle, WA. Apri1 29-May 2, 1979.

Horst, T. W. 1979. "A Review of Gaussian Diffusion - Deposition Models." PNL-SA-8009, presented at the Oak Pidge National Laboratory Symposium on Potential Environmental and Health Effects of Atmospheric Sulfur Deposition, October 14-18, 1979, Gatlinburg, TN.

Horst, T. W. 1979. "Lagrangian Similarity Modeling of Vertical Diffusion from a GroundLevel Source." PNL-SA-7587, presented at the Second Symposium on Turbulent Shear Flows, July 2-4, 1979, Imperial College, London.

Horst, T. W. 1979. "The Annual-Average Effect of the Deposition-Resuspension Process on Airborne Contamination Near the Surface." PNL-SA-6954, presented at the Fourth Symposium on Turbulence, Diffusion and Air Pollution of the American Meteorological Society, January 15-18, 1979, Reno, NV.

Huang, C. H. and R. L. Drake. 1979. "A Direct Method of Adjusting Windfield over Complex Terrain." PNL-SA-7249, presented at the Conference on Agriculture and Forest Meteorology and Fourth Conference on Biometeorology, April 2-6, 1979, Minneapol is, MN.

Garcia, S. R., K. B. 01 sen and D. R.

Kalkwarf. 1979. "Trace Element Concentrations in Colstrip's Coal-Fired Power Plant Plume." PNL-SA-7805, presented at the 34 th Northwest Regional Meeting of the American Chemical Society, June 13-15, 1979, Richland, WA.

Kalkwarf, D. R. and S. R. Garcia. 1979. "Sublimation of Polynuclear Aromatic Hydrocarbons from Coal Fly Ash." PNL-SA-7774, presented at the 34 th Northwest Regional Meeting of the American Chemical Society, June 13-15, 1979, Richland, WA.
McNaughton, D. J. 1979. "Emission Source Specification in a Regional Pollutant Transport Mode1." PNL-SA-7541, presented at the World Meteorological Organization Symposium on the Long-Range Transport of Pollutants and Its Relation to the General Circulation, October 1979, Sophia, Bulgaria.

McNaughton, D. J. and C. M. Berkowitz. 1979. "Overview of U.S. Research Activities in the Dispersion of Dense Gases." PNL-SA-7952, presented at the Symposium on Schwere Gase (Dense Gas), September 3-4, 1979, Frankfurt, Germany.

Michalsky, J. J., N. S. Laulainen, G. M. Stokes and E. W. Kleckner. 1979. "Differential Turbidity in an Arid Environment." PNL-SA-8035, presented at the Institute for Atmospheric optics and Remote Sensing (IFAORS), November 6, 1979, Baltimore, MD.

Miller, D. F. and A. J. Alkezweeny. 1979. "Aerosol Formation in Urban Plumes Over Lake Michigan." PNL-SA-7449, presented at the Conference on Aerosols: Anthropogenic and Natura 1--Sources and Transport, sponsored by the New York Academy of Sciences and the Air Pollution Control Association, January 9-12, 1979, New York, NY.

Nickola, P. W. 1979. "Field Measurements of the Benefits of Increased Stack Height." PNL-SA-7043, presented at the Fourth Symposium on Turbulence, Diffusion, and Air Pollution, January 15-18, 1979, Reno, NV.

Nickola, P.W. 1979. "Near Source to Mesoscale Tracers at Hanford." PNL-SA-7765, presented at the Atmospheric Tracer Workshop, May 22-24, 1979, Los Alamos, NM.

Orgill, M. M. 1979. "Terrain Effects on Atmospheric Transport and Dispersion--A Status Report." PNL-SA-7549, presented at the Fifth International Conference on Wind Engineering, July 8-13, 1979, Fort Collins, CO.

Orgi11, M. M., N. S. Laulainen, D. R. Drewes and R. N. Lee. 1979. "Aerosol Trace Elements and Visibility Measurements in Mountainous Terrain." PNL-SA-7565, presented at the Twenty-Fifth Annual Technical Meeting of the Institute of Environmental Sciences, April 29-May 2, 1979, Seattle, WA.

Sandusky, W. F. and D. S. Renne. 1979. "Application of Long-Range Transport Modeling to Assess Coal Development." PNL-SA-7028, presented at the Fourth Symposium on Turbulence, Diffusion and Air Pollution of the American Meteorological Society, January 1518, 1979, Reno, NV. 
Sandusky, W. F., W. J. Eadie and D. R. Drewes. 1979. "Long-Range Transport of Pollutants in the Pacific Northwest." PNL-SA7486, presented at the Twenty-fifth Annual Technical Meeting of the Institute of Environmental Sciences, April 29-May 2, 1979, Seattle, WA.

Scott, B. C. 1979. "Modeling of Atmospheric Wet Deposition to Lakes." PNL-SA7947, presented at the Division of Environmental Chemistry, American Chemical Society, September 9-14, 1979, Washington, DC.

Scott, B. C. 1979. "Pollutant Scavenging in Water Storms." PNL-SA-7465, presented at the 25th Annual Meeting of the Institute of Environmental Sciences, April 29-May 2, 1979, Seattle, WA.

Scott, B. C. 1979. "Wet Removal of Aerosol and Gas." PNL-SA-7948, presented at the Division of Physical Chemistry, American Chemical Society, September 9-14, 1979, Washington, $D C$.
Sehmel, G. A. 1979. "Airborne Plutonium Transported During Southwesterly Winds Near the Hanford Prosser Barricade." PNL-SA-7839, presented at the American Nuclear Society National Meeting, November 11-16, 1979, San Francisco, CA.

Sehmel, G. A. 1979. "Model Predictions and a Summary of Dry Deposition Velocity Data." PNL-SA-7944, presented at the Second Life Sciences Symposium on Potential Environmental and Heal th Consequences of Atmospheric Sulfur Deposition, October 14-18, 1979, Gatl inburg, TN.

Sehme1, G. A. 1979. "Particle and Gas Dry Deposition: A Review." PNL-SA-7157, presented at the American Chemical Society (Chemical Congress jointly with the Chemical Society of Japan) Symposium on Sampling and Analysis of Ambient Aerosols, Aoril 1-5, 1979, Hawaii. 
Author

Index 


\section{AUTHOR INDEX}

Abbey, O. B.; 1, 9

Alkezweeny, A. J.; 19, 53, 56, 58, 61

Arbuthnot, D. A.; 65

Berkowitz, C. M.; 48

Busness, K. M.; 66

Dana, M. T.; 39, 42

Davis, W. E.; 29, 30, 35, 76, 84

Doran, J. C.; 1, 9, 14

Drake, R. L.; 79

Drewes, D. R.; 39, 139

Droppo, J. G.; 9, 127

Eadie, W. J.; 29, 30, 35

Garcia, S. R.; 22

Glover, D. W.; 1, 39

Hales, J M.; $51,65,66$

Harris, S. D.; 39

Hodgson, W. H.; 99

Horst, T. W.; 1, 7, 9, 17

Huang, C. H.; 79

Kalkwarf, D. R.; 22

Kleckner, E. W.; 145

\author{
Larson, R. S.; 7 \\ Laulainen, N. S.; 19, 27, 53, 139, 143, 145 \\ Lee, R. N.; 63, 64, 139 \\ McNaughton, D. J.; 68, 69, 73, 87 \\ Michalsky, J. J.; 145 \\ Neff, W. D.; 7 \\ Nickola, P. W.; 1, 4 \\ Orgill, M. M.; 1, 7, 139 \\ Parker, G. B.; 133 \\ Rothert, J. E.; 39, 41 \\ Sandusky, W. F.; 29 \\ Schreck, R. I.; 1, 7 \\ Scott, B. C.; 43, 46, 87 \\ Sehmel, G. A.; 95, 97, 99, 102, 104, 107, 135 \\ Stokes, G. M.; 25, 145 \\ Thomas, C. W.; 118 \\ Thorp, J. M.; 125 \\ Young, J. A.; 118
}



Organization Charts

Distribution 


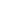




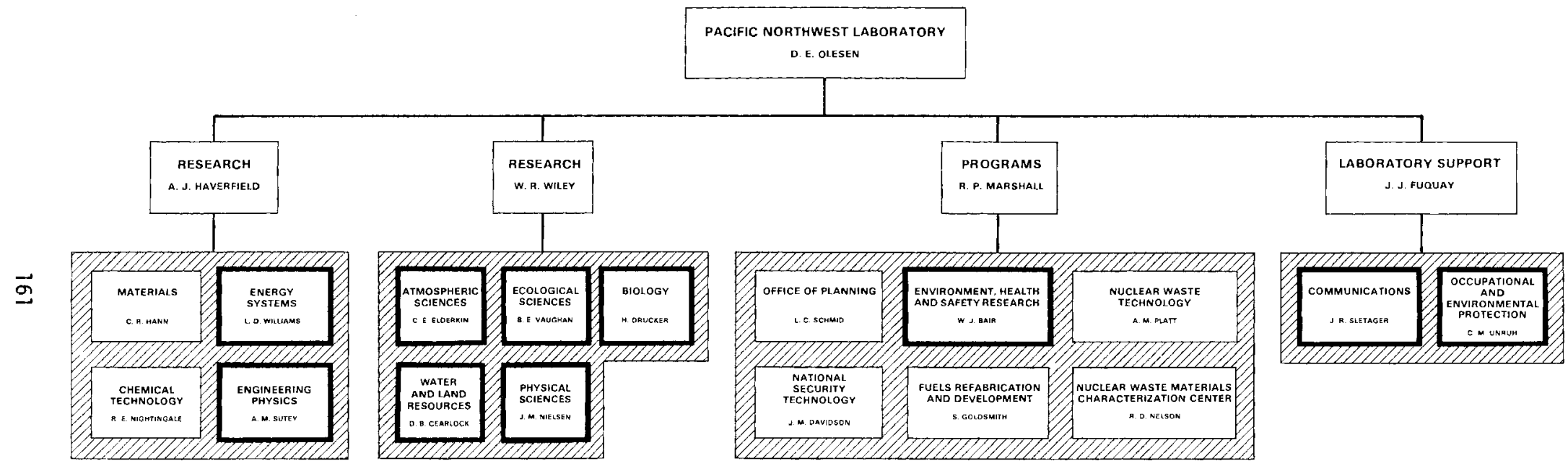

NOTE
HEAYY BLACK LNES DENOTE ORGANIZATIONAL
COMPONENTS IN WHICH ENVIRONMENT HEALT

AND AFETY RESEARCH IS BENG CONDUCTED
AS OF DECCMER 1 . 


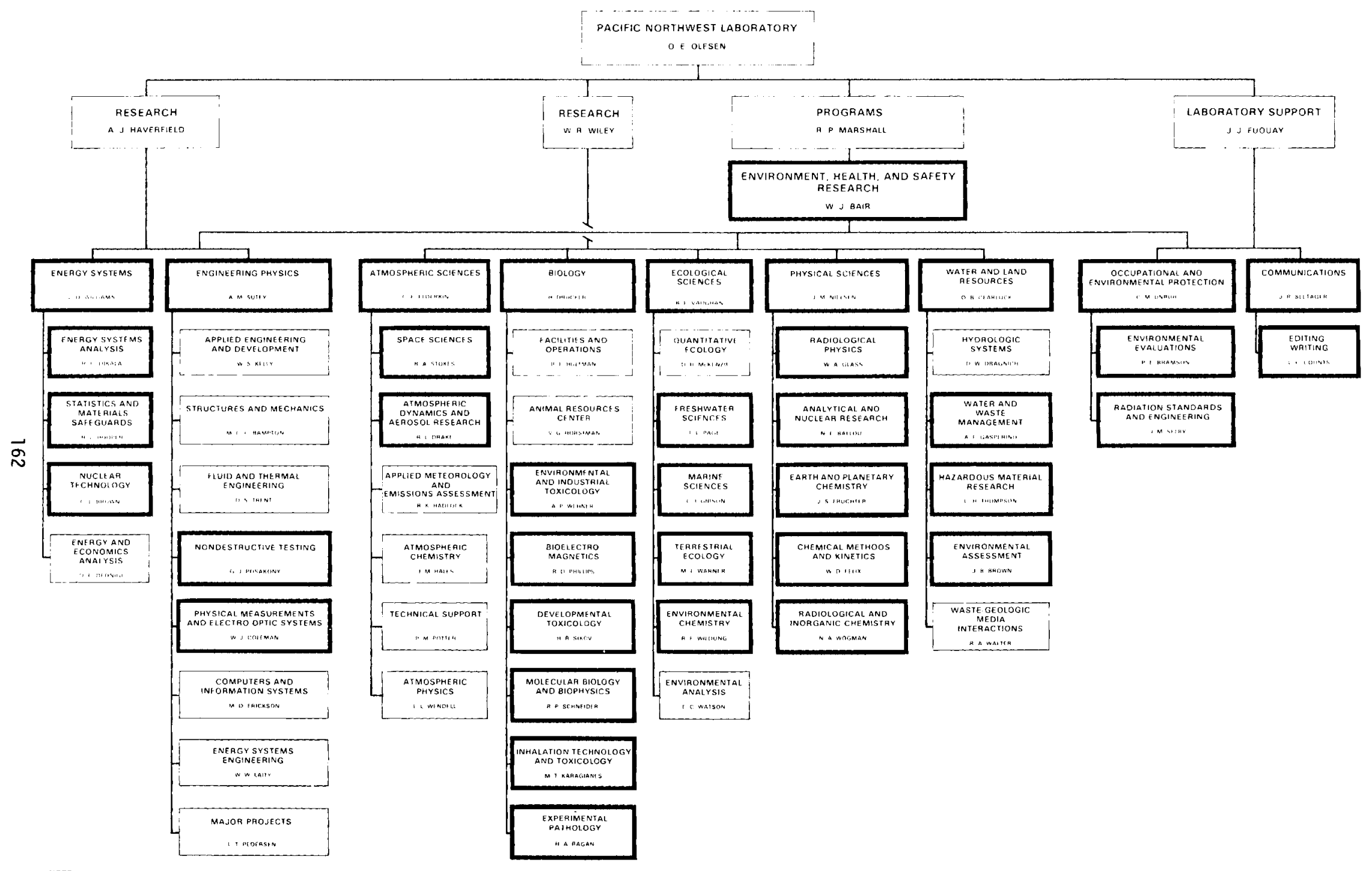

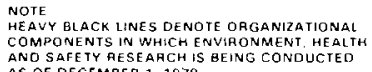


PNL-3300 PT 3

DISTRIBUTION

No. of

Copies

\section{OFFSITE}

A. A. Churm, Director Patent Division

DOE--Chicago Operations Office

9800 S. Cass Avenue

Argonne, IL 60439

Robert F. Abbey, Jr. Office of Nuclear Regulatory Research

U.S. Nuclear Regulatory Commission

Washington, DC 20545

R. Alexander

Nuclear Regulatory

Commission

Washington, DC 20545

E. L. Alpen

Lawrence Berkeley Laboratory

University of $\mathrm{Ca}$ ifornia

Building 90, Room 2056

No. 1 Cyclotron Road

Berkeley, CA 94720

L. Anspaugh

Lawrence Livermore Laboratory

University of California

P.0. Box 808

Livermore, CA 94550

S. I. Auerbach

Oak Ridge National Laboratory

P.0. Box $X$

Oak Ridge, TN 37830

J. A. Auxier

Oak Ridge llational

Laboratory

P.0. Box X

Oak Ridge, TN 37830

F. I. Badgley

University of Washington

Department of

Atmospheric Sciences

Seattle, WA 98195
No. of

Copies

J. S. Ball

Bartlesville Energy Research Center

Department of Energy

P.0. Box 1398

Bartlesville, OK 74003

D. S. Ballantine

Department of Energy

office of the Asst. Sec. for Environment

Washington, DC 20545

Harold Barkhau

Air Pollution Technical Information Center

U.S. Environmental Protection Agency

Research Triangle Park, NC 27711

N. F. Barr

Department of Energy

Office of the Asst. Sec. for Environment

Washington, DC 20545

S. Barr

Los Alamos Scientific Laboratory

University of California

P.0. Box 1663

Los Alamos, NM 87544

Bartlesville Energy Research Center

Attn: Library

Department of Energy

P.0. Box 1398

Bartlesville, OK 74003

B. Baskin

Wayne County Department of Health

Air Pollution Control Division

$1311 \mathrm{E}$. Jefferson

Detroit, MI 48207

R. W. Beadle

Department of Energy

Office of the Asst. Sec. for Environment

Washington, DC 20545
No. of

Copies

E. W. Bean

Rocky Flats Area Office

DOE--Albuquerque Operations Office

P.0. Box 928

Golden, CO 80401

D. Beirman

Chief, Document Service Branch

Central Intelligence Agency

Attn: CRS/DPSD/DSB/ IAS/409779/DB

Washington, DC 20505

J. R. Blair

Department of Energy

Office of the Asst. Sec. for Environment

Washington, DC 20545

R. P. Blaunstein

Department of Energy

Office of the Asst. Sec. for Environment

Washington, DC 20545

V. P. Bond

Brookhaven National Laboratory

Upton, Long Island, NY 11973

L. C. Brazely, Jr. Department of Energy

Environmental Control Technology Division Washington, DC 20545

G. A. Briggs

Atmospheric Turbulence and Diffusion Laboratory

NOAA, Oak Ridge, TN 37830

L. Brothers

Department of Energy Office of the Asst. Sec. for Environment

Washington, DC 20545 
ivo. of

Copies

W. W. Burr, Jr.

Department of Energy

Office of the Asst. Sec.

for Environment

Washington, DC 20545

Leo Bustand, Dean

College of Veterinary

Medicine

Washington State

University

Pullman, WA 99163

R. C. Clusen

Department of Energy

Office of the Asst. Sec. for Environment

Washington, DC 20545

J. A. Coleman

Department of Energy

Office of the Asst. Sec. for Environment

Washington, DC 20545

R. A. Conaway

Uepartment of Energy

Office of the Asst. Sec. for Environment

Washington, DC 20545

W. Cool

Nuclear Regulatory Commission

Washington, DC 20545

W. Cotton

Department of Atmospheric Sciences

Colorado State University

Fort Collins, c0 80521

Council on Environmental Qual ity

72 Jackson Place, N.W.

Washington, DC 20006

D. K. Craig

Department of Energy

Office of the Asst. Sec. for Environment

Washington, DC 20545

T. V. Crawford

Environmental Transport

Savannah River Laboratory

$E$. I. DuPont de liemours

Aiken, SC 29801
No. of

Copies

R. C. Dahlman

Department of Energy

Office of the Asst. Sec. for Environment

Washington, DC 20545

INancy S. Dailey

Ecological Sciences Information Center

Oak Ridge National Laboratory

P.0. Box $x$

Building 1505 R-322

Oak Ridge, TN 37830

J. Davis

ivuclear Regulatory

Commission

5650 Nicholson Lane

Rockville, BD 20854

J. J. Davis

Assistant Director of Research

Nuclear Regulatory Commission

Washington, DC 20545

L. J. Dea

Department of Energy

Office of the Asst. Sec. for Environment

Washington, DC 20545

A. W. Decora

Laramie Energy Research Center

Department of Energy

P.0. Box 3395

University Station

Laramie, WY 83071

J. M. Deutch

Department of Energy

Office of the Under Secretary

Washington, DC 20545

R. De Lorenzo

Department of Energy

Office of the Asst. Sec. for Environment

Washington, DC 20545

A. N. Dingle

Department of Atmospheric and Oceanic Science

University of Michigan

Ann Arbor, MI 48104
No. of

Copies

Director

Joint Center for Graduate Study

100 Sprout Road

Richland, WA 99352

G. P. Dix

Department of Energy

Office of the Asst. Sec. for Environment

Washington, DC 20545

T. J. Dobry

Department of Energy

Office of the Asst. Sec. for Energy Technology

Washington, DC 20545

27 DOE Technical Information Center

A. P. Duhamel

Department of Energy

Office ot the Asst. Sec. for Environment

Washington, DC 20545

J. Durham

U.S. Environmental

Protection Agency

ivational Environmental Research Center

Research Triangle Park, NC 27711

C. W. Edington

Uepartment of Energy

Office of the Asst. Sec. for Environment

Washington, DC 20545

C. Eifert

Department of Energy

Office of the Asst. Sec. for Environment

Washington, DC 20545

R. J. Engelmann

Environmental Research

Laboratories

National Oceanic and

Atmospheric

Administration

Boulder, CO 80302

Environmental Protection Agency/NERC, Heteorology Laboratory

Research Triangle. Park, NC 27711 
No. of

Copies

B. M. Erickson

DOE--Schenectady ilava?

Reactors Office

P.0. Box 1069

Schenectady, NY 12301

G. C. Facer

Department of Energy

Office of the Asst. Sec. for Defense Programs

Washington, DC 20545

C. W. Fischer

Department of Energy

Office of the Asst. Sec.

for Energy Research

Washington, DC 20545

P. La Fleur

National Bureau of

Standards

iluclear Reactor Laboratory

Gaithersburg, MD 20760

J. E. Flinn

Battelle Memorial Institute

Columbus Laboratories

505 King Avenue

Columbus, $\mathrm{OH} 43201$

Jack Foreman

National Oceanic and

Atmospheric Administration EDIS/CEAS D2XI

3300 Whitehaven street N.W.

Washington, DC 20235

T. G. Frangos

Department of Energy

office of the Asst. Sec. for Environment

Washington, DC 20545

R. E. Frank 7 in

Department of Energy

Office of the Asst.. Sec. for Environment

Washington, DC 20545

P. Frenzen

Argonne National Laboratory

9700 Cass Ävenue

Argonne, IL 60439

D. M. Gardiner

DOE--Chicago Operations

office

9800 South Cass Avenue

Argonne, IL 60439
iNo. of

Copies

M. E. Gates

DOE--Nevada Operations Office

P. 0. Box 14100

Las Vegas, INV 89114

Dom M. Geraghty

Energy Analys is \&

Environment Division

Electric Power Research Institute

$3412 \mathrm{Hillview} \mathrm{Avenue}$

P.0. Box 10412

Palo Alto, CA 94303

P. M. Gerhardt

Department of Energy

Office of the Asst. Sec. for Environment

Washington, DC 20545

G. Goldstein

Department of Energy

Office of the Asst. Sec. for Environment

Washington, DC 20545

J. T. Gol!

Conservation Division

U. S. Geological Survey

630 National Center

Reston, VA 22092

Lan Golomb

Office of Research

and Development

Energy Effects Division

Environmental Protection Agency

401 M Street, S.W.

Mail Stop RD682

Washington, DC 20460

1.. Gottlieb

Environmental Protection Agency

Office of Radiation

Programs

Washington, DC 20545

G. H. Gronhovd

Grand Forks Energy

Research Center

Department of Energy

Box 8213, University

Station

Grand Forks, ND 58202
No. of

Copies

T. J. Gross

Department of Energy

Office of the Asst. Sec. for Environment

Washington, DC 20545

F. Gustafson

Argonne National

Laboratory

9700 S. Cass Avenue

Argonne, IL 60439

C. Hakkarinen

Energy Analysis \& Environment Division

Electric Power Research Institute

3412 Hillview Avenue

P.0. Box 10412

Palo Alto, CA 94303

C. W. Hal1, Jr., Director

Office of Research and Development

Energy Effects Division

Environmenta 1 Protection Agency

401 Street, S.W.

Mail Stop RD682

Washington, DC 20460

S. R. Hanna

Atrilospheric Turbulence and Diffusion Laboratory

NOAA, Oak Ridge, TN 37830

J. H. Harley

Environmental Honitoring

Laboratory

376 hudson Street

Hew York, iv 10014

if. P. Hart

Department of Energy

Office of the Asst. Sec.

for Environment

Washington, UC 20545

E. B. Harvey

Department of Energy

Office of the Asst. Sec.

for Environment

Washington, DC 20545

J. W. Healy

Los Alamos Scientific

Laboratory

University of California

P.0. Box 1663

Los Alamos, INM 87544 
No. of

Copies

E. Held

U.S. NRC Directorate Regulatory Standards

Washingtion, DC 20545

A. N. Heller

Department of Energy

Office of the Asst. Admin. for Conservation

Washington, DC 20545

B. B. Hicks

Atmospheric Physics Section

Argonne National Laboratory

9700 Cass Avenue

Argonne, IL 60439

G. R. Hilst

Energy Analysis \& Environment Division

Electric Power Research Institute

$3412 \mathrm{Hillview} \mathrm{Avenue}$

P. 0. Box 10412

Palo Alto, CA 94303

J. C. Hock

Department of Energy

office of the Asst. Sec. for Environment

Washington, DC 20545

H. W. Hoffman

Oak Ridge National Laboratory

P.0. Box Y

Oak Ridge, TN 37830

J. Z. Holland

National Oceanic and

Atmospheric

Administration

iNorth Bethesda Office Center

11420 Rockville Hei.ghts

Rockville, HD 20852

H. L. Hollister

Department of Energy

Acting Deputy Asst. Sec. for Research

Office of Environment

Washington, DC 20545

C. F. Holoway

Oak Ridge National Laboratory

$\mathrm{X}-10, \mathrm{~B} / \mathrm{dg} .7710, \mathrm{Rm} .101$

Oak Ridge, TN 37830 iro. of

Copies

P. W. House

Department of Energy

Acting Deputy Asst. Sec. for Research

Office of Environment

Washington, DC 20545

F. P. Hudson

Department of Energy

Office of the Asst. Sec. for Environment

Washington, DC 20545

C. Jackson

DOE--San Francisco

Operations Office

133 Broadway

Wells Fargo Building

Oakland, CA 94616

R. M. Jefferson

Sandia Laboratories

P.0. Box 5800

Albuquerque, NM 87187

J. F. Johnson

Kenworth Trucking

P. 0. Box 1000

Kirkland, WA 98033

C. A. Jolly

Department of Energy

Office of the Asst. Sec. for Environment

Washington, DC 20545

J. W. Keizur

Sandia Laboratories

P. 0. Box 5800

Albuquerque, NM 87115

H. W. Kirby

Mound Laboratory

Monsanto Research Corporation

Miamisburg, $\mathrm{OH} \quad 45345$

J. B. Knox

Lawrence Livermore Laboratory

University of California

P.0. Box 808

Livermore, CA 94550

F. A. Koomanoff

Department of Energy

Office of the Asst. Sec. for Energy Technology Washington, DC 20545
No. of

Copies

C. Kuhlman

Department of Energy

Office of the Asst. Sec. for Energy Technology

Washington, DC 20545

R. L. Leith

Department of Energy

Office of the Asst. Sec. for Environment

Washington, DC 20545

J. A. Lenhard

DOE--0ak Ridge Operations Office

P.0. BOX E

Oak Ridge, TN 37830

Librarian

Battelle Memorial Institute

Columbus Laboratories

505 King Avenue

Columbus, $\mathrm{OH} 43201$

Librarian

Lawrence Radiation Laboratory

University of California

Technical Information

Dept., L-3

P.0. Box 808

Livermore, CA 94550

Librarian

Los Alamos Scientific Laboratory

P.0. Box 1663

Los Alamos, iNr 87544

Librarian

Research Library, Reference

Brookhaven ivational Laboratory

Upton, Long Is land, i. 11973

liej-Kao Liu

Systems Applications, Inc.

950 Northgate Drive

San Rafael, CA 94303

Steven E. Lindberg

Environmental Sciences Division

Oak Ridge ivational Library

P.O. Box $X$

Oak Ridge, TN 37830 
No. of

Copies

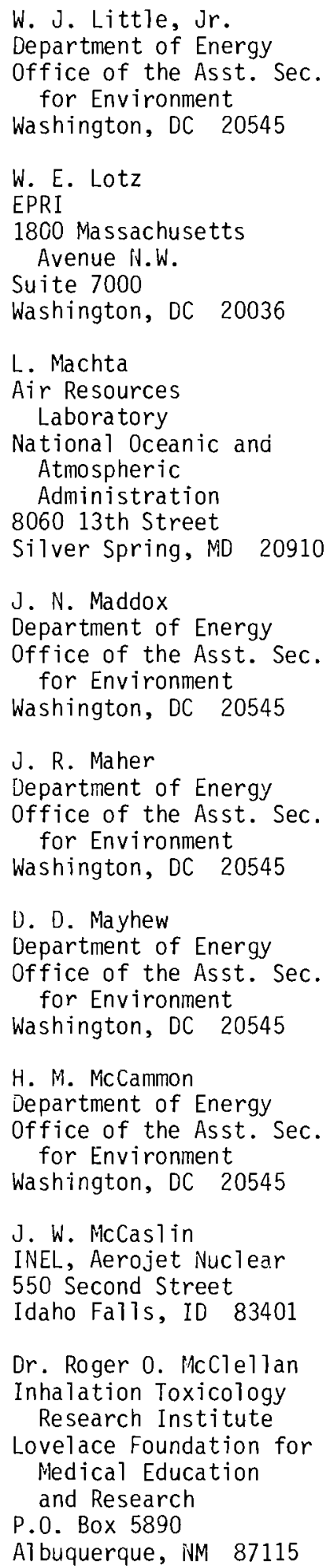

W. J. Little, Jr. Department of Energy

Office of the Asst. Sec. for Environment Washington, DC 20545

W. E. Lotz

EPRI

1800 Massachusetts

Avenue W.W.

Suite 7000

Washington, DC 20036

L. Machta

Air Resources Laboratory

National 0ceanic and Atmospheric Administration 8060 13th Street

Silver Spring, MD 20910

J. N. Maddox

Department of Energy

Office of the Asst. Sec. for Environment

Washington, DC 20545

J. R. Maher

Department of Energy

Office of the Asst. Sec. for Environment

Washington, DC 20545

D. D. Mayhew

Department of Energy

Office of the Asst. Sec. for Environment

Washington, DC 20545

H. M. McCammon

Department of Energy

Office of the Asst. Sec. for Environment

Washington, DC 20545

J. W. McCasl in

INEL, Aerojet Nuclear

550 Second Street

Idaho Falls, ID 83401

Dr. Roger 0. McClellan

Inhalation Toxicology

Research Institute

Lovelace Foundation for Medical Education and Research

P.0. Box 5890

Albuquerque, NM 87115

No. of

Copies

T. McCraw

Department of Energy

Office of the Asst. Sec.

for Environment

Washington, DC 20545

B. F. McCully

Department of Energy

Office of the Asst. Sec. for Environment Washington, DC 20545

C. B. Meinhold

Brookhaven National

Laboratory

Upton, Long Island

NY 11973

M. L. Mendelsohn

University of California

Lawrence Livermore Laboratory

P.0. Box 808

Livermore, CA 94550

Paul Michael

Meteorology Group

Erookhaven National

Laboratory

Upton, NY 11975

C. E. Miller, Jr.

Department of Energy

Office of the Asst. Sec. for Environment

Washington, DC 20545

Charles Miller

Environment Sciences/ Building 7509

Oak Ridge National Laboratory

P.0. Box $X$

Oak Ridge, TN 37830

W. Mills

Environmental Protection Agency

Washington, DC 20460

M. L. Minthorn, Jr.

Department of Energy

Office of the Asst. Sec. for Environment

Washington, DC 20545

D. R. Monti

Department of Energy

Office of the Asst. Sec. for Environment Washington, DC 20545 ivo. of

Copies

\section{B. Morgan}

DOE--Savannah River Operations office

P.0. Box A

Aiken, SC 29801

H. Moses

Carbon Dioxide and Climate Research Program

Office of Health and Environmental Research

Mail Stop E-201, Germantown

Washington, DC 20545

W. E. Mott

Department of Energy

Office of the Asst. Sec. for Environment

Washington, DC 20545

W. R. Ney

Executive Director

National Council on Radiation Protection and Measurements

7910 Woodmont Avenue

Suite 1061

Washington, DC 20014

NRC Advisory Committee on Reactor Safeguards

Uashington, DC 20555

G. Ortel

Department of Energy

Office of the Asst. Sec. for Energy Technology washington, DC 20545

R. S. Paul

Battelle lemorial Institute

Columbus Laboratories

505 King Avenue

Columbus, OH 43201

A. F. Perge

Department of Energy

office of the Asst. Sec. for Envirorment

Washington, DC 20545

D. F. Petersen

University of California

Los Alamos Scientific Laboratory

P.0. Box 1663

Los Alamos, NM 87545 
No. of

Copies

$$
\begin{aligned}
& \text { A. A. Pitrolo } \\
& \text { Morgantown Energy } \\
& \text { Research Center } \\
& \text { Department of Energy } \\
& \text { P.0. Box } 880 \\
& \text { Morgantown, WV } 26505 \\
& \text { G. B. Pleat } \\
& \text { Department of Energy } \\
& \text { Office of the Asst. Sec. } \\
& \text { for Defense Programs } \\
& \text { Washington, DC } 20545 \\
& \text { David Ra11, Director } \\
& \text { NIEHS } \\
& \text { P.0. Box } 12233 \\
& \text { Research Triangle Park, } \\
& \text { NC } 27709
\end{aligned}
$$

\section{R. Ray}

DOE--ivevada Operations Office

P.0. Box 14100

Las Vegas, IV 89114

W. Reese

DOE--Savannah River Operations Office

P.0. Box A

Aiken, SC 29801

C. R. Richmond

Oak Ridge National Laboratory

P.0. Box $X$

Dak Ridge, TN 37830

J. Roberston, Director

DOE--Region $X$ office

1992 Federal Building

915 Second Avenue

Seattle, WA 98174

Rockwell Hanford Operations

Basalt Waste Isolation Program

Attn: Betty King, Librarian

Columbia Bank Building

P.0. Box 800

Richland, WA 99352

J. R. Roeder

DOE--Albuquerque Operations Office

P.0. Box 5400

Albuquerque, NM 87115
No. of

Copies

S. L. Rose

Department of Energy

Office of the Asst. Sec. for Environment

Washington, DC 20545

D. H. Ross

Department of Energy

Office of the Asst. Sec.

for Environment

Washington, DC 20545

R. A. Scarano

Nuclear Regulatory

Commission

Mill Licensing Section

Washington, DC 20545

T. M. Schoenberg

DOE--Schenectady Naval

Reactors Office

P. 0. Box 1069

Schenectady, NY 12301

1.. Schulman

Department of Energy

office of the Asst. Sec. for Environment

Washington, DC 20545

R. G. Semonin

Illino is State water Survey

Box 232

Lirbana, IL 61801

J. Shapiro

Department of

Envirormental Health Sciences

School of Public Health

Harvard University

Boston, MA 02115

G. R. Shepherd Department of Energy

Office of the Asst. Sec. for Environment

Washington, DC 20545

R. J. Shull

Department of Energy

Office of the Asst. Sec. for Environment

Washington, DC 20545
No. of

Copies

W. K. Sinclair

Argonne National

Laboratory

9700 Cass Avenue

Argonne, IL 60439

W. Singlevich

Air Force Technical Applications Center/ TD-4

Patrick AFB, FL 32925

D. H. Slade

Department of Energy

Office of the Asst. Sec. for Enviroriment

Washington, OC 20545

D. A. Smith

Department of Energy

Office of the Asst. Sec. for Environment

Washington, DC 20545

D. Smith

Environmental Protection Agency

Washington, DC 20460

K. A. Smith

Sandia Laboratories

P.0. Box 5800

Albuquerque, NM 87187

J. H. Spickard

DOE--Idaho Operations

Commission

550 Second Street

Idaho Falls, ID 83401

R. C Srivastava

University of Chicago

Laboratory for Atmospheric Probing

Geophysical Sciences

5734 S. Ell is Avenue

Chicago, IL 60637

R. J. Stern

Department of Energy

Office of the Asst. Sec. for Environment

Washington, DC 20545

J. F. Stevens

Dayton Area Office

DOE--Albuquerque Operations office

P.0. Box 66

Miamisburg, $\mathrm{OH} 45342$ 
No. of

Copies

Frank Swanberg

Iuclear Regulatory

Commission

Washington, DC 20545

J. Swinebroad

Department of Energy

Office of the Asst. Sec. for Environment

Washington, DC 20545

Technical Information Service

Room 773A

Savannah River Laboratory

$E$. I. DuPont de Nemours and Company

Aiken, SC 29801

H. E. Thomas

Department of Energy

Office of the Asst. Sec. for Technology

Washington, DC 20545

J. E. Ti1lman

University of Washington

Department of

Atmospheric Sciences

Seattle, WA 98195

I. Van der Hoven

Air Resources Laboratory

National 0ceanic and

Atmospheric Administration

8060 13th Street

Silver Spring, MD 20910

G. L. Voelz

University of California

Los Alamos Scientific

Laboratory

P.0. Box 1663

Los Alamos, NM 87545

B. W. Wachholz

Department of Energy

Office of the Asst. Sec. for Environment

Washington, DC 20545

R. L. Watters

Department of Energy

Office of the Asst. Sec.

for Environment

Washington, DC 20545

S. Weinstein

Department of Energy

Office of the Asst. Sec. for Environment

Washington, DC 20545
No. of

Copies

1. Wender

Pittsburgh Energy

Research Center

Department of Energy

4800 Forbes Avenue

Pittsburgh, PA 15213

J. C. Whitnah

Department of Energy

Office of the Asst. Sec. for Environment

Washington, DC 20545

T. Williams

Department of Energy

Division of Policy

Analys is

Washington, DC 20545

M. M. Williamson

DOE--Idaho Operations

Commission

550 Second Street

Idaho Falls, ID 83401

J. W. Winchester

Florida State University

Department of

Oceanography

Tallahassee, FL 32306

M. A. Wolf

Air Resources Center

Oregon State University

Corvallis, OR 97331

R. W. Wood

Department of Energy

Office of the Asst. Sec. for Environment

Washington, DC 20545

W. Woodley

Experimental Meteorology Laboratory

University of Miami Branch

NOAA P.0. Box 8044

Coral Gables, FL 33124

R. C: Yoder

Rockwel1 International

P.0. Box 888

Golden, CO 80401

FOREIGN

S. Beilke

Umvel tbundesomt -

Pilotstation, Frankfurt

6 Frankfurt/Main

Feldbergstrasse 45,

WEST GERMANY
No. of

Copies

A. C. Chamberlain

Environmental and Medical

Sciences Division

0X11 ORA

AERA Harwe11,

oxfordshire, ENGLAND

G. H. Clark

Health Physics Research

Section

A.A.E.C. Research

Establishment

Private Mailbag,

Sutherland

New South Waies 2232

AUSTRALIA

H. Daw

Director, Division of Health, Safety and Waste Management

International Atomic Energy Agency

Vienna 1, Kaerntnerring 11 , AUSTRIA

Director

Commissiariat a l'Energie

Atomique

Centre d'Etudes

Nucleaires de Fontenayaux-Roses (Seine)

FRANCE

Director

Commonwealth Scientific and Industrial Research Organization

Aspendal, Victoria, AUSTRAL IA

Director

National Institute of

Radiological Sciences

4-9-1, Anagawa

Chiba-Shi, JAPAN

G. W. Dolphin

National Radiological

Protection Board

Harwe11, Didcot

oxfordshire OXII ORQ

ENGLAND

K. Edvarson

Forsvarets Forskingsanstalt

Research Institute of

Nation Defense

Avdeining 4, Stockholm 80

SWEDEN 
No. of

Copies

\section{Rzekiecki \\ Commissariat å l'Energie Atomique \\ Centre d'Etudes \\ Nucléaires de Cadarache \\ BP n 13-St. Paul \\ Lès Durance \\ FRANCE}

R. N. Sachdev
Air Monitoring Section
Bhabha Atmoic Research
Centre
Trombay, Bombay
400-085, INDIA
V. V. Shirvaikar
Meteorology Group
Environmental Studies
Section
Bhabha Atomic Research
Centre
Bombay-85 AS, INDIA
C. Shorrock
Battel le-Geneva
Geneva Research Centre
7 , Route de Drize
1227 Carogue-Geneva
SWITZERLAND
F. D. Sowby
International Commission
on Radiological Protection
Clifton Avenue
Sutton, Surrey
ENGLAND

No. of

Copies

E. Wallauschek

ENEA (OECD) Health and Safety Office

38, B1vd. Suchet

Paris IVI, FRANCE

ONSITE

DOE Richland

Operations Office

T. Austen

H. E. Ransom

M. White

Hanford Environmental

Health Foundation

D. G. Quilici

Pacific Northwest

Laboratory

W. J. Bair (20)

N. E. Ballou

D. B. Cearlock

J. P. Corley

R. L. Drake (40)

C. E. Elderkin (40)

J. W. Finnigan

J. C. Fox

J. J. Fuquay

A. G. Gibbs

R. K. Hadlock (15)
No. of

Copies

J. M. Hales (20)

A. J. Haverfield

D. L. Hesse1

J. V. Larson

G. B. Long (3)

J. D. Ludwick

S. Marks

R. P. Marshall

J. M. Nielsen

R. E. Nightingale

D. E. 0lesen

J. F. Park

H. M. Parker

R. W. Perkins

M. R. Peterson

P. M. Potter (10)

W. D. Richmond

L. C. Schwendiman

C. L. Simpson

J. R. Sletager

R. A. Stokes (15)

W. L. Templeton

R. C. Thompson

C. M. Unruh

B. E. Vaughan

E. C. Watson

L. L. Wende11 (10)

W. R. Wiley

R. K. Woodruff

J. A. Young

Biology Library (2)

Technical Information (5)

Publishing Coordination (2) 
